\title{
Benin: Poverty Reduction Strategy Paper
}

This poverty reduction strategy paper on Benin was prepared by a staff team of the International Monetary Fund as background documentation for the periodic consultation with the member country. It is based on the information available at the time it was completed in March 2011. The views expressed in this document are those of the staff team and do not necessarily reflect the views of the government of Benin or the Executive Board of the IMF.

The policy of publication of staff reports and other documents by the IMF allows for the deletion of market-sensitive information.

Copies of this report are available to the public from

International Monetary Fund • Publication Services

$70019^{\text {th }}$ Street, N.W. • Washington, D.C. 20431

Telephone: (202) 623-7430 • Telefax: (202) 623-7201

E-mail: publications@imf.org Internet: http://www.imf.org

\section{International Monetary Fund Washington, D.C.}




\section{REPUBLIC OF BENIN}

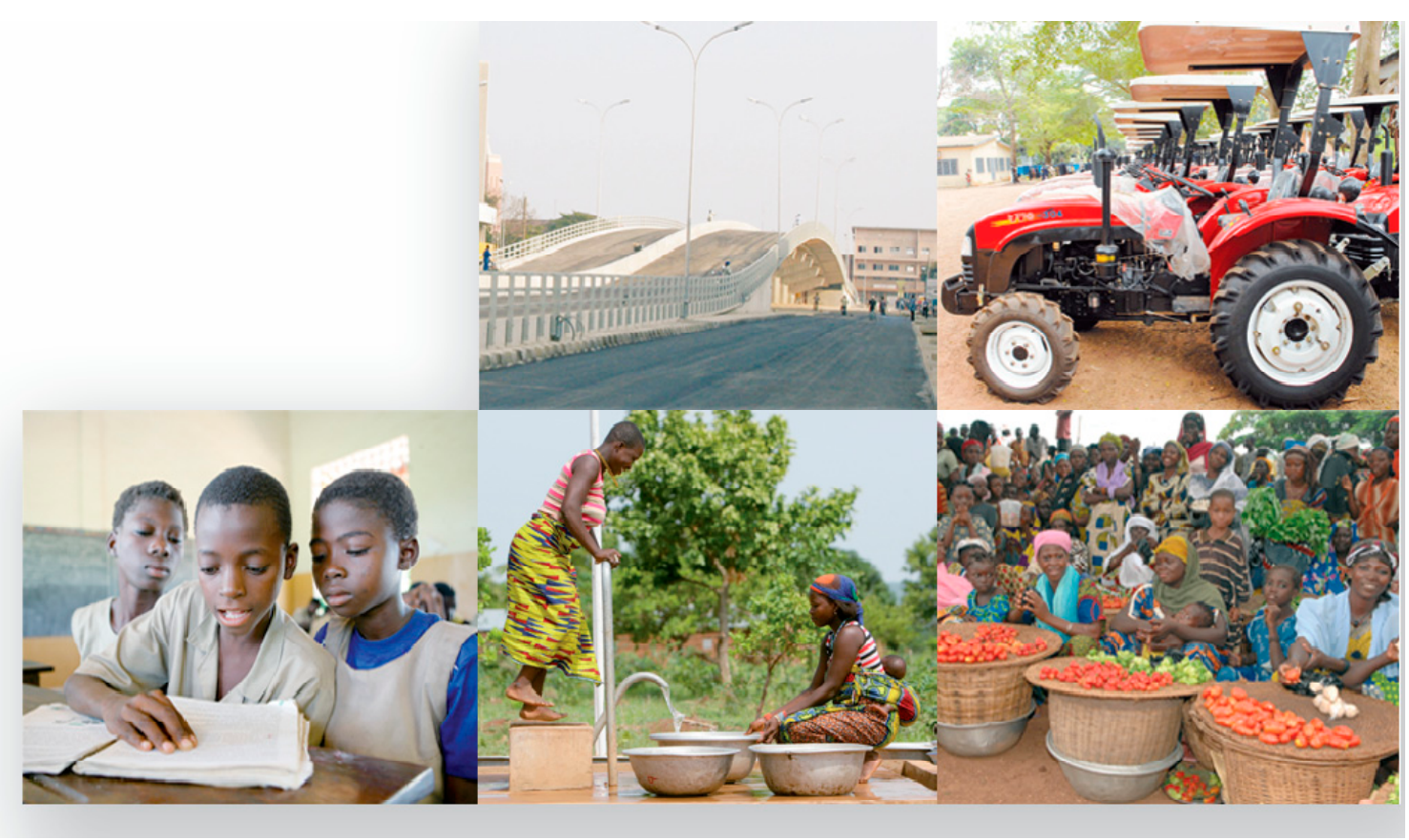

\section{GROWTH AND POVERTY REDUCTION STRATEGY}

\section{GPRS 2011-2015}




\section{REPUBLIC OF BENIN}

\section{GROWTH AND POVERTY REDUCTION STRATEGY}

GPRS 2011-2015

March 2011 


\section{TABLE OF CONTENTS}

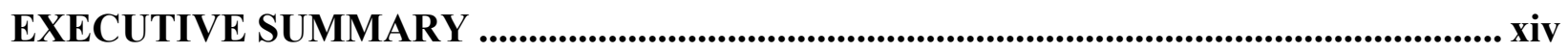

METHODOLOGY ........................................................................................................................ xiv

THE POVERTY SITUATION IN BENIN _........................................................................ $\mathrm{xV}$

GAINS FROM IMPLEMENTATION OF THE 2007-2009 GPRS ........................................ XV

MAIN PILLARS OF THE GPRS 2011-2015 _........................................................................ xvi

MACROECONOMIC AND BUDGETARY FRAMEWORK ................................................ xix

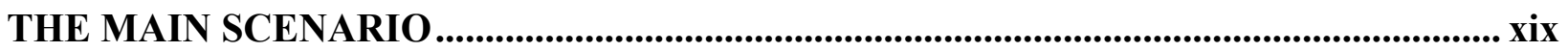

THE ALTERNATIVE SCENARIO................................................................................................ $\mathrm{xx}$

FINANCING MECHANISMS OF THE STRATEGY …...................................................... $\mathrm{xx}$

IMPLEMENTATION AND MONITORING OF THE STRATEGY .................................... xxi

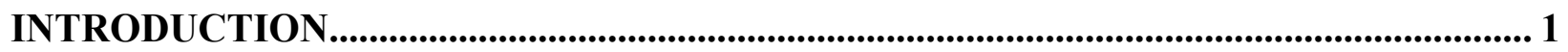

PART 1: STRATEGIC ASSESSMENT …………......................................................................... 3

CHAPTER 1: POVERTY DYNAMICS AND DETERMINANTS …..................................... 4

1.1 DIMENSIONS AND PROFILE OF POVERTY IN BENIN ………............................. 4

1.2 TRENDS AND MOBILITY IN POVERTY ……………………………………..... 7

1.3 GROWTH, INEQUALITY, AND POVERTY IN BENIN …………........................... 12

1.4 OVERVIEW: CRITICAL FACTORS FOR POVERTY REDUCTION IN BENIN .......... 13

CHAPTER 2: RECENT ECONOMIC AND SOCIAL PERFORMANCE ......................... 14

2.1 MACROECONOMIC FRAMEWORK SITUATION ……………............................. 14

2.2 PRINCIPAL ACHIEVEMENTS IN THE AREA OF HUMAN DEVELOPMENT .......... 19

2.3 PROGRESS IN INFRASTRUCTURE DEVELOPMENT ……………………......... 22

2.4 PERFORMANCE IN PROMOTING GOOD GOVERNANCE.................................... 23 
2.5 ACHIEVEMENTS AND SHORTCOMINGS OF DECENTRALIZATION AND

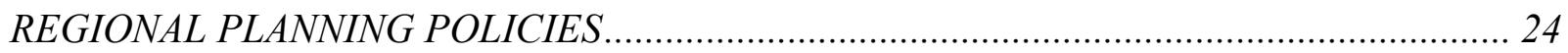

2.6 PROGRESS TOWARD ACHIEVING THE MDGS IN BENIN .................................... 24

CHAPTER 3: DEVELOPMENT CONSTRAINTS AND CHALLENGES IN BENIN .. 27

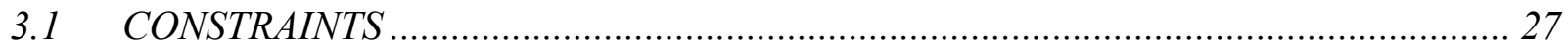

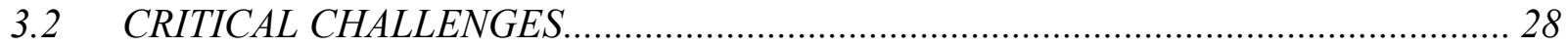

PART II: OPERATIONAL PILLARS ................................................................................. 31

CHAPTER 4: SUSTAINABLE ACCELERATED GROWTH AND ECONOMIC

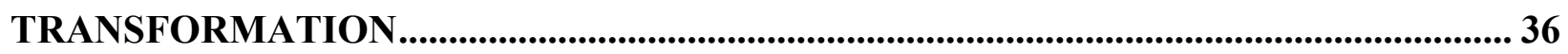

4.1 CONSOLIDATION OF THE MACROECONOMIC FRAMEWORK ……………......... 36

4.2 STIMULATION OF THE PRIVATE SECTOR AND ENTERPRISE DEVELOPMENT. 37

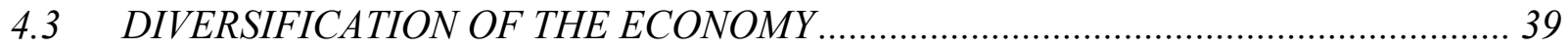

4.4 PROMOTION OF REGIONAL INTEGRATION AND ENTRY INTO GLOBAL

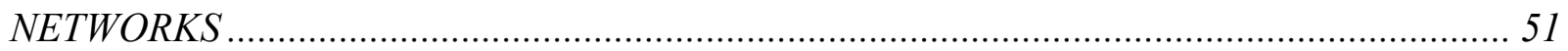

CHAPTER 5: INFRASTRUCTURE DEVELOPMENT........................................................53

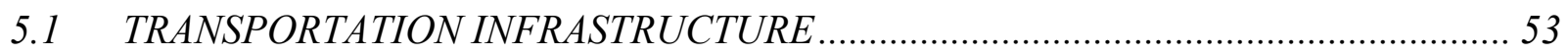

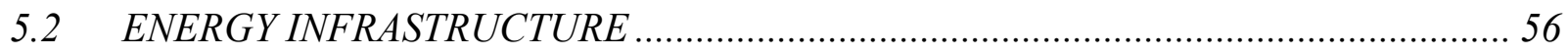

5.3 ICT INFRASTRUCTURE AND THE POSTAL SECTOR ……………………........... 58

5.4 WATER AND SANITATION INFRASTRUCTURE ……………….......................... 59

$5.5 \quad$ BUILDING CONSTRUCTION AND URBAN DEVELOPMENT ................................ 61

CHAPTER 6: BUILDING HUMAN CAPITAL .......................................................................6 63

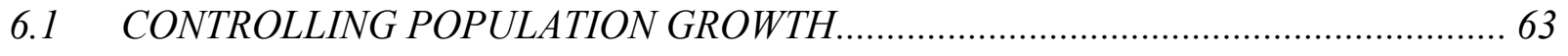

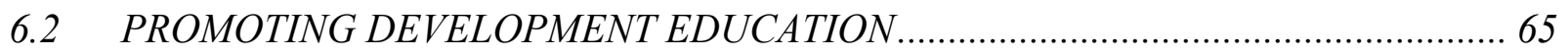

6.3 IMPROVING THE ACCESSIBILITY AND QUALITY OF HEALTH SERVICES.......... 69

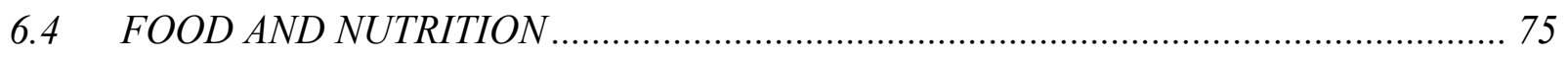

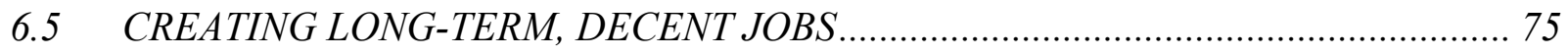


6.6 REDUCTION OF GENDER INEQUALITY ............................................ 76

6.7 ENHANCING SOCIAL WELFARE ................................................................. 77

6.8 PROMOTING THE DEVELOPMENT OF YOUNG PEOPLE AND LEISURE ........... 81

CHAPTER 7: ENHANCING THE QUALITY OF GOVERNANCE............................ 82

7.1 ENHANCING THE QUALITY OF PUBLIC FINANCIAL MANAGEMENT.............. 82

7.2 STRENGTHENING ADMINISTRATIVE GOVERNANCE..................................... 85

7.3 STRENGTHENING POLITICAL GOVERNANCE ............................................. 86

7.4 PROMOTING SECURITY AND PEACE .............................................................. 86

7.5 IMPROVING THE GOVERNANCE OF STATISTICAL INFORMATION ................. 87

7.6 PROMOTING HUMAN RIGHTS AND STRENGTHENING THE LEGAL CAPACITIES

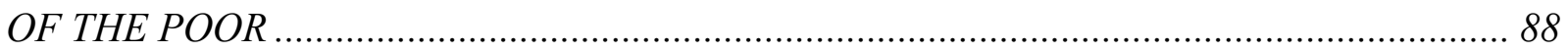

7.7 STRENGTHENING ENVIRONMENTAL GOVERNANCE .................................... 89

CHAPTER 8: BALANCED AND SUSTASINABLE NATIONAL DEVELOPMENT... 91

8.1 STRENGTHENING THE DECENTRALIZATION AND DECONCENTRATION

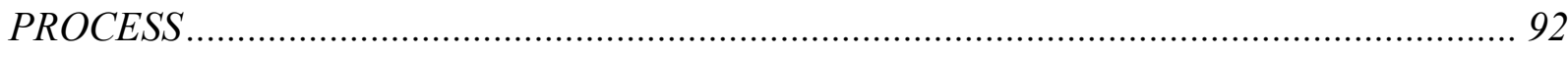

8.2 STRENGTHENING LAND USE MANAGEMENT FOR A DYNAMIC REGIONAL AND

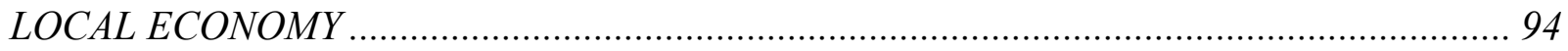

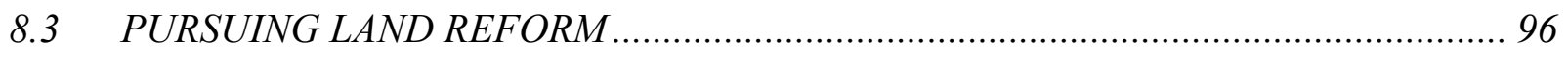

8.4 PROMOTING BORDER AREAS ............................................................. 97

8.5 MANAGING THE ENVIRONMENT AND NATURAL RESOURCES AND IMPROVING THE LIVING ENVIRONMENT ...................................................................... 98

8.6 MANAGEMENT OF NATURAL DISASTERS AND RISKS ................................ 100

PART III: STRATEGY IMPLEMENTATION FRAMEWORK.................................. 102

CHAPTER 9: GUIDELINES, IMPLEMENTATION AGENDA, AND MACROECONOMIC AND BUDGETARY IMPLICATIONS....................................... 103

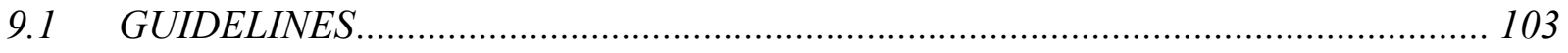

9.2 IMPLEMENTATION AGENDA .......................................................... 104 
9.4 IMPACT OF THE MACROECONOMIC AND BUDGETARY FRAMEWORK ON THE ATTAINMENT OF THE MDGS AND ON POVERTY REDUCTION.

CHAPTER 10: STRATEGY MONITORING AND EVALUATION MECHANISMS.. 115

10.1 INSTITUTIONAL FRAMEWORK FOR MONITORING AND EVALUATING

STRATEGY IMPLEMENTATION.

10.2 IMPLEMENTATION MONITORING MECHANISM …………............................ 117

10.3 PERFORMANCE EVALUATION SYSTEM ……..................................................... 118

10.4 BUILDING OF THE CAPACITIES OF MONITORING AND EVALUATION

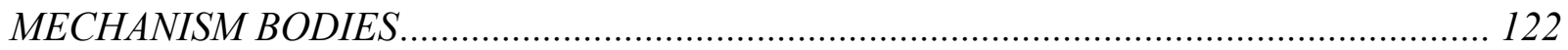

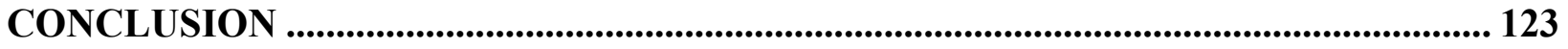

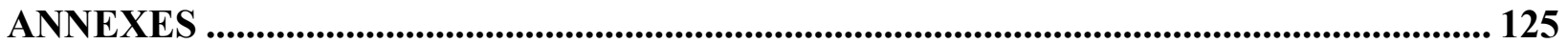

\section{List of Annexes}

Annex 1: Assumptions Underlying the GPRS 20112015 Macroeconomic Framework ............ 125

Annex 2: Structure of the Model for the GPRS 20112015 Macroeconomic Framework .......... 127

Annex 3: GPRS 20112015 Macroeconomic Framework …………………………………..... 133

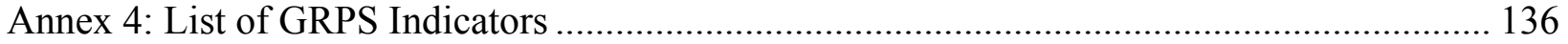

\section{List of Boxes}

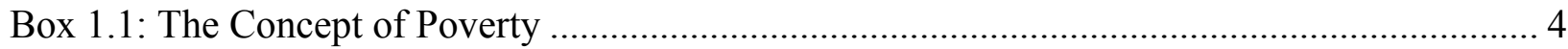

Box 6.1: Population Dynamic and Social Demand ..................................................................... 64

Box 6.2: Objectives and Strategic Orientations of the Child Protection Policy and Strategies in

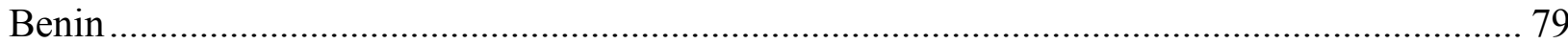

Box 7.1: Summary of the 2007 Report on "Public Expenditure and Financial Accountability

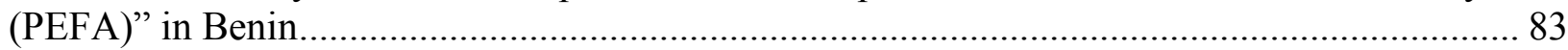

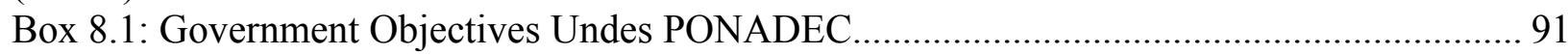

\section{List of Figures}

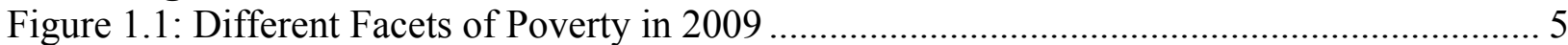

Figure 1.2: Extend of Different Facets of Poverty Based on Area of Residence …………............ 5

Figure 1.3: Poverty Trend (percentages) ................................................................................... 7

Figure 1.4: Breakdown of Hard-Core Poverty in Benin between 2006 and 2009 (percentages) ... 8

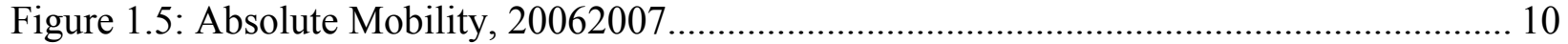

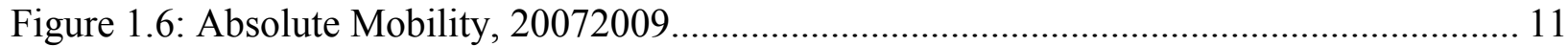

Figure 2.1: Evolution of the Economic Growth Rate ……….................................................. 14

Figure 2.2: Evolution of the Inflation Rate, Annual Movement from 2000July 2009 .................. 16

Figure 3.1: 20112015 GPRS Conceptual Framework .............................................................. 34 


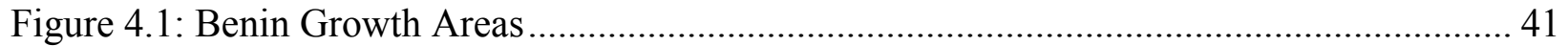

Figure 4.2: Agricultural Sector in Benin............................................................................. 43

Figure 4.3: Map of the Potential for the Development of Fish Farming in Benin..................... 45

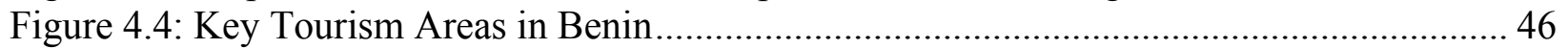

Figure 4.5: Map of Artisanal Activity Areas in Benin....................................................... 48

Figure 4.6: Beninese Construction Materials Potential .................................................... 50

Figure 10.1: Monitoring and Evaluation Mechanism, GRPS 3 ......................................... 120

\section{List of Table}

Table 1.1: Incidence of different forms of poverty based on department.................................. 6

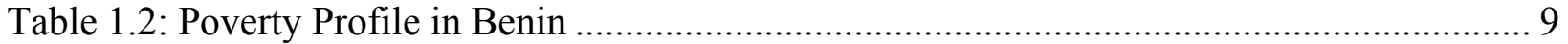

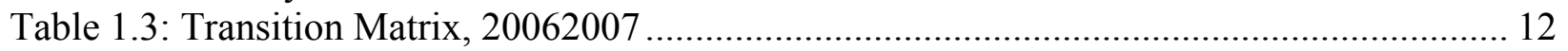

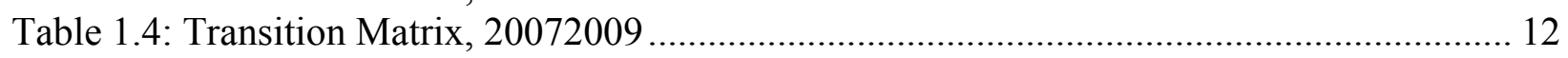

Table 1.5: Evolution of the Inequality Index (Ginin Index) in Benin ..................................... 12

Table 1.6: Breakdown of Changes in Poverty into Growth $(G)$ and Redistribution (R)

Components for the Period 20072009 ............................................................................. 13

Table 2.1: Evolution of Sectoral Contributions to the Growth Rate, 20072009....................... 15

Table 2.2: Evolution of Budget Aggregates, 20072009 (CFAF billions)................................. 17

Table 2.3: Evolution of Benin's Outstanding External Debt (CFAF billions) ............................ 18

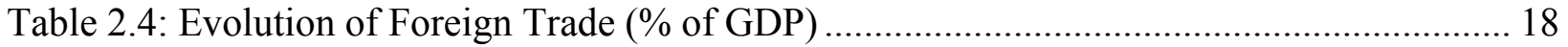

Table 2.5: Monetary Situation, 20072009 (CFAF billions).................................................... 19

Table 2.6: Overview of Constraints Identified for each MDG .............................................. 25

Table 9.1: Development of Economic Growth by Sector, 20101015.................................. 107

Table 9.2: Development of Revenue and Expenditures (as a percentage of GDP) .................. 109

Table 9.3: Percent Composition of the Financing of the Budget Deficit................................. 109

Table 9.4: Development of Public Sustainability Indicators ............................................... 110

Table 9.5: Breakdown of Budgetary Allocations by Sector, 20112015 .................................. 112

Table 9.6: Macroeconomic Indicators of the Alternative Scenario Percent of GDP unless

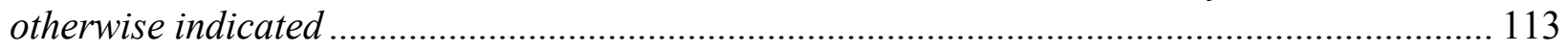

Table 9.7: Impact of the Individual Scenarios on MDG Indicators....................................... 113

Table 9.8: Impact of the Individual Scenarios on Poverty Indicators..................................... 114 


\section{ACRONYMS AND ABBREVIATIONS}

ACHPR

ADMA

ADSL

AEP

APAH

APIEx

APRM

ATRPT

$\mathrm{BCC}$

BCEAO

BEPP

BOOT

BOT

$\mathrm{BSC}$

BTP

BT-SA

CAA

CAD

CAME

CAPOD

CCIB

CCS

CDCC

CEB

CEN-SAD

CES

CFAF

CGI

CNE

$\mathrm{CNM}$

CNSS

CONAFIL

COTEB
African Charter on Human and Peoples' Rights

Agency for the Development of Agricultural Mechanization

Asymmetric Digital Subscriber Line

Drinking Water Supply

Hydro-agricultural Development Agency

Investment and Export Promotion Agency

African Peer Review Mechanism

Transitional Postal and Telecommunications Regulatory Authority

Behavior Change Communication

Central Bank of West African States

Public Policy Evaluation Office

Build, Own, Operate, Transfer

Build, Operate, Transfer

Coastal Sedimentary Basin

Construction and Public Works

Bénin Télécoms - Société Anonyme

Autonomous Amortization Fund

Departmental Administrative Conference

Procurement Agency for Essential Drugs

Development Policy Analysis Unit

Benin Chamber of Commerce and Industry

Communal Monitoring Committee

Departmental Council for Dialogue and Coordination

Benin Electricity Company

Community of Sahel-Saharan States

Economic and Social Council

Franc of the African Financial Community

General Tax Code

National Savings Bank

National Microfinance Committee

National Social Security Fund

National Commission for Local Finance

Benin Textile Company 


\begin{tabular}{|c|c|}
\hline $\mathrm{CPF}$ & Individual and Family Code \\
\hline CQP & Professional Accreditation Certificate \\
\hline CSPEF & Economic and Financial Program Monitoring Unit \\
\hline CSR & Corporate Social Responsibility \\
\hline DANIDA & Danish International Development Agency \\
\hline DDPD & Departmental Office for Planning and Development \\
\hline DEPOLINA & Declaration of National Policy on Adult Literacy and Education \\
\hline DEPOLIPO & Declaration of Population Policy \\
\hline DEPONAT & Declaration of National Land Use Policy \\
\hline DGAE & Directorate General for Economic Affairs \\
\hline DGB & Directorate General for the Budget \\
\hline DGE & Directorate General for Water \\
\hline DGFRN & Directorate General for Forests and Natural Resources \\
\hline DGGLD & Directorate General for Local Governance and Decentralization \\
\hline DGPD & Directorate General for Development Policy \\
\hline DGSPP & Directorate General for Project and Program Monitoring \\
\hline DPC & Directorate for Planning and Forecasting \\
\hline DPM & Directorate for Pharmacies and Drugs \\
\hline DPP & Directorate for Programming and Planning \\
\hline DSA & Debt Sustainability Analysis \\
\hline DSAF & Debt Sustainability Analysis Framework \\
\hline DTI & Indirect Duties and Taxes \\
\hline EAP & Environmental Action Plan \\
\hline ECF & Expanded Credit Facility \\
\hline ECOWAS & Economic Community of West African States \\
\hline EDP & Shared Development Space \\
\hline EDS & Demographic and Health Survey \\
\hline EFA & Education for All \\
\hline EMICoV & Integrated Modular Survey on Household Living Conditions \\
\hline EPA & Economic Partnership Agreement \\
\hline EPE & Equivalent Water Point \\
\hline EPI & Expanded Program on Immunization \\
\hline FADeC & Communal Development Support Fund \\
\hline FAO & Food and Agriculture Organization \\
\hline FCB & Grassroots Community Training \\
\hline FDI & Foreign Direct Investment \\
\hline
\end{tabular}




\begin{tabular}{|c|c|}
\hline FIAT & Land Use Planning Incentive Fund \\
\hline FNRB & Benin National Retirement Fund \\
\hline GDP & Gross Domestic Product \\
\hline GFP & Public Finance Management System \\
\hline GHG & Greenhouse Gas \\
\hline GPRS & Growth and Poverty Reduction Strategy \\
\hline GSE & Socioeconomic Groups \\
\hline GSM & Global System for Mobile Communication \\
\hline GTZ & German Agency for Technical Cooperation \\
\hline HICP & Harmonized Index of Consumer Prices \\
\hline HIPC & Heavily Indebted Poor Countries \\
\hline HIV/AIDS & Human Immunodeficiency Virus/Acquired Immune-Deficiency Syndrome \\
\hline ICT & Information and Communication Technology \\
\hline IMF & International Monetary Fund \\
\hline INSAE & National Institute for Statistics and Economic Analysis \\
\hline IP & Income Poverty \\
\hline IYCF & Infant and Young Child Feeding \\
\hline LLINs & Long Lasting Insecticide-Treated Nets \\
\hline LOLF & Budget Framework Law \\
\hline MCA & Millennium Challenge Account \\
\hline MDG & Millennium Development Goals \\
\hline MDGLAAT & Ministry for Decentralization, Local Governance, and Land Use Administration and Planning \\
\hline MDRI & Multilateral Debt Relief Initiative \\
\hline MEA & Millennium Ecosystem Assessment \\
\hline MEE & Ministry of Energy and Water \\
\hline MEF & Ministry of Economy and Finance \\
\hline MEMP & Ministry of Early Childhood and Primary Education \\
\hline MEPN & Ministry of the Environment and the Protection of Nature \\
\hline MESFTP & Ministry of Secondary Education and Technical and Professional Training \\
\hline MJLDH & Ministry of Justice, Legislation, and Human Rights \\
\hline MOSARE & Economic Reform Simulation and Analysis Model \\
\hline MSAM & Management of Severe Acute Malnutrition \\
\hline MSS & Social Security Association \\
\hline MTEF & Medium-Term Expenditure Framework \\
\hline NAPA & National Adaptation Program of Action \\
\hline NGO & Non-Governmental Organization \\
\hline
\end{tabular}




\begin{tabular}{|c|c|}
\hline NICT & New Information and Communication Technologies \\
\hline NLTPS & National Long Term Perspective Studies \\
\hline NMF & National Microfinance Fund \\
\hline NPV & Net Present Value \\
\hline NQCL & National Quality Control Laboratory \\
\hline OCBN & Benin-Niger Railway and Transport Organization \\
\hline OCS & Social Change Observatory \\
\hline ODA & Official Development Assistance \\
\hline ONAS & National Observatory for the Spatial Analysis of Development \\
\hline OSD & Strategic Orientations for Development \\
\hline OVC & Orphans and Vulnerable Children \\
\hline PAA-SGFP & Action Plan for Improvement of the Public Finance Management System \\
\hline PAGU & Urban Management Support Program \\
\hline PANAR & Results-based National Food and Nutrition Program \\
\hline PANF & National Family Action Plan \\
\hline PANLCD & National Action Plan to Combat Desertification \\
\hline PAP & Priority Action Program \\
\hline PARSEP & Support Program for Monitoring and Evaluation of Poverty Reduction Strategies \\
\hline PDC & Communal Development Plan \\
\hline PDDI & Departmental Plan for Intersectoral Development \\
\hline PDDSE & Ten-Year Education Sector Development Plan \\
\hline PEFA & Public Expenditure and Financial Accountability \\
\hline PGC & Poverty Growth Curve \\
\hline PHA & Promotion of Hygiene and Sanitation \\
\hline PHC & Housing and Construction Program \\
\hline PIHI & Package of High-Impact Interventions \\
\hline PIP & Public Investment Program \\
\hline PLAN 2D & Decentralization and Deconcentration Plan \\
\hline PNDCPGEM & National Capacity-Building Program for Global Environmental Management \\
\hline PNG & Net Position of the Government \\
\hline PNGDRN & National Program for Sustainable Natural Resource Management \\
\hline PNGE & National Environmental Management Plan \\
\hline PNM & Non-Income Poverty \\
\hline PNPG & National Gender Equality Promotion Policy \\
\hline $\mathrm{PO}$ & Payment Order \\
\hline PONADEC & National Decentralization and Deconcentration Policy \\
\hline
\end{tabular}




\begin{tabular}{|c|c|}
\hline PPP & Public-Private Partnership \\
\hline PRS & Poverty Reduction Strategy \\
\hline PSDAN & Strategic Plan for Food and Nutrition Development \\
\hline PSIA & Poverty and Social Impact Analysis \\
\hline PSRSA & Strategic Plan for Agricultural Sector Recovery \\
\hline PUASA & Emergency Food Security Support Program \\
\hline RAMU & Universal Health Insurance System \\
\hline RBBM & Results-Based Budget Management \\
\hline RBM & Results-Based Management \\
\hline RGHP & General Population and Housing Survey \\
\hline SA & Incorporated Company \\
\hline SASDE & Strategy to Accelerate the Survival and Development of Children \\
\hline SBEE & Benin Electricity Company \\
\hline SDAC & Master Plan for Communal Development \\
\hline SDE & Deconcentrated State Services \\
\hline SEA & Strategic Environmental Assessment \\
\hline SIEF & Ecological and Forestry Information System \\
\hline SIEP & Information System for Ongoing Evaluation \\
\hline SIGFIP & Integrated Public Finance Management System \\
\hline SIGIES & Integrated Economic and Social Information Management System \\
\hline SILP & Local Participatory Impact Monitoring \\
\hline SITEX & Textile Industrial Company \\
\hline SMEs & Small and Medium Enterprises \\
\hline SNAT & National Land Use Management Plan \\
\hline SNDS & National Strategy for Statistical Development \\
\hline SNIGS & National Information and Health Management System \\
\hline SODECO & Cotton Development Company \\
\hline SONAPRA & National Company for the Promotion of Agriculture \\
\hline SONEB & Benin National Water Company \\
\hline SONU & Emergency Neonatal and Obstetrical Care \\
\hline $\mathrm{SSC}$ & Collective Services Plan \\
\hline STAD & Land Use and Development Plan \\
\hline STI & Sexually Transmitted Infection \\
\hline TBES & Economic and Social Scorecard \\
\hline TBS & Gross Enrollment Rate \\
\hline TFP & Technical and Financial Partner \\
\hline
\end{tabular}


TFR

TIN

TNS

TOFE

TPM

UNCTAD

UNDP

UNFCCC

VAT

VHF

WAEMU

WTO
Total Fertility Rate

Single Taxpayer Identification Number

Net Enrollment Rate

Table of Government Financial Operations

Income Poverty Rate

United Nations Conference on Trade and Development

United Nations Development Program

United Nations Framework Convention for Climate Change

Value Added Tax

Very High Frequency

West African Economic and Monetary Union

World Trade Organization 


\section{EXECUTIVE SUMMARY}

Benin has been preparing and implementing poverty reduction strategies since 1999. After preparing the Interim Poverty Reduction Strategy (I-PRS) in 2000, the Poverty Reduction Strategy (PRS 1) for the 2003-2005 period served as both a strategic frame of reference and a framework for dialogue with the Technical and Financial Partners (TFPs). The Growth and Poverty Reduction Strategy (GPRS 2) for the 2007-2009 period made it possible to maintain the economic growth rate at roughly 4 percent on average and to achieve significant results in the social sectors, despite the different shocks experienced by Benin in recent years.

This Growth and Poverty Reduction Strategy (GPRS), which covers the 2011-2015 fiveyear period, is the product of a broad participatory process in which the public administration, economic agents, and civil society were closely involved during each phase. It draws on the long-term vision outlined in the "National Long Term Perspective Studies (NLTPS), BeninAlafia 2025" and on the Strategic Orientations for Development (OSDs) outlined by the Government in 2006. The GPRS 3 operationalizes these OSDs through a programmatic framework known as the Priority Action Program (PAP).

\section{METHODOLOGY}

The methodology used to prepare the GPRS 2011-2015 revolves around the following six major phases:

- The mid-term evaluation of the 2007-2009 GPRS. This evaluation made it possible to identify and analyze the strengths and weaknesses associated with implementation of the strategy and to determine the lessons applicable to the GPRS 2011-2015;

- The GPRS 2011-2015 national forum. Discussions at the forum led to a consensus on the major orientations and thrusts of the GPRS 2011-2015 to be submitted to the Government;

- Preparation of the note setting forth the major orientations of the GPRS 2011-2015. These orientations were approved by the Government at a cabinet meeting.

They present the strategic choices made by the Government in the context of the GPRS 2011-2015.

- Departmental and national consultations, which made it possible to share the major orientations of the GPRS 2011-2015 with all stakeholders, at both the national and deconcentrated levels;

- Drafting sessions by thematic group. These groups were composed of public administration officials, civil society and private sector representatives, as well as the Technical and Financial Partners (TFPs). The final document produced by these groups served as a frame of reference for preparation of the GPRS 2011-2015; and 
- Specific workshops on crosscutting themes, which facilitated, on one hand, assessment of the inclusion in the strategy of such crosscutting themes as gender, HIV/AIDS, demographic transition, the environment, and human rights and, on the other, the training of actors through these activities.

\section{THE POVERTY SITUATION IN BENIN}

In a bid to formulate an effective strategy, an analysis was done of the factors and driving forces behind poverty. This analysis made it possible to target the poor and determine the factors attributable to the slide into and out of poverty. In Benin, more than one in three persons (35.21 percent) lives below the subsistence level and one in three (30.8 percent) experiences myriad forms of deprivation from the standpoint of living conditions and property.

An analysis of these different forms of poverty by place of residence indicates that poverty is more prevalent in rural areas. An analysis of the factors that explain the persistence of poverty as well as the slide into and out of poverty points to the importance of educational level, field of work, access to credit, basic infrastructure, and initial income in reducing and lifting individuals out of poverty. By contrast, large household size (eight persons and more), seems to be one factor that greatly stymies the ability of individuals to lift themselves out of poverty.

Against this backdrop, the Government plans to implement accelerated economic growth and redistribution policies, which are likely to significantly reduce poverty and give impetus to Benin's efforts to achieve the Millennium Development Goals (MDGs), in particular by:

- Promoting the rural economy with a view to facilitating poverty reduction in rural areas;

- Controlling demographic growth, focusing on the strong correlation between poverty and household size;

- Reducing gender inequality;

- Strengthening social protection, particularly of the elderly;

- Strengthening basic infrastructure; and

- Strengthening the microcredit policy with the aim of facilitating access by the poor-in this case, women - to credit.

\section{GAINS FROM IMPLEMENTATION OF THE 2007-2009 GPRS}

The 2007-2009 GPRS helped strengthen the implementation process of the Paris Declaration on Aid Effectiveness. It enhanced dialogue between the Government and Technical and Financial Partners through various sectoral and joint reviews. In particular, this strategy fostered the conclusion and implementation of a memorandum of understanding between the Government and the eight Technical and Financial Partners on budget support. It also facilitated program approaches and joint mechanisms for the implementation of aid, such as the Fast Track Initiative in the education sector, the Pot Commun Eau Potable [Common Pot for Drinking 
Water] in the water sector, the Fonds d'Appui au Développement des Communes [Communal Development Assistance Fund] in the decentralization sector, and the Panier Commun [Common Basket] aimed at supporting inclusion of the gender component in policies and strategies.

The mid-term evaluation of the 2007-2009 GPRS indicated that, over its three-year implementation period, the annual average growth rate stood at 4.0 percent, an increase from the 3.3 percent noted during the implementation period of the PRS 1 . However, this rate remains below the minimum 7 percent required to achieve the Millennium Development Goals (MDGs) and points to a number of challenges to be tackled in the context of the GPRS 2011-2015, namely:

- Improving the business climate and quality of governance;

- Diversifying the economy;

- Improving road maintenance and rural roads;

- Improving the electricity sector;

- Ensuring the internal efficiency of the education system;

- Improving governance in the health field; and

- Implementing priority sector programs and projects efficiently, in particular improving the budget execution rate.

\section{MAIN PILLARS OF THE GPRS 2011-2015}

The strategic pillars of the GPRS 2011-2015 are the same as those set forth in the 20072009 GPRS. However, the content and scope of the priority fields in each area have been strengthened in light of the determinants and factors driving poverty in Benin, on one hand, and the new development constraints and challenges facing the country, on the other.

Consequently, consideration is given to such critical development issues as the employment of youth and women, opening up agricultural production zones, fostering rural economic growth, legal capacity building among the poor, reducing gender inequalities, and providing social protection and support. The same applies to thematic areas related to the organization of rural areas, agricultural diversification, demographic transition, and climate change.

The overall objective of the GPRS 2011-2015 is the improvement of the living conditions of the population. Specifically, projections are that the MDGs in the water, basic sanitation, primary education, and primary health care sectors will be achieved at the end of its implementation period, along with significant progress with respect to the other Millennium Development Goals.

The content of the five pillars of the 2011-2015 Growth and Poverty Reduction Strategy are as follows: 


\section{Pillar 1: Sustainable Acceleration of Growth and Transformation of the Economy}

The current economic growth rate (2.7 percent in 2009) remains too low to meet the basic needs of the Beninese population, whose intercensal growth rate stands at 3.25 percent. This weak performance is largely attributable to the lack of diversification and competiveness of the economy. In this regard, the Government is committed to accelerating reforms in order to diversify the economy and increase the growth rate to 7.5 percent by 2015 .

- The following four priority areas have been identified with the aim of boosting growth:

- Strengthening the macroeconomic framework;

- Promoting the private sector and developing enterprises;

- Diversifying the economy through the promotion of new export-oriented sectors;

- Fostering regional integration and integration into global networks.

\section{Pillar 2: Infrastructure Development}

Economic infrastructure plays a strategic role in the development process. It helps link economic operators to markets, reduce factor cost, improve the competitiveness of the economy, and provide essential services to the population (access to roads, drinking water, etc.), which impact the quality of life. Infrastructure therefore contributes to both economic growth and improvement of the living conditions of populations. For this reason, the Government has made it a key pillar of the strategy, which will be reflected in the implementation of major projects set forth in the Priority Action Program (PAP).

- Five priority areas have been identified in the infrastructure sector, namely:

- Transport infrastructure;

- Energy infrastructure;

- Communication and information and communication technologies;

- Water and sanitation infrastructure; and

- Construction and urban planning.

\section{Pillar 3: Strengthening Human Capital}

Despite the progress made in recent years with implementation of the various poverty reduction strategies, economic performance is not keeping up with ever-increasing social needs, owing to the high demographic growth rate. If this demographic trend continues, additional work will be needed in terms of developing human resources and expanding access to basic social services. For this reason, the Government has made human resource strengthening and 
development a key pillar of the strategy. This pillar will strengthen the social sphere and human capital, and thus underpin medium- and long-term economic growth.

The GPRS 2011-2015 programs to develop and strengthen human capital are grouped into six priority areas, namely:

- Controlling demographic growth;

- Promoting development-oriented education;

- Improving nutrition and sanitation conditions among the population;

- Creating decent employment;

- Reducing gender inequalities; and

- Strengthening social protection.

\section{Pillar 4: Improving the Quality of Governance}

The quality of governance is a key factor in the success of private sector promotion strategies, improvement of the quality of public expenditure, and government actions. For this reason, over the course of the next five years, the Government will strive to strengthen the quality of governance with the aim of enhancing the effectiveness of work in the public sphere. Priority programs in this area cover:

- Enhancing the quality of public finance management;

- Strengthening administrative governance;

- Strengthening political governance;

- Promoting statistical governance;

- Fostering environmental governance;

- Promoting peace and security; and

- Encouraging human rights protection and legal capacity building among the poor.

\section{Pillar 5: Balanced and Sustainable Development at the National Level}

Fostering Benin's economic emergence calls for the balanced development of the country as a whole. This development entails harnessing local resources and potential, which provide the foundation for employment and wealth, and reducing regional disparities in the area of infrastructure and facilities. To this end, the Government has undertaken reforms and actions in several areas, such as decentralization and deconcentration, land use planning, land tenure, and the environment. 
Despite this progress, much remains to be done to reverse the trends in the unequal distribution of the population throughout Benin; in poverty, which affects rural areas more than urban locations; in unequal access by the population to basic infrastructure and facilities; and in the weak regional and local economy. In this regard, during the 2011-2015 period, the Government will continue the work undertaken through the following six priority areas:

- Strengthening the decentralization and deconcentration process;

- Strengthening land use planning in order to spur the regional and local economy;

- Continuing land reform;

- Developing border areas;

- Managing the environment and natural resources and improving living conditions; and

- Managing natural disasters and risks.

\section{MACROECONOMIC AND BUDGETARY FRAMEWORK}

The design of the macroeconomic and budgetary framework took into account the strategic orientations and macroeconomic and sectoral policies identified using two scenarios:

- A main scenario built around the Government's desire to attain a growth rate of 7.5 percent in 2015 and achieve the Millennium Development Goals in the key sectors of education, health, and access to drinking water; and

- An alternative scenario corresponding to the macroeconomic framework for the economic and financial program supported by the IMF's Expanded Credit Facility (ECF).

\section{THE MAIN SCENARIO}

Implementation of the operational pillars should lead to sustainable growth in a context of controlled inflation and fiscal consolidation. Projections are that the growth rate will increase from 3.6 percent in 2011 to 7.5 percent in 2015, that is, an average of 6 percent over the 20112015 period, representing a two point net gain compared to the 2007-2009 GPRS.

Strengthening the basic infrastructure and continuing structural reforms would help boost production in the services and construction and public works sectors. Moreover, an improved governance and business climate stemming from acceleration of the pace of the reforms underway should spur private investment.

This scenario also provides for fiscal consolidation based on the implementation of development-oriented tax policies, expansion of the tax base to the informal sector through extension of the Single Taxpayer Identification Number (TIN), the provision of fewer tax 
exemptions, and the allocation of significant resources to quasi-public entities [régies financières]. Tax revenue as a percentage of $\mathrm{GDP}^{1}$ is expected to increase from 18.5 percent of GDP in 2011 to 19.3 percent in 2015. Consequently, the budget deficit (payment order basis) is expected to hold steady at approximately 5 percent of GDP during the period. The basic fiscal balance should improve, moving from -1.0 percent of GDP in 2011 to +0.5 percent of GDP in 2015, and thus be in line with the convergence criteria established by WAEMU.

The medium term expenditure framework (MTEF) for the main scenario provides for the optimal sectoral allocation of resources. Social sector appropriations ${ }^{2}$ are projected to account for 33.8 percent of total budget allocation during the 2011-2015 period, that is, 17.9 percent for education, 13.4 percent for health, and 2.4 percent for social and cultural development. This distribution is in line with the priority the Government intends to accord to universal education and investment in human capital in implementing the GPRS 2011-2015. Resources earmarked for production and commerce account for 12.3 percent of total allocations. These resources are expected to facilitate smooth implementation of the various development strategies and growth areas identified in the "Agenda for an Emerging Economy." Allocation for the development of productive infrastructure is projected to increase from 20 percent in 2011 to 28.3 percent in 2015 (an annual average of 24.3 percent during the period). The portions allocated to the governance, defense, and security and sovereignty sectors are, on average, estimated at 3.1 percent, 3.6 percent, and 2.5 percent, respectively, during the 2011-2015 period.

\section{THE ALTERNATIVE SCENARIO}

Inasmuch as constraints may be faced under the main scenario as a result of unexpected developments in the international sphere and with the mobilization of the resources necessary to achieve the range of MDGs selected, an alternative scenario has been identified. This scenario reflects the minimum activities to be carried out during the period and is based on the macroeconomic framework for the economic and financial program supported by the International Monetary Fund. It projects a real growth rate of 5.2 percent on average over the 2011-2015 period, with a GDP deflator of 2.4 percent. Revenue projections are 20.9 percent of GDP compared to 25.4 percent of GDP for public expenditure. The overall deficit, based on payment orders, is projected to be 4.5 percent of GDP on average during the 2011-2015 period.

\section{FINANCING MECHANISMS OF THE STRATEGY}

In order to mobilize the resources necessary for implementation of the GPRS 2011-2015, the Government will ensure better coordination of the various forms of assistance provided by the development partners, taking into account the priorities of the strategy and according priority to the forms of development assistance set forth in the principles of the Paris Declaration on Aid Effectiveness (overall budget support, sectoral or targeted budget support, and program-based

\footnotetext{
${ }^{1}$ Tax revenue relative to GDP.

${ }^{2}$ These appropriations pertain to investment and operations.
} 
support). Moreover, the Government will strive to establish all the conditions necessary to foster private sector participation in the Strategy. This process entails promoting foreign direct investment (FDI), developing public-private partnerships (PPPs) and introducing new financing instruments, strengthening banking services in the country, mobilizing national savings, and promoting microfinance.

\section{IMPLEMENTATION AND MONITORING OF THE STRATEGY}

In the new implementation and monitoring mechanism, priority will be given to assigning responsibility to the entities tasked with implementation of the different projects and programs contained in the Priority Action Program (PAP) set forth in the GPRS 2011-2015. For monitoring purposes, a basic list of indicators to track the GPRS 2011-2015 and MDGs has been prepared. These indicators will be updated based on the findings of the Integrated Modular Survey on Household Living Conditions (EMICoV). 


\section{INTRODUCTION}

Since the 1990s, the Republic of Benin has been firmly committed to social change, a source of well-being. This commitment reflects the desire of successive governments to lift the country out of poverty and place it on a path toward gaining emerging economy status, reflected in accelerated growth and sustainable human development. To this end, Benin prepared and implemented the 2003-2005 Poverty Reduction Strategy (PRS1) and the three-year Growth and Poverty Reduction Strategy (GPRS 2) covering the 2007-2009 period. Implementation of these strategies produced mixed results in the areas of economic growth and poverty reduction, owing to the external and internal shocks faced by the country in recent years.

The Growth and Poverty Reduction Strategy (2011-2015) seeks to correct the weaknesses in the first two strategies and give momentum to Benin's quest to achieve emerging economy status. It is based on the long-term development vision "Benin-Alafia 2025" and on the Strategic Orientations for Development (OSDs) set forth by the Government. The Strategy serves as the document for operationalizing these OSDs and, in particular, as the unifying framework for the interventions of Benin's development partners. In this respect, it serves as a mechanism for dialogue and coordination of the activities of the Technical and Financial Partners (TFPs), in accordance with Paris Declaration on Aid Effectiveness. The GPRS 2011-2015 seeks to strengthen economic growth with the aim of expediting Benin's achievement of the Millennium Development Goals (MDGs) by 2015. It is thus a fully integrated strategy that takes into account the new development constraints facing the country as well as the sectoral policy orientations adopted by the Government.

The GPRS 2011-2015 is the product of a participatory process that entailed intense discussions with all stakeholders, namely local elected officials, the central and deconcentrated governments, the TFPs, civil society, trade unions, and the private sector.

The methodology adopted entailed several phases and was spearheaded by a steering committee composed of civil society actors and government officials. The main phases of the process are as follows:

Mid-term evaluation of the 2007-2009 GPRS;

(ii) Organization of a national forum on the GPRS 2011-2015;

(iii) Preparation of the note setting forth the major orientations of the GPRS 2011-2015;

(iv) National and departmental consultations;

(v) Drafting activities by the thematic groups;

(vi) Assessment of the inclusion of crosscutting themes;

(vii) Preparation of the Strategy's Priority Action Program (PAP); and

(viii) Adoption and dissemination of the Strategy.

Effective implementation of the GPRS 2011-2015 and its Priority Action Program requires greater support from the international community in order to build on the gains made in 
recent years with respect to the development process and ensure the economic growth needed for Benin's sustainable and harmonious development.

The document consists of ten chapters grouped in three parts. Part I focuses on recent performance in the economic and social areas. Part II covers the strategic thrusts and priority intervention areas of the GPRS 2011-2015. Part III presents the implementation framework for the Strategy. 


\section{PART 1: STRATEGIC ASSESSMENT}

This part reviews Benin's performance in the economic and social spheres over the past three years. It is grouped into three sections. Chapter 1 assesses poverty in Benin. Chapter 2

covers recent performance in the economic and social areas. Chapter 3 addresses the constraints and challenges currently faced by Benin in its quest to become an emerging economy and eradicate poverty. 


\section{CHAPTER 1: POVERTY DYNAMICS AND DETERMINANTS}

1.1 This chapter analyzes the dynamics and determinants of poverty, using data from the Integrated Modular Survey on Household Living Conditions in Benin (EMICoV) of 2006, 2007, and 2009. For 2006, the data are drawn from the retrospective module administered on the first run, while the data for 2007 and 2009 come from aggregating the respective data from four runs and the follow-up survey.

1.2 Analysis of the dynamics and determinants of mobility in poverty will enable the Government to proceed with rational targeting of poor populations and obtain the maximum impact in terms of poverty reduction.

1.3 This chapter is organized into four sections. The first section highlights the multidimensional nature of poverty in Benin. Section 2 analyzes the dynamics of poverty in 2006, 2007, and 2009, as well as the determinants of mobility in poverty in Benin. The contributions of growth and inequality to changes in poverty in Benin are discussed in Section 3. Lastly, Section 4 provides an overview of the most critical factors for effective poverty reduction in Benin, based on lessons learned from previous analyses.

\subsection{DIMENSIONS AND PROFILE OF POVERTY IN BENIN}

\subsubsection{Multidimensional poverty}

1.4 A number of approaches are used to determine the level of poverty in Benin. Based on the monetary approach, the proportion of poor people in Benin in 2009 is estimated at 35.21 percent, which means that more than one of every three persons is living below the subsistence level.

1.5 On the other hand, non-income poverty-assessed on the basis of a composite index that is a linear combination of dichotomous variables of household living conditions and property or assets - indicates that 30.84 percent of the Beninese population is poor in terms of subsistence and property in 2009 .

\section{Box 1.1: The Concept of Poverty}

\footnotetext{
Income Poverty (PM)

In the monetary approach, household income is used as a living standards indicator. This is defined as the sum of all income, in cash and in kind, that is generally recurrent in nature and regularly received, at time intervals of one year or less, by the household or by its members. However, the difficulties in gathering reliable estimates of income prompt statisticians to turn instead to final consumption, which is often more accurately grasped from a statistical standpoint. Another argument in favor of using consumption as the living standards indicator revolves around the fact that consumption, not income, produces well-being.

Non-income poverty (PNM)

This approach combines the variables of household living conditions and property or assets. It seeks to pinpoint a number of difficulties, shortages, or privations in various areas of household subsistence conditions. The approach is objective but non-monetary. These areas may pertain to poverty of an "existential" nature (food or housing, for example) or a "social" nature (relations, employment, leisure activities, etc.). This form of poverty integrates the household's physical and financial assets (or wealth). The indicator also reflects the structural form of poverty because it focuses on stock that is relatively impervious to economic shocks.
} 
Figure 1.1: Different Facets of Poverty in 2009

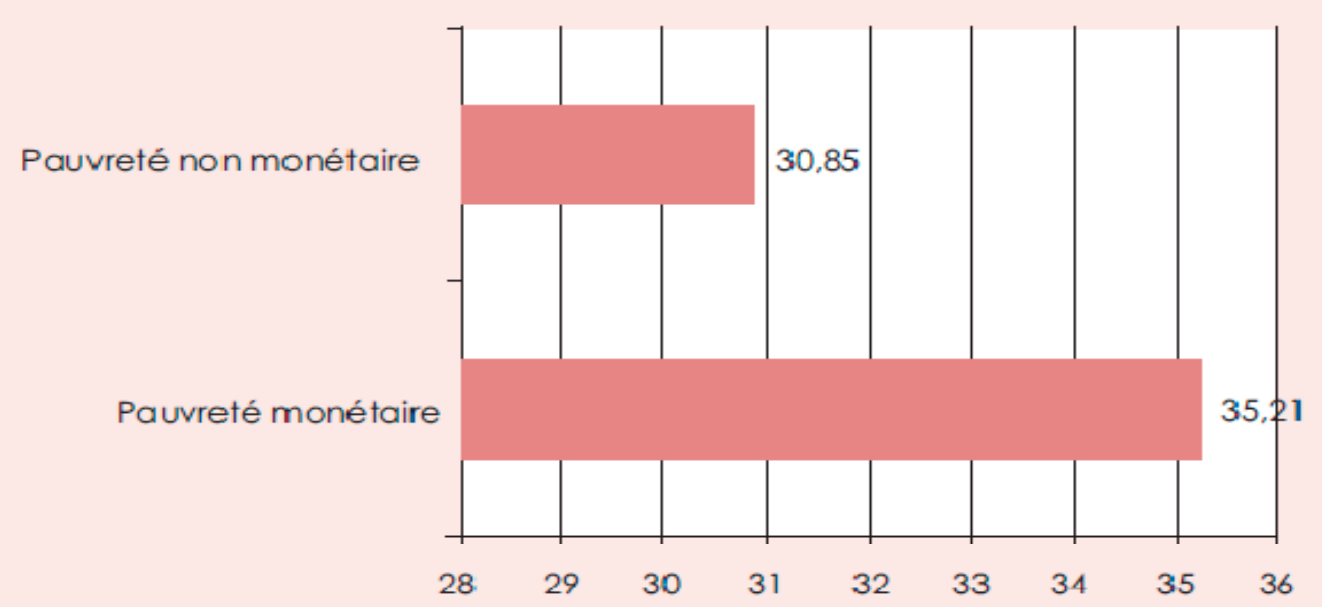

Source: INSAE EMICoV, 2010

Pauvreté non monétaire: $30.85 \%$

Non-income poverty: $30.85 \%$

Pauvreté monétaire: $35.21 \%$

Income poverty: $35.21 \%$

\subsubsection{Very high poverty in rural areas coupled with highly precarious conditions in urban} areas

1.6 Analysis of the various forms of poverty based on area of residence confirms that poverty is a more rampant phenomenon in rural areas than in urban areas. Regardless of the form of poverty, more than 35 percent of people are poor in rural areas, versus less than 30 percent in urban areas (Figure 2).

Figure 1.2: Extend of Different Facets of Poverty Based on Area of Residence

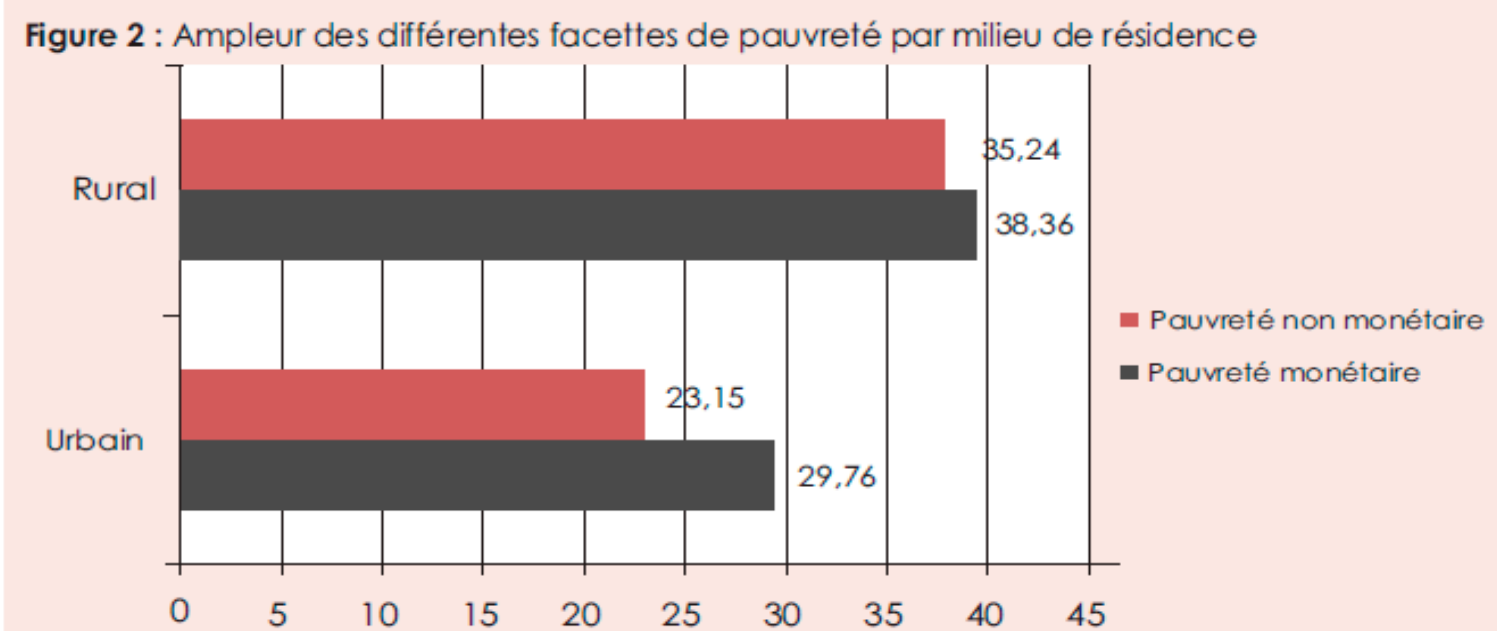

Source: INSAE EMICoV, 2010

\begin{tabular}{|l|l|}
\hline Rural & Rural \\
\hline Urbain & Urban \\
\hline Pauvreté non monétaire & Non-income poverty \\
\hline Pauvreté monétaire & Income poverty \\
\hline
\end{tabular}




\subsubsection{Poverty unevenly distributed among the country's departments and communes}

1.7 At the department level, Couffo, Mono, Zou, and Collines appear to be the poorest departments in 2009, with an incidence of income poverty above 40 percent, whereas in 2007 , Alibori and Borgou were the two poorest departments in Benin, with an estimated income poverty incidence of 43 and 39 percent respectively. Ouémé and Littoral departments remained the least poor in 2007 and 2009, with an incidence of 23 and 24 percent respectively in 2009.

1.8 With respect to non-income poverty (household living conditions and property or assets), Atacora is the most widely affected department, with an incidence of 69 percent of the population in 2009 (i.e. 38 points higher than the national level of incidence). It is followed, at a great distance, by Mono department, with an incidence of 45 percent. The least affected departments are Littoral, Collines, and Ouémé, with rates of 13, 17, and 19 percent respectively. This trend was the same in 2007.

Table 1.1: Incidence of different forms of poverty based on department

\begin{tabular}{|l|c|c|c|c|}
\hline & \multicolumn{2}{|c|}{ 2007 } & \multicolumn{2}{c|}{ 2009 } \\
\hline Department & IP & PNM & IP & PNM \\
\hline Alibori & 0.43 & 0.46 & 0.35 & 0.33 \\
\hline Atacora & 0.33 & 0.65 & 0.36 & 0.69 \\
\hline Atlantique & 0.36 & 0.31 & 0.37 & 0.24 \\
\hline Borgou & 0.39 & 0.46 & 0.28 & 0.32 \\
\hline Collines & 0.31 & 0.29 & 0.44 & 0.17 \\
\hline Couffo & 0.35 & 0.49 & 0.46 & 0.42 \\
\hline Donga & 0.34 & 0.39 & 0.31 & 0.21 \\
\hline Littoral & 0.26 & 0.17 & 0.23 & 0.13 \\
\hline Mono & 0.27 & 0.49 & 0.46 & 0.45 \\
\hline Ouémé & 0.25 & 0.28 & 0.24 & 0.19 \\
\hline Plateau & 0.35 & 0.44 & 0.33 & 0.28 \\
\hline Zou & 0.32 & 0.43 & 0.41 & 0.32 \\
\hline National & $\mathbf{0 . 3 2}$ & $\mathbf{0 . 4 0}$ & $\mathbf{0 . 3 5}$ & $\mathbf{0 . 3 1}$ \\
\hline
\end{tabular}

IP: Income poverty - PNM: Non-income poverty.

Source: INSAE, EMICoV, 2010.

1.9 At the commune level, income poverty appears, in 2009, to be most highly accentuated in the communes of Aplahoué, Zè, So-Ava, Toffo, and Karimama, with more than half of the population living below the poverty threshold. The three least poor communes are AbomeyCalavi, Porto-Novo, and Sème-Kpodji, each with an incidence between 18 and 19 percent.

\subsubsection{Hard-core poverty affecting nearly a quarter of the poor}

1.10 The combination of both forms of poverty provides a way to isolate hard-core poverty, estimated at 13.56 percent in 2009. These are unambiguously poor households because they display, all at the same time, weak consumer spending, poor living conditions, and asset privations. 
1.11 In rural areas, the proportion of households afflicted by hard-core poverty is estimated at 15 percent in 2009, versus 12.7 percent in urban areas. These results establish rural areas as essential targets in the fight against extreme poverty.

\subsection{TRENDS AND MOBILITY IN POVERTY}

\subsubsection{Non-income poverty in decline}

1.12 Between 2006 and 2007, income poverty fell by roughly 4 percentage points, versus 2.4 points in the case of non-income poverty (Figure 3). On the other hand, between 2007 and 2009, income poverty rose by 1.9 percentage points. This increase in income poverty between 2007 and 2009 is the result of the effects of the economic and financial crises, which caused household consumer spending to fall.

1.13 Non-income poverty registered a substantial decline of 9 percentage points, falling from 39.6 percent in 2007 to 30.85 percent in 2009 . This decline is the result of various actions taken by the Government during the period 2007-2009 to improve access to basic social services. In particular, these actions involved the construction of water points and school infrastructure.

Figure 1.3: Poverty Trend (percentages)

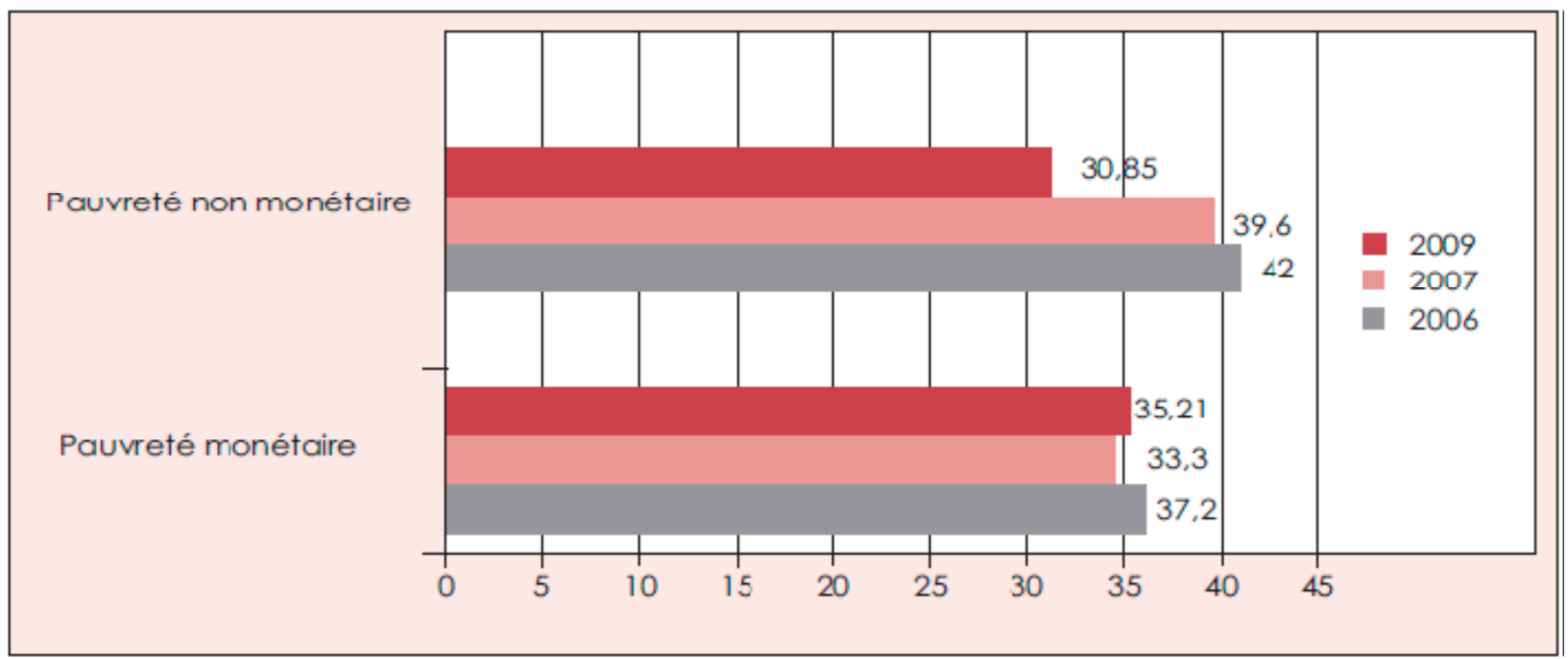

Source: INSAE, EMICoV, 2010.

\begin{tabular}{|l|l|}
\hline Pauvreté non monétaire & Non-income poverty \\
\hline Pauvreté monétaire & Income poverty \\
\hline
\end{tabular}

1.14 The poorest segment of the population (hard-core poverty) increased from 2007 to 2009 , rising from 7.8 percent of the population in 2007 to 13.4 percent in 2009 , i.e. an increase of 5.6 percentage points. This group, which was estimated at 11.4 percent in 2006 , had fallen by 3.6 points between 2006 and 2007. 
Figure 1.4: Breakdown of Hard-Core Poverty in Benin between 2006 and 2009 (percentages)

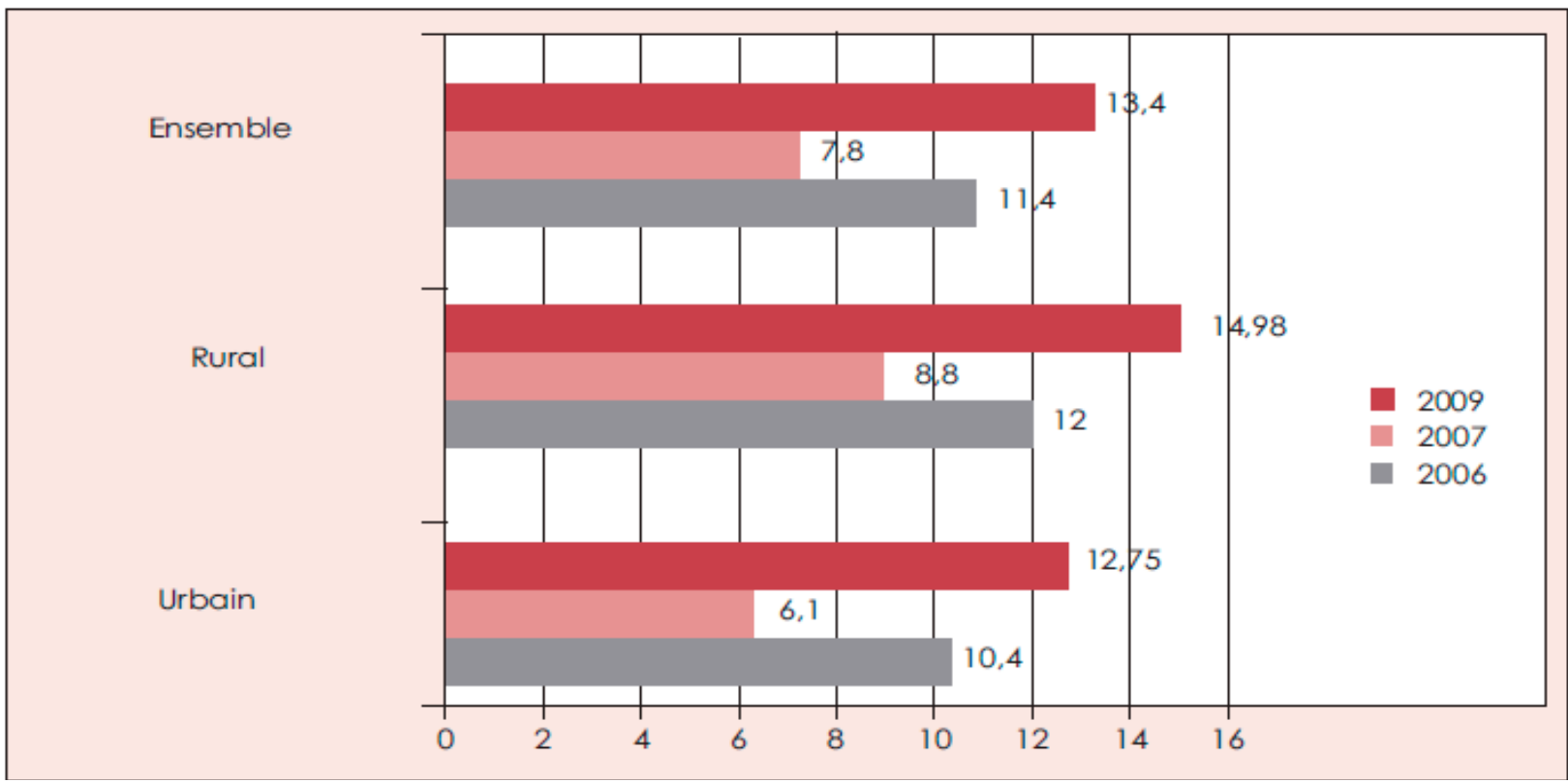

Source: INSAE, EMICoV, 2010.

\begin{tabular}{|l|l|}
\hline Ensemble & Total \\
\hline Rural & Rural \\
\hline Urbain & Urban \\
\hline
\end{tabular}

\subsubsection{A poverty trend that varies significantly depending on household characteristics}

1.15 Poverty specifically showed a very substantial decline for households headed by women between 2006 and 2007, falling from 36.1 to 26.5 percent, i.e. a reduction of some 9.6 percentage points. In 2009, the estimate is 30.39 percent for households headed by women, versus 36.17 percent for those headed by men.

1.16 Poverty also decreases in step with educational level, showing a major drop in households headed by someone with higher education $(-4.31$ percentage points for a level that was already low in 2006: 11.1 percent). Having a store of higher knowledge thus enables the individual to take better advantage of economic opportunities and improve his or her standard of living. In 2009, households headed by individuals with no education account for 1.26 times more poor persons in monetary terms than those headed by individuals with only a primary school education. The ratio climbs to 5.87 for higher education.

1.17 The age of the head of household also has a major effect on the poverty dynamics of family members. In fact, households headed by persons over the age of 60 showed a poverty incidence 1.81 times higher than that of households headed by persons under the age of 25 . The greatest decline was found among households headed by persons between the ages of 25 and 35 years (a decline of 10 percentage points).

1.18 Finally, with respect to employment sectors, the biggest increase in the number of poor between 2006 and 2009 occurred in the agriculture-livestock and fisheries sectors (an increase of 1.86 percentage points), while the number of poor working in the sectors of electricity and gas, 
banking and insurance, industry, construction and public works, and transportationcommunication all fell, with declines of more than 6 to 45 percentage points.

1.19 The greatest increases in poverty between 2007 and 2009 occurred in the sectors of agriculture-livestock-fisheries-forests, commerce, industry, transportation, and construction and public works, which do however account for most of the working population.

1.20 To reduce poverty more rapidly, Benin should urgently and actively promote an increase in the output and income of poor persons working in the agricultural sector in the broad sense.

Table 1.2: Poverty Profile in Benin

\begin{tabular}{|c|c|c|c|c|}
\hline & 2006 & 2007 & 2009 & $\begin{array}{l}\text { Difference } \\
\text { 2009-2007 }\end{array}$ \\
\hline $\begin{array}{l}\text { Sex of head of household } \\
\text { Male } \\
\text { Female }\end{array}$ & $\begin{array}{l}37.4 \\
36.1 \\
\end{array}$ & $\begin{array}{l}34.7 \\
26.5 \\
\end{array}$ & $\begin{array}{l}36.17 \\
30.39 \\
\end{array}$ & $\begin{array}{c}1.47 \\
3.8\end{array}$ \\
\hline $\begin{array}{l}\text { Area of residence } \\
\text { Cotonou } \\
\text { Other urban } \\
\text { Total urban } \\
\text { Rural }\end{array}$ & $\begin{array}{c}30 \\
36 \\
34.8 \\
38.5\end{array}$ & $\begin{array}{l}26.2 \\
28.8 \\
28.3 \\
36.1\end{array}$ & $\begin{array}{l}23.9 \\
31.5 \\
29.8 \\
38.4\end{array}$ & $\begin{array}{l}-2.3 \\
2.7 \\
1.5 \\
2.3\end{array}$ \\
\hline $\begin{array}{l}\text { Educational level of head of household } \\
\text { No education } \\
\text { Primary } \\
\text { Secondary } \\
\text { Higher } \\
\end{array}$ & $\begin{array}{l}41.5 \\
35.2 \\
26.4 \\
11.1\end{array}$ & $\begin{array}{c}35.9 \\
30.1 \\
32.5 \\
4.6 \\
\end{array}$ & $\begin{array}{c}39.89 \\
31.5 \\
20.64 \\
6.79 \\
\end{array}$ & $\begin{array}{c}3.99 \\
1.4 \\
-11.86 \\
2.19 \\
\end{array}$ \\
\hline $\begin{array}{l}\text { Age bracket of head of household } \\
\text { Under } 25 \text { years } \\
25-34 \text { years } \\
35-44 \text { years } \\
45-59 \text { years } \\
60 \text { years or more } \\
\end{array}$ & $\begin{array}{l}20.9 \\
32.9 \\
38.5 \\
38.7 \\
40.5\end{array}$ & $\begin{array}{c}16.4 \\
22.9 \\
34.6 \\
39 \\
36.2\end{array}$ & $\begin{array}{l}17.78 \\
35.04 \\
38.14 \\
34.72 \\
32.26\end{array}$ & $\begin{array}{c}1.38 \\
12.14 \\
3.54 \\
-4.28 \\
-3.94\end{array}$ \\
\hline $\begin{array}{l}\text { Employment sector of head of household } \\
\text { Agriculture-livestock-fisheries-forests } \\
\text { Industry } \\
\text { Water, electricity, gas } \\
\text { Construction and public works } \\
\text { Commerce and food service industry } \\
\text { Transportation and communications } \\
\text { Banking and insurance } \\
\text { Other services } \\
\text { Not applicable }\end{array}$ & $\begin{array}{c}41 \\
36.9 \\
47.2 \\
27.9 \\
30.4 \\
29.2 \\
19 \\
25.4 \\
38.4 \\
\end{array}$ & $\begin{array}{c}37.4 \\
23.9 \\
11.7 \\
16.1 \\
20.6 \\
17.8 \\
0 \\
16.5 \\
41.2 \\
\end{array}$ & $\begin{array}{c}42.86 \\
29.96 \\
1.74 \\
28.49 \\
25.68 \\
28.98 \\
2.69 \\
20.08 \\
28.08 \\
\end{array}$ & $\begin{array}{c}5.46 \\
6.06 \\
-9.96 \\
12.39 \\
5.08 \\
11.18 \\
2.69 \\
3.58 \\
-13.12 \\
\end{array}$ \\
\hline Total & 37.2 & 33.3 & 35.21 & 1.91 \\
\hline
\end{tabular}

Source: INSAE, EMICoV, 2010.

\subsubsection{Analysis of mobility in poverty in Benin}

1.21 The transitions of poverty in Benin are persistent and increasingly positive. In fact, of 100 households classified as non-poor in 2006, 15 became poor in 2007; on the other hand, of 100 
households classified as poor in 2006, 43 remained poor and 57 escaped poverty. ${ }^{3}$ Looking at the total numbers of the poor and non-poor, it turns out that a poor individual in 2006 has an even chance of escaping poverty one year later, while a non-poor individual in 2006 has a 78 percent chance of remaining non-poor. This demonstrates the higher degree of positive transitions versus negative transitions within the Beninese population.

1.22 In urban areas, the rate of exit from poverty comes to 59.5 percent, versus 55.1 percent for rural households. Thus, urban populations, having seen their average level of spending increase and its distribution change, have undergone more positive transitions than rural populations. Moreover, the rate of entry into poverty by non-poor households is higher in rural areas than in urban areas: 16.3 versus 11.9 percent.

1.23 In general, the mobility analysis has highlighted the existence of remarkable absolute mobility in terms of well-being. Between 2006 and 2007, there is a steep decline in the proportions of poor and very poor households, with a corresponding increase in other categories of well-being (average households, rich households, and richest households). Thus, starting at 20 percent in 2006 for each category ${ }^{4}$ of well-being, the percentage of households having maintained their level of well-being in the same category varies: a decrease of more than 4 percentage points for very poor households and poor households, and an increase by the same number of percentage points for average, rich, and richest households, reflecting the existence of a poverty exit process.

Figure 1.5: Absolute Mobility, 20062007

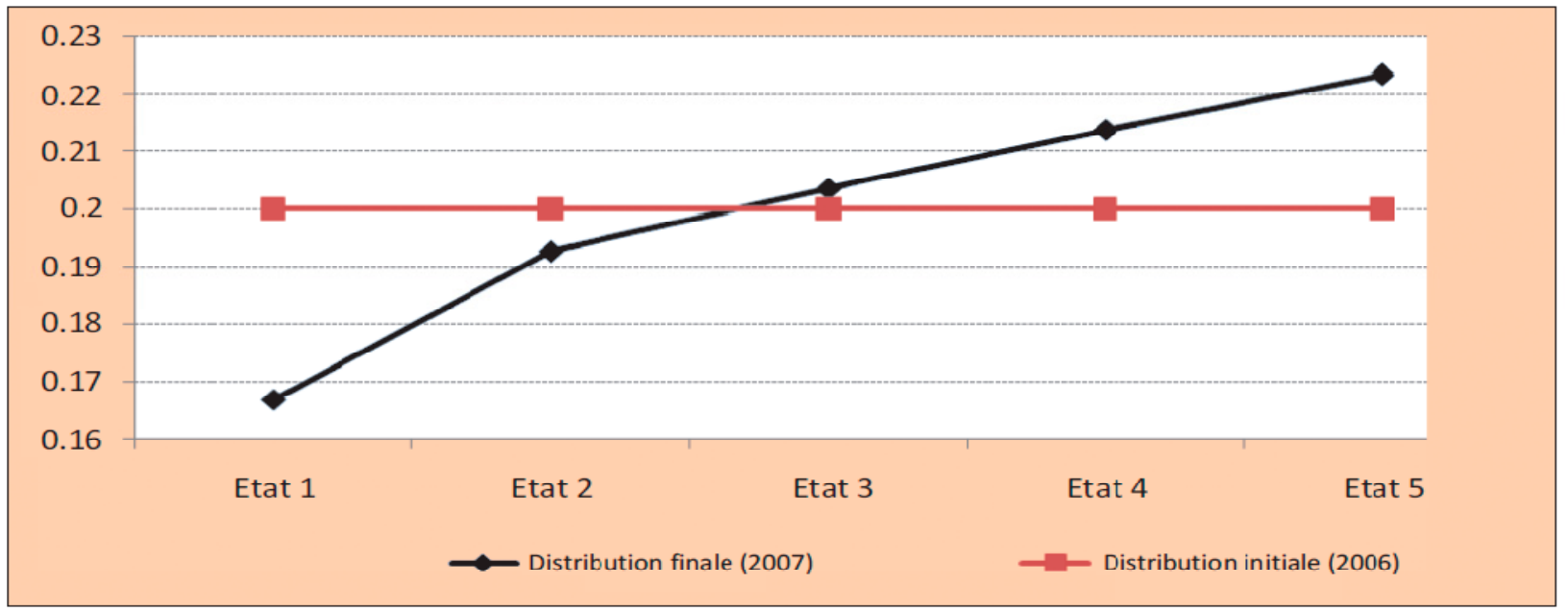

Source: From EMICoV data, 2006-2007.

\footnotetext{
${ }^{3}$ An analysis of household movements from the ranks of the poor to the nonpoor and vice versa was performed by using the transition matrix derived from sample group data established for both periods (Vodounou 2009). This served to highlight sedentary households (poor households in 2006 that remained poor in 2007, nonpoor households in 2006 that remained nonpoor in 2007) and migrants (those whose situation changed), i.e. the nonpoor (and, respectively, the poor) in 2006 who became poor (respectively nonpoor) in 2007.

${ }^{4}$ Category 1: very poor households; Category 2: poor households; Category 3: average households; Category 4: rich households; Category 5: richest households.
} 
11

\begin{tabular}{|l|l|}
\hline Etat 1 & Category 1 \\
\hline Etat 2 & Category 2 \\
\hline Etat 3 & Category 3 \\
\hline Etat 4 & Category 4 \\
\hline Etat 5 & Category 5 \\
\hline Distribution finale (2007) & Final distribution (2007) \\
\hline Distribution initiale (2006) & Initial distribution (2006) \\
\hline
\end{tabular}

Figure 1.6: Absolute Mobility, 2007-2009

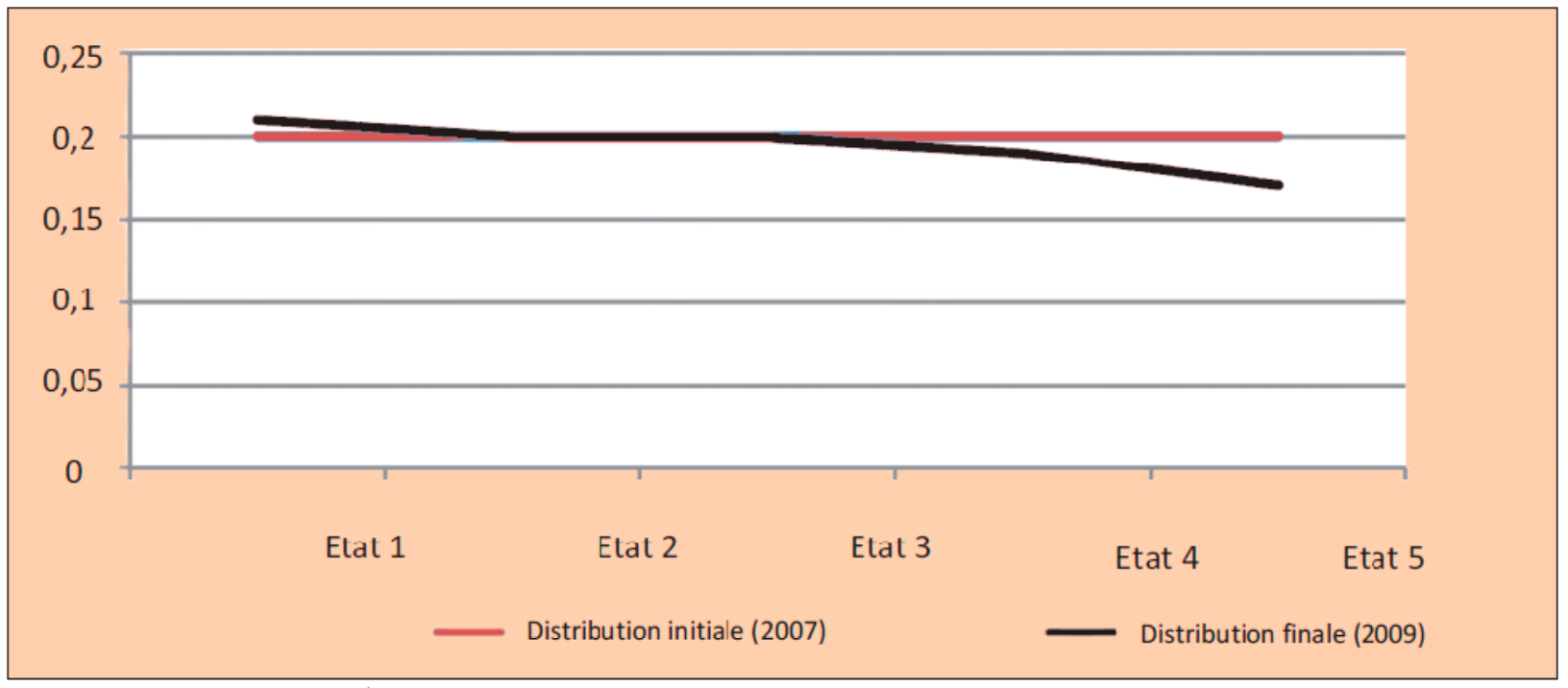

Source: From EMICoV data, 2007-2009.

\begin{tabular}{|l|l|}
\hline Etat 1 & Category 1 \\
\hline Etat 2 & Category 2 \\
\hline Etat 3 & Category 3 \\
\hline Etat 4 & Category 4 \\
\hline Etat 5 & Category 5 \\
\hline Distribution initiale (2007) & Initial distribution (2007) \\
\hline Distribution finale (2009) & Final distribution (2009) \\
\hline
\end{tabular}

1.24 This result can be explained by the consolidation of economic activity in 2007, sparking a sustained growth rate of 4.6 percent, versus 3.8 percent in 2006. The mobility analysis, based on the transition matrix, also shows that an average of 32.8 percent of households are sedentary (i.e. have not changed category) and, consequently, that the rate of persistence in the initial categories is relatively low. This trend indicates that there has been a relatively large transition between different categories of well-being.

1.25 Furthermore, of 100 households categorized as non-poor in 2007, 24 became poor in 2009. In contrast, of 100 poor households in Benin in 2007, 44 remained poor and 56 escaped poverty. Between 2007 and 2009, 30.1 percent of households were sedentary, and 32.5 percent underwent a positive transition by improving their category of well-being. On the other hand, 37.4 percent saw their category of well-being decline. 
Table 1.3: Transition Matrix, 20062007

\begin{tabular}{|l|c|c|c|c|c|}
\hline $\begin{array}{c}\text { Initial distribution } \\
\text { (2006) }\end{array}$ & \multicolumn{5}{|c|}{ Final distribution (2007) } \\
\hline & Category 1 & Category 2 & Category 3 & Category 4 & Category 5 \\
\hline Category 1 & 0.3477 & 0.2685 & 0.1862 & 0.1333 & 0.0642 \\
\hline Category 2 & 0.2166 & 0.2502 & 0.2403 & 0.1967 & 0.0963 \\
\hline Category 3 & 0.1263 & 0.2055 & 0.2532 & 0.2343 & 0.1807 \\
\hline Category 4 & 0.0852 & 0.1629 & 0.2136 & 0.276 & 0.2624 \\
\hline Category 5 & 0.0584 & 0.0767 & 0.1236 & 0.2284 & 0.5129 \\
\hline
\end{tabular}

Source: Estimates based on EMICoV data, 2006-2007, INSAE.

Table 1.4: Transition Matrix, 20072009

\begin{tabular}{|l|c|c|c|c|c|}
\hline $\begin{array}{c}\text { Initial distribution } \\
\text { (2007) }\end{array}$ & \multicolumn{5}{|c|}{ Final distribution (2009) } \\
\hline & Category 1 & Category 2 & Category 3 & Category 4 & Category 5 \\
\hline Category 1 & 0.3705 & 0.2638 & 0.1834 & 0.1176 & 0.0646 \\
\hline Category 2 & 0.2791 & 0.2512 & 0.2193 & 0.1539 & 0.0965 \\
\hline Category 3 & 0.2075 & 0.2305 & 0.2402 & 0.1974 & 0.1243 \\
\hline Category 4 & 0.1422 & 0.1838 & 0.2259 & 0.2448 & 0.2032 \\
\hline Category 5 & 0.0884 & 0.1111 & 0.1515 & 0.2448 & 0.4002 \\
\hline
\end{tabular}

Source: Estimates based on EMICoV data, 2007-2009, INSAE.

1.26 Analysis of the transition determinants confirms the same observations noted above concerning poverty trends based on characteristics of the head of household.

\subsection{GROWTH, INEQUALITY, AND POVERTY IN BENIN}

1.27 From the perspective of a pro-poor growth strategy, an analysis of trends in the incidence of poverty is not, by itself, sufficient for developing an overall assessment of the poverty situation. It needs to be rounded out by an analysis of the trend of inequalities in income distribution or spending to permit a full view of the dynamics of income poverty.

1.28 In fact, income inequality remains worrisome, despite a 0.08 percentage point decline over the period 2006-2009. The Gini index thus fell from 0.53 to 0.45 between 2006 and 2009. This reflects a better distribution of household income and consumer spending during this period. Nevertheless, this index remains high. In particular, urban areas continue to be a steady source of great inequalities in income.

Table 1.5: Evolution of the Inequality Index (Gini Index) in Benin

\begin{tabular}{|l|c|c|c|}
\hline & $\mathbf{2 0 0 6}$ & $\mathbf{2 0 0 7}$ & $\mathbf{2 0 0 9}$ \\
\hline Urban & 0.524 & 0.465 & 0.47 \\
\hline Rural & 0.481 & 0.416 & 0.37 \\
\hline Total Benin & $\mathbf{0 . 5 3 0}$ & $\mathbf{0 . 4 7 2}$ & $\mathbf{0 . 4 5}$ \\
\hline
\end{tabular}

Source: Based on EMICoV data (2006-2007, 2009), INSAE 2010. 
1.29 The increase in poverty between 2007 and 2009 is due more to the effects of growth than to the effects of redistribution. A breakdown of changes in poverty indices over the period 20072009 into redistribution and growth components shows the dominance of the growth component in comparison to the redistribution component. Thus, at the national level, the 1.9 percentage point increase in poverty incidence is the combined result of the contributions of the growth component (4.6 points) and the redistribution component (-2.6 points). This result shows that the increase in poverty between 2007 and 2009 is due more to a decline in household consumer spending than to the effects of inequality.

Table 1.6: Breakdown of Changes in Poverty into Growth (G) and Redistribution (R) Components for the Period 20072009

\begin{tabular}{|l|c|c|c|c|c|c|c|c|c|}
\hline & Change & \multicolumn{2}{|c|}{ Components } & Change & \multicolumn{2}{c|}{ Components } & \multicolumn{2}{c|}{ Change } & \multicolumn{2}{c|}{ Components } \\
\hline & P0 & G & R & P1 & G & R & P2 & G & R \\
\hline Urban & 1.45 & 2.77 & -1.32 & 0.01 & 1.13 & -1.12 & -0.33 & 0.66 & -0.99 \\
\hline Rural & 2.27 & 7.59 & -5.32 & 1.50 & 4.11 & -2.61 & 0.88 & 2.41 & -1.53 \\
\hline Total & 1.96 & 4.58 & -2.62 & 0.95 & 2.28 & -1.33 & 0.43 & 1.33 & -0.90 \\
\hline
\end{tabular}

P0 = poverty incidence $\quad$ P1 = poverty depth

Source: Based on EMICoV data, INSAE 2009.

\subsection{OVERVIEW: CRITICAL FACTORS FOR POVERTY REDUCTION IN BENIN}

1.30 The poverty analysis has shown, on the one hand, that poverty increased overall in Benin between 2007 and 2009 and also, on the other hand, that it continued to be characterized by a significant decline in non-income poverty.

1.31 Analysis of the components of change in poverty has highlighted the decisive role of redistribution and economic growth in poverty reduction. Thus, poverty reduction strategies to be implemented in Benin must not only aim for strong economic growth but also promote pro-poor redistribution policies.

1.32 Analysis of the factors underlying the persistence of poverty and the fact of entering or exiting poverty points to the importance of educational level, employment sector, access to credit, basic infrastructure, and initial income as determinants of poverty reduction. On the other hand, large household size (eight or more persons) appears to be a highly limiting factor in this regard.

1.33 In brief, analysis of the determinants of poverty suggests that special attention should be given to the following goals:

(i) promote the local economy to reduce poverty in rural areas;

(ii) control population growth, given the strong correlation that exists between poverty and large household size;

(iii) reduce gender inequalities;

(iv) strengthen social welfare, especially for senior citizens;

(v) strengthen basic infrastructure; and

(vi) strengthen microcredit policy to permit access to credit for the poor. 


\section{CHAPTER 2: RECENT ECONOMIC AND SOCIAL PERFORMANCE}

\subsection{MACROECONOMIC FRAMEWORK SITUATION}

2.1 The macroeconomic situation remained positive overall between 2006 and 2009 despite the energy, food, financial, and economic crises. It was characterized by:

(i) a moderate inflation rate;

(ii) a low level of external debt; and

(iii) an improvement in budgetary revenue, accompanied by containment of public expenditure, notwithstanding difficulties encountered in 2009.

Thus, Benin, like most African countries, was spared the effects of the first round of the world financial crisis, ${ }^{5}$ due to its weak integration into international financial markets. However, since 2009 the country has been feeling the effects of the second round of the crisis, reflected in a drop in international flows (foreign direct investment, migrants' remittances) and a slowdown of the national economy.

\subsubsection{Productive sector}

2.2 In 2009, the effects of the world crisis slowed economic growth, underway since 2006. Indeed, the growth rate increased from 3.8 percent in 2006 to 4.6 percent in 2007 and then 5.0 percent in 2008 (Figure 6). This growth was driven by the strong results recorded in the primary and tertiary sectors, particularly in the areas of trade and transport. However, the rate of growth fell in 2009 due to the second-round effects of the international financial crisis (decreases in exports and consumption) and the steps taken by Nigeria to address the food crisis. ${ }^{6}$ The estimated growth rate for 2009 is 2.7 percent.

Figure 2.1: Evolution of the Economic Growth Rate

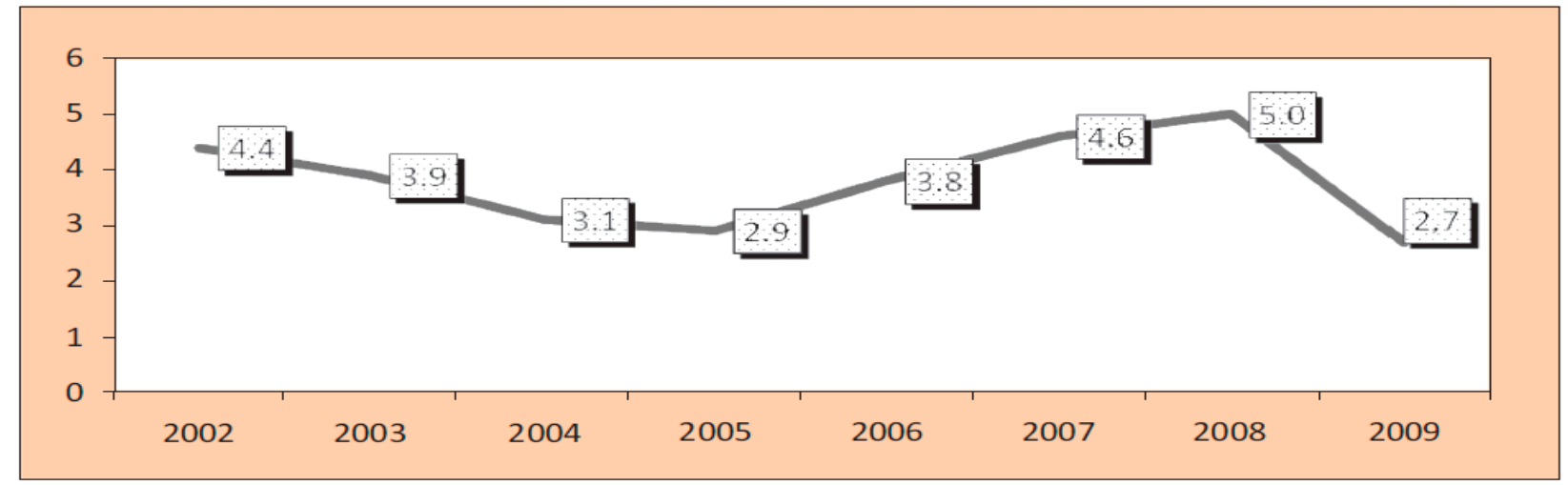

Source: From INSAE data, 2010.

\footnotetext{
${ }^{5}$ At the international level, the years 2008 and 2009 were marked by the harmful effects of the crises that plunged the world economy into a recession unrivaled since the Great Depression of 1929.

${ }^{6}$ Tariff reductions in Nigeria on imports of food products, particularly rice. There were consequences for Benin.
} 
2.3 Agriculture remains one of the key engines of economic growth, with a 0.9 percent average contribution to growth between 2007 and 2009. Agricultural sector performance can be attributed to non-cotton primary production and, among other factors, it can be traced to favorable rainfall, implementation of the Emergency Food Security Support Program (PUASA) in response to the food crisis, and the distribution of specific inputs for food production in 2009. In 2007, the output of cotton, the country's leading export crop, increased by 11.2 percent over 2006 as a result of:

(i) favorable rainfall conditions;

(ii) steps taken to reorganize sector stakeholders; and

(iii) wiping out of cotton growers' debts.

This spike in output did not continue into 2008 and 2009. In fact, cotton output began to decline in 2008 due to the industry's organizational difficulties. From a total of 268,054 metric tons in 2007, output fell to 220,000 metric tons for the 2008-2009 crop year and then 200,000 metric tons for the 2009-2010 crop year.

2.4 The secondary sector's contribution to economic growth is relatively small. During the period 2007-2009, this sector's contribution to growth in GDP averaged 0.6 percent. The industrial production index rose by 7.4 percent between 2007 and 2008. In 2009, it increased by 4.6 percent over 2008 .

2.5 The tertiary sector was hit hard by the world crisis but nevertheless accounts for the greatest contribution to growth in GDP. During the period 2007-2009, this sector achieved a 5.2 percent increase in added value, with a 1.5 percent average contribution to growth, attributable to the improved competitiveness of the Port of Cotonou pursuant to the various reforms undertaken in this sector, along with the arrival of a new telephone service operator in 2008. In 2009, however, the tertiary sector's contribution fell sharply, all the way from 2.1 percent in 2008 to 0.8 percent in 2009 .

Table 2.1: Evolution of Sectoral Contributions to the Growth Rate, 20072009

\begin{tabular}{|l|c|c|c|c|}
\hline & $\mathbf{2 0 0 7}$ & $\mathbf{2 0 0 8}$ & $\mathbf{2 0 0 9}$ & 2007-2009 Average \\
\hline Primary sector & 1.6 & 1.4 & 0.8 & 1.3 \\
\hline Secondary sector & 0.5 & 0.6 & 0.6 & 0.6 \\
\hline Tertiary sector & 1.7 & 2.1 & 0.8 & 1.5 \\
\hline Nonmarket services & 0.5 & 0.5 & 0.5 & 0.5 \\
\hline DTI and domestic VAT & 0.4 & 0.4 & 0.0 & 0.3 \\
\hline Total GDP & $\mathbf{4 . 6}$ & $\mathbf{5 . 0}$ & $\mathbf{2 . 7}$ & $\mathbf{4 . 1}$ \\
\hline
\end{tabular}

Source: DGAE/MEF, February 2010.

\subsubsection{Inflation}

2.6 Success in controlling inflation partly explains the macroeconomic stability of recent years. A deceleration of the price increases observed in 2006 was only temporarily reversed in 2008, under the weight of a spike in international prices for food commodities and energy. These price increases resulted in a one-time inflation rate of 7.9 percent in 2008, as compared to 1.3 percent in 2007. In 2009, inflation retreated due to falling international prices. Thus, the inflation 
rate returned to 2.2 percent in 2009, well below the community standard of 3 percent. The Government's actions aimed at promoting food crop production also contributed to the decline.

Figure 2.2: Evolution of the Inflation Rate, Annual Movement from 2000July 2009

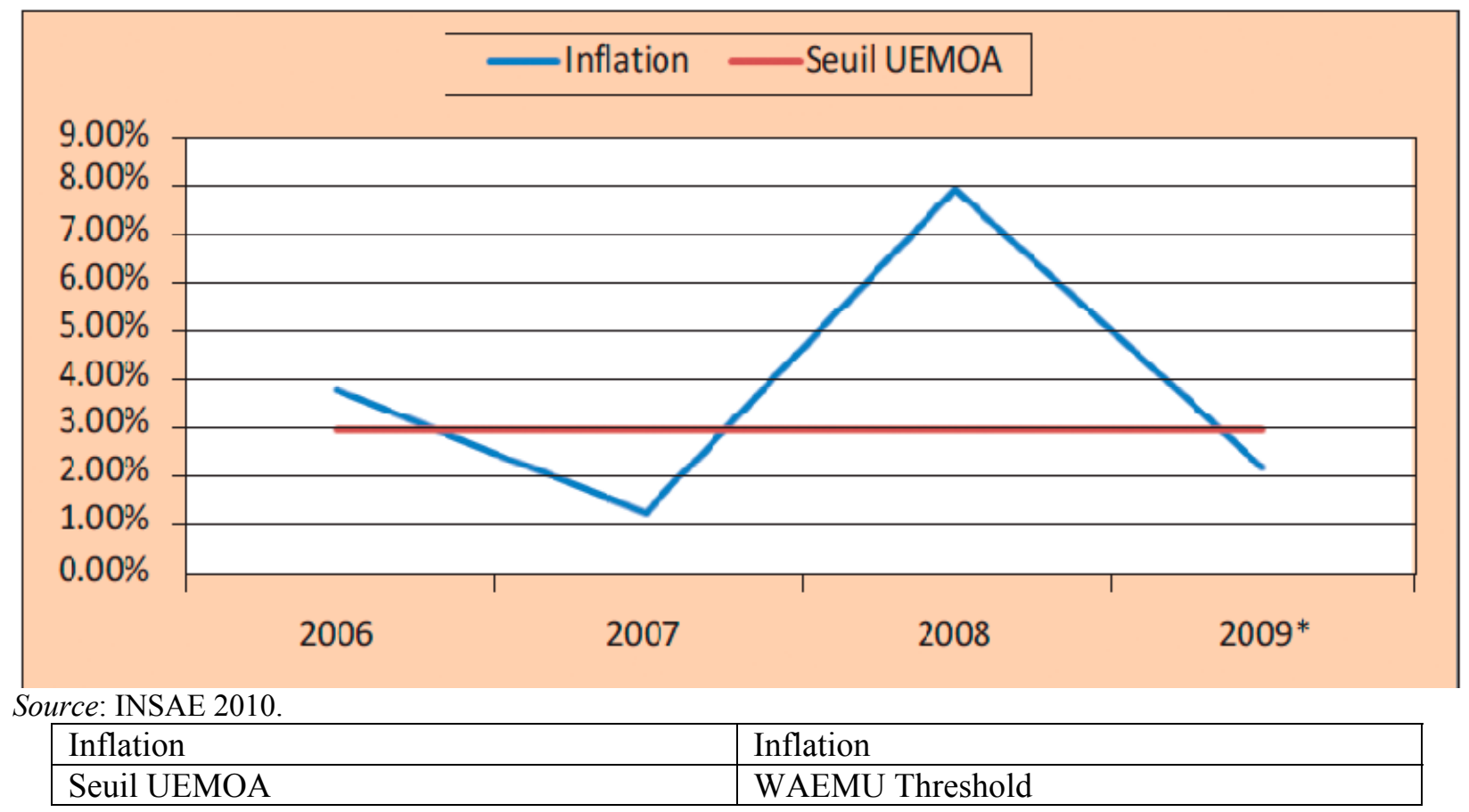

\subsubsection{Public finances}

2.7 Efforts to reorganize public finances have continued in a context of strong social pressures and worldwide economic crisis. Over the period 2007-2009, the Government's financial operations were characterized by consolidation in the mobilization of internal revenues and growth in government spending as required for 2007-2009 GPRS implementation. In fact, government revenues in 2008 came to CFAF 581.3 billion, i.e. a 6.1 percent increase over 2007. However, revenues then fell slightly, by 0.9 percent, in 2009 , due to the cumulative effects of the international financial and economic crisis and the decline in the re-export trade to Nigeria.

2.8 The tax authority reforms instituted by the Government resulted in higher domestic revenues. Total tax revenue rose from CFAF 196.6 billion in 2007 to CFAF 233.3 billion in 2008 , i.e. an increase of 18.7 percent. In 2009, revenue continued to increase by 3.4 percent compared to 2008. Tax performance over the period 2007-2009 is the result of measures taken by the Government, particularly:

(i) updating and simplification of the General Tax Code (CGI);

(ii) dissemination of the Single Taxpayer Identification Number (TIN); and

(iii) computerization of various services and proliferation of payment locations.

2.9 Growth in customs revenues slowed down in 2009. Customs revenues rose from CFAF 250.1 billion in 2007 to CFAF 278.9 billion in 2008, i.e. an increase of 11.5 percent. But in 2009 , 
customs revenues fell off, which was related to the decline in international trade and the drop in re-exports to Nigeria. Thus, estimated customs revenues for the year total CFAF 259.2 billion, i.e. a 7.0 percent decline compared to 2008 .

2.10 One-time mobilization of nontax revenues because the Government raised mobile communication licensing fees during the period 2007-2009. On average, nontax revenues rose from CFAF 41.7 billion over the period 2003-2005 to CFAF 81.9 billion over the period 20072009. This doubling of nontax revenues is mainly due to the payment, by all GSM operators, of the first installment of 50 percent in 2007, pursuant to the Government raising GSM licensing fees, which increased from CFAF 5 to 30 billion.

2.11 Public expenditure rose by 51.0 percent to ensure implementation of the 2007-2009 GPRS. In fact, spending rose on average from CFAF 458.1 billion during the period 2003-2005 to CFAF 691.9 billion over the period 2007-2009. Capital expenditure ( +66.4 percent) increased more than current expenditures ( +38.7 percent). Indeed, investments rose from CFAF 137.0 billion to CFAF 228.0 billion between the periods 2003-2005 and 2007-2009, versus an increase from CFAF 313.1 billion to CFAF 434.3 billion for current expenditures. However, spending experienced a one-time spike of 55.6 percent in 2009 due to a number of factors, including:

(i) transfer of contract employees to civil service;

(ii) evolution of the index point for permanent government employees;

(iii) granting of an allowance of 25 percent of the index point to teachers in connection with upgrading the teaching profession; and

(iv) granting of bonuses and benefits to employees in priority GPRS sectors (health, education, etc.).

Table 2.2: Evolution of Budget Aggregates, 20072009 (CFAF billions)

\begin{tabular}{|l|c|c|c|c|}
\hline & $\mathbf{2 0 0 7}$ & $\mathbf{2 0 0 8}$ & $\mathbf{2 0 0 9}$ & $\begin{array}{c}\mathbf{2 0 0 7 - 2 0 0 9} \\
\text { Annual Average }\end{array}$ \\
\hline Total revenue & 547.2 & 581.3 & 575.8 & 568.1 \\
\hline Tax revenue & 445.9 & 512.2 & 500.4 & 486.2 \\
\hline Nontax revenue & 101.3 & 69.1 & 75.4 & 81.9 \\
\hline Total expenditure & 585.5 & 684.6 & 805.5 & 691.9 \\
\hline Labor costs & 143.1 & 182.4 & 225.9 & 204.1 \\
\hline Public investment & 206.9 & 174.7 & 302.3 & 228.0 \\
\hline Budgetary contribution & 93.7 & 105.3 & 221.6 & 140.2 \\
\hline $\begin{array}{l}\text { Overall deficit based on payment } \\
\text { authorizations }\end{array}$ & $\mathbf{- 3 8 . 3}$ & $\mathbf{- 1 0 3 . 3}$ & $\mathbf{- 2 2 9 . 7}$ & $\mathbf{- 1 2 3 . 8}$ \\
\hline
\end{tabular}

Source: CSPEF, March 2010.

\subsubsection{Public debt}

2.12 In 2006, Benin benefitted from the HIPC and MDRI debt relief initiatives that made it possible to restructure public debt thanks to a significant reduction in outstanding external debt. The latter followed an upward trend from 2007 to 2009, from CFAF 299.70 billion in 2007 to CFAF 463.26 billion in 2009 (Table 8). Meanwhile, outstanding domestic debt rose from CFAF 243.9 billion in 2007 to CFAF 361.7 billion in 2009. This increase in domestic debt is connected 
to government intervention in the financial market involving Treasury bonds and bond issues. Overall, public debt remained viable throughout the period 2007-2009.

Table 2.3: Evolution of Benin's Outstanding External Debt (CFAF billions)

\begin{tabular}{|l|c|c|c|c|c|}
\hline & $\mathbf{2 0 0 5}$ & $\mathbf{2 0 0 6}$ & $\mathbf{2 0 0 7}$ & $\mathbf{2 0 0 8}$ & $\mathbf{2 0 0 9}$ \\
\hline Outstanding debt & 919.40 & 264.40 & 299.70 & 415.1 & 463.26 \\
\hline Bilateral debt & 144.6 & 65.1 & 58.8 & 73.6 & 78.7 \\
\hline Multilateral debt & 774.8 & 199.3 & 240.9 & 341.5 & 384.6 \\
\hline Outstanding debt/GDP (\%) & $40.00 \%$ & $11.30 \%$ & $9.92 \%$ & $13.96 \%$ & $17.33 \%$ \\
\hline
\end{tabular}

Source: CAA/MEF, March 2010.

\subsubsection{Balance of payments}

2.13 Benin's trade balance shows a structural deficit. The average trade balance deficit between 2007 and 2009 (Table 9) was equivalent to 9.9 percent of GDP. Indeed, over the period 2007-2009, imports steadily increased at a faster rate than exports.

Table 2.4: Evolution of Foreign Trade (\% of GDP)

\begin{tabular}{|l|c|c|c|}
\hline & $\mathbf{2 0 0 7}$ & $\mathbf{2 0 0 8}$ & $\mathbf{2 0 0 9}$ \\
\hline Exports & 19.0 & 19.3 & 18.6 \\
\hline Imports & 29.1 & 28.4 & 26.4 \\
\hline Trade balance & -10.1 & -9.1 & -7.8 \\
\hline Opening ratio & 48.1 & 47.7 & 44.4 \\
\hline Coverage ratio & 65.3 & 67.9 & 70.5 \\
\hline Current balance & -10.1 & -8.1 & -9.9 \\
\hline General balance & $\mathbf{5 . 9}$ & $\mathbf{1 . 4}$ & $\mathbf{- 1 . 6}$ \\
\hline
\end{tabular}

Source: BCEAO, March 2010.

2.14 There was an external current account deficit throughout the period 2007-2009. The current account deficit was equivalent to 9.9 percent of GDP in 2009, versus 8.1 percent in 2008 and 10.1 percent in 2007. This situation is mainly the result of:

(i) a decline in net services and public and private transfers under the effects of the international economic crisis; and, to a lesser extent,

(ii) deterioration of the trade balance, tied to the more pronounced slowdown of cotton and textile exports.

2.15 The Government's capital and financial transactions account balance showed a surplus throughout the period 2007-2009. From CFAF 363.6 billion in 2007, it fell to CFAF 271.9 billion in 2008. The estimated figure for 2009 is CFAF 260.2 billion.

2.16 Overall, the balance of payments showed a surplus over the period 2007-2008 but then showed a deficit in 2009. This deficit can be attributed to the second-round effects of the financial and economic crisis and the steps taken by Nigeria to address the food crisis. The deficit in 2009 came to CFAF 48.9 billion, versus surpluses of CFAF 36.9 billion in 2008 and CFAF 141.4 billion in 2007. 


\subsubsection{Monetary situation}

2.17 Money supply increased in 2009. The estimated figure for 2009 is CFAF 1,178.2 billion, versus CFAF 1,101.7 billion in 2008 and CFAF 867.9 billion in 2007 (Table 10). This increase in money supply is related to the increase in counterpart factors, namely domestic credit and net external assets.

Table 2.5: Monetary Situation, 20072009 (CFAF billions)

\begin{tabular}{|l|c|c|c|}
\hline & $\mathbf{2 0 0 7}$ & $\mathbf{2 0 0 8}$ & $\mathbf{2 0 0 9}$ \\
\hline Net external assets & 656.5 & 691.6 & 645.9 \\
\hline Domestic credit & 229.4 & 437.7 & 591.8 \\
\hline Government's net position & -298.2 & -186.8 & -106.7 \\
\hline Economy appropriation & 527.6 & 624.5 & 698.5 \\
\hline Money supply & 867.9 & $1,101.7$ & $1,181.4$ \\
\hline Available means of payment & 246.4 & 365.6 & 341.1 \\
\hline Fiduciary circulation & 238.8 & 356.7 & 332.2 \\
\hline Postal check account deposits & 7.6 & 8.9 & 8.9 \\
\hline Bank deposits & 621.5 & 736.1 & 840.4 \\
\hline Net other elements (items) & 18.1 & 27.6 & 52.0 \\
\hline
\end{tabular}

Source: BCEAO, March 2010.

2.18 Domestic credit rose from CFAF 229.4 billion in 2007 to CFAF 593.1 billion in 2009, i.e. an increase of 158.5 percent over this period. This growth in domestic credit can be attributed to a 33.9 percent increase in the economy appropriation in 2009 compared to 2007. The Net Position of the Government (PNG) deteriorated over this period, moving from CFAF -298.2 billion to CFAF -113.6 billion, reflecting the Government's growing reliance on the regional financial market, in the form of government debt (treasury bonds and notes). Net external assets underwent a 3 percent decline, falling from CFAF 656.5 billion in 2007 to CFAF 637.0 billion in 2009.

2.19 In brief, an economic and financial flows analysis, based on the savings-investment approach, shows that the current deficits observed over the period 2007-2009 stem primarily from the public sector (75.9 percent), to the detriment of the private sector ( 28.5 percent). This situation can be explained by the accumulation of budget deficits and the inadequacy of private savings in the face of a steadily growing volume of investment. To finance its deficit, the public sector has relied on both external and internal financing. In 2009, the public sector received CFAF 142.6 billion in external financing, i.e. CFAF 77.4 billion in grants and CFAF 65.3 billion in long- and medium-term capital. Domestically, the Government has turned to the banks for a total of CFAF 80.0 billion. This use of bank financing by the Government has resulted in a contraction of domestic credit extended to the private sector, which could cause the private sector to be supplanted by the public sector.

\subsection{PRINCIPAL ACHIEVEMENTS IN THE AREA OF HUMAN DEVELOPMENT}

2.20 Implementation of GPRS 2 has resulted in a number of major achievements in regard to basic social services and health care. Significant improvements have been made in the education, health, nutrition, and gender equality sectors. However, substantial efforts still need to be made in all these sectors. 


\subsubsection{Education sector}

2.21 Education sector performance has improved over the last three years. Actions taken under the 2007-2009 GPRS, with support from Technical and Financial Partners, were focused primarily on the following themes:

(i) pursue free maternal and primary education;

(ii) establish the Budgetary Common Fund for basic education;

(iii) upgrade the status of the teaching profession; and

(iv) take specific measures in support of other levels of education.

2.22 With respect to maternal education, these actions resulted in improved levels of preschool enrollment, consistent with the objectives of the Ten-Year Education Sector Development Plan (PDDSE). Indeed, from 4.5 percent in 2007, the preschool gross enrollment rate rose to 7.6 percent in 2008 and 8.04 percent in 2009, with a target of 9 percent.

2.23 With respect to primary education, the results are encouraging. The gross enrollment rate (TBS) increased from 92.9 percent in 2006 to 104 percent in 2007, and then rose by 5.1 points to reach 109.1 percent in 2009, thus indicating massive attendance by children outside the primary school age bracket ( 6 to 11 years of age). This situation is explained by the very high level of the CI gross admission rate, which rose from 109 percent in 2006 to 140 percent in 2009. Meanwhile, the percentage of girl pupils increased from 44.4 percent in 2006 to 46 percent in 2009, and the admission of girls to CI rose from 104 percent in 2006 to 137.9 percent in 2009, denoting an improvement in girls' school attendance.

2.24 An analysis of the net enrollment rate (TNS) for children of 6-11 years of age shows overall improvement during the period 2006-2007. At the national level, the TNS rose from 61.1 percent in 2006 to 76.2 percent ( 78.3 percent of boys and 73.9 percent of girls) in 2007, with a target of 100 percent in 2015.

2.25 However, shortcomings have been noted in terms of internal effectiveness. The repeater rate increased from 10 percent in 2007 to 13 percent in 2009, while the completion rate failed to improve, falling from 66 percent in 2007 (56 percent for girls) to 65 percent in 2009 (57 percent for girls).

2.26 The illiteracy rate remains high for persons of 15 or more years of age. From roughly 30 percent in 1990, the literacy rate had climbed to 60.5 percent by 2007 , i.e. an increase of two percentage points per year. This rate of increase remains very modest in comparison to the pace needed to meet the MDGs. In addition, the trend has been unfavorable to women: the literacy rate for women of 15-24 years of age is 50 percent, versus 72.4 percent for men.

\subsubsection{Health sector}

2.27 Health indicators have shown improvement, but overall they have not reached the targets set for them. The health services utilization rate went from 45.6 percent in 2007 to 46.1 percent in 2009, while the pentavalent vaccine coverage rate increased for children of 0-11 months of age, rising from 96 percent in 2007 to 98 percent in 2009. The percentage of children under 5 
years of age sleeping under treated mosquito netting remained stable between 2008 and 2009, i.e. 56.3 percent versus a target of 60 percent in 2009.

2.28 Conversely, the rate of births assisted by medical or paramedical staff showed a decline, falling from 82 percent in 2007 to 78.6 percent in 2009. The health services utilization rate for children of 0-5 years of age also showed a decline, from 83.3 percent in 2007 to 76.5 percent in 2008. This decline is linked to the preventive measures taken as part of the malaria control efforts, since malaria is the leading cause of visits to health facilities in Benin (roughly 40 percent). In particular, these preventive measures involve:

(i) the campaign to distribute free-of-charge 1.7 million Long Lasting InsecticideTreated Nets (LLINs) in 2007 for children of 0-5 years of age; and

(ii) training for radiotherapists, for community health workers, and for mothers/caretakers of children on how to treat fever at home, with recognition of the telltale signs of serious malaria.

2.29 In addition, the new actions undertaken by the Government, particularly free Caesarean deliveries starting in 2009, should lead to better results in the area of maternal and neonatal health. These actions will be reinforced through the National Agency to Manage Free Caesarean Care, created in 2009, which received a grant of CFAF 2.5 billion in 2010, versus CFAF 0.2 billion in 2009. This initiative aims to reduce maternal and neonatal mortality by covering the expenses associated with Caesarean deliveries, the cost of which is unaffordable for underprivileged populations. The initiative benefitted 11,543 women between April 1 and December 31, 2009. This figure is expected to at least double in 2010.

\subsubsection{Food and nutrition}

2.30 The distribution of consumer spending on food products (EMICoV, 2006 and 2007) shows that 26.5 percent of the population suffered from hunger in 2007, versus 23.1 percent in 2006. Thus, the number of undernourished persons increased by 3.4 percentage points between 2006 and 2007. This upward trend appears to be due to the effects of the food crisis ${ }^{7}$ that arose in 2007. Based on area of residence, the results show that food poverty is more dominant in rural areas (28.4 percent) than in urban areas (23.2 percent).

\subsubsection{Gender}

2.31 The implementation of various laws and measures ${ }^{8}$ has resulted in a stronger legal and institutional framework for reducing inequalities between the sexes and better participation by

\footnotetext{
${ }^{7}$ According to the 2009 FAO report, the spike in food commodity prices and the recent international financial crisis have increased hunger around the world. As such, the number of undernourished persons in Benin could grow substantially ( $>26$ percent between 2008 and 2009).

${ }^{8}$ Adoption of Law 2002-07 of August 24, 2004 establishing the Individual and Family Code (CPF); the national policy on girls' education and training, adopted on April 11, 2007; the national policy on promoting gender equality in Benin, adopted in March 2009; Law 2006-19 of September 5, 2006 establishing penalties for sexual harassment and protections for victims in the Republic of Benin; Law 2005-31 of April 5, 2006 on HIV/AIDS prevention, coverage, and control in the Republic of Benin.
} 
women in the development process, although such participation by Beninese women remains very far from the objective of parity. As for women's participation in decision-making bodies, there has been some limited progress in the parliament and in local representation, as follows:

(i) a 3 point increase in women's representation in the National Assembly: 10 percent for the current term (2007-2011) versus 7.22 percent for the preceding term (2003-2007); and

(ii) a 0.43 point increase in women's representation at the most recent local elections, held in 2008: 4.18 percent (60 women elected out of 1,435 communal councilors), versus 3.75 percent (46 women elected out of 1,199 communal councilors) at the 2003 elections.

\subsection{PROGRESS IN INFRASTRUCTURE DEVELOPMENT}

2.32 The actions undertaken in basic infrastructure sectors have resulted in the construction and rehabilitation of several roads, an increase in the household electric power coverage rate, and improved access to safe drinking water.

\subsubsection{Road system}

2.33 A number of actions have been carried out to develop earth roads, rehabilitate and maintain paved roads, build specific road system structures, and develop and maintain rural roads. In particular, the total length of rural roads that were developed or rehabilitated came to $1,208.6 \mathrm{~km}^{9}$ in 2009 , versus $2,441.2 \mathrm{~km}$ in 2008 and 2,213.3 $\mathrm{km}$ in 2007 . Development of these roads has served to reduce the isolation of producing areas and facilitate the marketing of agricultural products. In addition, the city modernization initiatives have resulted in the construction of several specific structures, especially in Cotonou (Houéyiho and Steinmetz overpasses). Still, the road system condition index, after improving from 71.0 percent in 2006 to 78.0 percent in 2007, deteriorated in 2008 (62 percent) because of the inadequate pace of maintenance. It then improved to 76.0 percent in 2009 .

\subsubsection{Electric power}

2.34 With respect to electric power coverage, the results are consistent with the Energy for Poverty Reduction and Development Program, to wit:

(i) expansion and upgrading of power grids, both in urban areas (Cotonou, Porto-Novo, Abomey-Calavi, etc.) and in rural areas (Akpassi, Pira, etc.);

(ii) continuation of the work on interconnecting the North Togo and North Benin power grid; and

(iii) completion of several expansions of the low voltage and medium voltage grid. These actions have produced substantial results: the national electrification rate came to 27.7 percent in 2009, versus 25.6 percent in 2008 and 24.7 percent in 2007. The rural electrification rate, for its part, came to 3.1 percent in 2009 , versus 2.5 percent in

\footnotetext{
${ }^{9}$ Including $271 \mathrm{~km}$ of rural roads constructed by Rural Engineering.
} 
2008 and 1.9 percent in 2007. However, the sector still suffers from heavy dependence on external actors and weak development of national energy production capacities. In addition, the regulatory and institutional framework continues to provide little incentive to the private sector to become involved in energy production.

2.35 Improving access to safe drinking water has been a special concern of the Government, with support from its Technical and Financial Partners. The main accomplishments in this sector are reflected in a safe drinking water servicing rate of 55.1 percent in rural and semi-urban areas in 2009, versus 49.9 percent in 2008 and 46.5 percent in 2007, plus an increase in new Equivalent Water Points (EPEs) from 1,206 in 2006 to 1,884 in 2009.

\subsection{PERFORMANCE IN PROMOTING GOOD GOVERNANCE}

2.36 The indicators for monitoring the quality of governance show mixed results, both in terms of strengthening the rule of law and in terms of accelerating government reform. The indicators pertaining to the rule of law deteriorated between 2006 and 2007 due to social movements in the justice sector. Improvements were however noted from 2007 to 2008. Thus, over the three years $(2007,2008$, and 2009), the following changes occurred:

(i) the rate of closed cases went from 24.2 percent in 2007 to 31 percent in 2008 , then to 25.1 percent in 2009;

(ii) the average duration of civil proceedings fell from 10.4 months in 2007 to 7.7 months in 2008 , then to 6.7 months in 2009;

(iii) the average duration of preventive detentions in investigative cases fell from 17.3 months in 2007 to 14.2 months in 2008, then to 12 months in 2009; and

(iv) the prison occupancy rate improved overall during the period 2007-2009, ranging from 194 in 2007 to 205 in 2009, compared to a level of 323 in 2006.

2.37 With respect to financial governance, the indicator most carefully tracked is the rate of use of Payment Orders ${ }^{10}$ (POs), which declined sharply from 9.53 percent in 2007 and 12.3 percent in 2008 to 4.98 percent in 2009. This falloff is due to the Government's decision to seek to regulate and limit the issuance of Payment Orders. However, the persistently low budget execution rate should be noted. In 2009, the operating budget execution rate based on payment orders came to 78 percent, with a very low rate of just 35.2 percent for investments from own resources.

\footnotetext{
${ }^{10}$ POs constitute a special procedure for public expenditure execution. A distinction is drawn between SIGFIP POs and Treasury POs. SIGFIP POs are expenditures laid out in the budget, authorized and approved by the Comptroller, but to be scheduled after the event. These expenditures follow so-called "special" procedures set forth by statute. They are regularly reconciled throughout the year and must be equal to zero after the event. Treasury "budget-type" POs are expenditures made according to a procedure not covered by statute to deal with expenses deemed urgent, which may or may not be authorized.
} 


\subsection{ACHIEVEMENTS AND SHORTCOMINGS OF DECENTRALIZATION AND REGIONAL PLANNING POLICIES}

2.38 The indicators pertaining to decentralization, already showing improvement, are expected to grow stronger, particularly with the vote on the intercommunality law and adoption of the National Decentralization and Deconcentration Policy (PONADEC) by the Government in 2009. Thus, the indicator "number of development regions set up and formalized" increased from 4 in 2007 to 10 in 2009. Similar results were achieved for several other indicators, particularly:

(i) the proportion of regional and local administration expenditures in relation to total spending in the general State budget, which was 8.8 percent in 2009 versus 4.1 percent in 2007;

(ii) transfers to local administrations, which greatly increased between 2007 and 2009 due to the start-up of FADeC (Communal Development Support Fund), rising from 1.5 percent of the general State budget in 2007 to 3.7 percent in 2009; and

(iii) the proportion of capital expenditure in relation to total commune expenditure, which increased from 26 percent in 2007 to 45.6 percent in 2009.

\subsection{PROGRESS TOWARD ACHIEVING THE MDGs IN BENIN}

2.39 Benin, taking stock of the September 2000 commitment regarding MDGs, has firmly involved itself in the work of achieving the MDGs by 2015. This political commitment has taken concrete form at the national level in a continuous effort to take MDGs into account whenever forward-looking and strategic policies are being considered for the country's development. Nonetheless, ten years later, the progress made toward achieving the MDG targets remains slow in certain sectors. This situation is essentially due to the insufficiency and the quality of economic growth generated, as well as problems with governance-especially economic and administrative governance - and, as a corollary, the persistence of poverty.

2.40 In fact, a detailed analysis of MDG-related trends shows that, for certain targets, the country is on track and, if the efforts are sustained, the probability of reaching these targets by 2015 is high. This is true, in particular, of the targets related to universal access to primary education, reduction of the infant mortality and infant-child mortality rates, and access to safe drinking water. However, inequalities persist, based on gender, area of residence, region, and socioeconomic category.

2.41 This progress has been achieved in particular through community-based initiatives in the areas of girls' education, detection of malnutrition in children under five years of age, and more equitable access to safe drinking water. All these actions highlight the necessity of community involvement in (and ownership of) development programs. Furthermore, the national awareness of the necessity of achieving the MDGs is reflected in the planning, programming, budgeting, and monitoring and evaluation of development programs and projects (e.g. in preparing program budgets and annual work plans and in organizing sectoral and national reviews, etc.). 
Table 2.6: Overview of Constraints Identified for each MDG

\begin{tabular}{|c|c|c|c|c|}
\hline & $\begin{array}{l}\text { MDG-Based } \\
\text { Planning } \\
\text { Framework }\end{array}$ & Financing & $\begin{array}{l}\text { Service Delivery at the } \\
\text { Local Level }\end{array}$ & $\begin{array}{c}\text { Project } \\
\text { Implementation and } \\
\text { Monitoring and } \\
\text { Evaluation (M\&E) }\end{array}$ \\
\hline MDG 1 & $\begin{array}{l}\text { - Low growth } \\
\text { and insufficient } \\
\text { pro-poor } \\
\text { growth } \\
\text { strategies } \\
\text { - Continuous } \\
\text { effort of MDG- } \\
\text { oriented } \\
\text { strategic } \\
\text { planning } \\
\text { - PSRSA } \\
\text { development } \\
\text { - PSDAN } \\
\text { development }\end{array}$ & \multirow[t]{3}{*}{$\begin{array}{l}\text { In general, } \\
2007-2009 \\
\text { GPRS } \\
\text { appropriatio } \\
\text { ns fall short } \\
\text { of MDG } \\
\text { needs for } \\
\text { the period } \\
2009-2015 \\
(60.5 \% \text { of } \\
\text { needs in } \\
2010) \\
\text { - Education: } \\
93.3 \%\end{array}$} & $\begin{array}{l}\text { - Weak outreach } \\
\text { (advisory support for } \\
\text { rural development and } \\
\text { nutrition, availability } \\
\text { of inputs) } \rightarrow \text { low } \\
\text { productivity } \\
\text { - Fragmentation and } \\
\text { small size of farms }\end{array}$ & $\begin{array}{l}\text { - Absence of a } \\
\text { specific, operational } \\
\text { M\&E system in the } \\
\text { agriculture sector }\end{array}$ \\
\hline MDG 2 & $\begin{array}{l}\text { - Development of } \\
\text { the Ten-Year } \\
\text { Education } \\
\text { Sector } \\
\text { Development } \\
\text { Plan } \\
\text { - Development of } \\
\text { the } \\
\text { decentralization } \\
\text { and } \\
\text { deconcentration } \\
\text { policy, which } \\
\text { needs to be } \\
\text { actually } \\
\text { implemented }\end{array}$ & & $\begin{array}{l}\text { - Weak local supervision } \\
\text { - Greatly inadequate } \\
\text { numbers of teachers } \\
\text { and facilities } \\
\text { (classrooms, bench } \\
\text { tables, school } \\
\text { canteens) and } \\
\text { insufficient } \\
\text { educational materials } \\
\text { - Long-term } \\
\text { abandonment of in- } \\
\text { service teacher training } \\
\text { - School access } \\
\text { sometimes limited by } \\
\text { parents' low income } \\
\text { - Resource management } \\
\text { still centralized }\end{array}$ & $\begin{array}{l}\text { - Weak capacity of } \\
\text { primary education } \\
\text { departments in } \\
\text { regard to } \\
\text { management of the } \\
\text { project cycle } \\
\text { - Absence of a reliable } \\
\text { information system } \\
\text { (school map, number } \\
\text { and condition of } \\
\text { facilities, etc.) } \\
\text { - Absence of an } \\
\text { operational M\&E } \\
\text { system }\end{array}$ \\
\hline MDG 3 & $\begin{array}{l}\text { - Attention to the } \\
\text { transversality of } \\
\text { gender issues in } \\
\text { the principal } \\
\text { strategy papers } \\
\text { - Existence of a } \\
\text { ministry } \\
\text { responsible for } \\
\text { promoting } \\
\text { gender equality } \\
\text { since the 1990s } \\
\text { - Existence of a } \\
\text { unit to promote }\end{array}$ & & $\begin{array}{l}\text { - Low intervention } \\
\text { capacity in the field } \\
\text { - Impediments to actions } \\
\text { in the field in support } \\
\text { of women's equality } \\
\text { (socio-cultural barriers, } \\
\text { low levels of education } \\
\text { and vocational } \\
\text { training, access to } \\
\text { funds and inputs, etc.) } \\
\text { - Low representation of } \\
\text { women in the political } \\
\text { and economic spheres }\end{array}$ & $\begin{array}{l}\text { - Weak capacity of } \\
\text { units responsible for } \\
\text { promoting gender } \\
\text { equality in regard to } \\
\text { management of the } \\
\text { project cycle } \\
\text { - Lack of statistics } \\
\text { disaggregated by sex } \\
\text { - Necessity of } \\
\text { providing the } \\
\text { ministry responsible } \\
\text { for promoting gender } \\
\text { equality with a good }\end{array}$ \\
\hline
\end{tabular}




\begin{tabular}{|c|c|c|c|c|}
\hline & $\begin{array}{l}\text { gender equality } \\
\text { in all the } \\
\text { ministries }\end{array}$ & \multirow[t]{4}{*}{ resources } & & M\&E system \\
\hline $\begin{array}{l}\text { MDG } 4 \\
\text { MDG } 5 \\
\text { MDG } 6\end{array}$ & $\begin{array}{l}\text { - Development of } \\
\text { the National } \\
\text { Health Sector } \\
\text { Development } \\
\text { Plan for the } \\
\text { period 2009- } \\
2018 \\
\text { - Absence of } \\
\text { local adaptation } \\
\text { of the National } \\
\text { Health Sector } \\
\text { Development } \\
\text { Plan }\end{array}$ & & $\begin{array}{l}\text { - Weak quality of } \\
\text { services in the field } \\
\text { (human resource } \\
\text { problems, limited } \\
\text { technical capacity, } \\
\text { etc.) } \\
\text { - Low rate of utilization } \\
\text { of health facilities } \\
\text { (39\%) due especially } \\
\text { to low household } \\
\text { income } \\
\text { - Heavy concentration of } \\
\text { medical staff ( } 80 \%) \text { in } \\
\text { urban centers } \\
\text { - Malnutrition and poor } \\
\text { hygiene } \\
\text { - Insufficient supply of } \\
\text { lower-risk maternity } \\
\text { services }\end{array}$ & $\begin{array}{l}\text { - Existence of a good } \\
\text { M\&E system } \\
\text { - Regular consultation } \\
\text { with sector TFPs }\end{array}$ \\
\hline MDG 7 & $\begin{array}{l}\text { - Constant } \\
\text { attention to the } \\
\text { transversality of } \\
\text { the environment } \\
\text { in various } \\
\text { strategy papers } \\
\text { - Existence of a } \\
\text { housing policy } \\
\text { - Existence of a } \\
\text { global policy on } \\
\text { access to safe } \\
\text { drinking water } \\
\text { - Lack of } \\
\text { planning tools } \\
\text { for the water } \\
\text { and energy } \\
\text { sector }\end{array}$ & & $\begin{array}{l}\text { - Water access and } \\
\text { quality jeopardized by } \\
\text { physical and climatic } \\
\text { constraints } \\
\text { - Good community- } \\
\text { based capacity for } \\
\text { managing the } \\
\text { structures } \\
\text { - Existence of a housing } \\
\text { bank } \\
\text { - Constraints related to } \\
\text { procurement } \\
\text { procedures }\end{array}$ & $\begin{array}{l}\text { - Weak capacity of } \\
\text { environmental } \\
\text { departments to } \\
\text { implement the } \\
\text { activities of } \\
\text { multilateral } \\
\text { agreements on } \\
\text { environmental issues } \\
\text { - Weak capacity of } \\
\text { water departments in } \\
\text { regard to } \\
\text { management of the } \\
\text { project cycle } \\
\text { - Existence of a } \\
\text { system for } \\
\text { monitoring water } \\
\text { resources and the } \\
\text { condition of } \\
\text { waterworks } \\
\text { - Regular consultation } \\
\text { with water sector } \\
\text { TFPs }\end{array}$ \\
\hline MDG 8 & $\begin{array}{c}\text { Absence of a } \\
\text { trade policy }\end{array}$ & & & $\begin{array}{l}\text { - Weak capacity in } \\
\text { regard to the } \\
\text { mobilization, } \\
\text { management, and } \\
\text { coordination of aid }\end{array}$ \\
\hline
\end{tabular}

Source: Report on MDGs in Benin, 2000+10. 


\section{CHAPTER 3: DEVELOPMENT CONSTRAINTS AND CHALLENGES IN BENIN}

\subsection{CONSTRAINTS}

3.1 Based on the diagnostic analysis, Benin will not be able to create wealth and shrink the boundaries of poverty unless numerous development constraints are overcome.

\subsubsection{Structural constraints}

3.2 The Beninese economy has lacked diversification and competitiveness for several decades. It remains dominated by agriculture and agricultural services, while industry remains an undeveloped sector. In the agricultural sector, the archaic nature of the production tools, the reliance on a single export crop, the inadequacy and defective condition of infrastructure, the absence of appropriate financing, and underemployment are all to be deplored. Industrialization still has not taken off, even though the first attempts date back to the colonial era, involving primary processing of agricultural products. Thus, in today's Benin, neither agriculture nor industry offers an adequate path for achieving competitiveness. The economy's weak competitiveness can be explained by the insufficient infrastructure to support production, particularly in the areas of transportation, energy, and communications. Furthermore, due to structural rigidity and weak diversification, the national economy remains highly vulnerable to external shocks.

3.3 Furthermore, the local economy remains largely undeveloped as a result of the lack of economic specialization of the country's regions. This situation is basically due to the fact that management of the country is still only slightly decentralized, and the exploitation of available natural resources remains weak.

\subsubsection{Organizational constraints}

3.4 Benin has not yet managed to create an attractive environment for investors. The business environment remains unfavorable, despite the efforts made. Major constraints persist, especially administrative red tape, insecure land tenure, and corruption.

3.5 Notwithstanding significant advances from the perspective of democratization, Benin still has an ineffective government that is highly centralized and that lacks a results-oriented culture of accountability. These governance problems underlie, in particular, poor allocation and inefficient use of budget resources, as well as limited capacity to mobilize Official Development Assistance (ODA). Consequently, the need for additional resources that are required for accelerating progress toward reaching the MDGs in 2015 is still relatively high, despite the country's potential. Currently, coverage of this need for financing remains constrained by the inadequacy of domestic financial resources and the weak capacity of national stakeholders to plan, and especially to implement and monitor, public policies.

3.6 Furthermore, despite the existence of a legal and regulatory framework that is conducive to decentralization and the exercise of power by development beneficiaries, policy design and implementation at the decentralized level remain limited, while the process of transferring skills and resources to the communes is just barely beginning. 
3.7 Similarly, the lack of adequate and appropriate human resources for effectively guiding the country's development constitutes a major impediment to improving the effectiveness of government action. These constraints are reflected in weak government capacity and the high cost of operating the government. This situation also influences private sector development because training opportunities do not match market needs.

3.8 The structural reforms undertaken in recent years have focused mainly on state divestiture from productive sectors while seeking to strengthen the macroeconomic situation, the effectiveness of public expenditure, the accountability of sectoral ministries, the fiduciary framework, and the transparency of accounting and financial information. However, the pace of implementation of these reforms has been hindered by weak human and institutional capacities.

\subsubsection{Other constraints}

3.9 Uncontrolled population growth represents a real obstacle to development efforts in Benin. Indeed, Benin's population is growing at a rate of 2.9 percent, with a basic total fertility rate of 5.7 children per woman on average. Such population growth generates high social demand at a time when economic growth remains weak.

3.10 In addition, Benin remains highly vulnerable to climate change. Climatic disruptions compromise the living conditions of populations already victim to poverty and ecosystem degradation. Agricultural production systems and, in particular, cropping techniques, including the agricultural calendar, are directly affected by variability in the seasonal climatic regimen. This variability is characterized by a shortening of the rainy season, a decline in rainfall in the interior, an increase in rainfall and the risk of flooding in the coastal zone, excessive heat, and violent winds.

3.11 More specifically, the increasingly unpredictable nature of the rainy season upsets the agricultural calendar and contributes to a drop in crop yields. As a corollary, in certain regions of the country, food commodities have run short and food products have gone up in price. The impact on the environment and health is substantial, especially with densification of populations and growing pollution in urban areas, intensification of rural-urban migration and food insecurity, desertification and soil depletion, growing impoverishment of populations, and all the related risks.

\subsection{CRITICAL CHALLENGES}

3.12 The diagnostic analysis shows that Benin does have experience in sectoral program implementation, which needs to be consolidated and built upon. Moreover, the country faces constraints that must be overcome without delay. Thus, there are four major critical challenges to be met in the quest for a new dynamic of economic and social development. 


\subsubsection{First challenge: improve the sectoral and overall competitiveness of the economy}

3.13 Actions to be taken to achieve accelerated and sustained growth, consistent with the objective of 7 percent needed to meet the Millennium Development Goals (MDGs), revolve mainly around the following:

(i) strengthen the stability of the macroeconomic framework, which was severely disrupted in 2009, principally due to the effects of the world crisis and budgetary difficulties;

(ii) improve the business climate in order to facilitate business development; and

(iii) diversify the economy to improve its capacity to withstand adverse shocks and strengthen its engines of growth.

\subsubsection{Second challenge: reduce inequalities in access to basic social services}

3.14 To combat poverty effectively, in addition to a renewal of economic growth, it is also important to adopt strategies incorporating the reduction of inequalities and to implement appropriate redistribution policies. ${ }^{11}$ To these ends, there is a need to identify the different forms of inequality faced by certain populations, particularly the most underprivileged ones (inequalities in terms of social, monetary, and living conditions and in terms of opportunities), as well as the socioeconomic mechanisms by which these inequalities were produced, in order to set in place appropriate redistribution tools.

3.15 In the economic literature, it has been demonstrated that the redistribution of assets (physical and financial capital) and equitable access to human and social capital are more efficient and generate more lasting effects on poverty than does strict income redistribution. ${ }^{12}$ From the viewpoint of mitigating inequalities, meaningful coverage of the social needs of populations thus becomes imperative. Significant advances have been made in this area in recent years, despite the repercussions of the shocks endured, as reflected in the 3.9 percentage point improvement in poverty and living conditions between 2006 and 2007. However, the high level of this poverty indicator (37 percent in 2007 and 35.21 percent in 2009) could be due in particular to a still insufficient supply of public services, especially in terms of health, water, and sanitation infrastructure, notwithstanding the laudable efforts made by the Government and its Technical and Financial Partners. This is clearly borne out by the weakness of the social indicators (see Chapter 2).

3.16 Thus, when it comes to improving basic social services, major challenges still exist. In this regard, the following actions, among others, should be strengthened:

(i) improve the internal efficiency of the education system;

(ii) improve governance in the health sphere;

\footnotetext{
${ }^{11}$ See Damien Mededji, "Politiques de croissance pro-pauvre: conditions pour l'atteinte de l’OMD n ${ }^{\circ}$," February 2010.

${ }^{12}$ See Barro 2000.
} 
(iii) improve road maintenance and develop rural roads;

(iv) rehabilitate the electric power sector; and

(v) ensure effective implementation of projects and programs in priority sectors, particularly through higher capital budget execution rates.

\subsubsection{Third challenge: rectify disparities between different areas of the country}

3.17 More than half the communes of Benin showed a higher poverty incidence than the national average in 2007 and 2009. These results demonstrate the scope of poverty in some of the country's communes and the need to promote a decentralization policy capable of helping local communities find the resources needed to engage in effective poverty reduction.

\subsubsection{Fourth challenge: improve the management of public affairs}

3.18 The implementation of high-quality governance at all levels is a prerequisite for boosting the capacity to implement effectively economic and social policies intended to place the country on the path to economic emergence. 


\section{PART II: OPERATIONAL PILLARS}

Part II presents the 2011-2015 GPRS operational pillars. Five pillars were identified, each of which is broken down into priority intervention areas, along with broad measures to be implemented during the period 2011-2015. The five operational pillars are to:

(i) promote sustainable, accelerated economic growth and transformation;

(ii) promote infrastructure development;

(iii) build human capital;

(iv) boost the quality of governance; and

(v) promote balanced and sustainable development countrywide. 
3.19 The Growth and Poverty Reduction Strategy gives operational form to two major frameworks for elaborating development policy, namely:

(i) the "Benin Alafia 2025" vision, based on long-term perspective studies, worded as follows: "The Benin of 2025 is a leader among countries, a well governed nation of unity and peace, with a prosperous and competitive economy, cultural influence, and social well-being"; and

(ii) the Strategic Orientations for Development (OSDs) which lay out strategic mediumterm development policy choices based on the "Benin Alafia 2025" vision, while also taking into account the Millennium Development Goals (MDGs).

3.20 Furthermore, Benin shares the vision and the strategic goals embraced by the African Union, NEPAD, ECOWAS, and WAEMU, as well as the governance principles adopted at the regional and subregional levels.

3.21 Based on all these documents, the 2011-2015 GPRS sets, as a general objective for 2015, a substantial improvement in living conditions. Such an improvement requires strong and sustained economic growth, around 6 percent on average over the entire period. This would result in poverty reduction, with incidence falling from 35.21 percent of the population in 2009 to 25 percent in 2015. On this basis, it is expected that the MDGs will be met in 2015 in a number of sectors - specifically, water, basic sanitation, primary education, and primary health care - and that significant progress will be made in regard to the remaining Millennium Development Goals.

3.22 The implementation timeframe for the new GPRS extends for five years to take into account the evaluation results of the previous GPRS, which revealed that the three-year period 2007-2009 was too short, given the objectives assigned to the strategy, particularly in terms of bringing operational form to the strategic pillars and priority programs that were identified.

3.23 The operational pillars identified for the 2011-2015 GPRS are identical to those of the 2007-2009 GPRS. However, the content and scope of the priority intervention areas have been strengthened in view of the challenges and new development constraints now facing the country.

3.24 Sustainable acceleration of economic growth and transformation is expected through:

(i) consolidation of the macroeconomic framework;

(ii) private sector revitalization and business development;

(iii) diversification of the economy; and

(iv) promotion of regional integration and Benin's integration into world networks.

3.25 The second pillar calls for infrastructure development as an underpinning of economic growth and as a factor for improving the quality of life. This includes, in particular:

(i) transportation infrastructure;

(ii) energy and water infrastructure; 
(iii) Information and Communication Technology (ICT) infrastructure; and

(iv) construction and town planning.

3.26 The third operational pillar of the Government's strategy is to build human capital. This improvement in human resources will be achieved through:

(i) population growth control;

(ii) promotion of development education;

(iii) improvement in the quality of health and nutrition services;

(iv) promotion of sustainable and decent employment;

(v) strengthening of social welfare and national solidarity and promotion of gender equality; and

(vi) promotion of youth, sport, and leisure.

3.27 The fourth pillar represents the Government's policy on strengthening the quality of governance. It stresses the following themes:

(i) improved management of public finances;

(ii) issues of good administrative and political governance;

(iii) security and peace;

(iv) governance of statistical information; and

(v) environmental governance.

3.28 The fifth pillar focuses on balanced and sustainable development throughout the country. The Government intends to strengthen:

(i) the policy of promoting the local and rural economy;

(ii) the decentralization-deconcentration process;

(iii) border management;

(iv) natural resources management and improvements in the living environment; and

(v) management of natural disasters and risks.

3.29 Figure 8 describes the relationships among these different operational pillars, which need to function synergistically to ensure the success of the 2011-2015 GPRS. The policies envisioned in the five pillars are discussed in the following chapters. 
Figure 3.1: 20112015 GPRS Conceptual Framework

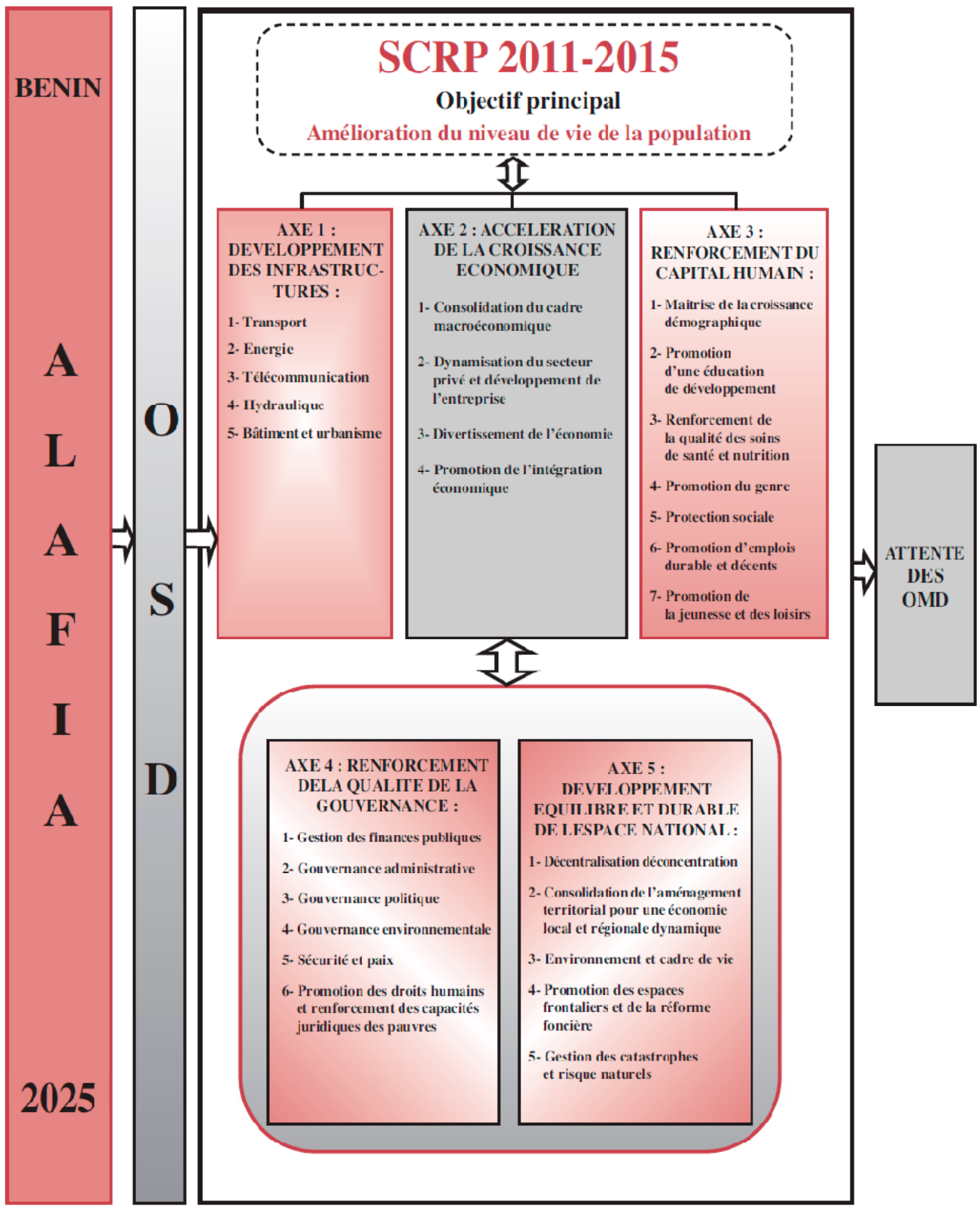


2011-2015 GPRS

Principal Objective:

Improve the Standard of Living

BENIN ALAFIA $2025 \rightarrow$ OSDs $\rightarrow$ PILLARS $\rightarrow$ ACHIEVE MDGs

PILLAR 1: INFRASTRUCTURE DEVELOPMENT

1. Transportation

2. Energy

3. Telecommunications

4. Water supply

5. Construction and town planning

PILLAR 2: ACCELERATE ECONOMIC GROWTH

1. Consolidation of macroeconomic framework

2. Private sector revitalization and business development

3. Diversification of the economy

4. Promotion of economic integration

PILLAR 3: BUILD HUMAN CAPITAL

1. Population growth control

2. Promotion of development education

3. Strengthening of the quality of health and nutrition care

4. Promotion of gender equality

5. Social welfare

6. Promotion of sustainable and decent employment

7. Promotion of youth and leisure

PILLAR 4: BOOST THE QUALITY OF GOVERNANCE

1. Management of public finances

2. Administrative governance

3. Political governance

4. Environmental governance

5. Security and peace

6. Promotion of human rights and strengthening of the legal capacities of the poor

PILLAR 5: BALANCED AND SUSTAINABLE DEVELOPMENT COUNTRYWIDE

1. Decentralization-deconcentration

2. Stronger regional planning to promote a dynamic local and regional economy

3. Physical and living environment

4. Promotion of border spaces and land reform

5. Management of natural disasters and risks 


\section{CHAPTER 4: SUSTAINABLE ACCELERATED GROWTH AND ECONOMIC TRANSFORMATION}

4.1 The priority actions necessary to achieve sustainable accelerated economic growth and economic transformation include:

(i) consolidation of the macroeconomic framework;

(ii) stimulation of the private sector;

(iii) diversification of the economy; and

(iv) promotion of regional integration and Benin's entry into global networks.

\subsection{CONSOLIDATION OF THE MACROECONOMIC FRAMEWORK}

4.2 Accelerated growth requires macroeconomic stability. By reducing the uncertainties resulting from unsustainable increases in public expenditure, borrowing and inflation, a stable macroeconomic framework makes it possible to reduce the volatility of the economy with a view to improving social welfare. The Government is therefore determined to implement a consistent macroeconomic policy based on the economic and financial program supported by the Extended Credit Facility approved by the Executive Board of the International Monetary Fund (IMF) on June 14, 2010. This policy involves:

(i) fiscal consolidation;

(ii) control of inflation; and

(iii) monitoring of the macroeconomic environment.

4.3 Fiscal consolidation will be pursued to create the fiscal space needed to increase public investment and priority spending in the social sectors. Although implementation of the 20052009 economic and financial program supported by the IMF resulted in fiscal consolidation through 2008, signs of weakening appeared in 2009. Sizable fiscal overruns were observed, particularly, an increase in domestically financed capital spending of over 100 percent compared with 2008 and an increase in the wage bill of 24 percent between 2008 and 2009. Consequently, the Government is resolved to pursue and strengthen fiscal consolidation by mobilizing increased public revenues and more effectively managing public expenditure.

4.4 To increase revenues, the Government will focus on:

(i) accelerating the tax reforms;

(ii) enhancing the capacities of the tax and customs administrations and the synergies between them;

(iii) stepping up the fight against fraud and corruption;

(iv) providing tax support for growth and development financing;

(v) bringing the informal sector into the tax net;

(vi) introducing a tax system that promotes small savings, microcredit and the informal sector; 
(vii) effectively implementing universal use of the single taxpayer identification number (TIN); and

(viii) opening the one-stop shop for foreign trade in the Port of Cotonou.

4.5 The Government intends to better target spending in support of growth and poverty reduction. It will also continue its reform of the public enterprises, particularly the electricity company (SBEE), and will ensure that the Benin National Retirement Fund (FNRB) remains viable in order to limit the fiscal impact of their deficits. To this end, the decision has been made to split the SBEE into a public asset management company responsible for developing electricity production and transportation infrastructure and a privately managed semi-public electricity distribution company. As well, there are plans to draft a new law governing pensions based on the actuarial audit of the FNRB carried out in September 2009.

4.6 To control inflation, economic policy will continue to target an inflation rate of under 3 percent, the level required under the WAEMU convergence, stability, growth and solidarity pact.

4.7 To anticipate delayed reactions of the economy to exogenous shocks, the Government will strengthen the existing economic monitoring mechanisms. These mechanisms will make it possible to anticipate, track and provide warnings on factors in the domestic and external environment that could influence the economy in the short and medium term.

\subsection{STIMULATION OF THE PRIVATE SECTOR AND ENTERPRISE DEVELOPMENT}

4.8 Promotion of strong and sustained economic growth is based on stimulation of the private sector as a source of wealth and jobs. This approach requires an increased focus on:

(i) improving the business environment;

(ii) pursuing and completing the structural reforms under way;

(iii) adopting and implementing a tax system in support of development;

(iv) promoting industry;

(v) promoting small and medium enterprises (SME); and

(vi) facilitating access to credit.

\subsubsection{Improving the business environment}

4.9 To reach the average level seen in the emerging economies for the business environment, the Government intends to implement the necessary reforms resulting from the World Bank's report on the business environment, "Doing Business." To this end, the Government will:

(i) simplify procedures and reduce costs and delays in starting a business and obtaining a construction permit;

(ii) improve the protection of shareholders against abuses by strengthening their procedural rights; 
(iii) reduce tax constraints and simplify tax payment procedures by reducing the number of returns to be filed and by a proposing a staggered payment option for companies;

(iv) simplify customs clearance procedures by opening the one-stop shop in the Port of Cotonou; and

(v) improve the handling of commercial disputes related to contract enforcement by training judges in the use of simplified procedures that promote negotiated solutions.

\subsubsection{Pursuing and completing the structural reforms}

4.10 To strengthen the international and sectoral competitiveness of the Beninese economy, the Government is determined to complete the structural reforms under way, particularly in the electricity and telecommunications sectors and the Port of Cotonou. These reforms will help to reduce the cost of the factors of production and thus make companies more competitive. To this end, the Government intends to:

(i) adopt a regulatory framework for the electricity sector so as to open up the sector to private operators and establish a regulatory authority for the sector;

(ii) create the conditions for improving the quality of the services provided by mobile telephone companies;

(iii) open up Bénin Télécoms S.A. to private investment; and

(iv) continue the reforms aimed at improving the services provided by the Port of Cotonou.

\subsubsection{Implementing a tax system in support of development}

4.11 The Beninese tax system does not yet fulfill the requirements necessary to facilitate business development. To remedy this, the Government established a Task Force on Tax and Development, which completed its report in October 2010. This report recommends the implementation of reforms that are aimed at:

(i) expanding the tax base, particularly to cover the informal sector, and reducing exemptions in order to make taxation more equitable;

(ii) simplifying the tax structure;

(iii) simplifying tax procedures to make them more practical and easier to understand; and

(iv) modernizing the operation of the tax administration and providing capacity building.

\subsubsection{Promoting industry}

4.12 The industrial base is still new (7.8 percent of GDP in 2009). ${ }^{13}$ To promote competitive companies in processing industries, there are plans to:

(i) promote the creation and development of new competitive industrial companies;

\footnotetext{
${ }^{13}$ Share of manufacturing and mining in GDP.
} 
(ii) continue to strengthen the institutional, legal, judicial and regulatory environment;

(iii) overhaul the investment code to enhance incentives;

(iv) promote fora for dialogue and discussion among participants in the industrial sector;

(v) provide capacity building for industrial companies and support and training structures;

(vi) implement appropriate institutional reforms to make Benin more attractive to foreign direct investment (FDI) in areas such as mining, hydrocarbons and other sectors with a strong multiplier effect; and

(vii) create an Investment and Export Promotion Agency (APIEX).

\subsubsection{Promoting small and medium-sized enterprises (SME)}

4.13 Beninese SMEs represent an untapped potential for the creation of wealth and jobs. The Government intends to make such companies more competitive and capable of moving into the external markets, further processing local commodities, and creating more jobs. To this end, there are plans to:

(i) build the capacities of institutions that support SMEs; and

(ii) establish a development fund and a guarantee fund for SMEs.

\subsubsection{Facilitating access to credit}

4.14 Businesses require access to appropriate financing if they are to expand. The creation of a microfinance development support fund and the development of microfinance institutions have helped to ease some constraints in the financing of small production entities. The National Microfinance Development Policy prepared in 2007 will be further strengthened via the microlending program for the very poor. As well, the National Program for Entrepreneurship and Youth Employment will be strengthened. Similarly, an agricultural entrepreneurship project will be introduced with the support of the UNDP and the Songhai Center.

4.15 The Government will also continue to ensure that financial institutions operate in an environment conducive to their development and their contribution to the financing of economic activities. Given the difficulties encountered by those involved in the agricultural sector in mobilizing resources, the project for the creation of an agricultural bank will be implemented.

\subsection{DIVERSIFICATION OF THE ECONOMY}

4.16 The Beninese economy is not very diversified and its economic structures are still fragile. There are three main structural difficulties:

(i) the cotton sector, which represents 80 percent of export revenues, 45 percent of tax revenues, 13 percent of the formation of national GDP in terms of value added, and 60 percent of the industrial fabric of the country, still has organizational difficulties despite progress in recent years;

(ii) the rapid expansion of the informal sector, which creates substantial constraints in terms of management and the promotion of development policies; and 
(iii) the high degree of dependence on Nigeria via re-export trade, which introduces a significant vulnerability into the Beninese economy.

4.17 The structural weakness of the economy and its vulnerability to exogenous shocks (fluctuations in international prices, rainfall) point to the need for diversification through the optimal exploitation of the growth areas identified in the Agenda for an Emerging Economy. In response to this, diversification of the economy, divided into sectoral strategies, will be organized on the basis of four priority growth areas and two additional high-potential growth areas.

The four priority growth areas are:

(i) trade-logistics;

(ii) cotton-textiles;

(iii)agriculture and the agri-food industry; and

(iv)tourism-culture-handicrafts.

4.18 These growth areas are characterized by their significant contribution to stimulation of the economic base and poverty reduction. Under an affirmative action policy, they will benefit from direct support in the form of financing for physical infrastructure to attract participants to the sector as well as guidance in the search for medium- and long-term refinancing facilities, advisory services on access to markets and technology, human resources training, tax incentives, etc. 
Figure 4.1: Benin Growth Areas

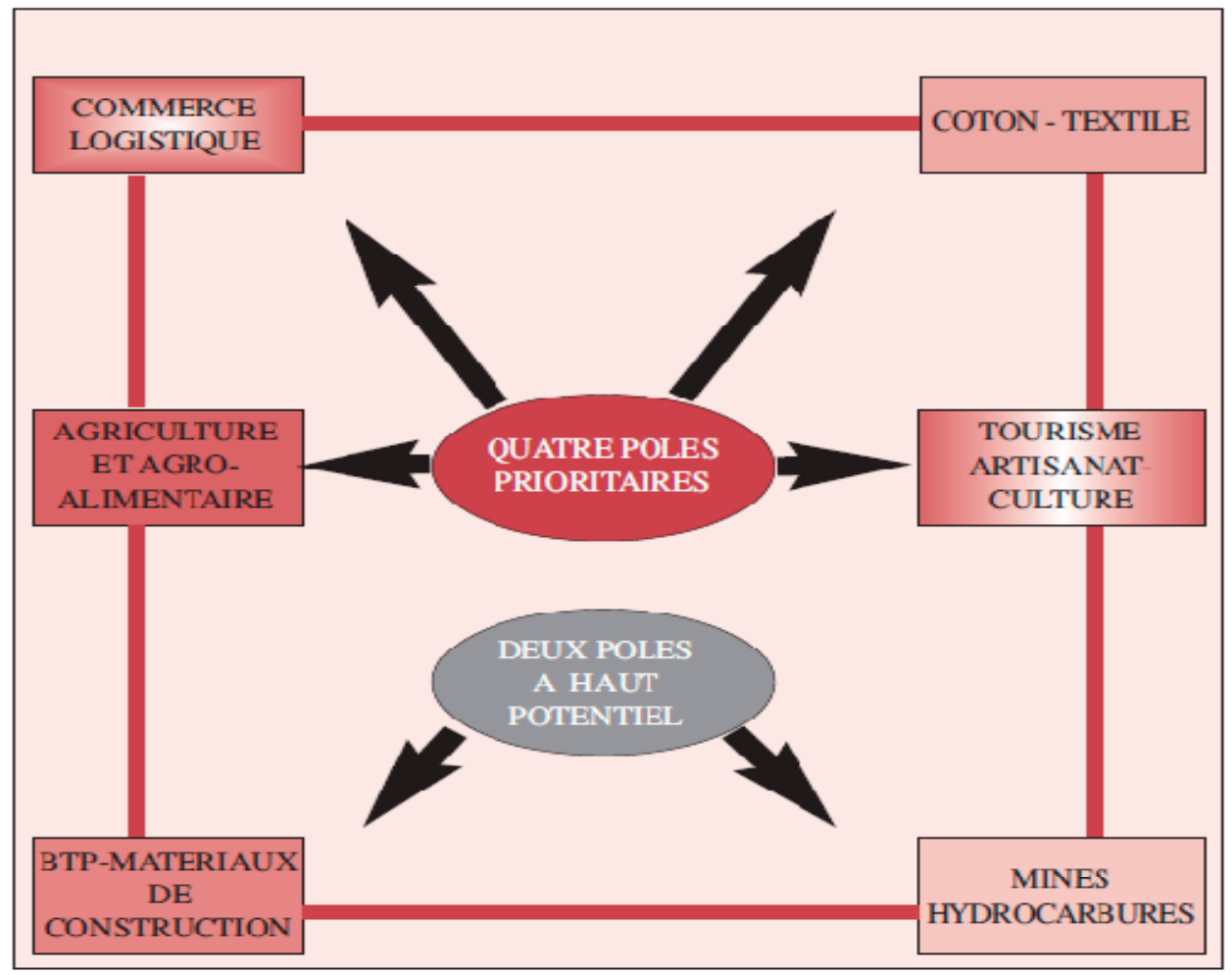

Key:

Trade

Cotton-Textiles

Logistics

Agriculture and

Agri-food Industries

Construction and Public Works-

Construction Materials
Four Priority

Growth Areas

Two High-Potential

Growth Areas
Tourism, Handicrafts and Culture

Mining

Hydrocarbons

4.19 The two high-potential growth areas are:

(i) construction and public works-construction materials; and

(ii) mining and hydrocarbons.

These growth areas will benefit from an improved business environment to attract investment.

\subsubsection{The four priority growth areas}

4.20 Trade-Logistics. Because of its geographic location, Benin constitutes a point of contact for trade between countries in the hinterland and Central Africa. It therefore has a vocation in the medium term to be a regional platform for high value added businesses and services. However, competition between ports in the region of the Gulf of Guinea is still strong and is expected to increase in the coming years. To improve the competitiveness of the national economy and the subregional and international positioning of Benin from a logistical point of view, the 
Government intends to make "Trade-Logistics" the backbone of the country's economic development, particularly through the modernization and expansion of the port infrastructure, rehabilitation and development of the rail network, and construction of dry ports, particularly at Parakou, and a second deep water port at Sèmè.

4.21 The reforms to make the port infrastructure more competitive will be combined with improvements in urban transportation, rail infrastructure and air transport services. This multimodal approach will significantly improve Benin's logistical competitiveness, which is essential for its economic development.

4.22 Cotton-Textiles. Despite the reforms undertaken over the past 10 years, including, in particular, the creation of the ginning company (SODECO) in 2008 by splitting off the industrial plant from the agricultural promotion company (SONAPRA), the cotton sector, which has seen its output decline steadily in recent years, faces numerous problems:

(i) overcapacity of the ginning plants, which affects their profitability;

(ii) lack of organization of representation for the sector, making it difficult to negotiate transaction costs and forcing the Government to arbitrate;

(iii) obsolescence and lack of competitiveness of textile entities in the Government's portfolio in the face of a market open to fraud and competition from used clothing;

(iv) competition from imported textiles; and

(v) declining revenues for cotton farmers, who are increasingly turning to food crops. The Government hopes to revitalize this sector by continuing its restructuring, providing capacity building for sector participants, and focusing on value-added niches. The aim is to bring production to at least 500,000 metric tons by 2015 (compared to current output of 200,000 metric tons) in order to meet the ginning capacity through an increase in acreage under cultivation to 400,000 ha and average yield to 1.5 metric tons per ha.

To this end, the Government intends to:

(i) create a genuine development plan that will locate and specialize cotton crops in the most appropriate agro-ecological zones;

(ii) focus training and generalize the use of the most appropriate technical methods to obtain better yields and combat parasites and disease;

(iii) diversify cotton crops by exploiting the water resources and land in the catchment areas from the north to the south of Benin, which create numerous favorable agro-ecological zones;

(iv) make cotton a vector for a diversified and integrated agricultural strategy.

4.23 A sustainable cotton strategy cannot be based on an isolated cotton sector. The cotton sector must be combined with other sectors such as textiles. However, the textile sector constitutes a very small outlet for the country's cotton production (barely 3 percent of national cotton output is processed in Benin). The textile sector faces difficulties resulting from the debt of the main textile entities, a lack of working capital, obsolescent equipment, and an aging staff. The Government is planning to restructure the sector. 
4.24 Agriculture and Agri-Food Industries. The country's agricultural potential seems rich and diversified from the north to the south (see Figure 10). However, Benin remains a poor agricultural country, exporting agricultural commodities with low value added and only benefiting from traffic with neighboring countries that results from its location as a transit country. The major deficiencies in the agri-food sector are essentially:

(i) its weak exporting capacity;

(ii) theoretical self-sufficiency in grains and food products but hampered by the lack of control over regional flows, particularly toward Nigeria;

(iii) a serious deficit in animal proteins;

(iv) genuine potential for diversified crop development; and

(v) weak infrastructure in support of competitiveness.

Figure 4.2: Agricultural Sector in Benin

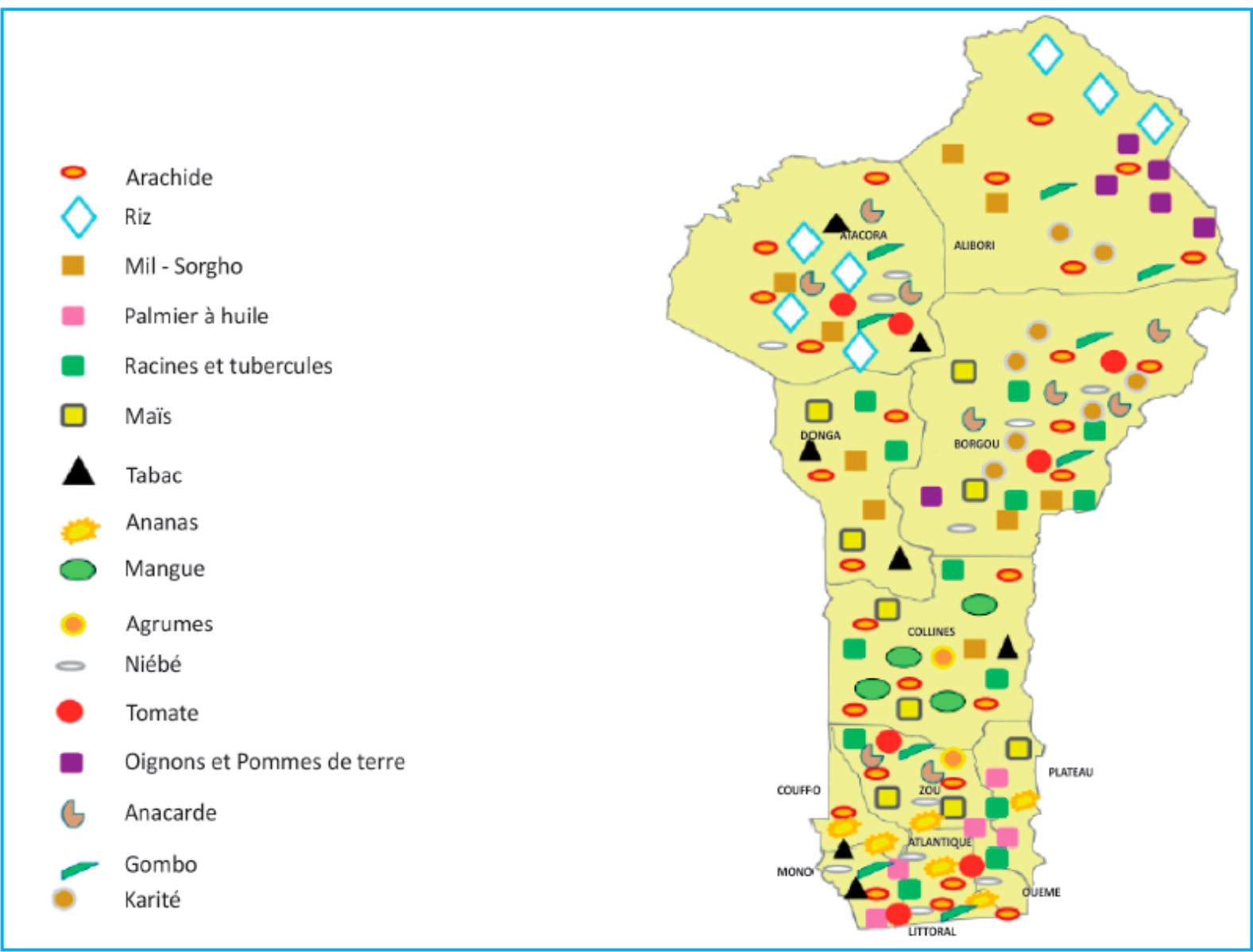

Source: Benin's Agenda for an Emerging Economy: Phase 2.

Key:

Groundnuts

Rice

Millet - Sorghum

Palm oil 
Roots and tubers

Corn

Tobacco

Pineapple

Mango

Citrus fruit

Cowpeas

Tomatoes

Onions and potatoes

Cashew nuts

Okra

Sheanuts

4.25 To correct these deficiencies, the Strategic Plan for Agricultural Sector Recovery (PSRSA) is being finalized. This agricultural policy paper makes the sector one of the essential engines for revitalizing Benin's economic and social development. It calls for reforms that are aimed in particular at improving agricultural productivity and production. Specifically, these reforms involve:

(i) modernizing agriculture through appropriate mechanization and control of water resources;

(ii) promoting agricultural entrepreneurship, diversification of agro-industry and professionalization of sector participants;

(iii) developing the Ouémé and Niger River valleys;

(iv) implementing the "value-added chain" approach in promoting agricultural subsectors; and

(v) implementing the strategy for the diversification of agricultural products.

4.26 As well, the Government plans to establish "integrated agri-food territorial centers." This will make it possible for the agri-food industry to export a diversified range of high value-added products to the international and regional markets. The conditions required for this are:

(i) improvement of the business environment and dialogue with local and international investors;

(ii) genuine corporate social responsibility (CSR) as a counterpart to the benefits granted to investors, translated in terms of commitment to training farmers, educating them in the technical methods for modern production, and integrating and marketing their output; and

(iii) investment by the Government and its partners in infrastructure, logistics and support for the competitiveness of the appropriate agri-food subsectors.

4.27 Benin has substantial sources of water that are well distributed across the country and that constitute a potential for the development of fisheries and aquaculture with a view to selfsufficiency (see Figure 11). Fisheries and aquaculture occupy 15 percent of the total labor force (25 percent of the agricultural sector labor force), contribute 3 percent to national GDP, and also account for more than two-thirds of consumption of animal proteins. However, this subsector suffers from a number of constraints that hamper its development: 
(i) overuse of surface waters;

(ii) the high cost of investment; and

(iii) the difficulty for fisheries products in obtaining access to the markets of the European Union countries.

To eliminate these constraints, the Government plans to:

(i) streamline the management of the subsector;

(ii) develop aquaculture; and

(iii) build institutional capacities.

In this way the Government plans to increase fisheries production to at least 150,000 metric tons to satisfy the needs of the population for fish products.

Figure 4.3: Map of the Potential for the Development of Fish Farming in Benin

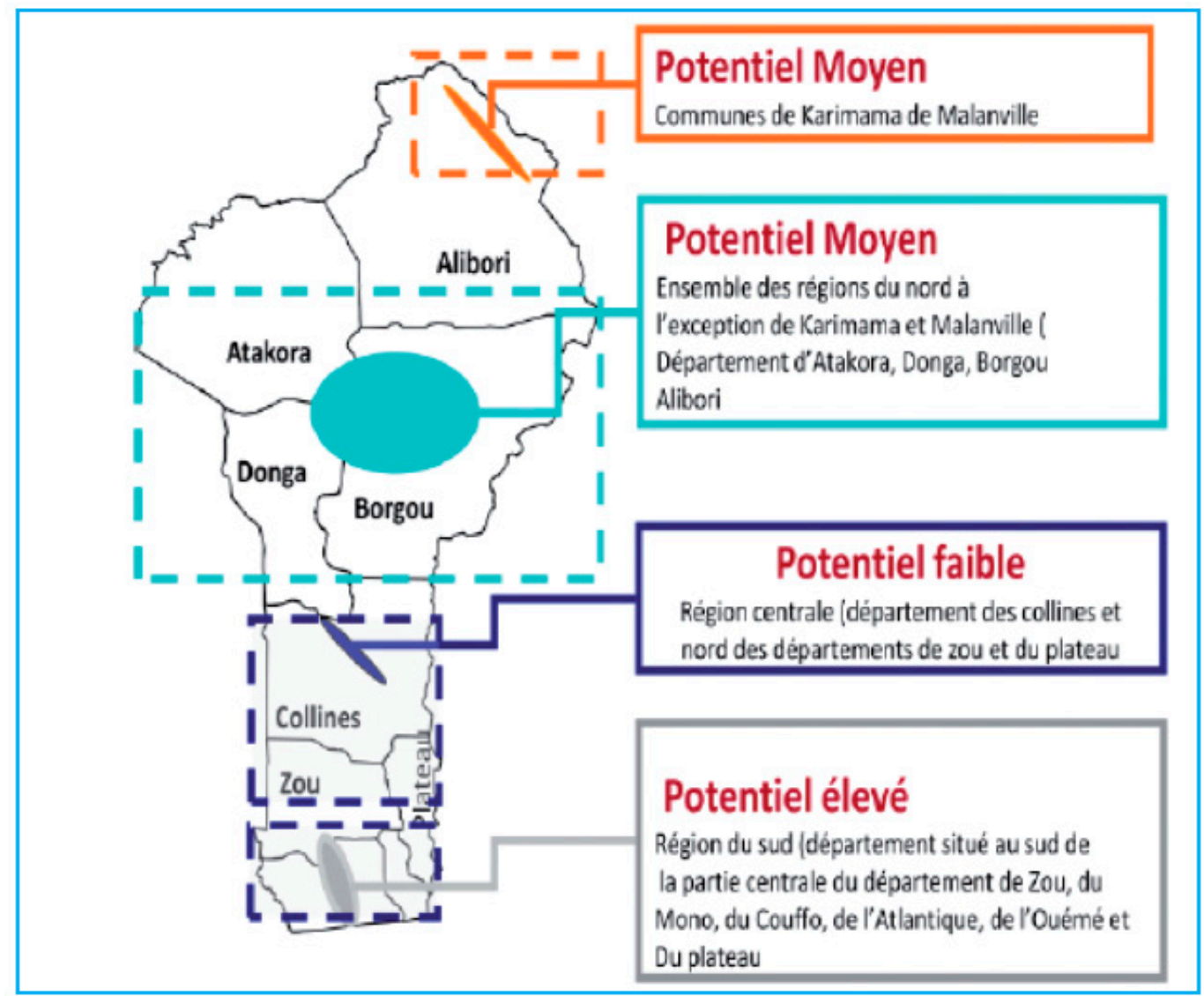

Source: Benin's Agenda for an Emerging Economy: Phase 2.

Key:

Average Potential: Communes of Karimama and Malanville

Average Potential: All of the regions in the north of the Atakora, Donga, Borgou and Alibori Departments, with the exception of Karimama and Malanville

Low Potential: Central region (Collines Department and northern part of Zou and Plateau Departments)

High Potential: Southern region (area located south of the central part of Zou Department) and Mono, Couffo, Atlantique, Ouémé and Plateau Departments 
4.28 Tourism-Culture-Handicrafts. Tourism represents the second most important source of foreign exchange after cotton, as Benin has considerable and diversified tourism potential (see Figure 12). However, tourist arrivals have increased very little, in comparison with the WAEMU zone as a whole. From 1998 to 2005, they increased at an average annual rate of 10 percent in the WAEMU zone, compared with 2 percent for Benin. The development of tourism in Benin has been hampered by the lack of infrastructure, inaccessibility of sites, small number and poor quality of the hospitality infrastructure, lack of training of personnel, poor service (especially in hotels), lack of incentives targeting tourism investments and poor air transport service. In this context, the Government plans to implement reforms aimed at promoting tourism, particularly by:

(i) updating and implementing the tourism development policy;

(ii) starting up important programs (including the "Fisheries Road" project); and

(iii) through the development of tourism sites, preparing an off-site infrastructure plan facilitating tourism access and investment in the context of Public-Private Partnerships (PPPs).

Figure 4.4: Key Tourism Areas in Benin

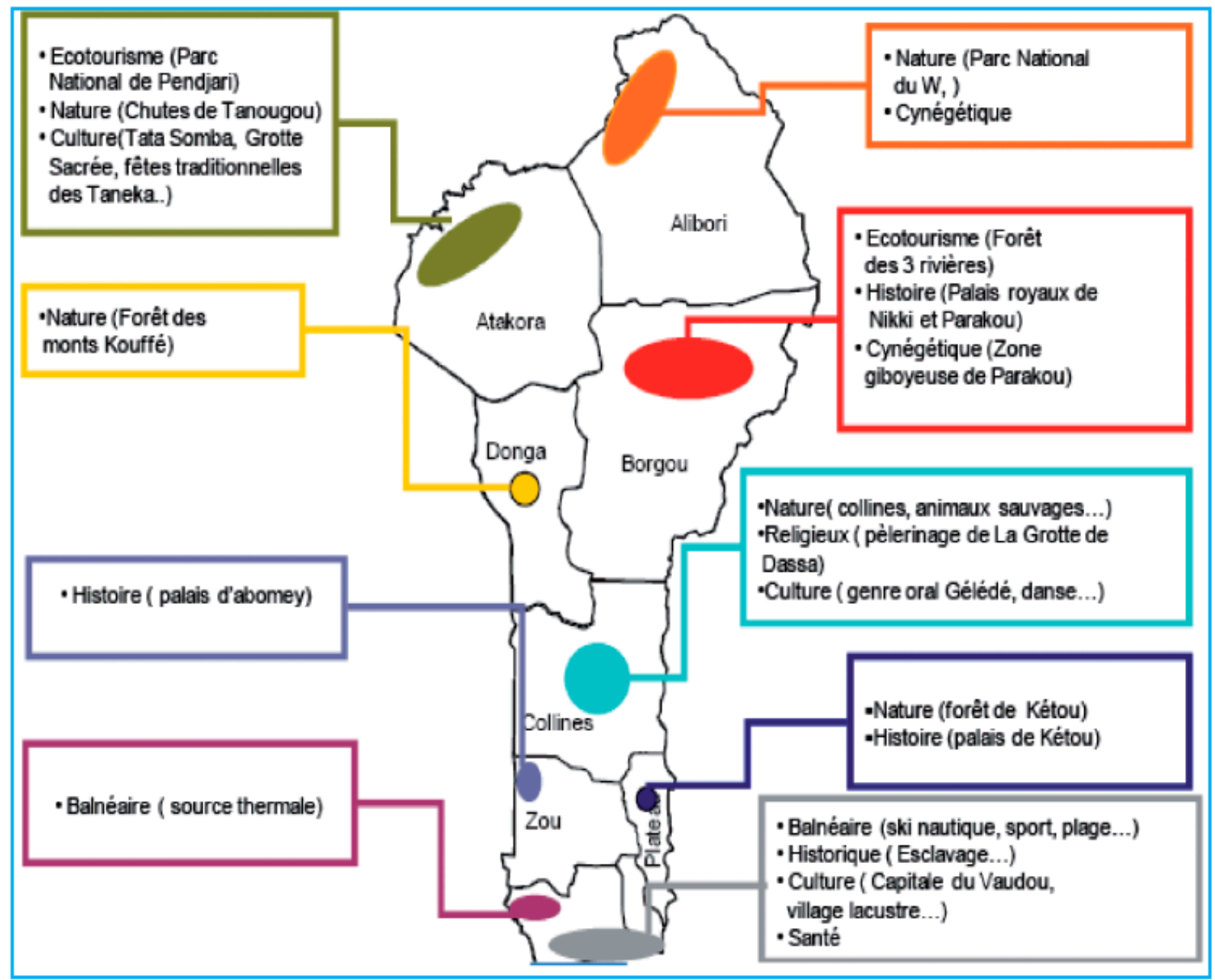

Source: Benin's Agenda for an Emerging Economy: Phase 2. 
Key:

Left-hand side of map:

- Ecotourism (Pendjari National Park)

- Nature (Tanougou Falls)

- Culture (Tata Somba, Taneka Sacred Grotto, Taneka traditional feasts, etc.)

- $\quad$ Nature (Kouffé mountain forest)

- History (Abomey palace)

- Seaside (hot springs)

Right-hand side of map:

- Nature (W. National Park)

- Game

- Ecotourism (Three Rivers Forest)

- History (Nikki and Parakou Royal Palaces)

- Game (Parakou Game Reserve)

- Nature (hills, wild animals, etc.)

- Religion (Grotto of Dassa pilgrimage)

- Culture (Gélédé oral culture, dance, etc.)

- Nature (Kétou Forest)

- History (Kétou Palace)

- Seaside (water skiing, sports, beaches, etc.)

- History (slavery)

- Culture (Capital of Vaudou, lake basin village, etc)

- Health

4.29 Although highly diversified in Benin (see Figure 13), the handicrafts sector faces enormous difficulties:

(i) poor training of artisans;

(ii) insufficient financial resources for self-financing and difficulties accessing credit;

(iii) rudimentary artisanal technology; and

(iv) limited competitiveness of local artisanal products.

4.30 In light of these difficulties, the Government has surveyed and prepared the Inventory of Artisanal Trades and developed the Handicraft Sector Development Project. In addition, the Government plans to expand the handicraft subsector through specific incentives in liaison with the National Policy for the Development of Handicrafts in Benin and support for high valueadded export-oriented artisanal subsectors. The required actions cover the five focuses for this sector:

(i) improvement of overall conditions;

(ii) promotion of the organization of sector participants;

(iii) enhancement of knowledge, savoir-faire and self-reliance;

(iv) promotion of the development of artisanal microenterprises; and

(v) promotion of the social welfare of artisans. 
Figure 4.5: Map of Artisanal Activity Areas in Benin

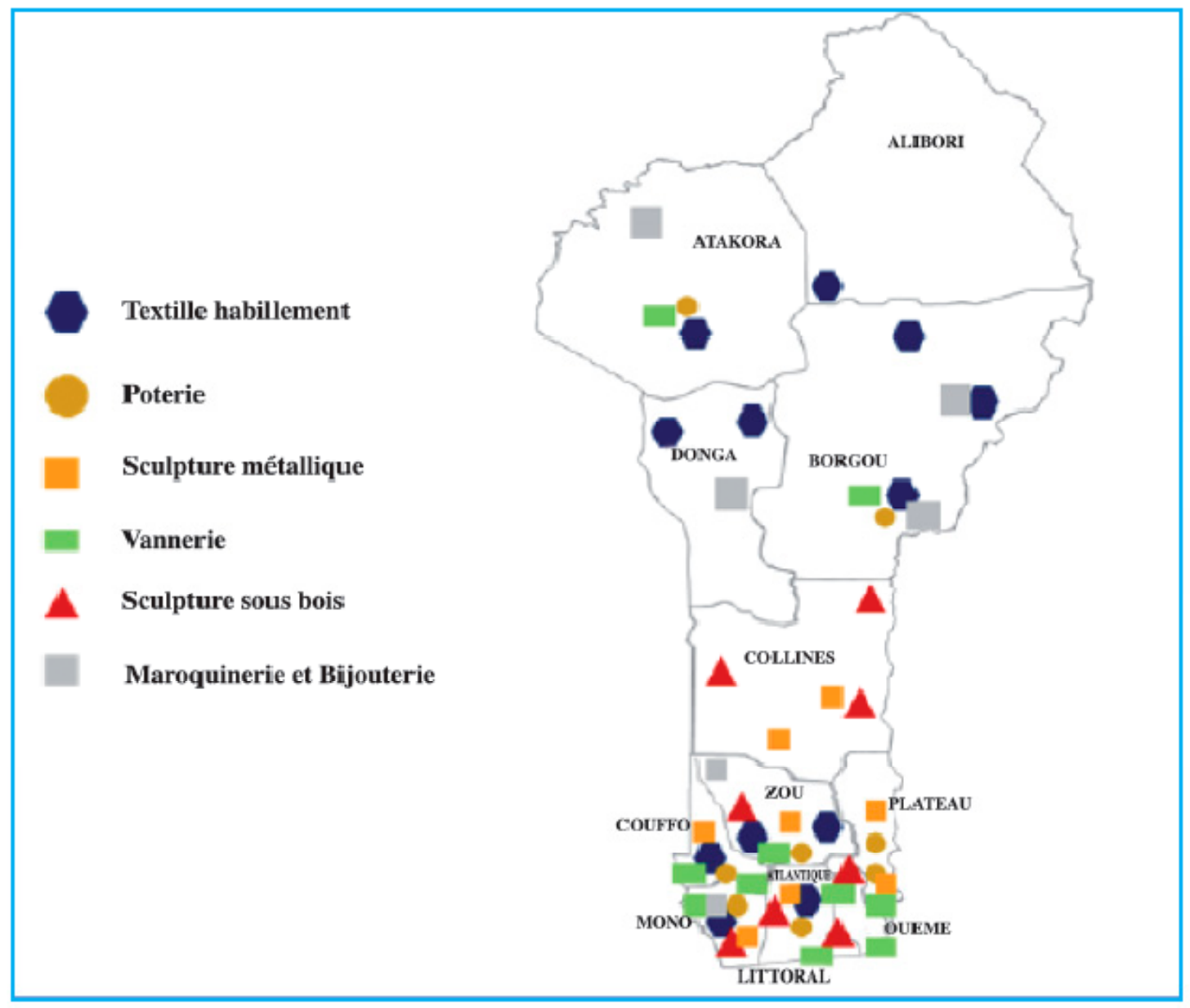

Source: Benin's Agenda for an Emerging Economy: Phase 2.

Key:

Textile-clothing

Pottery

Metallic sculpture

Basket making

Wood sculpture

Leather goods and jewelry

4.31 The culture subsector contributes to the development of tourism and artisanal activities. The difficulties in this subsector relate to:

(i) technical and financial weakness of industries and cultural operators;

(ii) lack of suitable spaces for the performing arts and cultural activities; and

(iii) limited conservation, protection and enhancement of cultural goods.

Consequently, the Government intends to finalize its cultural policy, which aims to:

(i) protect and promote the tangible and intangible cultural heritage; 
(ii) develop cultural industries;

(iii) improve accessibility to books and reading;

(iv) improve the context for the creation of intellectual works; and

(v) develop the organizational and managerial capacities of participants in the cultural sector.

\subsubsection{The two high-potential growth areas}

4.32 Construction and public works-construction materials. Housing is of capital importance given population growth and rapid urbanization. High population growth and rapid urbanization are factors in the long-term development of the construction and public works market. As a result, two areas must be tackled:

(i) rural housing, to counteract ongoing rural depopulation; and

(ii) urban housing and infrastructure, to counteract the tendency towards the growth of shantytowns through the implementation of public housing programs.

4.33 There are also important needs in the area of large-scale infrastructure. Because its financial resources are limited, the Government intends to make use of partnerships with the private sector for the development and optimal implementation of large infrastructure projects (ports and airports, highways, tourism facilities, buildings). In this context, some legislation will be updated and an institutional and legislative framework for public-private partnerships will be finalized and submitted to the National Assembly.

4.34 The construction and public works sector is a genuine potential growth niche. The sectoral recovery will lead to high demand for construction materials. Benin has substantial raw materials in its soil and subsoil that will help revitalize the construction and public worksconstruction materials growth area (Figure 14). Apart from ornamental stone, this potential is today underexploited. Therefore, the Government also plans to implement a policy for the use of local construction materials and renewable energies in housing and infrastructure programs. 
Figure 4.6: Beninese Construction Materials Potential

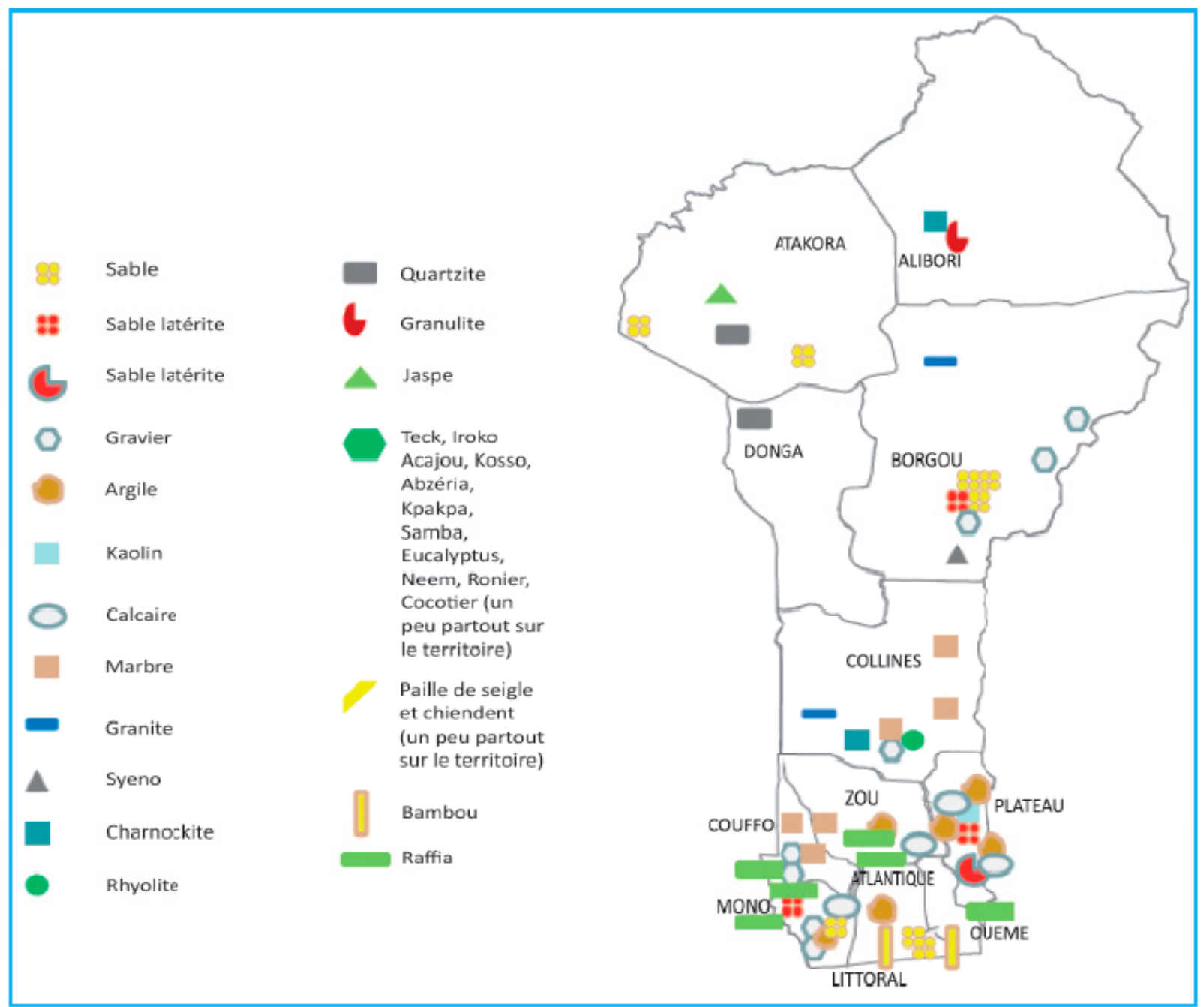

Source: Benin's Agenda for an Emerging Economy: Phase 2.

Key:

Sand

Laterite sand

Laterite sand

Gravel

Granulite

Jasper

Teak, Iroko

African mahogany, African redwood

Clay

Abzeria

Lenke

Kaolin

African whitewood

Eucalyptus

Limestone

Neem, African fan palm

Coconut palm (more or less

Marble through the country)

Granite

Rye and wheatgrass

straw (more or less

Syeno-granite throughout the country)

Charnockite

Bamboo

Rhyolite

Raffia 
4.35 Mining and hydrocarbons. Analysis of Benin's mineral resource potential reveals the existence of identified exploitable deposits. Moreover, mineral indications for a wide range of mineral products are kindling a great deal of hope and require large investments for the identification of new deposits. Benin has three sedimentary basins, but oil exploration and/or drilling is ongoing only in the Coastal Sedimentary Basin. The mining and hydrocarbons sector is characterized by:

(i) a lack of or out-of-date pre-feasibility studies to attract investors;

(ii) a lack of promotional information on identified mining areas;

(iii) illegal and inefficient extraction of some mineral resources by artisanal miners, including gold, gravel, sand, clay, etc.;

(iv) outdated and nonfunctional survey, laboratory analysis and pilot production equipment and lack of appropriate premises;

(v) lack of oil information centers on non-coastal sedimentary basins; and

(vi) lack of refineries.

4.36 The Government's ambition is to make the mining and hydrocarbons sector one of the engines of industrialization and economic growth. Several priority actions have been identified in this area including, for the mining sector:

(i) promotion and management of Benin's mining potential;

(ii) identification and management of the supply of non-beach sand;

(iii) identification and development of Benin's mineral resources; and

(iv) feasibility studies on proven deposits.

In the area of hydrocarbons, the priority actions involve:

(i) redefinition of the basic coastal sedimentary basin;

(ii) study and construction of the hydrocarbons analysis laboratory;

(iii) enhancement of the safety of ocean facilities and combating of hydrocarbon pollution of the ocean;

(iv) strengthening and modernization of the oil and gas products distribution infrastructure; and

(v) recovery and rehabilitation of the refueling base for petroleum activities in the Port of Cotonou.

\subsection{PROMOTION OF REGIONAL INTEGRATION AND ENTRY INTO GLOBAL NETWORKS}

4.37 Benin must open up to the rest of the world in order to develop economies of scale and expand the markets for its products and services, given the limited size of the domestic market (less than 10 million inhabitants). The need for regional integration is therefore not only a matter of the necessary political will but especially a question of survival for the national economy. 
4.38 The economic promotion policy aims to effectively reduce the barriers to regional and international trade. To this end, Benin intends to further exploit its strategic position as a link between Nigeria and the WAEMU and as an outlet for the countries of the hinterland. The Government will therefore focus on ensuring that:

(i) a mechanism is set up to improve economic integration with the WAEMU and ECOWAS countries;

(ii) support is provided for the enhancement of community policies; and

(iii) the system for tracking regional integration is implemented.

\subsubsection{Enhancement of regional economic integration}

4.39 The Government has decided to:

(i) pursue the development of its potential for transit services in order to make Benin a platform for trade;

(ii) strengthen bilateral cooperation with Nigeria, particularly to reduce the volume of illegal trade with that country;

(iii) develop channels for trade in food products for which there is high demand in the subregion (particularly in Nigeria and Niger), in order to increase its output of these products; and

(iv) promote the creation of joint ventures intended to ensure complementarity of the factors of production in order to develop Benin's industrial potential.

4.40 Within the regional organizations, the Government will continue to support the efforts to enhance integration of the African Union, ECOWAS and WAEMU. In particular, Benin will make a point of signing, ratifying and implementing all protocols and charters adopted and contributing actively to the financing and implementation of community programs.

\subsubsection{Promotion of development diplomacy}

4.41 The Government will make sure to:

(i) enhance Benin's sustained presence in international organizations and improve its diplomatic staffing levels;

(ii) develop trade with other countries; and

(iii) actively promote foreign direct investment. 


\section{CHAPTER 5: INFRASTRUCTURE DEVELOPMENT}

5.1 Economic infrastructure that complies with international standards is essential for the promotion of economic growth. Because of its cross-cutting nature, infrastructure plays a key role in the development of all other sectors. The Government of Benin, with the support of the TFPs, has consequently developed a general transportation strategy for the period 2007-2011, including a specific strategy for rural transportation.

5.2 The Government's vision for infrastructure is to have Benin evolve from its current position as a transit country to a platform for logistical and export services, based in particular on an integrated infrastructure system and high-quality transportation services. The implementation of the 2007-2009 GPRS, with the efforts invested by the Government and the achievements in terms of development of economic infrastructure, has made it possible to increase trade. However, several challenges remain in the area of infrastructure that must be met so that the country's economic potential may be fully exploited.

5.3 The Government has therefore decided to step up its investment in infrastructure during the period 2011-2015. To that end, it has set targets in the following five priority intervention areas:

(i) transportation infrastructure;

(ii) energy infrastructure;

(iii) communications and information and communications technology infrastructure;

(iv) water and sanitation infrastructure; and

(v) building construction and urbanization.

\subsection{TRANSPORTATION INFRASTRUCTURE}

\subsubsection{Road infrastructure}

5.4 Owing to its geographic location and the Port of Cotonou, Benin is a natural link between the WAEMU countries and Nigeria; a transit country for the transportation of merchandise to and from Niger; and an access channel for Burkina Faso, Mali, Chad and Nigeria. However, many constraints prevent Benin from benefiting from this comparative advantage, in particular:

(i) its rather dilapidated road infrastructure;

(ii) poor national coverage, particularly the deficiency of the network of rural roads in providing access to isolated communities;

(iii) limited access to community social infrastructure; and

(iv) limited resources for the Roads Fund.

5.5 The road infrastructure sector is also characterized by the recurrent problem of the anarchical occupation of rights-of-way, which affect construction costs; the increasingly limited availability of lateritic materials used for road construction and maintenance; insufficient 
monitoring; and the lack of sanctions for axle overloading, which is a factor in the rapid deterioration of the road network.

5.6 During the period 2011-2015, the Government intends to maintain and increase the road infrastructure network to support economic development and social welfare.

5.7 To this end, five priority actions have been selected, involving, in particular:

(i) better maintenance and protection of the road network, including monitoring of axle loads;

(ii) development of rural transportation infrastructure, which involves expanding the network of rural roads to support the flow of agricultural goods and promote access to basic social services;

(iii) rehabilitation, modernization and expansion of the national road network;

(iv) diversification and modernization of modes of transport; and

(v) consideration of gender, the environment and climate change issues in transportation strategies.

\subsubsection{Rail infrastructure}

5.8 The railroad is an efficient means of mass transport owing to its safety, low cost, and low environmental impact, despite the high investment required. However, the rail sector is characterized by deteriorating tracks, an insufficient and aging fleet of locomotives, lack of a rail link between Parakou and Niamey, out-of-date legal texts governing the rail company, failure to control road-rail competition, and the lack of a national rail transport policy.

5.9 To remedy the weaknesses identified, the government has set itself the objective of providing effective rail transportation service in support of economic growth. To that end it intends to:

(i) expand the rail infrastructure; and

(ii) promote rail transport.

\subsubsection{Port infrastructure}

5.10 The maritime and port sector is involved in 90 percent of Benin's trade. It therefore plays an important role in the national economy, given the country's geographic location, and generates traffic. However, many problems affect this sector, particularly:

(i) the limited number of berths, given the increase in traffic over the past 10 years;

(ii) the lack of specialization of spaces and area congestion;

(iii) the low productivity of handling operations;

(iv) slow cargo removal operations; and

5.11 the continued lack of security in the port area and along the Beninese corridor. To indentify adequate solutions for these dysfunctions, the Government has set itself the 
objective of improving the performance of the Port of Cotonou and the quality of services provided to sector users over the next five years. To that end, the Government will implement the following three priority actions:

(i) improvement and expansion of port infrastructure;

(ii) improvement of services offered to users of the Port of Cotonou; and

(iii) development of a policy for the management and exploitation of ocean resources.

\subsubsection{River and lagoon transportation infrastructure}

5.12 River and lagoon transportation is still in its infancy and is used by people on a noncommercial basis. The main problems to be resolved concern the lack of basic infrastructure, lack of technical and financial resources in the local communities, and insufficient knowledge of the characteristics of waterways. To rise to the challenges of this sector the Government intends to:

(i) develop navigable channels in waterways;

(ii) promote river-lagoon transportation services and intermediate means of transport; and

(iii) continue to implement the project for the development of river-lagoon transportation and tourism between Cotonou, Porto-Novo and the surrounding areas.

\subsubsection{Air transport infrastructure}

5.13 The air transport sector is characterized by:

(i) the lack of domestic air transportation, owing to the geographic size of the country and therefore the lack of domestic market;

(ii) a single international airport, located in Cotonou, whose runway is too short (at $2400 \mathrm{~m}$ ) to readily handle certain types of jumbo jets, while the possibilities of extending it are limited;

(iii) the limited capacity of the entity responsible for inspecting and supervising flights;

(iv) the limited capacity of the Cotonou airport;

(v) the lack of facilities at airports in the interior of the country; and

(vi) the inefficiency of the entity responsible for certifying and monitoring airlines.

5.14 In light of these problems, the Government has set itself the objective of making Benin an airport services and operations platform by promoting the development of air transportation services. Specifically, the Government plans to strengthen Benin's international airport infrastructure and operational capacities and promote the development of domestic air traffic. The priority actions selected are:

(i) construction and equipment of the Tourou airport;

(ii) establishment and equipment of the air transport brigade at Cardinal Bernardin Gantin international airport; and 
(iii) implementation of the regional air transport security and safety project in Western and Central Africa.

5.15 For the integrated development of the transportation sector, the availability of infrastructure must be combined with a subsequent supply of transportation services and promotion of intermediate means of transport to allow companies to reduce production costs, ensure that the market is adequately supplied, and develop economic activities.

\subsection{ENERGY INFRASTRUCTURE}

5.16 The energy sector is a key link in the development process. It plays an important role in the productive sector and helps to improve the social capital by contributing to the achievement of the objectives of the social sectors, particularly education and health.

5.17 Benin has substantial potential in renewable energies but they are underexploited, with the exception of firewood. The solar and wind energy subsectors have been studied but no largescale specific projects have as yet been developed. About 10 medium- and high-capacity hydroelectric sites exist, as well as 85 small-capacity sites.

5.18 The Government's general objective for the next five years is to provide Benin with the resources that will provide it with a secure supply of sufficient high-quality energy services at optimal cost. Specific actions for the most important subsectors are described below.

\subsubsection{Electricity subsector}

5.19 There is a substantial gap between what has been achieved and the planned objectives, despite the adoption in March 2006 of the action program for the electrification of local communities, which was to have accelerated the electrification of local communities throughout the country. The average electrification rate actually achieved in 2009 in rural areas was 3.1 percent, compared with a forecast of 6.6 percent. The average rate of access of households to electricity actually achieved at the national level in the same year was 27.1 percent, compared with a forecast of 33.7 percent in the program for the development of energy services initiated in connection with the MDGs.

5.20 Moreover, the electrical energy supply situation is characterized by:

(i) a high degree of dependency on countries in the subregion, particularly Côte d'Ivoire, Ghana and Nigeria;

(ii) a relatively high energy loss rate on the national electrical grid, varying between 15 and 20 percent;

(iii) poor technical and financial performance of companies in the sector (CEB, SBEE). Since April 2006, Benin has suffered a very serious energy crisis that has been reflected in numerous electricity outages, which have a damaging effect on the national economy; and

(iv) a pricing policy that prevents companies in the sector from covering the costs of supplying electrical energy. 
5.21 To remedy these deficiencies, the Government intends to:

(i) expand production capacity and electrical energy distribution and transportation channels;

(ii) promote rural electrification and energy control;

(iii) introduce a sectoral pricing and financing policy; and

(iv) develop institutional and regulatory capacities and improve personnel qualifications.

\subsubsection{Petroleum products subsector}

5.22 The supply of petroleum products is characterized by total dependency on the rest of the world owing to the lack of an oil refinery in Benin, a large parallel market for petroleum products, and limited distribution networks for the petroleum products of licensed companies in the sector, which do not cover the entire country adequately.

5.23 The Government's objectives in this area are to strengthen the legislative and regulatory framework and to stimulate petroleum product supply and distribution activities. Six priority actions have been identified in this context:

(i) amendment of legislation and regulations;

(ii) securing of the supply of petroleum products in Benin and the countries in the hinterland;

(iii) expansion and modernization of the oil and gas distribution infrastructure;

(iv) promotion of mini distribution stations to replace informal channels;

(v) diversification of sources for the supply of petroleum products; and

(vi) construction of new storage depots and gas stations.

\subsubsection{Biomass energy subsector}

5.24 Biomass energy plays an important role in the supply of energy in Benin owing to its share in total final energy consumption (60 percent in 2005). It essentially involves firewood, charcoal and, to a certain extent, plant waste. However, the sector does face a number of constraints:

(i) lack of organization and planning of forestry operations;

(ii) lack of knowledge of changes in forest cover;

(iii) low rate of taxation of forestry products in comparison with other countries in the subregion; and

(iv) limited accessing of modern energy sources by households owing to the preference for traditional cooking methods.

5.25 To promote biomass energy, the Government has set itself the following objectives:

(i) to strengthen national capacities for planning and management of the domestic fuel subsector and for controlling biomass energy; and 
(ii) to promote access of households to modern cooking equipment and modern biomass energy applications.

Five priority actions have been identified:

(i) development of institutional capacities in the subsector;

(ii) design and establishment of the Ecological and Forestry Information System (SIEF);

(iii) improved access of households to gas cooking equipment and improved stoves;

(iv) support for local producers of ethanol or gas cooking equipment; and

(v) development of the production of bioenergies, including biofuels.

\subsection{ICT INFRASTRUCTURE AND THE POSTAL SECTOR}

\subsubsection{ICT}

5.26 Significant reforms have been implemented in the information and communications technology (ICT) sector in recent years, as part of the effort to expand the infrastructure and service supply in order to reduce costs. A review of the legal framework for the telecommunications sector shows that the current laws are inadequate for the development of this strategic sector and do not meet the expectations of public and private operators. The historic operator, Bénin Télécoms S.A. (BT-SA), faces significant difficulties. The population covered by the mobile telephone network was estimated at 45 percent in 2007, thus contributing to improved universal access. However, the public does not yet benefit from all of the advantages of this coverage and operators suffer from a lack of effective operational regulations (interconnection, management of frequencies, management of disputes) and the lack of an appropriate legal and regulatory framework. Most of these local networks are saturated and cannot accept new subscribers.

5.27 The Government has therefore undertaken to modernize the legal framework to facilitate the harmonious development of the sector and to allow Benin to transition more effectively to an information society. Specifically, the priority actions that are required are:

(i) the entry into operation of the Transitional Postal and Telecommunications Regulatory Authority (ATRPT) for the efficient operation of fixed and mobile spectrum control stations;

(ii) incentives for more cost-effective exploitation of fiber optics; and

(iii) acquisition and/or development of telecommunications infrastructure maintenance equipment. Moreover, the restructuring and opening up of Bénin Télécoms S.A. to private investment is another of the priority actions in the context of a gradual liberalization of the other components of the sector, which are still under a monopoly.

5.28 A substantial effort has been made to develop and implement a consistent national ICT plan. Benin does have a significant advantage, i.e., the direct connection with the SAT3 undersea cable, which enables it to offer companies, households and neighboring countries access to highspeed Internet. In addition to the provision of access to the Internet, call centers are a new 
activity that is expanding rapidly. The development of the sector is nonetheless constrained by a lack of financing.

5.29 The actions that the Government will take during the period 2011-2015 are aimed at creating a dynamic sector through:

(i) implementation of the ICT access strategy in rural or isolated areas;

(ii) completion of pilot projects such as the e-Government project, particularly in the form of remote downloading of administrative procedures and computerization of administrative services; and

(iii) creation of an environment favoring e-entrepreneurship.

\subsubsection{The postal sector}

5.30 The post office is still one of the most important means of communication for the public, particularly the most disadvantaged segments of the population, for both mail and transfers of money. The appearance of private companies, particularly financial networks, on the Beninese market are breaking into the postal monopoly, which has created a twofold challenge for La Poste du Bénin S.A., i.e., competition from private operators and adjustment of production processes to new technologies in order to create innovative services for customers.

5.31 La Poste du Bénin S.A. is still facing a number of difficulties, i.e.:

(i) low level of debt collection;

(ii) lack of knowledge of the market;

(iii) lack of a business culture among its staff;

(iv) an inadequate information system;

(v) lack of automation of window operations;

(vi) lack of interconnection of the network of post offices;

(vii) lack of cost accounting; and

(viii) lack of synergy between $\mathrm{CCP}$ and $\mathrm{CNE}$ accounts.

5.32 Therefore, the Government has set itself three essential objectives:

(i) drafting of the Postal and Electronic Communications Code;

(ii) establishment of the Postal and Electronic Communications Regulatory Authority; and

(iii) restructuring and modernization of La Poste du Bénin S.A.

\subsection{WATER AND SANITATION INFRASTRUCTURE}

\subsubsection{Water resources}

5.33 Water resources are sufficient to meet the country's current and future needs. However, these resources are distributed unevenly, both seasonally and across the national territory, 
resulting in cyclical water shortages in some areas. The service delivery rate in rural areas increased by 20 percentage points between 2002 and 2009, from 35.2 percent in 2002 to 55.1 percent at end-2009. The Drinking Water Supply (AEP) is a government priority. The various efforts of the Benin National Water Company (SONEB) to increase water resources have resulted in an increase in the number of subscribers by around 23 percent, from 115,352 subscribers in 2004 to 141,883 in 2008.

5.34 The major challenges relate to:

(i) promotion and development of the control of water resources;

(ii) introduction of good governance of water and harmonious intersectoral coordination;

(iii) management of water as a national asset; and

(iv) sustainable management of ecosystems and proper management of water-related risks.

5.35 To respond to these challenges, the Government has set itself the objective of transitioning toward integrated water resource management (IWRM) and has identified the following six priority actions to be implemented in the context of the 2011-2015 GPRS:

(i) increased decentralization of the decision making process in favor of the communes, which plan on the basis of user demand;

(ii) greater involvement of users in financing, management, renewal of equipment, and monitoring of works;

(iii) increased production capacity and more water treatment plants;

(iv) construction of new water towers and reservoirs;

(v) extension and densification of networks in order to supply new communities; and

(vi) promotion of the private sector in construction, operation, monitoring and social intermediation activities.

\subsubsection{Sanitation}

5.36 In 2007, the Government adopted a national policy for the sustainable management of wastewater treatment in urban areas. This policy will provide the urban wastewater treatment sector with the technical, technological, economic, legal and institutional instruments it needs to achieve the Millennium Development Goals (MDGs). While the rate of coverage of excreta disposal systems is relatively high in urban areas, it remains low in the secondary cities. Moreover, the rate of wastewater disposal in urban areas is close to zero ( 0.4 percent), the majority of wastewater being dumped outside in streets and canals.

5.37 To respond to these challenges, the Government intends to implement the following key actions in a favorable institutional framework:

(i) capacity building for the key participants in the sector; and

(ii) development of blueprints for wastewater treatment for the major cities. The actions will also target improving the level of access to sanitation services through the promotion of adequate infrastructure. 


\subsection{BUILDING CONSTRUCTION AND URBAN DEVELOPMENT}

5.38 The right to housing is an inalienable human right. Consequently, the issue of housing and urban development is a sustainable human development concern in Benin. In the context of the 2007-2009 GPRS, several actions were implemented to reduce the number of inhabitants of slums by half by 2015 , as promoted by the United Nations. In recent years, Benin has made a great deal of progress in the areas of building construction and urban development, but much remains to be done if the MDGs on housing are to be achieved.

\subsubsection{Building construction}

5.39 Good housing conditions contribute to the personal fulfillment of human beings. Nevertheless, the housing sector has long suffered from the lack of a clearly defined national policy. Rural housing has generally been excluded from policies and strategies. Furthermore, construction techniques have improved little and most local industries for the production of construction materials are still in their infancy. The difficulties in the construction and public works sector can be summarized as follows:

(i) lack of a clear definition of the relations between the Government and the various professional associations and societies;

(ii) lack of a policy and strategy for the promotion and development of construction and public works trades;

(iii) lack of promotion of the employment of young professionals in the construction and public works sector; and

(iv) lack of organization of the professions of broker, salesperson, owner/tenant, real estate agent, promoter and developer.

5.40 To respond to these challenges, the Government intends, in the short and medium term, to:

(i) increase the supply of housing;

(ii) rehabilitate the Government's housing inventory and promote the intensive use of local construction materials. The actions identified to achieve these objectives over the next five years involve improving and cleaning up housing through the implementation of the Housing and Construction Program (PHC).

5.41 Six priority actions will be implemented, i.e.:

(i) establishment and organization of a system of cooperation among housing professionals;

(ii) contribution to the establishment of a system for the rational production of local construction materials, development of land plots and construction of housing in cities;

(iii) introduction of a system for the supply of housing services;

(iv) creation of opportunities for the development of housing and improvement of the quality of existing housing; 
(v) improvement of unsanitary housing and poverty reduction; and

(vi) drafting of legal texts and instruments for the control of land ownership so as to facilitate access to ownership for the largest possible number of citizens.

\subsubsection{Urbanization}

5.42 The lack of an effective land-use planning policy has led to uncontrolled urbanization. Cities face pollution problems owing to household trash, fecal sludge, liquid waste, tailpipe emissions and noise pollution, which are sources of waterborne diseases, acute respiratory infections and cardiovascular disease.

5.43 To respond to the challenges in the area of urbanization, the Government plans to:

(i) promote the economic development of cities;

(ii) combat coastal erosion; and

(iii) strengthen land tenure security.

The planned priority actions through the implementation of the Urban Management Support Program (PAGU) focus on:

(i) improving urban governance and the living environment;

(ii) coordination of actions in favor of urban development and control of urban mobility;

(iii) more rapid construction of water and sanitation infrastructure;

(iv) development of basic geographic equipment;

(v) protection of the coastline east of the Siafato breakwater; and

(vi) protection and rational management of coastal and river bank areas in Benin. 


\section{CHAPTER 6: BUILDING HUMAN CAPITAL}

6.1 Despite progress made in recent years with the implementation of the Growth and Poverty Reduction Strategy (GPRS 2), economic performance has not been sufficient to meet the growing social demands effectively. Although the social indicators have improved, they remain troubling. The education system suffers from deficiencies that prevent it from responding to development needs. Mortality rates remain high. ${ }^{14}$ The persistence of gender inequalities hampers women's access to basic social services and opportunities. Human capital, an essential factor in economic growth and development - particularly in the new context of globalization in which knowledge, savoir-faire, and life skills play a key role in increasing productivity and reducing poverty - is today a constraint owing to high population growth and the limited skills of the labor force.

6.2 The Government intends to enhance the potential of human capital by:

(i) controlling population growth;

(ii) promoting development education;

(iii) improving the health and nutrition of the population;

(iv) creating decent jobs;

(v) enhancing and expanding social welfare;

(vi) promoting gender equality; and

(vii) promoting youth and leisure.

\subsection{CONTROLLING POPULATION GROWTH}

6.3 The Beninese population has been growing steadily, at a rate of growth of 2.8 percent between 1979 and 1992, and of 3.2 percent between 1992 and 2002. Given its natural growth rate of 2.9 percent (RGPH 3), Benin is classified among the high-fertility Sub-Saharan African countries. The high fertility level (Total Fertility Rate of 5.7 children per woman) is explained by early marriages, the low contraceptive rate (6.2 percent), increasingly unmet family planning needs (30 percent in 2006 compared with 27 percent in 2001), persistent polygamy measured at 27 percent among men in 2002 and 39 percent among women, and high fertility levels (21.5 percent) among adolescents (15-19 years). This situation is particularly troubling in that reproductive health programs for adolescents and young people are still very limited. The high population growth potential will lead to a high level of social demand in the coming years (see Box 2) if current trends continue. Thus, maintenance of the annual population growth rate in the current context of insufficient wealth creation risks holding back development efforts.

6.4 Therefore, the Government has decided to implement the following priority actions: ${ }^{15}$

\footnotetext{
${ }^{14}$ In 2006, infant mortality was 67 per thousand; childhood mortality stood at 125 per thousand; and maternal mortality was measured at 397 deaths per 100,000 live births.

${ }^{15}$ These actions are based on the Declaration of Population Policy (DEPOLIPO) adopted in 1996 and revised in 2006.
} 
(i) promotion of responsible fertility through better access to reproductive health information and services;

(ii) promotion of research and studies on the interconnections between population levels and poverty;

(iii) promotion of mandatory school enrollment for children, particularly by enrolling and keeping girls in school through the secondary level;

(iv) promotion of mandatory registration of vital statistics, particularly births;

(v) integration of demographic variables in development policies and programs at the national, regional and local levels;

(vi) enhancement of the collection of socio-demographic data broken down by gender and improvement of the database;

(vii) promotion of advocacy and behavior change communication in the area of population policy; and

(viii) enhancement of multisectoral and multidisciplinary institutional coordination on the management of population issues by means of better facilitation by the National Commission on Human Resources and Population.

\section{Box 6.1: Population Dynamic and Social Demand}

Benin is characterized by sustained population growth resulting from a high and steady level of fertility, gradually declining mortality, and significant migratory flows. The population of Benin increased from 6,769,914 inhabitants in 2002 to 8.78 million inhabitants in 2010 and is expected to reach 10 million inhabitants by 2014 and a little over 13 million by 2027 .

Although, in accordance with the DEPOLIPO, the promotion of a "responsible fertility policy" [will make] it possible to bring the Total Fertility Rate (TFR) down from 5.7 children per woman today to 4.8 children in 2015 and 3.9 children around 2027, the growth of the population will remain quite high and the population will total around 12 million by 2027 . This results from the fact that the decline in fertility goes hand-in-hand, over the period, with a more rapid increase in the proportion of persons of reproductive age.

This population dynamic in Benin creates a number of challenges in terms of social demand (nutrition, education, health, employment, housing and urban management) and the availability of the factors of production.

The first consequence of population growth over the coming 28 years is the reduction in available arable land per capita. From around 1.04 ha in 2002, [per capita] arable land will decline by more than half by 2015 ( $0.47 \mathrm{ha})$ and three quarters by $2025(0.25$ ha). This sizable decline is explained in part by the use of extensive agriculture with old-fashioned techniques, and by the expansion of cities, which will house more of the population than they do today (60 percent of the total population by 2030).

The population growth also increases the demand for education. The school-age population at the primary level, which totaled 1,281,911 in 2002, is expected to reach 1,635,496 by 2015, the target year for the Millennium Development Goals (MDGs), Education For All (EFA) and Benin's Ten-Year Education Sector Development Plan (PDDSE). By 2030, the school-age population will total 2,361,016. Meeting this demand will require the recruitment of approximately 22,000 new teachers at the primary level between 2007 and 2015 and another 23,000 between 2015 and 2030. The Government will therefore need to recruit an average of 3,000 teachers per year at the primary level between 2007 and 2015 and around 1,500 to 2,000 per year between 2015 and 2030 .

In the area of investment, the Government should continue its efforts to renovate, construct and equip schools. At the primary level, under the scenario 1 hypotheses, the Beninese education system will need 25,320 classrooms between 2010 and 2015 in order to function properly. Therefore about 4,200 classrooms on average will need to be built per year between 2010 and 2015 .

Population growth should result in a supply of 33 to 44 doctors per 10,000 inhabitants during the period 1999-2025. The number of new nurses is estimated at $125-135$ per year, bringing the total staffing level to between 6,270 and 6,560 by 2030 . This staff is expected to work in health centers, the number of which will increase from 448 in 2006 
to 664 in 2011, 792 in 2015, 1,228 in 2025, and 1,459 in 2030. If current standards remain unchanged, the rate of population growth will imply the construction and equipment of 31 to 37 health centers and two hospitals on average per year, from 39 in 2006 to 157 in 2030. In 2010, 10 additional health zones will be required. If nothing is done, the country will need to make approximately 18 additional health zones operational by 2015 to ensure the right of the population to health care.

Source: Study of the Impact of Population Growth on Development, 2008.

\subsection{PROMOTING DEVELOPMENT EDUCATION}

6.5 Economic and social development requires high-quality human resources, for which education is one of the determining factors. Despite the Government's efforts, the education sector still suffers from dysfunctions related to the substandard quality and inequity of the supply of education. To improve this situation, the Government's general approach, set out in the TenYear Education Sector Development Plan (PDDSE), will focus on the following areas:

(i) improved guidance of the education system;

(ii) better teaching quality;

(iii) improvement of the supply of education;

(iv) improvement of human resources management;

(v) reduction of gender and regional disparities;

(vi) increased role of the private sector and local communities in providing education;

(vii) establishment of a legal framework governing the partnership between the public authorities and the private sector; and

(viii) improved social dialogue with the social partners.

\subsubsection{Nursery school}

6.6 The nursery school subsector is somewhat stagnant, as reflected in the low rate of early childhood education for children between 3 and 5 years old. The Government therefore plans to increase the enrollment rate for very young children from 4 percent in 2006 to 15 percent in 2015. To achieve this, the following actions will be taken:

(i) improvement in the quality of education provided by designing and implementing programs adapted to very young children;

(ii) recruitment of nursery school teachers with higher qualifications and annual provision of an essential package of integrative group activities to each public nursery school;

(iii) improvement of private nursery school education; and

(iv) increased demand through per child subsidies.

\subsubsection{Primary education and general secondary education}

6.7 Primary education has benefited in recent years from substantial investment by the Government and the technical and financial partners. Nevertheless, some problems remain, specifically: 
(i) equity problems, which are reflected in an unequal distribution of numbers between the various regions and a gap in the enrollment ratios for girls and boys;

(ii) the poor retention rate, related to a high repeater rate and the existence of many schools that suffer from disruptions in the school year;

(iii) the lack and poor quality of teachers, especially in isolated areas;

(iv) deficiencies in the implementation of new study programs; and

(v) the lack of schoolbooks and educational materials, affecting both teachers and pupils.

6.8 To remedy these deficiencies, the Government's priority actions will aim to:

(i) achieve universal completion of primary school by 2015;

(ii) significantly improve the retention rate for pupils in the school system, particularly girls;

(iii) reduce grade repetition;

(iv) promote the enrollment of girls;

(v) improve the quality of education;

(vi) improve administrative and educational management and ensure guidance of the subsector;

(vii) continue to promote high-quality, child-friendly schooling; and

(viii) support private education through training for private school teachers.

6.9 Moreover, owing to the disparities in the enrollment rates between girls and boys at the general secondary school level, specific measures are planned to promote the enrollment of girls in lower secondary education, i.e.:

(i) implementation of a national policy and support mechanism to promote the access of girls to lower general secondary education and to keep them in school;

(ii) evaluation of the operation of existing girls' hostels to identify corrective measures to be taken to improve them;

(iii) development and introduction of a tutoring program for female students at the commune level; and

(iv) development and introduction of a coaching program (education support) for students at the commune level, particularly in disadvantaged communes.

\subsubsection{Vocational and technical education subsector}

6.10 This subsector provides the best opportunity for dealing with the recurring problem of the mismatch between training and labor market needs. The education system has for years been unable to establish a critical mass of competent talent to promote sustained agricultural and industrial development. The vocational and technical education subsector currently suffers from a number of weaknesses:

(i) insufficient and not very diverse training opportunities; 
(ii) lack of a guidance policy for students; and

(iii) equity problems, both in the distribution of education throughout the country and in the consideration of gender issues.

6.11 To remedy these problems, the Government intends to implement the following priority actions:

(i) development and diversification of the supply of education;

(ii) improvements in quality and gender equity;

(iii) improvement in subsector management and planning;

(iv) reorientation of vocational schools based on clusters of targeted projects;

(v) redeployment of training opportunities in institutions based on the comparative advantages of the regions and to take account of job opportunities in departments;

(vi) introduction of a training plan that matches business needs;

(vii) incentives to encourage vocational and technical training for girls; and

(viii) development of specific HIV/AIDS education programs for students.

\subsubsection{Higher education and scientific research subsector}

This sector is characterized by:

(i) the mismatch between the training provided and the real needs of the labor market;

(ii) the lack of infrastructure and teaching staff; and

(iii) weaknesses in subsector management and guidance.

6.12 To train high-level professionals who can provide an impetus for development, the Government intends to continue to support this type of education by:

(i) reorienting higher education toward the country's development needs;

(ii) improving higher education management and guidance;

(iii) improving quality and gender equity;

(iv) granting scholarships to the most deserving students and to girls and facilitating the access of girls to university residences;

(v) improving the living and working conditions of teachers; and

(vi) improving infrastructure to accompany the LMD (Bachelor's-Master's-Doctorate) reform.

6.13 Moreover, the culture of excellence in Benin is an asset that the country can use to establish a regional training system. To achieve this, it is essential that rigor become the watchword in the implementation of training programs, their alignment with subregional programs, and the development of the admissions infrastructure. This will require: 
(i) promotion and enhancement of regional programs for professional training in existing Bachelor's, Master's and Ph.D. programs;

(ii) support for the creation of new professional training programs at the Bachelor's and Master's levels based on national capacities and regional and national demand; and

(iii) enhancement of the financial and managerial capacities of public and private institutions offering targeted professional training with a regional focus.

6.14 Technical and scientific research, which is intended to be an essential tool of human development, suffers from:

(i) a lack of qualified scientific personnel and adequate financial resources;

(ii) organizational and performance deficiencies;

(iii) a lack of openness of research to development needs and inefficiencies of the various research institutes and centers;

(iv) research planning difficulties; and

(v) insufficient laboratories, scientific equipment and documentary resources.

6.15 Given the importance of research for economic and social development, the Government's priority actions will involve:

(i) establishing a fund to support the promotion of scientific and technological research;

(ii) developing and implementing a policy and consistent program of scientific, technological and biomedical research; and

(iii) supporting all research units for the implementation of the policy to promote scientific and technical research.

\subsubsection{Literacy}

6.16 Despite efforts over the past several decades, the illiteracy rate for individuals 15 years of age and older is still high, with significant disparities between departments and genders. According to the data of the third General Population and Housing Survey (RGPH-3) in 2002, the illiteracy rate is 67.4 percent nationally, and 78.1 percent for women. The subsector continues to face institutional problems and problems of quality, relevance and efficiency, resulting in high dropout rates, failure rates and rates of relapse into illiteracy, owing to a lack of consistent and relevant initial literacy, post-literacy and targeted training programs.

6.17 In this context, the Government's priority actions aim to:

(i) effectively implement the Declaration of National Policy on Adult Literacy and Education (DEPOLINA);

(ii) ensure equitable access to literacy programs;

(iii) improve the quality and effectiveness of programs;

(iv) promote literacy among women; and

(v) improve the literacy subsector management and guidance. 


\subsection{IMPROVING THE ACCESSIBILITY AND QUALITY OF HEALTH SERVICES}

6.18 Improving the health of the population is a major concern for the Government. The Government's vision for public health includes three Millennium Development Goals (MDGs), namely:

(i) reducing the under-five mortality rate;

(ii) improving maternal health;

(iii) combating HIV/AIDS, malaria and tuberculosis.

6.19 This vision is based on the following findings:

(i) the epidemiological profile has changed very little during the past five years and is dominated by three main pathologies (malaria, acute respiratory infections, gastrointestinal diseases);

(ii) demographic trends include population growth and growing urbanization;

(iii) there are interactions between the health of the population and other fields (economy, environment, education, etc.);

(iv) the needs of the population in terms of the response capacity, availability and quality of health care are growing steadily; and

(v) there is a need to strengthen the public-private partnership.

6.20 During the period 2011-2015, the health policy, in line with the MDGs, will focus on two areas:

(i) preventing and combating disease and improving the quality of care; and

(ii) management and support.

\subsubsection{Preventing and combating disease and improving the quality of care}

6.21 The priority actions in this area are:

(i) promotion of hygiene and basic sanitation;

(ii) reproductive health;

(iii) combating of priority diseases;

(iv) combating of communicable diseases;

(v) combating of non-communicable diseases;

(vi) promotion of traditional medicine and treatments;

(vii) promotion of mental health;

(viii) promotion of health in schools and universities;

(ix) promotion of health research; and

(x) promotion of ethics in the health sector. 
6.22 Hygiene and basic sanitation. The Government will pursue its policy in the area of hygiene and sanitation by means of three priority measures:

(i) promotion of hygiene and sanitation (PHA);

(ii) regulation, policing and sanctions; and

(iii) promotion of key favorable behaviors (drinking water hygiene, wastewater removal, washing of hands with soap and water, food hygiene, and housing hygiene).

6.23 Reproductive health. The Government's policy in the area of reproductive health has the following objectives:

(i) making more rapid improvements in the reduction of maternal, infant and neonatal mortality;

(ii) promoting reproductive health among adolescents and young people; and

(iii) continuing to control population growth. The Government will ensure effective implementation of this policy through:

- promotion of reproductive health (including HIV/AIDS), particularly among adolescents and young people;

- repositioning of family planning by improving access to and use of safe, effective, affordable and acceptable family planning services;

- improvement of the quality of targeted prenatal clinics and attended births;

- $\quad$ strengthening of Emergency Neonatal and Obstetrical Care (SONU);

- prevention of obstetrical fistulae;

- combating of STI/HIV/AIDS, with particular emphasis on high-risk groups;

- improvement of the essential care of newborns;

- nutrition;

- immunization;

- integrated management of childhood illnesses in clinics and in the community;

- quality assurance;

- promotion of operational research into traditional practices and belief systems that prevent the use of contraception; and

- promotion of behavior change communication.

6.24 Combating priority diseases. Aware of the continuing high levels of morbidity and mortality, the Government intends to continue to implement strategies to combat priority diseases (STI/HIV/AIDS, malaria and tuberculosis). In the area of HIV/AIDS prevention, the Government's priority actions will focus on:

(i) prevention and identification of cases, with particular emphasis on high-risk groups;

(ii) universal access to treatment and care; 
(iii) combating of discrimination;

(iv) care of Orphans and Vulnerable Children (OVC); and

(v) support for infected and affected persons.

For tuberculosis, the two priorities selected are identification of cases and continuity of treatment. At the same time, the synergy between the tuberculosis and HIV/AIDS programs will be strengthened both in terms of identification of cases and the handling of co-infections.

For malaria, the emphasis will be placed on prevention and case handling, based on cross-cutting support strategies such as behavior change communication, epidemiological and entomological monitoring, and research.

6.25 Combating communicable diseases. Other communicable diseases (African human tripanosomiasis), potential epidemic diseases (meningitis, cholera, measles) and diseases to be eradicated/eliminated (poliomyelitis, maternal and neonatal tetanus) will receive particular attention through the strengthening of the integrated epidemiological surveillance system and the capacity of staff to promptly and effectively handle epidemics.

6.26 Combating non-communicable diseases. The Government will step up its actions to combat non-communicable diseases (diabetes, high blood pressure, obesity, sickle cell anemia, epilepsy, cancer, glaucoma, etc.) by promoting practical prevention measures and continuing to systematically implement and improve the capacity of the system to handle these diseases. Given the increase in traffic accidents and their health consequences, the Government will implement road safety prevention and awareness measures over the coming five years. In addition, the Government plans to use isotropic techniques to better handle major diseases such as cancer, heart disease, pediatric diseases, metabolic diseases and infections. These techniques have the advantage of being sensitive, reliable, rapid and low-cost.

6.27 Promotion of traditional medicine and treatments. Given the importance of traditional medicine and treatments in Beninese society, the Government will make better use of local therapeutic resources by making an inventory of existing traditional recipes, establishing a quality control mechanism and promoting the use of local products.

6.28 Promotion of mental health. Mental health is increasingly seen as a factor in well-being, at both the household level and the community level. The Government's strategies will target the integration of mental health activities in existing primary health care approaches by ensuring basic care for the entire population.

6.29 Promotion of health in schools, universities, and the workplace. The Government intends to promote the health and safety of pupils, students and workers in order to improve productivity. In this context, there are plans to provide basic health care free of charge to pupils and students in schools and universities. As well, such care will be provided to workers at an affordable cost through the Universal Health Insurance System (RAMU).

6.30 Promotion of health research. To facilitate and restructure the decision-making process, the Government's strategy will consist of developing health research and using and 
disseminating the results, primarily by increasing the human and material resources allocated to research institutions.

6.31 Promotion of ethics. In addition to the respect of ethical standards by researchers, both in the development of research protocols and in their implementation, the Government will ensure that health officials at all levels in the health pyramid comply with the ethical standards of their profession (respect of technical standards and norms in their day-to-day work). Particular emphasis will be placed on respect of human beings (reception, enlightened consent, confidentiality, dignity and human rights).

\subsubsection{Support and management interventions.}

\subsection{These involve:}

(i) strengthening infrastructure, equipment and maintenance;

(ii) capacity building;

(iii) building institutional and partnership capacities;

(iv) preparing the health care districting map;

(v) improving quality assurance, ethics and medical liability;

(vi) promoting the community approach;

(vii) improving the availability of drugs, reagents and supplies;

(viii) promoting diagnostic research and transfusion safety.

6.33 Strengthening infrastructure, equipment and maintenance. The Government will make sure that the construction, rehabilitation and equipment of health units are planned in accordance with the health care districting map. A national strategy for the maintenance of equipment will be adopted and implemented. Given national needs and the cost of health evacuations abroad, the Government plans to support the establishment of a "Hospital of Excellence" that will:

(i) handle almost all pathologies;

(ii) provide specialized capacity building by serving as a further training center; and

(iii) become a destination for countries in the subregion.

6.34 Strategy for building capacity. This will involve disseminating and implementing the National Health Care and Human Resources Development Plan by:

(i) establishing a health care human resources observatory;

(ii) developing effective and equitable incentive mechanisms based on performance at all levels of the health care pyramid;

(iii) adopting and implementing a career plan that is consistent with the vision for and needs of the sector;

(iv) aligning the intake capacities and curriculums of public and private training institutions with basic and ongoing training needs; and 
(v) improving the qualifications of health care personnel consistent with the needs of the sector by means of a continuous training plan that is adopted and implemented efficiently.

6.35 Building institutional and partnership capacities. The effective implementation of the sectoral policy involves the development of a compact that focuses on:

(i) development of a partnership among all stakeholders;

(ii) adoption and implementation of a national strategy for establishing contractual relationships;

(iii) strengthening of the National Information and Health Management System (SNIGS), which will be included in the basic training and retraining of health care personnel;

(iv) establishment of the joint tracking-assessment framework; and

(v) implementation of the recommendations of audits in decentralized and outlying areas and the development of the sectoral health policy.

6.36 Preparing the health care districting map and implementing the Package of HighImpact Interventions (PIHI) to achieve the MDGs. A health care districting map will be prepared in accordance with the sector objectives, taking into account:

(i) PIHIs by level;

(ii) standards and norms by type of structure;

(iii) changes in geographic, demographic and epidemiological characteristics of the population to be covered;

(iv) sectoral equipment and maintenance policy;

(v) possible availability of resources;

(vi) definition of roles and responsibilities by level;

(vii) definition of new ways of achieving success;

(viii) results-based planning and financing; and

(ix) updating of the various training curriculums by professional category and their application through the use of tools and instruments to track and assess actions in the sector, particularly supervision and monitoring by level.

6.37 Improving quality assurance, ethics and medical liability. To ensure quality and continuity of care, the Government's strategy will consist of:

(i) strengthening the system of referrals and further referrals by involving communities and taking account of the availability of all the required resources;

(ii) developing proposals for new hospitals;

(iii) adopting standards and procedures that are consistent with the PIHIs by level;

(iv) reviewing regulations on ethics and medical liability; and 
(v) implementing a quality assurance approach for outpatient and hospital care based on performance contracts by level.

6.38 Promoting the community approach. The development and implementation of PIHIs by level will require active involvement of the communities. Therefore, the Government plans to develop a national policy for the involvement of communities at all levels of the health care pyramid through:

(i) active participation on institutional management committees;

(ii) strengthening of community initiatives;

(iii) encouragement and guidance in the establishment of community health care cooperatives; and

(iv) identification and selection of effective community contacts.

6.39 Moreover, to guarantee effective and continued access to high-quality essential health care services, the Government will:

(i) revise the pricing of health care services at all levels of the public and private health care pyramid;

(ii) step up the promotion of systems for the coverage of disease risks through the development of universal health insurance and health care cooperatives for inhabitants of rural areas and workers in the informal sector and medical assistance for the poor and destitute; and

(iii) develop certain "free" priority services for mothers and children under five.

6.40 Improving the availability of drugs and reagents, vaccines, and other supplies. To ensure the availability of safe, high-quality and low-cost drugs, vaccines and reagents, the Government intends to strengthen the institutional capacity of the Procurement Agency for Essential Drugs (CAME), the technical capacity of the National Quality Control Laboratory (NQCL) and the regulatory role for the pharmaceutical sector of the Directorate for Pharmacies and Drugs (DPM). It will continue to implement the policy for the decentralization and rational management of drugs at the intermediate and peripheral levels and the integration of new vaccines in routine expanded programs on immunization (EPIs).

6.41 Promoting diagnostic screening and blood transfusion safety. The Government's priority actions in this area will aim to steadily improve the quality of health care services by ensuring:

(i) a regulatory and legislative framework for diagnostic screening and blood transfusions;

(ii) administrative and financial autonomy of the blood transfusion subsector;

(iii) training of professionals in diagnostic screening and blood transfusion; and

(iv) establishment of reference laboratories that are up to date on new technologies. 


\subsection{FOOD AND NUTRITION}

6.42 Given the scope of the nutritional problems, characterized by undernourishment and malnutrition, and their consequences for health, and given the clear impact of significant nutritional improvement on the performance of human capital, the Government intends to make nutrition the focus of development and to implement the Strategic Plan for Food and Nutrition Development (PSDAN), operated through the Results-Based National Food and Nutrition Program (PANAR). Specifically, the Government will implement the following priority actions:

(i) promotion of adequate nutrition for women, infants and young children;

(ii) monitoring of micronutrient deficiencies (particularly vitamin A, iron, iodine and zinc);

(iii) integrated management of malnutrition in all programs;

(iv) promotion of infant and young child feeding (IYCF) (including by means of breast feeding only);

(v) better nutrition for adolescent girls, pregnant women and breast-feeding women;

(vi) community-based management of severe acute malnutrition (MSAM);

(vii) development and implementation of a nutrition communications plan;

(viii) revitalization of the National Committee on Food and Nutrition and its regional contacts;

(ix) enhanced tracking of the food situation and nutritional status of the population; and

(x) improvement of the technical and physical capacities of communities to promote food and nutrition security in vulnerable groups.

6.43 In addition, efforts will be continued to protect the population against spiraling prices for food products, particularly through the promotion of local food production.

\subsection{CREATING LONG-TERM, DECENT JOBS}

6.44 Unemployment and underemployment remain major concerns for the Government, given the imbalance of the labor market owing in particular to the arrival of a large number of job seekers each year in the face of a limited supply of jobs, reflecting the low absorption capacity of the economy. Convinced that decent employment is the best way to overcome poverty, the Government will ensure that the strategic choices for the enhancement of the key development growth areas - particularly the "trade-logistics-transport" growth area, the "agri-food" growth area and the "tourism, culture and handicraft" growth area - are implemented, since they appear to show potential for an effective and sustainable response to the employment problems.

6.45 Specifically, the Government's strategy will consist in:

(i) promoting self-employment;

(ii) promoting salaried employment;

(iii) increasing the productivity of the informal sector;

(iv) improving the system of vocational training; and 
(v) promoting information and communications on employment.

6.46 As poverty is more prevalent in rural areas than in urban areas, the development of rural areas will be one of the "ways out" of the employment crisis. For this reason, taking account of the factors hampering the development of agriculture, particularly the lack of financing, climate uncertainties and hardships, the Government intends to complete the process of creating the agricultural bank, the Agency for the Development of Agricultural Mechanization (ADMA) and the Hydro-Agricultural Development Agency (APAH), to promote the creation of agricultural and non-agricultural businesses that will generate income and employment in rural areas.

\subsection{REDUCTION OF GENDER INEQUALITY}

6.47 General and specific diagnostic analyses of poverty, supported by data broken down by gender, indicate a very marked disparity between men and women. For this reason, the Government in 2008 adopted the National Gender Equality Promotion Policy (PNPG). The implementation of the PNPG aims to:

(i) systematically consider gender issues in all areas and at all levels;

(ii) guarantee equality of opportunity and equal access to and control over resources for men and women;

(iii) create an environment favorable to the implementation of strategies aimed at mainstreaming gender issues;

(iv) ensure better coordination of gender equality actions; and

(v) promote research and dissemination of data broken down by gender in all areas.

6.48 These objectives will be implemented via the following actions:

(i) the introduction of measures for genuine gender equality and equity of access to education, literacy and decision-making structures in all areas (individual, family, community, national and international);

(ii) improvement of the mainstreaming of gender equality at all levels and the actual application of national and international laws and conventions promoting gender equality and equity;

(iii) strengthening of the commitment of civil society and enhancement of awareness on the part of both men and women of the promotion of gender equality while ensuring substantial involvement of men in the process;

(iv) independence of women and better gender mainstreaming in Communal Development Plans (PDC); and

(v) reduction of the income poverty of women and guarantee of equitable access to and control over resources. 


\subsection{ENHANCING SOCIAL WELFARE}

6.49 Social welfare consists of the set of public and private measures implemented to protect the population against social risks and to guarantee their access to essential services. It contributes to economic growth by improving labor productivity and social stability. During crises, social transfers or social security benefits act as social and economic stabilizers.

6.50 With the support of the TFPs and civil society, the government will deploy efforts to strengthen social welfare. Despite these efforts, a substantial portion of the population remains without access to basic social services or economic opportunities and does not truly enjoy full economic and social rights. The perverse effects of globalization and the various crises exacerbate social inequalities, while the traditional solidarity and community assistance mechanisms are weakening. Social exclusion, which is particularly acute for the most vulnerable (women, children, the disabled and the elderly), creates a widening gap between an affluent minority and large impoverished segments of society.

6.51 To improve the situation, the Government will focus its efforts on:

(i) improving the management and guidance of social welfare issues;

(ii) establishing a core set of social protections; and

(iii) strengthening and expanding social security systems based on the promotion of traditional and national solidarity mechanisms.

\subsubsection{Improving the management and guidance of social welfare issues}

6.52 To improve the management and guidance of social welfare issues, the Government will emphasize:

(i) strengthening knowledge of the social welfare mechanisms; and

(ii) developing a holistic social welfare policy that takes into account issues relating to social assistance, social insurance and regulation. It will involve consolidating what has already been achieved and expanding social security coverage by reforming the social welfare arrangements, while developing mechanisms to monitor the impact of crises on the poor and vulnerable. The objective is to gradually integrate all segments of society that have until now been left out of the social welfare system. To this end, the Government will ensure that social safety nets are established for vulnerable segments of the population via targeted subsidies.

\subsubsection{Establishing a core set of social protections}

6.53 The social safety net consists of set of basic social rights and services to which all citizens should have access. The Government's intervention in this area will focus on:

(i) universal access to health care and essential services, particularly for the very poor and vulnerable;

(ii) promotion of the family;

(iii) promotion of women; 
(iv) child protection and development;

(v) protection and integration of the disabled; and

(vi) support for the elderly.

6.54 Universal access to health care and essential services. In this context, the Government will strengthen the universal system of health insurance coverage, via the RAMU. This will involve introducing a set of mechanisms based on existing social welfare systems, including health cooperatives, the objective of which is to improve the financial affordability of health services.

6.55 Promotion of the family. The family, which is the basic social unit, is the preferred context for basic socio-affective and psycho-motor education and training of the individual, and for culture and the exercise of religious faith. The family circle is the focal point for the training of the individual in social life, as it prepares the individual and predisposes him/her to the acquisition of knowledge, savoir-faire and life skills. However, today the family unit is disintegrating as a result of the economic crises and the gradual disappearance of standards of social control. This destruction of the family is perceived by social participants as a threat to childhood development, social cohesion and peace, and, as a result, as a barrier to development.

6.56 For this reason, the Government has decided to focus special attention on:

(i) improving the living conditions of families;

(ii) promoting positive family values;

(iii) protecting and preserving the family;

(iv) establishing centers to track issues relating to the family in each commune and in the ministerial departments;

(v) disseminating Law 2002-07 of August 24, 2004, which establishes the Persons and Family Code;

(vi) implementing the National Family Action Plan (PANF);

(vii) strengthening the capacities of institutions that promote the family and households that foster orphans and vulnerable children;

(viii) providing support to orphanages and shelters for children in difficult circumstances;

(ix) educating young people in family life; and

(x) conducting research on family issues to obtain further knowledge of the factors behind family instability.

6.57 Promotion of women. Women represent 51.5 percent of the Beninese population (RGPH 3). Given their demographic importance, their role in the stability of households, and their contribution to the production of goods and services, the Government, with the contribution of civil society organizations and the support of the TFPs, is working to improve the legal status and socio-economic condition of women. Despite significant progress made, Beninese women still remain subject to socio-cultural values that determine their social future. 
6.58 For this reason, the Government intends to take the following actions:

(i) promote education and training for girls and women, focusing in particular on keeping girls in the education system;

(ii) improve the respect of the legal status of women;

(iii) appreciate and take account of the work done by women;

(iv) appreciate cultures and traditions that are favorable to the development of women; and

(v) continue to combat violence against women.

6.59 Child protection and development. Given the difficulties facing children, the Government, with the support of the TFPs, has undertaken actions that target the well-being of children. Despite efforts made, the status of children remains a matter of some concern. Benin has become a veritable hub for the trafficking of children in West Africa. The mortality and morbidity rates for children under five remain high; malnutrition and anemia continue to be rampant; violations of the rights of children and adolescents occur daily; and access to basic social services remains limited.

6.60 Aware that Benin's development depends on the quality of its children today, the Government has decided to "guarantee the respect of the rights of children and adolescents and their equitable access to essential social services." The priority actions focus on:

(i) implementation of the national child protection policy and strategies;

(ii) expansion of "child protection" centers to the ministries responsible for essential social services;

(iii) implementation of the national integrated child development policy and strategies;

(iv) implementation of the national action plan to combat trafficking in children for labor exploitation purposes;

(v) creation of a protection fund for children and adolescents; and

(vi) implementation of the child adoption mechanism.

Box 6.2: Objectives and Strategic Orientations of the Child Protection Policy and Strategies in Benin

The overall objective is to implement a consistent global strategy for the protection of vulnerable children based essentially on coordination between three related components, namely:

(i) vulnerability prevention;

(ii) rehabilitation/reintegration and tracking of vulnerable children; and

(iii) promotion of the rights of children.

To achieve this objective, seven strategic orientations have been defined:

(i) improvement of knowledge on the status of vulnerable children and the quality of protection available;

(ii) strengthening of the capacities of Government and private institutions responsible for the protection of children;

(iii) adoption and effective application of laws for the protection of children;

(iv) improvement and extension of prevention, rehabilitation and reintegration services for children; 
(v) enhanced awareness, mobilization and strengthening of the competencies of families and communities;

(vi) improvement of access to information and participation for children; and

(vii) enhancement of cooperation and partnerships.

The strategic orientations have been set out in a five-year action plan in a document entitled "Action Plan for the Protection of Children."

Source: Action Plan for the Protection of Children.

6.61 Promotion and integration of the disabled. Disabled persons in general, and disabled women in particular, are marginalized and subject to discrimination, exclusion and social prejudice. To improve this situation, the Government will implement the following priority actions:

(i) multisectoral management of disabled persons; and

(ii) awareness raising in favor of equity, equality, solidarity, social justice and restoration of the dignity of which the disabled have so long been robbed.

6.62 Support for the elderly. To better care for the elderly, the Government has adopted the National Plan on Active Aging, the aim of which is to improve the quality of life of the elderly. During the coming five years, the Government will implement this plan, with emphasis on:

(i) promotion of the health and well-being of the elderly; and

(ii) combating of the social exclusion of the elderly.

6.63 Strengthening and expansion of social security systems. In Benin, only salaried workers in the formal public and private sectors benefit from the existing social security institutions, namely: the National Social Security Fund (CNSS) and the Benin National Retirement Fund (FNRB). Workers in the informal sector, who make up 95 percent of the labor force, are excluded from the services of these institutions and therefore the Government will emphasize:

(i) strengthening of the social security institutions; and

(ii) consolidation of social cooperatives and their interconnection with the statutory institutions.

\subsubsection{Strengthening of the social security institutions}

6.64 At the CNSS, actions aim to improve the benefits provided and to encourage employers to sign up their workers. At the FNRB, the Government will undertake reforms aimed at improving its financial position, as it is currently recording a substantial deficit.

6.65 Consolidation of social cooperatives. Several community-based social cooperatives have developed since the 1990s to handle social risks, particularly the health of individuals in the informal and agricultural sectors. Therefore, in the early 2000s, the Government established the Social Security Association (MSS), which is today a national institution providing health and age-related services to workers in the informal sector. The actions to be taken by the Government in this context for the consolidation of social cooperatives focus on: 
(i) implementation of the WAEMU regulations on social cooperatives;

(ii) support for the development of social cooperatives; and

(iii) revitalization of the old age arm of the MSS by linking it with the CNSS in order to give workers in the informal sector the possibility of receiving a pension.

\subsection{PROMOTING THE DEVELOPMENT OF YOUNG PEOPLE AND LEISURE}

6.66 The political will to promote the development of young people is reflected in a growing interest in this important segment of the population. Measures in favor of young people focus in particular on:

(i) mobilization and participation of young people in the development process;

(ii) promotion of group activities for young people;

(iii) preparation for job qualification and employment;

(iv) enhancement of health and social integration;

(v) promotion of healthy socio-educational and leisure activities;

(vi) promotion of access to economic resources and means of production for the benefit of young people;

(vii) promotion of informal education and life skills for young people; and

(viii) promotion of access to information on and the documentation of young people.

6.67 Moreover, recognizing the importance of leisure in strengthening human capital owing to its impact on the well-being of the population, the Government will establish local sports infrastructure in the communes and promote women's access to sports. For soccer, in particular, the Government, together with other countries, will develop training for Beninese young people in schools and training centers in those countries.

6.68 Finally, the promotion of behavior change communication (BCC) is essential in strengthening human capital. To this end, a communications plan will be developed in each of the areas of human capital to eliminate all socio-cultural obstacles that diminish the impact of the actions taken. 


\section{CHAPTER 7: ENHANCING THE QUALITY OF GOVERNANCE}

7.1 Good governance is essential, at all levels and in all sectors, to create an environment conducive to business and economic growth. Accordingly, the Government has adopted enhancing the quality of governance as an operational pillar to guide public action in the 20112015 five-year period.

7.2 Several mechanisms are in place to ensure the practice and the culture of good governance in Benin. At the regional level and within the framework of the New Partnership for Africa's Development (NEPAD), Benin participates in the African Peer Review Mechanism (APRM). A peer review was carried out in 2007 and an action plan was prepared to remedy governance dysfunctions and deficiencies in Benin. The Government plans to implement the action plan in seven priority intervention areas, namely:

(i) enhancing the quality of public financial management;

(ii) strengthening administrative governance;

(iii) strengthening political governance;

(iv) promoting security and peace;

(v) promoting human rights and strengthening the legal capacities of the poor;

(vi) improving the governance of statistical information; and

(vii) strengthening environmental governance.

\subsection{ENHANCING THE QUALITY OF PUBLIC FINANCIAL MANAGEMENT}

7.3 Since the early 2000s, Benin has pursued numerous reforms aimed at improving public financial management. The Technical and Financial Partners (TFP) that assisted the Government in the implementation of these reforms have promoted a variety of instruments for analyzing public financial management systems.

7.4 The Government's objective in this regard is to have a transparent and reliable management system that will enhance its credibility with the TFPs and ensure that the public financial management system is used in accordance with the Paris Declaration on Aid Effectiveness. In this context, the Government and the TFPs used the PEFA ${ }^{16}$ methodology to assess public financial management performance in September 2007. This report takes stock of the public financial management (PFM) system, based on performance indicators covering the various dimensions of public financial management (see Box 4). The purpose of this evaluation is to provide the authorities and the TFPs with reference values that can be used to measure future progress in the improvement of public financial management.

7.5 Following the 2007 assessment, and taking previous analyses into account, the Government prepared an action plan to improve the public financial management system, which

\footnotetext{
${ }^{16}$ Public Expenditure and Financial Accountability
} 
serves as the reference framework for public financial reforms. The Government's priority actions focus primarily on the budget cycle, including:

(i) Budget formulation;

(ii) Budget preparation;

(iii) Budget execution;

(iv) Budgetary control and accountability; and

(v) Promotion of a culture of transparency in the management of public affairs.

\section{Box 7.1: Summary of the 2007 Report on "Public Expenditure and Financial Accountability (PEFA)" in Benin}

The PEFA-2007 assessment focuses on public financial management practices in 2007, and the data analysis concerned the three previous fiscal years (2004-2006). Scores are given to 28 high-level indicators and three indicators more directly related to donor practices, based on the methodology and tables described in the manual disseminated by the PEFA Secretariat in June 2005.

The PEFA report presents an analysis of four (4) dimensions of the public financial management system:

(i) Budget credibility: the report shows that although the budget is credible, its credibility could be enhanced by limiting undistributed appropriations and by more closely monitoring the payment authorities.

(ii) Budget comprehensiveness and transparency: the report emphasizes that the draft budget laws do not include all the data required for analyzing the budget in relation to the macroeconomic data and the actual financial situation. It also points out the lack of comprehensiveness of the budget and the difficulty of obtaining budget information.

(iii) Budget cycle: deficiencies were noted in the domestic policy-based budgeting plans; the predictability and control of budget execution; accounting; recording of information and financial reports; surveillance and external auditing.

(iv) Donor practices: the report mentions major efforts by the TFPs to adhere to the principles of the Paris Declaration concerning alignment and harmonization, but also points out that the predictability of assistance is still insufficient.

Source: Action Plan to Improve Public Financial Management in Benin (2009-2013).

\subsubsection{Budget formulation}

7.6 The Government's approach to budget formulation is to "make Results-Based Budget Management (RBBM) an integrated and coordinated management tool that will ensure the delivery of services and put public finances squarely in the service of development and citizen welfare." The objective is to establish a clear and transparent presentation of budget documents reflecting public policies. Accordingly, the Government plans to:

(i) adopt the Budget Framework Law (LOLF), in conformity with the directives of the WAEMU; and

(ii) adapt the public financial management software to the new nomenclature (SIGFIP, ASTER, SIGFIP-ASTER interface, SIPIBE, SUNKWAE). 


\subsubsection{Budget preparation}

7.7 The Government wants to ensure that the budgetary process is based on implementation of the strategic pillars of the PRGS, with a view to making the exact amount of necessary funds available on a timely basis. The priority actions programmed concern:

(i) improvement of the circulation of budget information between the central Government and the communes, through the consolidation of budget data, particularly at the territorial government level;

(ii) summary of the revenue and expenditure budgets of offices and establishments, attached to the General State Budget;

(iii) stabilization of the schedule of budget tasks and the accountability of sectoral ministries; and

(iv) presentation to Parliament, in early July of each year, of the major budget orientations for the next three years, with a view to internalization of the WAEMU directive on budget laws.

\subsubsection{Budget execution}

7.8 The objective is to reduce the discrepancies between budget appropriations and payment credits and to improve the monitoring of the execution of the State budget. The initial actions, provided for in the Action Plan, aim at improving the rate of expenditure execution through:

(i) strengthening the capacities of actors in the "Planning, Programming, Budgeting, and Monitoring/Assessment" chain;

(ii) updating public procurement tools in conformity with the new public procurement code; and

(iii) modernizing the management of the public procurement procedures.

\subsubsection{Accountability}

7.9 The objective is to reduce the current long delay in submitting budget review laws for parliamentary approval; this lag negatively affects the obligation of accountability. The Government will therefore make every effort to ensure that budget review laws are voted on within the regulatory time limits.

\subsubsection{Promotion of a culture of transparency in the management of affairs.}

7.10 The people of Benin aspire to the strengthening and entrenchment of democracy in a climate of peace and national unity. However, certain dishonest practices such as corruption, lack of transparency in procurement, theft, extortion, embezzlement, mismanagement and impunity tarnish the country's image and contribute to the loss of credibility. Moreover, they undermine private investment, economic development and the collection of tax revenue. To remedy this situation, the following actions are planned:

(i) preparation, simplification and dissemination of public service procedures manuals; 
(ii) strengthening of the supervision and penalty mechanisms; and

(iii) promotion of such key values as ethics, integrity, patriotism, concern for the general interest and sense of responsibility.

\subsection{STRENGTHENING ADMINISTRATIVE GOVERNANCE}

7.11 The deepening of measures aimed at the construction of a development administration capable of promoting private sector dynamism and curbing corruption is a key element of the Government's policy. However, the reforms carried out within the Government to enhance its role in economic, social and cultural development are not yet fully operational. Consequently, in the 2011-2015 period the Government plans to work on:

(i) accelerating administrative reforms; and

(ii) pursuing legal and judicial reforms.

\subsubsection{Accelerating administrative reforms}

7.12 In the context of accelerating administrative reforms, the Government's objectives will be to:

(i) improve administrative performance; and

(ii) promote a culture of republican government.

7.13 Regarding the improvement of administrative performance, three priority actions will be taken:

(i) streamlining of structures and administrative organization, as a follow-up to the clarification of the State's responsibilities, in keeping with the principal of subsidiarity;

(ii) promotion of results-based management principles in the Public Administration; and

(iii) pursuit of the reform of the civil service and improvement of human resources management.

7.14 To promote a culture of republican government, the Government has chosen two actions:

(i) pursuit of sectoral structural reforms to make deconcentration and decentralization actual realities; and

(ii) development of a solid partnership with civil society organizations in order to develop transparency and accountability in the management of public afffairs. In addition, the Government will review the policy on the remuneration of civil servants with a view to the establishment of a development administration in the service of the general interest and the private sector.

\subsubsection{Pursuit of legal and judicial reforms}

7.15 In pursuing legal and judicial reforms, the Government will continue its efforts to:

(i) make the justice system more accessible; 
(ii) modernize the legislative framework by preparing new codes (vote on the draft criminal code and the draft code of criminal procedure, monitorpromulgation of the code of administrative, social and commercial civil procedure).

\subsection{STRENGTHENING POLITICAL GOVERNANCE}

7.16 Democracy in Benin has progressed significantly since the National Civil Society Conference of February 1990, but additional efforts are needed to keep alive the consensus achieved by the people. Consequently, the Government will lead actions to strengthen democracy and the rule of law.

7.17 During 2011-2015, in the area of strengthening democracy and the rule of law, the following actions are planned:

(i) ensure the proper functioning of constitutional instutions;

(ii) continue and step up the restoration and strengthening of the authority of the State; and

(iii) promote and keep alive social dialogue, identify and cultivate ethical principles in the organization and coordination of political life.

7.18 Regarding the proper functioning of constitutional institutions, the Government has decided to create and promote a framework for consultation and political dialogue with the institutions of the Republic.

7.19 In the area of continuing and stepping up the restoration and strengthening of the authority of the State, the Government intends to take the following priority actions:

(i) continue the awareness-raising campaign organized by the Ministry responsible for Administrative and Institutional Reform to promote civic spirit, discipline, as well as ethical and citizen values; and

(ii) continue contributing to the restoration and strengthening of the authority of the State and of moral, lay and religious figures.

7.20 In the area of social dialogue, the State will continue its efforts to create, organize and promote a framework to strengthen concerted governance among political parties and movements, and between the Government and the unions, to ensure the negotiation and conclusion of a political agreement among all political parties aimed at ensuring peaceful elections. To strengthen this process and enhance its credibility, the Government has chosen to put in place a computerized voters' roll [Liste Electorale Permanente Informatisée LEPI].

\subsection{PROMOTING SECURITY AND PEACE}

7.21 Security and peace are crucial for preserving the people's livelihood, reducing poverty and ensuring attainment of the MDGs. Despite the efforts made, security and peace remain major concerns in view of the highly divergent geopolitical situation. Indeed, Benin is part of a constantly changing world in which globalization is on the rise, with numerous problems, including: 
(i) organized cross-border crime;

(ii) international terrorism;

(iii) cybercrime;

(iv) drug abuse and illegal drug trafficking; and

(v) proliferation of small arms.

7.22 Faced with these challenges, the Government intends to:

(i) guarantee lasting security for the entire population and for institutions to enable them to carry out their activities and development responsibilities in peace and tranquility, by ensuring the free movement of persons and goods throughout the national territory, building new infrastructures and equipping prefectures and city halls with digital VHF transmitter-receivers;

(ii) guarantee the security of persons and the protection of their property; and

(iii) strengthen national sovereignty in border areas with a view to ensuring national security and creating better living conditions for populations in those areas.

7.23 Actions will also be taken to promote cooperation between the defense and security forces and the public. These actions will focus on the contribution of:

(i) military engineering to infrastructure projects;

(ii) army and police health services to health coverage in Benin, to the prevention of epidemics, and to public health; and

(iii) firefighters to combating disasters of all types and to providing assistance in the event of traffic accidents.

7.24 The Government will also continue participating in African and international peacekeeping operations by sending contingents of the armed forces or groups of civilian and military observers to countries where peace and security are seriously threatened.

\subsection{IMPROVING THE GOVERNANCE OF STATISTICAL INFORMATION}

7.25 The availability of statistical information is essential for managing the development process and for monitoring and implementing the PRGS. Consequently, in October 2008, the Government adopted the National Statistical Development Policy to respond effectively to the statistical data requirements of development strategies and programs. To that end, the Government plans to diversify statistical information and improve its quality. The Government will ensure governance of the statistical system through:

(i) control [of the] credibility of statistics by the National Statistics Council (CNS); and

(ii) strengthening of the independence and capacities of the various components of the CNS.

7.26 Moreover, in the 2011-2015 period, large-scale statistical operations will be carried out, particularly the Demographic and Health Survery (EDS) and the Integrated Modular Survey on 
Household Living Conditions (EMICoV) in 2011, and the fourth General Population and Housing Census (RGPH 4) in 2012.

\subsection{PROMOTING HUMAN RIGHTS AND STRENGTHENING THE LEGAL CAPACITIES OF THE POOR}

7.27 Following a long process that began in 1996 with the Estates-General on Justice, the Government conducted a thorough analysis of the justice sector. One objective was defined: strengthen the rule of law by instituting "a high-quality, efficient, credible and accessible justice system contributing to the social peace and development of Benin."

\subsubsection{Promotion of human rights}

7.28 Several human rights advances are worth noting:

(i) the guarantee, in the Constitution of December 11, 1990, of basic human rights and public freedoms, in keeping with the African Charter on Human and People's Rights of June 18, 1981;

(ii) the organization of a number of training and awareness-raising workshops for the public;

(iii)the establishment of local networks and school clubs in certain localities;

(iv) support and capacity building for civil society organizations involved in the promotion of human rights;

(v) the organization of periodic visits to detention centers and other holding facilities; and

(vi) support for minors in trouble with the law.

7.29 Despite these efforts, certain serious, negative trends persist, in particular:

(i) poor detention conditions in civilian prisons (overcrowding, only one meal per day, unsanitary conditions); and

(ii) long periods of preventive detention and violations of children's rights (child trafficking and justice for minors).

7.30 The promotion and protection of human rights is impeded by obstacles of all kinds, including:

(i) the impossibility of the State, for financial reasons, to ensure the effective enjoyment of rights for all citizens;

(ii) widespread illiteracy and socio-cultural impediments that hinder the implementation of women's rights recognized in international legal instruments and in the Code of Persons and the Family;

(iii)insufficient dissemination of international and national legal instruments on human rights; and

(iv) the operational inadequacy of legal and judicial assistance. 
7.31 Faced with these new challengages, the Government plans to step up its efforts in 20112015 with five priority actions:

(i) improving detention conditions through the construction of new prisons;

(ii) monitoring the legislation on children's rights and its dissemination, through the enactment of implementing decrees for the law on child trafficking, the second part of the Children's Code;

(iii)monitoring passage of the law on legal assistance, its dissemination and its implementation;

(iv)providing adequate support for minors in trouble with the law; and

(v) disseminating human rights information.

\subsubsection{Strengthening the legal capacities of the poor}

7.32 The Government is aware that poverty is also a consequence of the population's insufficient legal capacity. The lack of a legal culture is a source of obscurantism and impoverishment. The objective is to include the law in civil culture and effect the incorporation of positive law and its implementing mechanisms. To that end, the Government plans to implement the recomendations on strengthening the legal capacities of the poor set out in the "Legal Empowerment of the Poor (LEP)," including in particular:

(i) comprehensive application of the law establishing the judicial system of the Republic of Benin, with a view to making the justice system more accessible;

(ii) increase of the staffing of representatives of the law and improvement of their distribution throughout the national territory;

(iii)implementation of the actions of dissemination and communication, explanation of judicial language and streamlining of procedures, especially those related to judicial assistance, in order to put the law within the reach of all persons seeking justice;

(iv)creation of a specific national fund to facilitate access to justice for the poor; and

(v) promotion of the code of conduct and ethics within the Inspectorate-General of Justice Services, public prosecutors' offices, courts of appeal and other judicial and quasijudicial authorities.

\subsection{STRENGTHENING ENVIRONMENTAL GOVERNANCE}

7.33 Environmental governance requires that decision makers and the entire population take account, for both the current and future generations, of the quality of the environment and respect for natural systems in production methods, consumption patterns and systems for the disposal and elimination of waste from all sources. The Government remains committed, despite the efforts made in recent years, to bequeathing a healthy environment to future generations by preserving ecological diversity - the basis of the national productive system - and by developing strategies for adapting to and mitigating the harmful effects of climate change. 
7.34 The Government has therefore chosen to strengthen the system for controlling transactions involving products posing threats to human health and environmental quality. Accordingly, the Government plans to:

(i) promote implementation of the Charter on Environmental Governance and put in place a mechanism for monitoring compliance with the charter;

(ii) strengthen the means of rapid intervention by all police corps related to protection of the environment, and activate the national mechanism to manage cross-border migration and strengthen livestock entry points; and

(iii)establish an environmental unit within each sectoral ministry and prefecture. 


\section{CHAPTER 8: BALANCED AND SUSTASINABLE NATIONAL DEVELOPMENT}

8.1 The option of making Benin an emerging country requires harmonious development of the entire national territority. Such development requires the optimization of local resources and potentialities - the basis for the creation of jobs and wealth-and the reduction of spatial disparities in respect of infrastructure and equipment. To that end, the Government has launched reforms and actions in several fields, such as decentralization-deconcentration, land use planning, land tenure and the environment. The adoption in 2009 of the National Decentralization and Deconcentration Policy (PONADEC) with three main objectives (see Box 5 ), the continued implementation of the Declaration of National Land Use Policy (DEPONAT) adopted in 2002, the pursuit of actions to combat environmental degradation, the process of putting in place an integrated and long-term land-tenure system and awareness in the face of natural disasters and risks together formed the basis for balanced and sustainable national development in the 2007-2009 period.

\section{Box 8.1: Government Objectives Under PONADEC}

PONADEC is a policy designed to facilitate attainment of the development objectives set by the Government by making the territory a driver of development. The overall objective of PONADEC is to "Create the institutional and organizational conditions necessary for balanced and sustainable territorial development based on concerted local governance and optimization of the potentialities of local governments, in order to energize grassroots development."

Three specific objectives result:

- implement a harmonious and balanced land use management policy encompassing the entire national territory, in order to achieve sustainable and equitable development;

- ensure implementation of the principles of territorial good governance through modern and efficient administration;

- reduce poverty by improving access to basic services and optimizing the economic potentialities of the communes.

Source: PONADEC 2009.

8.2 Despite these noteworthy advances, much remains to be done to reverse the trends of an unevenly distributed population, poverty that is more prominent in rural than in urban areas, unequal access to basic infrastructure and equipment and a stagnant local and regional economy. Consequently, the Government's plan for the 2011-2015 period is to continue ongoing efforts in the six following priority intervention areas:

(i) strengthening the decentralization and deconcentration process;

(ii) strengthening land use management for a dynamic regional and local economy;

(iii) pursuing land reform;

(iv) promoting border areas;

(v) managing the environment and natural resources and improving the living environment; and

(vi) managing natural disasters and risks. 


\subsection{STRENGTHENING THE DECENTRALIZATION AND DECONCENTRATION PROCESS}

8.3 Strengthening the decentralization and deconcentration process was one of the Government's key objectives and commitments in adopting PONATEC. Indeed, the 2002-2007 period saw the installation of local governments, the establishment of the relevant institutional mechanism and the implementation of actions supporting the launch of new communes. In 2008 (the year in which new local officials were elected), a qualitative leap was made in the decentralization process, which will give the communes sufficient capacities to take up the functions devolved to them. The Government's role will be to support local initiatives by adapting the sectoral ministries' approach to intervention to the decentralization context.

8.4 The main actions of the Government to strengthen the decentralization-deconcentration process are:

(i) increasing the communes' financial resources;

(ii) reinforcing the communes' human resources;

(iii) strengthening local governance;

(iv) providing technical support to communes through strategic mechanisms;

(v) preparing the Decentralization-Deconcentration Plan (2D Plan) in the ministries;

(vi) strengthening the role of coordination and the prefectures' means of intervention; and

(vii) reorganizing deconcentrated government services within departments.

\subsubsection{Increasing the communes' financial resources}

8.5 The level of transfers to territorial governments as a percentage of total General State Budget expenditures, although rising, is still relatively low (1.5 percent in 2007 and 1.9 percent in 2008). ${ }^{17}$ To ensure the development of the communes, the Government plans to:

(i) reallocate public resources, based on responsibility sharing and in conformity with the communes' financing requirements;

(ii) work with the communes on the mobilization of local resources and align local taxation with existing resource deposits; and

(iii) put in place a mechanism for resource equalization and access to borrowing for local governments.

8.6 The ministries responsible for decentralization and finance will thus ensure that resource transfers are effective and aligned with needs. The National Commission for Local Finance (CONAFIL) is the preferred instrument for this monitoring, and the Communal Development Support Fund (FADeC) the tool for effecting the transfers.

\footnotetext{
${ }^{17}$ Source: 2009 PRGS Progress Report.
} 


\subsubsection{Reinforcing the communes' human resources}

8.7 The communes are facing a major shortage of qualified human resources. At the start of the decentralization process, senior management represented about 6 percent of the personnel in active service in the communes. The situation has changed little, despite the efforts of the communes themselves. Improving human resources for the development of the communes requires:

(i) the definition of a framework of occupations and of the quantitative and qualitative needs of communes to serve as the basis for organizing the personnel of the territorial governments (territorial civil service);

(ii) the targeted recruitment of men and women, as well as the definition of training needs; and

(iii) the creation, in the medium term, of a territorial civil service.

\subsubsection{Strengthening local governance}

8.8 To improve local governance, the Government will support the communes in:

(i) strengthening democratic mobilization around the development objectives of communes, recognizing, in the first place, the vital role of the various socioprofessional actors of the territory in supporting grassroots development;

(ii) coordinating effectively with traditional authorities;

(iii) improving the functioning of communal authorities, especially the Communal Council and the standing committees, which can be opened up to concerned actors in the territory to increase their involvement; and

(iv) ensuring the participation of women in the management of local affairs.

\subsubsection{Providing technical support to communes through operational mechanisms}

8.9 The Government plans to promote an open mechanism to assist local governments that will permit the mobilization of various actors in support of the communes. The guiding principle of this support is the institutional strengthening of communes and inter-communal entities. Along these same lines, the Government will further encourage decentralized cooperation, which provides opportunities for exchanges with other elected officials and local government personnel, especially in the area of know-how.

\subsubsection{Preparation of the 2D Plan in the ministries}

8.10 To implement territorial government reform, the Government will oversee the design and implementation of Decentralization-Deconcentration Plans (2D Plans) by each ministry. The preparation of these plans will take into account the legislative and regulatory principles governing the distribution of functions among actors and the allocation of the resulting human, financial and material resources. Each ministry must be able to clearly mention how and which resources it intends to devolve to departments and transfer to communes, in keeping with the texts on decentralization. 


\subsubsection{Strengthening the role of coordination and the prefectures' means of intervention}

8.11 In the prefectures, the Government's actions will be aimed at:

(i) reorganization of their services, as well as a qualitative strengthening of their human resources; and

(ii) the definition of work methods and procedures between the prefecture and other Deconcentrated State Services (SDE). The Prefect will be supported in his role of coordinator of territorial development by relying on such frameworks for concerted action as the Departmental Council for Dialogue and Coordination (CDCC) and the Departmental Administrative Conference (CAD), as well as tools such as the Departmental Plan for Intersectoral Development and the resulting departmental program budget, which will ensure the transmission of the State's priorities to the departments.

\subsubsection{Reorganization of Decentralized State Services (SDE) at the departmental leveI}

8.12 The Government will oversee a reorganization of departmental services around the State's core missions (sovereignty, social, educational, economic, logistical, planning, financial and administrative). Human, material, and technical resources will be allocated for these services, to optimize their role.

\subsection{STRENGTHENING LAND USE MANAGEMENT FOR A DYNAMIC REGIONAL AND LOCAL ECONOMY}

8.13 Diversification of the economy remains one of the key options for promoting faster growth. It requires optimization of the various regional or local potentialities in which the country abounds. In other words, Benin should promote a strong and dynamic regional and local economy. To that end, the Government has adopted a land use planning policy with the following major objectives:

(i) establish the decentralization process in viable and relevant economic areas capable of promoting regional and local development; and

(ii) harmoniously promote the installation of consistent, well-distributed equipment and infrastructure throughout the territory in order to support national, regional and local production and improve public access to basic services.

8.14 The efforts involved in implementing the 2007-2009 PRGS led to the realization of a number of actions related to:

(i) the establishment of an institutional framework conducive to land use planning;

(ii) the development of spatial planning and management tools to promote greater consistency in public action; and

(iii) the promotion of Shared Development Spaces (EDP) for regional or local production and for the operationalization of intercommunal cooperation. 
8.15 The Government plans to consolidate these gains by:

(i) strengthening the legislative, organizational and regulatory framework of land use planning;

(ii) continuing the organization of EDPs;

(iii) planning development and land use management at the national level;

(iv) planning development and land use management at the subnational level;

(v) promoting and "contractualizing" the partnership between the State and the communes;

(vi) strengthening the tools used to finance regional or local land use planning; and

(vii) strengthening the urban-rural relationship for a viable rural economy.

\subsubsection{Strengthening the legislative, organizational and regulatory framework of land use planning}

8.16 The Government will oversee completion of the legislative, organizational and regulatory framework of land use planning by enacting the land use planning law currently being drafted. The purpose of this law is to provide a legal framework for the orientations and objectives of DEPONAT and to lay down principles and procedures governing the roles, relationships and rules of play among those responsible for land use planning.

\subsubsection{Continuing the organization of Shared Development Spaces}

8.17 EDPs are a useful tool for organizing the regional or local economy around one or more of the resources used to create wealth and jobs. Experience in the organization of Shared Development Spaces based on the principle of intercommunal cooperation, which began in 2007 , should be gradually expanded to the entire territory in the years to come. Thus, without losing their autonomy and their corporate and legal personality, contiguous communes with socioeconomic, geographical and cultural realities in common will continue to pool their resources in order to take fuller advantage of shared regional potentialities, organize production networks, and thus lay the foundation for a strong, high-performance local economy.

\subsubsection{Planning development and land use management at the national level}

8.18 To underpin the national economy with a relevant spatial organization and a network of consistent and proportionate infrastructures and equipment for the long term, the Government will ensure that the various instruments and tools for spatial planning at the national level are prepared and implemented, namely:

(i) the National Land Use Management Plan (SNAT) or Spatial Agenda, together with land use management directives and land use management guidelines;

(ii) Collective Services Plans (SSC), which will allow the sectors to break with vertical logic and work with greater consistency in space; and

(iii) the biennial report of the National Observatory for the Spatial Analysis of Development (ONAS) on the dynamism and attractiveness of the various territories. 


\subsubsection{Planning development and land use management at the subnational level}

8.19 To join national with local ambitions and give long-term visibility to regional and local development, the Government is committed to supporting local governments in:

(i) preparing the Master Plan for Communal Development (SDAC) and the Land Use and Development Plans (STAD) in the various development territories established;

(ii) preparing territorial projects for the development territories established, in order to ensure implementation of the land use management plans drawn up and specify the various actions to be taken for the effective use of shared resources; and

(iii)establishing the territorial information system (spatial database) in the communes, to assist elected officials in monitoring and assessing the level of development of their locality, as well as in the spatial orientation of their development actions.

\subsubsection{Promoting and "contractualizing" the partnership between the State and the communes}

8.20 To facilitate implementation of the territorial projects, the Government will oversee the preparation and implementation of State-Territory development program contracts. These program contracts will ensure the successful implementation of territorial projects, based on contracting procedures, the preparation of which is essential.

\subsubsection{Strengthening the tools used to finance land use planning}

8.21 The Government will ensure that the existing mechanisms for financing land use planning are strengthened, particularly with regard to upgrading the equipment and infrastructures of localities. Accordingly, it will launch the Land Use Planning Incentive Fund (FIAT), referred to in the DEPONAT, to promote interregional balance. Thus, in the context of strengthening the decentralization process, the resources mobilized by the communes with Government support (private capital, borrowing on the financial markets) will contribute to execution of the investments necessary for regional and local development.

\subsubsection{Strengthening the urban-rural relationship for a viable rural economy}

8.22 Most rural localities seem remote or even cut off from the nearest urban center, which seriously hampers the launch of the rural economy. The Government plans to strengthen the ties between cities and their surrounding areas through the development of communication infrastructures, energy and agro-industrial infrastructures, and the related road networks. The aim is to facilitate the mobility of persons and the flow of goods produced in rural areas to the cities for national consumption, processing or export.

\subsection{PURSUING LAND REFORM}

8.23 The process of accelerating growth and poverty reduction in Benin requires a sizable flow of investments aimed at developing the potentialities of the various regions and localities. The sustainability and security of such investments require that the Government reform the land sector. Thanks to the work of the various units responsible for the sector, improvements have 
been made. However, at the conclusion of implementation of the 2007-2009 PRGS, the reform could not be achieved.

8.24 The importance of this reform led the Government to pursue actions aimed at:

(i) definition of a modern and consistent political, legal and regulatory framework;

(ii) development and placement in service of a simple and accessible registration system and the formalization of property rights, particularly the Rural Property Plan (PFR);

(iii) implementation of tools to ensure property security throughout Benin;

(iv) reorganization and strengthening of land management structures;

(v) capacity building for units responsible for the settlement of land and government property disputes;

(vi) establishment of a reliable land information system;

(vii) introduction of a development property tax system;

(viii) implementation of tools for land use planning and regional and border management; and

(ix) implementation of tools for the servicing of development areas.

\subsection{PROMOTING BORDER AREAS}

8.25 Upon becoming an independent country, Benin inherited approximately 2,011 km of borders shared with Nigeria $(768 \mathrm{~km})$, Togo $(604 \mathrm{~km})$, Burkina Faso $(280 \mathrm{~km})$ and Niger $(250$ $\mathrm{km})$. These areas pose challenges and are increasingly the focus of rarely settled disputes between Benin and its immediate neighbors. The most recent and very troubling case is the Koulou Koualou border dispute between Benin and Burkina Faso. In addition, there are several border localities where the Beninese population is drawn to neighboring countries that offer a full range of services and equipment.

8.26 It is in this context that the Government decided to implement a new, pragmatic form of border management designed to promote peace, security and stability and to facilitate the integration and sustainable development of the country. Benin adheres to the border policy of WAEMU and ECOWAS, which are conducting pilot experiments in border cities and areas. The actions to be taken to promote border areas include:

(i) the installation of socio-community infrastructures and equipment in border areas;

(ii) the promotion of cross-border cooperation and the development of cross-border areas or cities shared with adjacent countries; and

(iii)the adoption of an integrated approach to ensure the security of border areas. 


\subsection{MANAGING THE ENVIRONMENT AND NATURAL RESOURCES AND IMPROVING THE LIVING ENVIRONMENT}

8.27 With a predominantly rural population, the economic profile of Benin is largely determined by its natural resources. Population growth and the attendant human activities place a great deal of pressure on those resources, which accelerates the degradation of environmental quality. Consequently, the two requirements of satisfying needs by taking resources from and disposing of waste in nature, on the one hand, and combating environmental degradation and pollution, on the other, are not easily reconciled.

8.28 In rural areas, the problem takes the form of soil degradation and the pollution of bodies of water and waterways as a result of the overuse of chemical inputs, the removal of soil, the falling levels of bodies of water and waterways caused by silting, the degradation of ground vegetation by itinerant farming, logging, wildland fires and overgrazing. In urban and semiurban areas, the environmental problems that affect the quality of life and the health of populations include:

(i) surface water and air pollution, exacerbated by the widespread use of imported used equipment and vehicles and the presence of petroleum products on sidewalks;

(ii) floods;

(iii)uncontrolled dumping and open-air defecation;

(iv)proliferation of slums in the major cities; and

(v) outdoor disposal of industrial and biomedical wastes.

8.29 These problems are exacerbated by:

(i) insufficient advisory support and education on the environment;

(ii) the lack of tools needed by professional associations and public liaison personnel to promote protection of the environment;

(iii)the inability of local governments to mobilize resources for environmental management; and

(iv) the harmful effects of climate change.

8.30 For the Government, the objective is to meet these challenges as a prerequisite for achieving sustainable growth. It is therefore important to implement policies and programs adapted to each region of the territory to safeguard natural resources and protect the environment, so as to provide the population with a living environment that is conducive to human welfare. The Government's priority actions under the 2011-2015 PRGS are focused on:

(i) promoting environmental best practices;

(ii) promoting integrated management of the living environment; and

(iii)rational management of forests and natural resources. 


\subsubsection{Promoting environmental best practices}

8.31 In this area, the Government will ensure that the national development process is carried out in conformity with the global environmental provisions and standards contained in the various conventions ratified by Benin. To that end, it will:

(i) strengthen the system for the incorporation of environmental concerns in all development projects and in decision-making processes, through implementation of the Strategic Environmental Assessment (SEA);

(ii) develop environmental management tools such as the Millennium Ecosystem Assessment (MEA) approach promoted by the United Nations; and

(iii)implement regional and international conventions.

\subsubsection{Promoting integrated management of the living environment}

8.32 The Government is resolutely engaged in efforts to provide the population with a healthy living environment while at the same time creating job opportunities for young people and women and enabling them to acquire the knowledge, values, behaviors and practical skills that are necessary in the field of environmental management. Accordingly, it plans to help the State's decentralized and deconcentrated agencies to:

(i) promote intercommunal dynamics for the management of solid, liquid and biomedical wastes accumulating in cities and hospitals;

(ii) mitigate the economic and health-related effects of air pollution on the populations of large urban centers;

(iii)promote urban forestry and ecotourism;

(iv)develop a varied communication plan addressing the main environmental problems of each department and commune; and

(v) strengthen the capacities of the environmental police.

\subsubsection{Rational management of forests and natural resources}

8.33 To successfully implement its national forestry policy objectives, Benin has adopted a piloting instrument in the form of a program called the "National Program for Sustainable Natural Resource Management (PNGDRN)." In this context, the Government has selected a package of structuring and operational actions that, in the next five years, will constitute priorities for the promotion of rational forest and natural resources management. These actions involve:

(i) reorganizing the sector comprising forests, natural resources, government-owned plantations and fragile ecosystems;

(ii) mobilizing resources for the forestry sector;

(iii) providing operational management units for classified forests and protected State forests;

(iv) maintaining the environmental, economic and social functions of forests within the framework of land use planning; 
(v) strengthening the sustainability of timber potential, in conformity with international conventions;

(vi) improving the participatory management of forestry and wildlife natural resources; and

(vii)promoting an integrated approach to management of the nation's natural resources.

\subsection{MANAGEMENT OF NATURAL DISASTERS AND RISKS}

8.34 Unlike many other countries, Benin has for years been spared certain natural disasters. Today, however, there can be no doubt that the threat of natural disasters and risks exists. Indeed, the country is experiencing, inter alia, coastal erosion, droughts, increasingly severe and destructive floods, and in 2009 was hit with earth tremors in a number of southern and central localities. Actions are therefore needed to prevent or anticipate sudden and unexpected disasters, which will impact development efforts and investments.

8.35 Consequently, the Government's strategy will be based overall on the following:

(i) civil defense;

(ii) the management of climate risks; and

(iii)the management of risks related to coastal erosion.

\subsubsection{Civil defense}

8.36 Civil defense is one of the core responsibilities of the Public Administration. In view of its role in risk prevention and in the management of accidents and disasters, the Government plans to take actions aimed at:

(i) improving the institutional framework of civil defense;

(ii) formulating and implementing a national civil defense policy; and

(iii)modernizing and strengthening the operational capacities of civil defense units.

\subsubsection{Management of climate risks}

8.37 Like other countries in the world, Benin must deal with the effects of climate change (cyclical droughts, recurring floods, desiccation of arable land, pollution and dwindling water resources, etc.). The consequences of this phenomenon impact communities in climate-sensitive sectors such as agriculture, forestry, fisheries, water resources and the environment and, in turn, food security and development. Climate change is a major concern of the Government, which will take actions aimed at:

(i) capacity building at different levels to interpret and communicate relevant climate information and to advise local communities;

(ii) strengthening the institutional and technical capacities of the civil service, civil society organizations and communities for the assessment of local risks and vulnerabilities and for the formulation of climate-sensitive development plans and policies; 
(iii)promoting practical adaptive solutions to climatic variability and future climate change risks; and

(iv)promoting the expansion and sharing of knowledge about climate change, through awareness raising and risk management activities and the development of speciessensitive policies.

\subsubsection{Management of risks related to coastal erosion}

8.38 The encroachment of the Atlantic Ocean is currently one of the critical problems that the Government of Benin and, more broadly, the WAEMU countries concerned must face. In the space of 40 years the coast of Benin has eroded more than four hundred meters in certain places, or nearly ten (10) meters a year. The consequences are often damaging to coastal populations: homes engulfed and hotel infrastructures swept away. To minimize any further degradation of exposed coastal areas, the Government has taken steps to:

(i) protect the coast east of the Siafato breakwater;

(ii) conduct sensitivity studies of the coast between Ouidah and Togbin;

(iii)conduct a feasibility study on protecting the coast between Hillacondji and Grand-Popo; and

(iv)begin protecting and rationally managing all seacoast and riverbank areas. 


\section{PART III: STRATEGY IMPLEMENTATION FRAMEWORK}

Part III presents the framework for the implementation of the GPRS 2011-2015 and consists of two chapters. The first chapter discusses the implementation modalities and the macroeconomic and budgetary implications of the strategy. The second chapter covers the GPRS 2011-2015 monitoring and evaluation mechanism. 


\section{CHAPTER 9: GUIDELINES, IMPLEMENTATION AGENDA, AND MACROECONOMIC AND BUDGETARY IMPLICATIONS}

\subsection{GUIDELINES}

9.1 The implementation of GPRS 2011-2015 should be guided by the key principles listed below and universally considered to contribute to the success of development and poverty reduction strategies. ${ }^{18}$

Principle 1: Integration and efficient management of sectoral programs

9.2 Poverty is multidimensional. Therefore, in order to achieve maximum effectiveness, sectoral programs should be not only complementary, but also integrated. Their administrative costs should be minimized by streamlining and rationalizing program procedures and optimizing the use of available human, material and financial resources

Principle 2: Better targeting of the poor and of the programs

9.3 A refined breakdown of the poor at the sectoral and geographical levels should ensure that the programs delivered to the individual targets are those that most appropriately meet the targets' specific needs. Further surveys will help to disaggregate the population of the poor into more meaningful distinct categories (such as subsistence farmers or urban craftsman). Every poor person will thereby be provided with an effective package of services, including credit opportunities, training, technical and technological assistance and modern infrastructure.

9.4 Because women are more vulnerable to poverty, the gender dimension will be considered systematically in all phases, including action planning, budgeting and evaluation.

9.5 A proactive approach must be taken, encouraging program managers to reach out to the poor rather than expect the poor to come forward. Such an approach will enable the poor to understand their role better and to take ownership of the programs.

Principle 3: Decentralization of the poverty reduction strategy

9.6 Every community must prepare its own communal development plan (PDC) in line with national program goals. Accordingly, poverty reduction funds will be allocated to the communities in the framework of the decentralization process.

Principle 4: Results-based management

9.7 The mission of GPRS 2011-2015 is to transform life for the population, particularly through the attainment of the MDGs, and to enable Benin to advance towards comprehensive development. Consequently, the success of the strategy will be mainly measured not only on the basis of activities carried out or funds mobilized, but also by the strategy's capacity to attain the

\footnotetext{
${ }^{18}$ Cf. Moubarack LO (2003), "Lutte contre la pauvrete, changer de paradigm" ("Poverty reduction, paradigm shift").
} 
goals specified at the outset. To that end, results-based management (RBM) will be systematically applied to all stages of the planning, implementation, and monitoring and evaluation process.

Principle 5: Alignment of the programs of technical and financial partners (TFPs) with the GPRS

9.8 TFPs will be invited to align their country programs with the GPRS, in accordance with the principles of the Paris Declaration on the efficiency of development aid.

9.9 Before their implementation, programs and projects proposed by TFPs must be assessed with all due attention in order to ensure that they are consistent with the objectives and lines of action adopted by the country.

Principle 6: Encouragement of subsidiarity and partnership

9.10 To the extent possible, public institutions must focus on the planning and overall monitoring of the activities carried out, and subcontract implementation to grassroots organizations, the private sector and NGOs. The private sector will be invited to participate in the development strategy effort through in-kind and financial contributions to the programs aimed at the poor. Public-Private Partnership (PPP) will also be promoted in the areas of design, funding, building, management and maintenance of projects serving the public interest. The sectors typically or potentially concerned include those of drinking water, wastewater treatment, sanitation, transport, energy, telecommunications, tourism, health and education.

9.11 The adoption of PPP is basically motivated by the need for increased effectiveness in the use of public funds and for better value for money in certain services of general interest. With regard to the funding of infrastructure investment, PPP relaxes State budget constraints by involving the private sector in risk-taking. Recourse to private capital reduces the need for public borrowing.

Principle 7: Political neutrality towards the targets and the beneficiaries

9.12 The various poverty reduction programs and projects must be managed without taking into consideration the political views or negotiating power of the groups concerned.

\subsection{IMPLEMENTATION AGENDA}

\subsubsection{Implementation instruments}

9.13 The GPRS will be operationalized through two main planning instruments: the Priority Action Program (PAP) and the Communal Development Plans (PDCs). The PAP comprises all priority investments and activities called for by the strategic action lines. It is a translation of the GPRS into projects and programs in full consistency with the Public Investment Program (PIP), and strengthens the program budgets of each sector. The PAP serves as a link between the GPRS and the budget programs and between the strategy and the annual State budget, which constitutes the main strategy implementation instrument. 
9.14 Every line ministry must draw up an annual work program including the PAP lines of action that fall within its area of responsibility and the respective operational means of implementation.

9.15 The PDCs, through which the GPRS is operationalized at the decentralized level, reflect the strategic action lines and priority investments contained in the master PAP. In other words, the PDCs are a projection of the PAP activities at the local level. Certain grassroots projects, therefore, will be implemented through the Community Led Development (CLD) approach, which promotes community-based participatory development and is based on the following principles:

(i) Grassroots community training (FCB);

(ii) Delegation of project implementation control to the communities;

(iii) Boosting of the local economy through recourse to local expertise.

\subsubsection{Implementation resources}

9.16 Effective implementation of the GPRS 2011-2015 requires intensive mobilization of resources. The Government, therefore, will set up adequate procedures for the mobilization of internal and external resources. With regard to external resources mobilization, the Government would appreciate receiving from its partners, as a priority, forms of assistance compatible with the principles of the Paris Declaration on the efficiency of development aid (general budget support, sectoral or targeted budget support, and program approach forms of support). Mobilization of such types of assistance clearly requires improvements in public finance management and timely preparation of State accounts. Accordingly, the Government plans to pursue the work launched in that area, with TFP support. Moreover, joint partner assistance mechanisms, particularly those set up in the sectors of water, education (joint budgetary fund), decentralization, and the public finance management system, would be strengthened and expanded to other sectors. In particular, a program-approach type of joint fund for the health sector will be established with TFP support. Such support will be based on the commitment, in the form of a compact between the Government and its development partners, to a common vision and to joint, increased and predictable funding aimed at the attainment of consensual results assessed through predefined performance criteria and a transparent monitoring and evaluation system.

9.17 The Government will also take steps to set up such joint mechanisms in the other sectors that contribute to the attainment of the MDGs, such as agriculture, environmental protection, transport, justice and energy.

9.18 The private sector will be invited to contribute to financing the strategy. This process involves the promotion of foreign direct investment (FDI), the encouragement of PPPs, the introduction of new funding instruments, the development of banking services in the country and the mobilization of savings at the national level.

9.19 In accordance with the Paris Declaration on the efficiency of development aid, the Government will strengthen the alignment and harmonization process through the promotion of 
joint (Government-partners) thematic and sectoral groups. The Government's objective is the eventual formulation of a joint assistance strategy for the country.

\subsubsection{Prerequisites for successful implementation}

9.20 The effective implementation of the GPRS 2011-2015 presupposes a stable macroeconomic framework, a peaceful social situation and a prospering international environment conducive to economic development. Since 2009, the international economy has been experiencing the severest crisis since 1929. Persistence of that crisis could undermine the objectives pursued through the implementation of the GPRS. The attainment of these objectives depends on, inter alia, the revitalization of the production process (mechanization of agriculture and implementation of the Strategic Plan for Agricultural Sector Recovery (PSRSA)) and the operationalization of the core growth- and development-areas identified by the Government.

9.21 The implementation of the GPRS 2011-2015 also relies on the pursuit of structural reforms ensuring the availability of factors necessary for production (energy, telecommunications and appropriate infrastructure) and on the improvement or facilitation of trade relations with neighboring countries (particularly Nigeria and the hinterland economies) for greater subregional integration.

9.22 The GPRS 2011-2015 should benefit from the implementation of the Action Plan for Improvement of the Public Finance Management System (PAA-SGFP) 2009-2013. The PAASGF will lead to effective revenue collection by the fiscal authorities and a higher rate of absorption of credits allocated to the line ministries, particularly in the implementation of the PAP under the GPRS 2011-2015.

9.23 The partners' alignment with national procedures according to the Paris Declaration on the efficiency of development aid should accelerate the disbursement of the external resources needed to fund the strategy in the period 2011-2015. Ownership by all segments of society is crucial to the success of the strategy. The Government will therefore implement a communication plan in order to improve cooperation between the implementation mechanisms and the beneficiary population groups.

\subsection{MACROECONOMIC AND BUDGETARY FRAMEWORKS}

\subsubsection{Macroeconomic framework}

9.24 The macroeconomic and budgetary framework underlying the implementation of the courses of action of the GPRS 2011-2015 is based on sectoral economic growth projections reflecting the uncertainties of the international context and the actual potential of the Beninese economy. ${ }^{19}$ The framework also envisages attaining certain MDG targets, including education, health, drinking water and sanitation targets, towards which noteworthy progress was achieved

\footnotetext{
${ }^{19}$ See Annex 1.
} 
during the implementation of the GPRS 2007-2009, but does not operationalize all of the financing requirements for achieving the MDGs as a whole. ${ }^{20}$

9.25 The results of the medium-term macroeconomic and financial framework indicate that, during the GPRS 2011-2015 implementation period, the Beninese economy may achieve significant and sustained growth against a backdrop of controlled inflation and consolidated public finance. The growth rate could increase from 3.6 percent in 2011 to 7.5 percent in 2015, averaging 6.0 percent over the period 2011-2015 (Table 12). This means a net gain of 2.0 percentage points compared to the GPRS 2007-2009.

9.26 Strong and sustainable medium-term growth. During the period 2011-2015, growth would essentially stem from the expected dynamic performance of the primary and tertiary sectors. In particular, the implementation of the PSRSA and of the ongoing reform of the cotton sector is expected to raise the level of agricultural output and thereby lead to a recovery of production in the food-processing sector. Moreover, the enhancement of basic infrastructure and the continuation of structural reforms would contribute to an increase in production in the sectors of services, and construction and public works (BTP).

9.27 On the demand side, improved governance and a better business climate as a result of the acceleration of the various ongoing reforms (related to, inter alia, land, justice and the opening of the capital of public enterprises) should encourage private investment, and so should increased public investment in basic infrastructure, with a view to attaining a growth rate of 7.5 percent in 2015.

Table 9.1: Development of Economic Growth by Sector, 20101015

\begin{tabular}{|l|r|r|r|r|r|r|r|c|}
\hline & $2003-05$ & \multicolumn{1}{|c|}{$2007-09$} & \multicolumn{1}{|c|}{2010} & 2011 & 2012 & 2013 & 2014 & 2015 \\
\hline Primary sector & 2.6 & 3.9 & 2.3 & 3.1 & 4.8 & 5.3 & 6.0 & 6.3 \\
\hline Agriculture & 2.2 & 4.1 & 1.9 & 2.9 & 5.0 & 5.5 & 6.0 & 6.5 \\
\hline Animal breeding & 3.4 & 3.5 & 3.5 & 3.5 & 4.5 & 5.0 & 6.5 & 6.5 \\
\hline Fishing and silviculture & 3.9 & 3.5 & 3.2 & 3.5 & 4.0 & 4.5 & 5.0 & 5.0 \\
\hline Secondary sector & 2.6 & 4.4 & 3.2 & 2.9 & 5.9 & 7.6 & 8.2 & 8.8 \\
\hline Manufacture & 1.3 & 3.7 & 1.8 & 3.0 & 5.0 & 8.0 & 9.0 & 10.0 \\
\hline Energy & 5.2 & 2.3 & 14.5 & 3.0 & 10.0 & 5.0 & 5.0 & 5.0 \\
\hline $\begin{array}{l}\text { Construction and public works } \\
\text { (BTP) }\end{array}$ & 5.3 & 6.8 & 1.9 & 2.5 & 6.0 & 8.0 & 8.0 & 8.0 \\
\hline Tertiary sector & 4.1 & 4.4 & 3.1 & 3.9 & 5.7 & 6.6 & 7.4 & 8.0 \\
\hline Trade & 4.1 & 4.4 & 2.0 & 4.0 & 6.0 & 7.0 & 8.0 & 9.5 \\
\hline $\begin{array}{l}\text { Transport and } \\
\text { telecommunications }\end{array}$ & 4.1 & 5.9 & 3.1 & 3.5 & 6.0 & 7.0 & 8.5 & 8.0 \\
\hline Other services & 3.9 & 3.3 & 3.8 & 3.7 & 6.0 & 6.0 & 6.0 & 6.0 \\
\hline Non-commercial services & 4.2 & 4.5 & 4.7 & 5.3 & 7.5 & 8.0 & 8.0 & 8.0 \\
\hline $\begin{array}{l}\text { Indirect duties and taxes (DTI) } \\
\text { and domestic (VAT) }\end{array}$ & 4.6 & 3.2 & 1.8 & 4.2 & 6.0 & 7.0 & 7.0 & 7.5 \\
\hline GDP & $\mathbf{3 . 3}$ & $\mathbf{4 . 1}$ & $\mathbf{2 . 8}$ & $\mathbf{3 . 6}$ & $\mathbf{5 . 6}$ & $\mathbf{6 . 5}$ & $\mathbf{7 . 0}$ & $\mathbf{7 . 5}$ \\
\hline
\end{tabular}

Source: Directorate General for Economic Affairs (DGAE), Ministry of Economy and Finance (MEF), June 2010.

\footnotetext{
${ }^{20}$ See Annex 2.
} 
9.28 The GPRS 2011-2015 should reach cruising speed by 2012. As a result of a wait-and-see attitude in the private sector in view of planned presidential and legislative elections, economic recovery between 2010 and 2011 is expected to be only partial. Beginning in 2012, the economy should benefit from the full effect of the PSRSA, the reform of public enterprises, the improvement of the business climate and the increase in energy supply capabilities as a result of the establishment of independent power producers (IPPs) ready for operation. The growth rate is therefore expected to increase from 3.6 percent in 2011 to 5.6 percent in 2012.

9.29 The acceleration of private investment in 2013 and 2015 as a result of increased competitiveness subsequent to improvements related to the production factors-including energy, telecommunications, transport, the economic and social infrastructure, and the workforce $^{21}$ - should boost the growth rate to 7.5 percent in 2015 .

9.30 Balance of payments stability. The current account position of the balance of payments is expected to become stable in the medium-term thanks to the propitious development of the exports of goods and services. As a result of increased production of exportable cotton and foodstuffs, exports should account for a higher share of GDP, vindicating the Government's support for diversified exports. Imports should also become stable, not only in view of private investment and the Government's large-scale projects policy, but also because the increased agricultural supply and a more developed industrial sector would meet a greater share of domestic demand.

9.31 Prices under control. Despite increased investment, the domestic absorption of higher output remains moderate. In fact, as a percentage of GDP, private and public consumption have slightly declined, while exports have strongly progressed. This has made it possible to maintain price stability and meet the West African Economic and Monetary Union (WAEMU) convergence objective.

9.32 Consolidated public finance. The budgetary policy followed in the period 2011-2015 helps to maintain the stability of the macroeconomic framework, and allows for compliance with economic reform objectives. As a result of the introduction of development taxation, the broadening of the tax base through the extension of the single taxpayer identification number (TIN) to the informal sector, the monitoring of tax exemptions and the considerable means made available to the fiscal authorities, the tax-to-GDP ratio will improve from 18.5 percent in 2011 to 19.3 percent in 2015 .

\footnotetext{
${ }^{21}$ The GPRS aims at the attainment of MDGs 2, 4 and 5. Attaining these MDGs will have an impact not only on public spending, but also on the quality of the workforce by improving the workers' education, skills and health. Such improvements, in turn, should raise productivity.
} 
Table 9.2: Development of Revenue and Expenditures (as a percentage of GDP)

\begin{tabular}{|l|r|r|r|r|r|r|r|}
\hline & 2010 & 2011 & 2012 & 2013 & 2014 & 2015 & $\begin{array}{c}\text { Averag } \\
\mathrm{e}\end{array}$ \\
\hline Total revenue & 20.1 & 20.3 & 20.9 & 21.1 & 21.1 & 21.1 & 20.9 \\
\hline Tax revenue & 17.3 & 18.5 & 18.8 & 19.2 & 19.2 & 19.3 & 19.0 \\
\hline Non-tax revenue & 2.8 & 1.8 & 2.0 & 1.9 & 1.8 & 1.7 & 1.9 \\
\hline Total expenditures & 25.9 & 25.7 & 26.2 & 26.0 & 25.6 & 25.0 & 25.7 \\
\hline Salary and wage costs & 7.5 & 7.3 & 7.3 & 7.2 & 7.0 & 6.7 & 7.1 \\
\hline Public investment & 8.8 & 8.6 & 8.9 & 9.0 & 9.0 & 8.9 & 8.9 \\
\hline Primary balance (restrictive definition) & -0.6 & -0.1 & 0.1 & 0.4 & 0.6 & 1.0 & 0.4 \\
\hline $\begin{array}{l}\text { Overall deficit (based on payment } \\
\text { authorizations) }\end{array}$ & -5.8 & -5.4 & -5.3 & -4.9 & -4.5 & -3.9 & -4.8 \\
\hline
\end{tabular}

Source: Economic and Financial Program Monitoring Unit (CSPEF), DGAE, MEF.

9.33 Considerable efforts have been made by the Government to ensure the stability of public expenditure as a percentage of GDP (at approximately 26 percent over the entire period). This performance is due to the implementation of the PAA-SGFP 2009-2013, is expected to facilitate control over salary and wage costs and operating expenses, and should improve the rate of execution of investment expenditures. As a result, public spending on investment would remain stable around 9.0 percent of GDP. That stability, coupled with strengthened expenditure quality control, should ensure that spending is channeled into truly productive investment and no longer serves to finance the Administration's operating expenses.

9.34 Consequently, the budgetary balance (based on payment authorizations) will remain stable around 5 percent of GDP over the period. As a percentage of GDP, the basic budgetary balance is expected to increase from -1.0 in 2011 to +0.5 in 2015 , in line with WAEMU convergence criteria.

9.35 Financing of the budget deficit. The deficit will be financed with concessional loans (87.1 percent), budget support by multilateral and bilateral partners (13.1 percent) and internal resources (3.9 percent), namely funds from the privatization of public enterprises and public loans issued on the financial and subregional markets. This last option may be envisaged during the GPRS 2011-2015 implementation period, given that the country's public debt sustainability and public finance viability were enhanced in 2006 under the Heavily Indebted Poor Countries (HIPC) initiative and the Multilateral Debt Relief Initiative (MDRI) for external debt reduction.

Table 9.3: Percent Composition of the Financing of the Budget Deficit

\begin{tabular}{|l|r|r|r|r|r|r|}
\hline & 2011 & 2012 & 2013 & 2014 & 2015 & $\begin{array}{c}\text { Averag } \\
\mathrm{e}\end{array}$ \\
\hline Budget deficit & 100.00 & 100.00 & 100.00 & 100.00 & 100.00 & 100.00 \\
\hline Internal financing & 7.5 & 1.2 & 4.3 & 8.9 & 12.8 & 3.9 \\
\hline External financing & 91.1 & 85.7 & 86.9 & 86.7 & 85.0 & 87.1 \\
\hline Projects & 78.4 & 81.9 & 91.4 & 98.6 & 104.4 & 90.9 \\
\hline Budget support & 15.2 & 14.3 & 14.5 & 11.4 & 9.9 & 13.1 \\
\hline Financing gap & 16.4 & 13.1 & 8.8 & 4.4 & 2.2 & 9.0 \\
\hline
\end{tabular}

Source: MEF, June 2010. 
9.36 Public debt sustainability. The new debt sustainability analysis framework (DSAF) for low-income countries, which has been developed by the IMF (see Box 7, Annex 2), provides for five sustainability benchmarks determined, for each country, as a function of the applicable country policy and institutional assessment of the World Bank. ${ }^{22}$ Sustainability has been analyzed for the period 2010-2030 as follows:

Table 9.4: Development of Public Sustainability Indicators

\begin{tabular}{|l|c|r|r|r|r|r|r|r|r|r|}
\hline & Benchmarks & 2010 & 2011 & 2012 & 2013 & 2014 & 2015 & 2020 & 2025 & 2030 \\
\hline NPV/ GDP & $<40$ & 15.8 & 17.0 & 18.2 & 19.5 & 20.5 & 21.4 & 28.8 & 33.0 & 29.0 \\
\hline NPV/ Exports & $<150$ & 85.4 & 91.0 & 96.2 & 101.8 & 104.4 & 106.3 & 111.3 & 99.4 & 71.8 \\
\hline NPV/ State revenue & $<250$ & 76.4 & 83.3 & 87.4 & 91.6 & 96.5 & 101.5 & 125.1 & 131.9 & 110.3 \\
\hline Debt servicing / Exports & $<20$ & 3.9 & 3.6 & 3.6 & 3.2 & 2.8 & 2.3 & 2.4 & 4.0 & 4.1 \\
\hline $\begin{array}{l}\text { Debt servicing / State } \\
\text { revenue }\end{array}$ & $<30$ & 3.5 & 3.3 & 3.2 & 2.9 & 2.6 & 2.2 & 2.7 & 5.3 & 6.4 \\
\hline
\end{tabular}

Source: MEF, March 2010.

On the basis of the main hypotheses underlying the macroeconomic framework of the basic scenario of the GPRS 2011-2015, debt sustainability analysis leads to the following findings:

- $\quad \mathrm{NPV}^{23} / \mathrm{GDP}$ ratio: This indicator compares the present value of future flows of the debt to national wealth. The ratio remains lower than the 40 percent benchmark, increasing from a 15.8 percent minimum in 2010 to a 33 percent maximum in 2024, subsequently declining to 29 percent in 2030 .

- NPV/exports ratio: This indicator compares the present value of future flows of the debt to the income generated by the country's exports of goods and services. The ratio varies around 100 percent, clearly below the 150 percent benchmark.

- NPV/State revenue ratio: This indicator compares the present value of future flows of the debt to the internal revenue from taxes. The ratio does not exceed 134 percent, attained in 2024, while the benchmark is 250 percent.

- Debt servicing/exports ratio: This indicator varies under the 20 percent benchmark. This shows that the projected export income meets debt (capital and interest) servicing requirements over the period considered.

- Debt servicing/State revenue ratio: This indicator also varies under the 20 percent benchmark. This implies the sustainability of the country's public finance, namely the ability to meet debt servicing requirements over the period considered, even under the constraint of using only State revenue to that end.

9.37 In sum, the basic GPRS 2011-2015 scenario ensures the sustainability of public finance and of the public debt. In view of the comfortable margins achieved in relation to the sustainability benchmarks (see Figure 17) and in accordance with the new rules on external debt

\footnotetext{
${ }^{22}$ Country Policy and Institutional Assessment Index (CPIA).

${ }^{23} \mathrm{NPV}=$ Net present value.
} 
limits with regard to IMF-supported programs, residual financing needs may be funded, to a certain extent, with non-concessional loans without significantly affecting the risk profile of the country's overall debt. ${ }^{24}$

\subsubsection{Medium-Term Expenditure Framework (MTEF)}

9.38 For purposes of budgetary management efficiency in the period 2011-2015, sectoral MTEFs have been made consistent with the macroeconomic framework. Most of the initial sectoral MTEFs were too ambitious in view of actual budgetary constraints. This alignment allows for a more systematic and efficient management of sectoral policies in the face of available budgetary resources.

9.39 The aggregate MTEF ensures an optimal resource distribution to the various sectors. For the period 2011-2015, allocations ${ }^{25}$ to the social sectors account on the average for 33.8 percent of total budgetary provisions, and are broken down as follows: 17.9 percent for education, 13.4 percent for health and 2.4 percent for social and cultural development. These provisions essentially give priority to achieving MDG targets in the areas of education, health and sanitation in the framework of the implementation of the GPRS 2011-2015.

9.40 Resources earmarked for the sectors of production and trade account for 12.3 percent of total allocations and would facilitate the efficient implementation of the various development strategies of the growth pillars identified in "Benin 2025, Agenda for an Emerging Economy"

9.41 Budgetary allocations for the development of production infrastructure would increase from 20.0 percent in 2011 to 28.3 percent in 2015 , averaging 24.3 percent over the period. In that connection, the Government plans to pursue the large-scale projects policy launched in 2006 and necessary for the development of the secondary and tertiary sectors and for stimulating economic growth, as well as increase public investment expenditure on access to drinking water (such investment should average 9.6 percent over the period 2011-2015).

9.42 Expenditures related to governance, defense, security and sovereignty should, on the average, account for, respectively, 7.0, 4.0 and 2.5 percent of the State's general budget during the period 2011-2015.

\footnotetext{
${ }^{24}$ According to the debt sustainability analysis carried out jointly by the IMF and the World Bank in March 2010 , the excessive indebtedness risk faced by the country remains moderate.

${ }^{25}$ For operational and investment expenditures.
} 
112

Table 9.5: Breakdown of Budgetary Allocations by Sector, 20112015

\begin{tabular}{|l|r|r|r|r|r|r|}
\hline & 2011 & 2012 & 2013 & 2014 & 2015 & $\begin{array}{c}2011-15 \\
\text { average }\end{array}$ \\
\hline Social sectors & 29.6 & 31.6 & 33.5 & 35.8 & 38.3 & 33.8 \\
\hline Education & 16.4 & 17.0 & 17.5 & 18.6 & 20.0 & 17.9 \\
\hline Health & 11.4 & 12.7 & 13.8 & 14.2 & 15.0 & 13.4 \\
\hline Social and cultural development & 1.7 & 1.9 & 2.2 & 3.0 & 3.3 & 2.4 \\
\hline Production and trade & 10.2 & 11.3 & 12.1 & 13.3 & 14.4 & 12.3 \\
\hline Production infrastructure & 20.0 & 22.1 & 24.6 & 26.8 & 28.3 & 24.3 \\
\hline Governance & 6.2 & 6.4 & 7.1 & 7.5 & 7.6 & 7.0 \\
\hline Political & 1.6 & 1.2 & 1.0 & 1.0 & 1.0 & 1.2 \\
\hline Economic & 4.5 & 5.2 & 6.1 & 6.5 & 6.6 & 5.8 \\
\hline Defense and security & 6.5 & 4.6 & 3.8 & 3.0 & 2.3 & 4.0 \\
\hline Sovereignty & 2.9 & 2.5 & 2.5 & 2.4 & 2.0 & 2.5 \\
\hline Total for ministries and institutions & 75.3 & 78.5 & 83.7 & 88.9 & 92.9 & 83.8 \\
\hline Other budgets & 24.7 & 21.5 & 16.3 & 11.1 & 7.1 & 26.2 \\
\hline Budget total & 100.0 & 100.0 & 100.0 & 100.0 & 100.0 & 100.0 \\
\hline
\end{tabular}

Source: MEF, June 2010.

\subsubsection{Alternative macroeconomic framework}

9.43 Unforeseeable circumstances related to the international environment may result, under the preceding scenario, in inadequate mobilization of the resources necessary for the attainment of the set of MDG targets selected. ${ }^{26}$

9.44 It is therefore appropriate to envisage an alternative scenario approaching the macroeconomic framework of the new economic and financial program concluded with IMF in June $2010 .^{27}$

9.45 Based on a GDP deflator of 2.4 percent, the real growth rate is expected to average 5.2 percent during the period 2011-2015. State revenue and public expenditures are expected to account for, respectively, 20.9 and 25.4 percent of GDP. The total deficit, based on payment authorizations, should account for 4.5 percent of GDP on the average over the period in question and be financed with concessional resources that do not affect public debt sustainability.

\footnotetext{
${ }^{26}$ Namely, targets in the areas of education, health, drinking water and sanitation.

${ }^{27}$ And reviewed in September 2010.
} 
Table 9.6: Macroeconomic Indicators of the Alternative Scenario Percent of GDP unless otherwise indicated

\begin{tabular}{|l|r|r|r|r|r|r|}
\hline & 2011 & 2012 & 2013 & 2014 & 2015 & $\begin{array}{c}2011-15 \\
\text { average }\end{array}$ \\
\hline Real growth rate & 3.5 & 4.7 & 5.6 & 6.0 & 6.0 & 5.2 \\
\hline Total revenue & 20.0 & 20.6 & 21.1 & 21.3 & 21.3 & 20.9 \\
\hline Total expenditure & 25.7 & 25.7 & 25.3 & 25.2 & 25.0 & 25.4 \\
\hline $\begin{array}{l}\text { Overall deficit (based on payment } \\
\text { authorizations) }\end{array}$ & -5.7 & -5.1 & -4.1 & -3.9 & -3.7 & -4.5 \\
\hline Current account deficit & -8.1 & -7.6 & -7.6 & -7.5 & -7.2 & -7.6 \\
\hline Public investment & 8.9 & 8.7 & 8.6 & 8.8 & 8.8 & 8.8 \\
\hline Private investment & 13.6 & 14.1 & 14.5 & 15.0 & 15.5 & 14.5 \\
\hline Cotton production (thousand tons) & 283.0 & 308.2 & 333.5 & 358.7 & 384.0 & 333.5 \\
\hline
\end{tabular}

Source: MEF, June 2010.

9.46 As a result of the development of exports of goods and services, the current account deficit of the balance of payments is expected to improve progressively, as a percentage of GDP, from 8.1 in 2011 to 7.2 percent in 2015 . In particular, cotton production is expected to increase from 283,000 tons in 2011 to 384,000 tons in 2015, thereby averaging 333,500 tons per year. The rate of investment should slightly increase over the period, with public and private investment accounting on the average for, respectively, 8.8 and 14.5 percent of GDP.

\subsection{IMPACT OF THE MACROECONOMIC AND BUDGETARY FRAMEWORK ON THE ATTAINMENT OF THE MDGs AND ON POVERTY REDUCTION}

9.47 The impact of each scenario on the non-monetary MDG indicators has been assessed by the method set forth in Agenor et al. (2006). That approach makes it possible to determine, for any given macroeconomic framework, the respective profile of MDGs 2, 4 and 5.

Table 9.7: Impact of the Individual Scenarios on MDG Indicators

\begin{tabular}{|l|c|c|c|c|c|c|c|c|c|c|c|}
\hline & 2007 & 2008 & 2009 & 2010 & 2011 & 2012 & 2013 & 2014 & 2015 \\
\hline \multicolumn{7}{|c|}{ GPRS scenario } \\
\hline Primary school enrollment ratio (\%) & 104.0 & 104.4 & 109.1 & 109.1 & 110.6 & 111.2 & 111.6 & 112.3 & 113.2 \\
\hline Infant mortality (children under 5 per 1000 births) & 125.0 & 117.7 & 118.6 & 119.2 & 102.6 & 93.8 & 86.6 & 80.2 & 74.3 \\
\hline $\begin{array}{l}\text { Prevalence of malnutrition (underweight infants per } \\
\text { 1000 births) }\end{array}$ & 15.1 & 15.2 & 15.2 & 15.9 & 4.8 & 1.6 & 0.0 & 0.00 & 0.0 \\
\hline Life expectancy at birth (years) & 60.8 & 61.8 & 61.6 & 61.3 & 67.4 & 69.4 & 70.7 & 71.0 & 71.8 \\
\hline Access to drinking water (\%) & 66.3 & 66.5 & 69.2 & 71.5 & 73.9 & 76.3 & 78.7 & 81.1 & 83.5 \\
\hline & Alternative scenario & \multicolumn{7}{|c|}{} \\
\hline Primary school enrollment ratio (\%) & 104.0 & 104.4 & 109.1 & 109.2 & 109.3 & 109.9 & 110.3 & 111.2 & 112.5 \\
\hline $\begin{array}{l}\text { Infant mortality (among children under 5 per 1000 } \\
\text { births) }\end{array}$ & 125.0 & 117.7 & 118.6 & 119.2 & 108.3 & 98.7 & 93.1 & 87.4 & 80.3 \\
\hline $\begin{array}{l}\text { Prevalence of malnutrition (underweight infants per } \\
\text { 1000 births) }\end{array}$ & 15.1 & 15.2 & 15.2 & 15.9 & 10.9 & 6.7 & 6.2 & 5.8 & 3.8 \\
\hline Life expectancy at birth (years) & 60.8 & 61.8 & 61.6 & 61.3 & 64.1 & 66.5 & 66.7 & 67.0 & 68.2 \\
\hline Access to drinking water (\%) & 66.3 & 66.5 & 69.2 & 71.5 & 73.9 & 74.3 & 74.6 & 75.1 & 75.5 \\
\hline
\end{tabular}

Source: MEF, June 2010. 
9.48 The implementation of the GPRS under the basic scenario leads close to the targets of MDGs 2, 4 and 5 and improves life expectancy at birth by at least 10 years between 2007 and 2015.

9.49 Although it leads close to MDG 2, the alternative scenario contributes weakly to the attainment of MDGs 4 and 5 and improves life expectancy at birth by only 7 years between 2007 and 2015.

9.50 The impact of both scenarios on poverty indicators is assessed by micro-simulation, ${ }^{28}$ which makes it possible to determine, for any given macroeconomic framework, the related profiles of poverty and distribution.

Table 9.8: Impact of the Individual Scenarios on Poverty Indicators

\begin{tabular}{|c|c|c|c|c|c|c|c|c|}
\hline & 2007 & 2010 & 2011 & 2012 & 2013 & 2014 & 2015 & 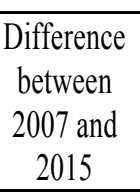 \\
\hline \multicolumn{9}{|c|}{ GPRS scenario } \\
\hline Incidence of poverty & 33.3 & 34.1 & 32.3 & 30.1 & 28 & 26.5 & 25.0 & -8.3 \\
\hline Depth of poverty & 9.5 & 9.8 & 9.1 & 8.3 & 7.5 & 7.0 & 6.5 & -3.0 \\
\hline Severity of poverty & 4.0 & 4.2 & 3.8 & 3.4 & 3.1 & 2.9 & 2.6 & -1.4 \\
\hline \multicolumn{9}{|c|}{ Alternative scenario } \\
\hline Incidence of poverty & 33.3 & 33.9 & 33.2 & 32.5 & 32.3 & 32.0 & 31.7 & -1.6 \\
\hline Depth of poverty & 9.5 & 9.8 & 9.5 & 9.2 & 9.1 & 8.9 & 8.8 & -0.7 \\
\hline Severity of poverty & 4.0 & 4.2 & 4 & 3.9 & 3.8 & 3.7 & 3.7 & -0.3 \\
\hline
\end{tabular}

Source: MEF, on the basis of National Institute for Statistics and Economic Analysis (INSAE) and DGAE data, June 2010.

9.51 The implementation of the GPRS under the basic scenario leads to a reduction of income poverty by approximately 8 percentage points between 2007 and 2015 . The incidence of income poverty will decline from 35.21 percent in 2007 to 25.0 percent in 2015 .

9.52 That decline will be more significant (percentage points) in the rural areas than in the urban areas (amounting to, respectively, 9.5 and 6.2 percentage points), not only as a result of income generation based on the dynamic development of economic activities, but also, mainly, because a substantial part of State transfers to households (inter alia, free education and health care, and microfinance) affects the rural more than the urban areas. Accordingly, the severity of poverty, which measures income inequality among the poor, declines on the average more significantly in the rural than in the urban areas (by 0.9 and 0.7 percentage points, respectively).

9.53 The alternative scenario reduces the incidence of income poverty by 1.6 percentage points between 2007 and 2015. The decline in this case is slight because the levels of expenditure envisaged under this scenario, particularly in relation to transfers, personnel and investment, are relatively low compared to the basic scenario.

\footnotetext{
${ }^{28}$ See Annex 2.
} 


\section{CHAPTER 10: $\quad$ STRATEGY MONITORING AND EVALUATION MECHANISMS}

\subsection{INSTITUTIONAL FRAMEWORK FOR MONITORING AND EVALUATING STRATEGY IMPLEMENTATION}

10.1 Progress has been achieved with regard to the GPRS 2007-2009 monitoring and evaluation mechanism through the involvement of the actors in the various stages of the process. Such cooperation has promoted dialogue between civil society, the TFPs, the private sector and the Government. However, these improvements did not secure all of the expected results. For instance, the priority ministries were not equal to expectations for lack of human, material and financial resources and because of inadequate internal coordination. Moreover, cooperation between the central level, the decentralized level and civil society was not sufficiently active.

10.2 In order to attain efficiently the goals set in the GPRS 2011-2015, a strong participatory monitoring and evaluation mechanism is necessary. The new institutional framework for such a mechanism will not only facilitate stakeholder involvement, but will also, especially, define the various responsibilities of the actors (the Government, the Administration, the local authorities, the private sector, civil society and the TFPs) at all stages of the monitoring and evaluation process. Thereby, ownership of the process will be stimulated at all levels, and it will be possible to take the aspirations of all social components into account.

10.3 Accordingly, building on the achievements and learning from the limitations of past strategies, ${ }^{29}$ the Government plans to set up a revamped participatory mechanism and introduce appropriate instruments in order to ensure that strategic lines of action are effectively implemented.

10.4 In view of basic political and economic options adopted by the country, namely involvement of the population and public-private partnership, a mechanism comprising a strategic and a technical level has been designed in the framework of decentralization.

10.5 The strategic level is tasked with providing guidelines for an effective implementation of the strategy and for coordinating the strategy implementation mechanism as a whole at the national level.

10.6 The technical level is tasked with operationalizing the guidelines formulated at the strategic level. Thus, the institutional mechanism ${ }^{30}$ for monitoring and evaluation of the GPRS 3 comprises:

(i) A Governance Board;

(ii) A Steering Committee;

\footnotetext{
${ }^{29}$ Poverty Reduction Strategy (PRS) 1 and GPRS 2007-2009.

${ }^{30}$ Although it basically consists of two strategic bodies, like the institutional mechanism for implementation, the institutional mechanism for monitoring and evaluation has been strengthened with non-State actors (trade unions and the civil society bodies monitoring Government activities) and with all central and decentralized administration bodies responsible for Government policy monitoring and evaluation.
} 
(iii) Decentralized GPRS 2011-2015 monitoring committees (see Figure 15).

10.7 The Governance Board consists of the Minister for Planning and Development, the Minister of Economy and Finance, and the Ministers in charge of line departments. Chaired by the Minister for Planning and Development, the Governance Board cooperates closely with the heads of the diplomatic missions.

10.8 The Governance Board meets at least once every six months, establishes the basic guidelines for GPRS 2011-2015 monitoring and coordination, and discusses policy with the TFPs. The joint annual review of the GPRS, attended by all members of the Governance Board and the Steering Committee, is a formal event for the examination of the progress achieved in implementing the GPRS 2011-2015.

10.9 The Steering Committee is responsible for ensuring the effectiveness of the administrative and technical monitoring of procedures and the availability of the various monitoring instruments. It consists of the Economic and Financial Program Monitoring Unit (CSPEF), the Social Change Observatory (OCS), the Directorate General for Development Policy (DGPD), the Directorate General for Economic Affairs (DGAE) and the National Institute for Statistics and Economic Analysis (INSAE). On an ongoing basis, the CSPEF serves as the secretariat and organizes the work of the Steering Committee in relation to the following specific tasks:

(i) Coordination of the administrative monitoring of the GPRS 2011-2015, in close cooperation with the ministries;

(ii) Coordination of the technical monitoring of the GPRS 2011-2015;

(iii) Coordination of the involvement of the stakeholders, namely the Administration, the private sector, civil society and the TFPs, in the GPRS 2011-2015 participatory process;

(vi) Preparation of annual monitoring reports on the GPRS 2011-2015 as a whole.

10.10 With regard to the technical monitoring of the strategy, the Steering Committee must work in close cooperation with the TFP technical group for GPRS and budgetary support monitoring, and with the network of civil society organizations engaged in citizen monitoring of Government policies.

10.11 At the sectoral level, the monitoring of priority actions and programs falls within the competence of the ministries concerned, particularly the Monitoring and Evaluation Units and the statistical services of the Programming and Planning Directorates (DPPs). In facilitating the coordination of procedures and ensuring consistency within the information system, these services rely on so-called "focal points." They also ensure, at the centralized level, the collection of information necessary for monitoring.

10.12 At the decentralized level, the monitoring mechanism must be strengthened. To that end, the Government will ensure the effective operation of the Departmental Monitoring Committees (CDS) and the Communal Monitoring Committees (CCS). With a view to consistency of action, decentralized monitoring should internalize the second generation PDCs. 
10.13 The CDSs are responsible for monitoring the implementation of the departmental programs of action and for collecting and analyzing the department's sectoral statistical data. They are chaired by the Prefects of the departments and their secretariat is provided by the departmental Directors for Development.

10.14 A CCS is chaired by the mayor and is responsible for the collection of communal statistical data, under the supervision of the CDS. The CCSs meet once every quarter and submit to the Prefects of the departments reports on their work and quarterly reports on the implementation of the GPRS in accordance with the PDCs. These reports are used in the preparation of the departmental reports.

\subsection{IMPLEMENTATION MONITORING MECHANISM}

10.15 The monitoring mechanism comprises the following two components:

(i) Statistical monitoring of poverty, household living conditions and economic and social development;

(ii) Monitoring of the physical output and budgetary performance of priority projects and programs.

\subsection{Component 1: Statistical monitoring of poverty, household living conditions and economic and social development}

Products. Component 1 is expected to accomplish its main mission, which consists in organizing and supervising activities aimed at monitoring the well-being of the population and development, through the collection of data from households, administrative bodies and production units, the processing of such data by means of the Integrated Economic and Social Information Management System (SIGIES), the production of Economic and Social Scorecards (TBESs), the drawing up of national accounts and the periodic preparation of a poverty map to accompany the progress report on the implementation of the GPRS 2011-2015.

Responsible bodies. The responsible bodies are the main producers of social and economic statistics, namely, INSAE, DGAE, the GDP - Table of Government Financial Operations (TOFE) Committee, the Central Bank of West African States (BCEAO), CSPEF and DPPs of priority ministries. INSAE ensures the coordination of this system.

10.17 Component 1 will be based on the action plans of the National Strategy for Statistical Development (SNDS). The GPRS 2011-2015 will be monitored with the help of statistical surveys $^{31}$ related to the SNDS. In particular, the second Integrated Modular Survey on Household Living Conditions (EMICoV 2), which will be carried out in 2011 in conjunction with the fourth Demographic and Health Survey (EDS 4), will update and deepen the information on income and non-income poverty. Moreover, census-related maps will be drawn up in 2011 to support the General Population and Housing Survey (RGPH4) of 2012.

\footnotetext{
${ }^{31}$ See Table 22, Annex 3.
} 
10.18 These major surveys will help to draw up refined thematic geographic maps (inter alia, poverty, school, health, and social and communal infrastructure maps) in order to streamline Government action for development through better targeting of the poor and to supply reliable information to all stakeholders of the development process at the national and local levels.

\subsection{Component 2: Monitoring of the physical output and budgetary performance of priority projects and programs}

Mission. This component makes it possible to follow up on the programs and projects provided for in the PAP of the GPRS 3, and consists of the following two subcomponents:

(i) Physical monitoring of output;

(ii) Budgetary monitoring of priority programs.

Products. The following products will be developed:

(i) Annual reports on the implementation of programs and projects, including budget programs;

(ii) A database on the projects.

Responsible bodies. The coordination of this subsystem is ensured by the Directorate General for Project and Program Monitoring (DGSPP). Other participating bodies are the CSPEF, ministry DPPs and such central agencies as the Directorate General for the Budget (DGB), the Autonomous Amortization Fund (CAA), the Directorate General for Local Governance and Decentralization (DGGLD), and the Departmental Offices for Planning and Development (DDPDs).

10.20 Main product expected from the monitoring mechanism. The final output of the GPRS 2011-2015 monitoring mechanism is a progress report, which unifies the findings of the strategy implementation monitoring system as a whole. The progress report will be drawn up annually through a participatory procedure involving all of the stakeholders and coordinated by the permanent secretariat of the Steering Committee. The report must include a summary of recent developments, a description of advances achieved in implementing the GPRS 2011-2015 by strategic line of action, and a recapitulation of PAP implementation. Moreover, the report must be detailed, state why the goals set were or were not attained, and propose solutions in the event of bottlenecks.

\subsection{PERFORMANCE EVALUATION SYSTEM}

10.21 In the case of earlier GPRSs, periodic evaluations of implementation suffered from weaknesses in the information collection system and from the inadequate involvement of actors at the grassroots level. The evaluations were usually launched or promoted by the Administration to fulfill its commitments to the TFPs. In order to avoid such flawed practices, a system for assessing the impact of policies and programs will be set up at the internal and external levels. The mission, expected products and body responsible for evaluation internal to the Administration are described below. 
Mission. The system must measure the impact of policies and activities on the target groups and on the pursuit of development objectives (growth, poverty reduction, and social development). This assessment will relate program and project implementation to changes in the development and well-being of the target groups. The timing of evaluation studies in relation to sectoral planning and sectoral-strategy and GPRS 2011-2015 reviews must be improved. Such studies must also help to assess the effectiveness of priority programs in view of the strategy's long-term goals.

Products. The following studies will be carried out:

(i) Selective studies to assess the impact of policies and programs on poverty, according to specifications reviewed annually and reflecting GPRS 2011-2015 priorities;

(ii) A study to assess the effectiveness of poverty-reduction sectoral strategies and Government policies. Impact assessment instruments, such as the Poverty and Social Impact Analysis (PSIA) and Local Participatory Impact Monitoring (SILP), will be reinforced at the central and decentralized levels.

Responsible body. The work of this subsystem is coordinated by the OCS Coordination Unit, which, in cooperation with the monitoring mechanism actors, should:

(i) Identify and select the key problems to be analyzed;

(ii) Identify service providers, namely internal or external actors (inter alia, research centers and consultants);

(iii) Allocate resources;

(iv) Monitor study implementation and dissemination and the use of feedback to fine-tune policies and programs.

The other actors of the system are the Public Policy Evaluation Office (BEPP), INSAE, DGAE, CSPEF, DGPD, the Development Policy Analysis Unit (CAPOD), research centers and networks, and the monitoring and evaluation units of the priority sectors. 
Figure 10.1: Monitoring and Evaluation Mechanism, GRPS 3

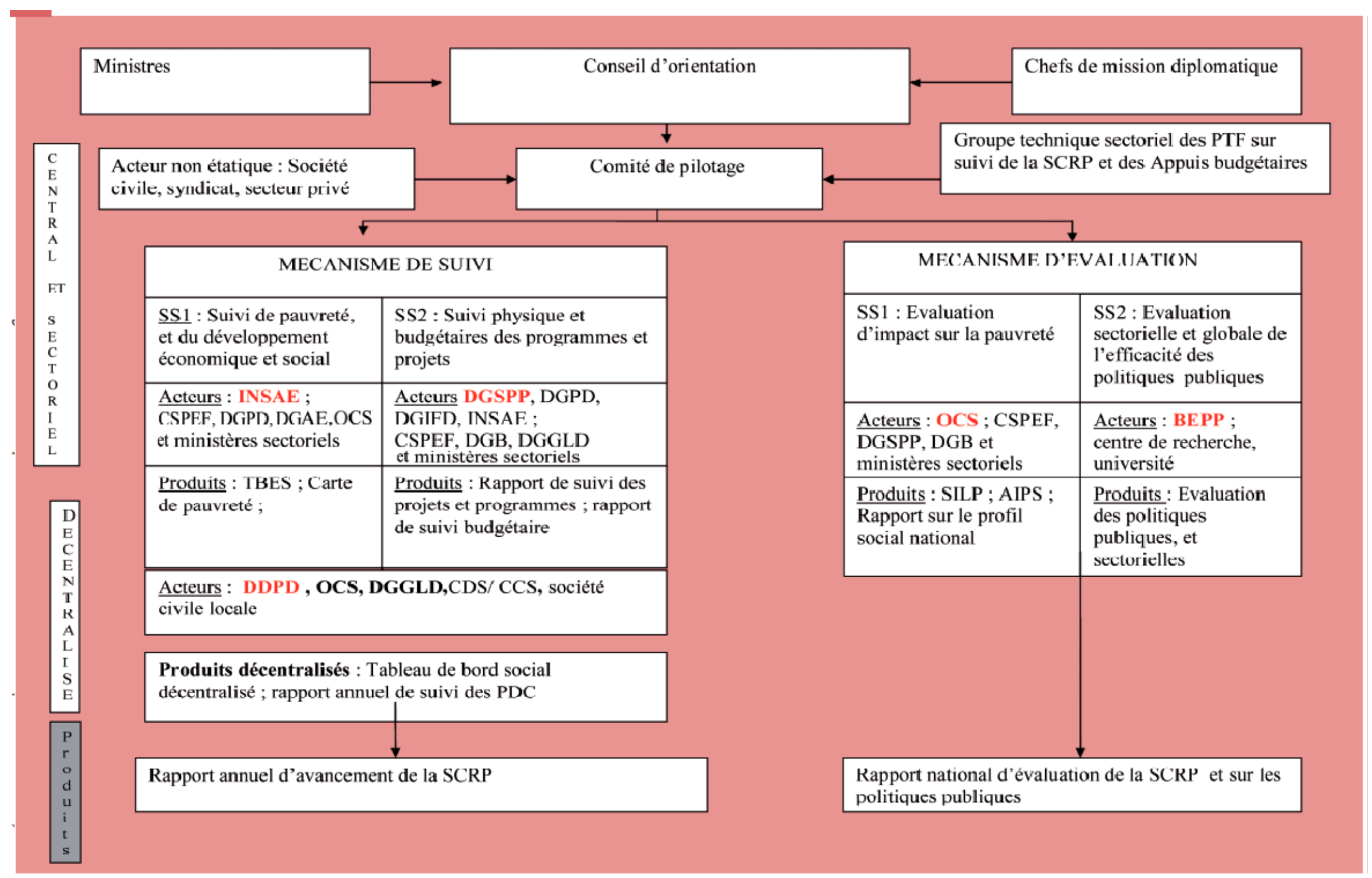




\begin{tabular}{|c|c|}
\hline French & English \\
\hline Ministres & Ministers \\
\hline Conseil d'orientation & Governance Board \\
\hline Chefs ... diplomatique & Heads of diplomatic missions \\
\hline Acteur ... privé & $\begin{array}{l}\text { Non-State actors: Civil society, trade unions and the private } \\
\text { sector }\end{array}$ \\
\hline Comité de pilotage & Steering Committee \\
\hline Groupe ... budgétaires & $\begin{array}{l}\text { TFP technical group for GPRS and budgetary support } \\
\text { monitoring }\end{array}$ \\
\hline CENTRAL ET SECTORIEL & CENTRAL AND SECTORAL \\
\hline DÉCENTRALISÉ & DECENTRALIZED \\
\hline Produits & Products \\
\hline MÉCANISME DE SUIVI & MONITORING MECHANISM \\
\hline SS1 ... social & $\begin{array}{l}\text { Component 1: Monitoring of poverty, household living } \\
\text { conditions and economic and social development }\end{array}$ \\
\hline Acteurs: INSAE ... sectoriels & $\begin{array}{l}\text { Actors: INSAE, CSPEF, DGPD, DGAE, OCS and line } \\
\text { ministries }\end{array}$ \\
\hline Produits ... pauvreté & Products: TBESs and poverty map \\
\hline Acteurs ... locale & $\begin{array}{l}\text { Actors: DDPD, OCS, DGGLD, CDS/CCS and local civil } \\
\text { society }\end{array}$ \\
\hline Produits ... PDC & $\begin{array}{l}\text { Decentralized products: Decentralized social scorecard and } \\
\text { annual monitoring report on PDCs }\end{array}$ \\
\hline Rapport annuel ... & Annual GPRS progress report \\
\hline $\mathrm{SS} 2 \ldots$ projets & $\begin{array}{l}\text { Component 2: Monitoring of the physical output and } \\
\text { budgetary performance of priority projects and programs }\end{array}$ \\
\hline Acteurs: DGSPP ... sectoriels & $\begin{array}{l}\text { Actors: DGSPP, DGPD, DGIFD, INSAE, CSPEF, DGB, } \\
\text { DGGLD and line ministries }\end{array}$ \\
\hline Produits ... budgétaire & $\begin{array}{l}\text { Products: Projects and programs monitoring report and } \\
\text { budgetary monitoring report }\end{array}$ \\
\hline MÉCANISME D'ÉVALUATION & EVALUATION MECHANISM \\
\hline SS1 ... pauvreté & Component 1: Assessment of impact on poverty \\
\hline Acteurs: OCS ... sectoriels & Actors: OCS, CSPEF, DGSPP, DGB and line ministries \\
\hline Produits ... national & $\begin{array}{l}\text { Products: SILP, PSIa and Report on the national social } \\
\text { profile }\end{array}$ \\
\hline SS2 ... publiques & $\begin{array}{l}\text { Component 2: Sectoral and overall evaluation of the } \\
\text { effectiveness of Government policies }\end{array}$ \\
\hline Acteurs: ... université & Actors: BEPP, research centers and universities \\
\hline Produits ... sectorielles & Products: Evaluation of Government and sectoral policies \\
\hline Rapport national ... & $\begin{array}{l}\text { National report on GPRS evaluation and on Government } \\
\text { policies }\end{array}$ \\
\hline
\end{tabular}




\subsection{BUILDING OF THE CAPACITIES OF MONITORING AND EVALUATION MECHANISM BODIES}

10.22 The shortage of human or financial resources continues to constitute a major obstacle to the adequate operation of the mechanism. Generally speaking, budgetary resources must be directly allocated to the bodies responsible for processing information in the technical monitoring mechanisms, particularly the monitoring bodies in line ministries. In order to support the monitoring and evaluation mechanism, a common fundraising facility, coordinated by OCS, was set up in 2006 with the support of the Danish International Development Agency (DANIDA), the German Agency for Technical Cooperation (GTZ) and the Swiss Agency for Development and Cooperation (SDC). However, the operation of that fund needs to be improved so as to ensure:

(i) Optimal allocation of resources to the various actors of the mechanism;

(ii) Consistency of the activities financed through the fund and of the related products with the monitoring and evaluation mechanism;

(iii) Increased responsibilities for the individual stakeholders in the process. Such reinforcement of the facility would render its contributions more effective.

The above improvements require:

(i) Increasing the number of partners participating in the common fundraising facility;

(ii) Ensuring that the facility's technical management group allocates resources so as to enhance the responsibility of the various actors through RBM;

(iii) Using the monitoring and evaluation capacity building plan drawn up under the Support Program for Monitoring and Evaluation of Poverty Reduction Strategies (PARSEP). 


\section{CONCLUSION}

10.23 Drawn up on the basis of a broad participatory process, the GPRS 2011-2015 constitutes a framework unifying all of the sectoral strategies and a reference document for dialogue with the development partners for the period 2011-2015. Essentially, the GPRS 2011-2015 reflects the fundamental documents of Benin's medium- and long-term strategies and of the Millennium Development Goals (MDGs).

10.24 Successful implementation of the strategy will depend on ownership of its content by the various actors responsible for implementation and on the support provided by the development partners. To that end, measures must be taken to:

(i) Ensure actual ownership of the content of the strategy by the Administration, the local government authorities, the private sector and civil society;

(ii) Mobilize and ensure the efficient use of the internal and external resources necessary for the implementation of the strategy;

(iii) Build the institutional and human capacities required at the central, regional and local levels for effective monitoring of the strategy.

10.25 Meetings will be organized periodically with all actors in order to consolidate and promote dialogue at the social, technical and political levels with a view to assessing the progress achieved and considering appropriate corrective measures. 


\section{BIBLIOGRAPHY}

\begin{tabular}{|c|c|}
\hline Carlier, K. 2003. & $\begin{array}{l}\text { Country Case Study: Assessment of Benin's Mid-Term Expenditure } \\
\text { Framework. London: Overseas Development Institute. }\end{array}$ \\
\hline $\begin{array}{l}\text { Fozzard, A., M. Holmes, J. } \\
\text { Klugman, and K. Withers. } \\
2002 .\end{array}$ & $\begin{array}{l}\text { "Dépenses Publiques," Livre de Références des DSRP (“Public } \\
\text { Spending," PRSP Sourcebook), Chapter 6. Washington, DC : } \\
\text { World Bank. }\end{array}$ \\
\hline $\begin{array}{l}\text { Holmes, M. and A. Evans. } \\
2003 .\end{array}$ & $\begin{array}{l}\text { A Review of Experience in Implementing Medium Term } \\
\text { Expenditure Frameworks in a PRSP Context: A Synthesis of Eight } \\
\text { Country Studies. }\end{array}$ \\
\hline Lo, M. 2003. & $\begin{array}{l}\text { "Lutte contre la pauvreté, changer de paradigm" in Le Sénégal } \\
\text { émergent, ("Poverty Reduction, Paradigm Shift" in Emerging } \\
\text { Senegal). Walfadjiri publications. }\end{array}$ \\
\hline Republic of Benin. 2006. & $\begin{array}{l}\text { "Orientations Stratégiques de Développement du Bénin (2006- } \\
\text { 2011)," Le Bénin émergent ("Strategic goals for development in } \\
\text { Benin, 2006-2011," Emerging Benin). Cotonou. November } 2006 .\end{array}$ \\
\hline Republic of Benin. 2007. & $\begin{array}{l}\text { Analyse contextuelle pour la réforme de l'environnement } \\
\text { institutionnel du Bénin ("Contextual Analysis for Reforming the } \\
\text { Institutional Framework in Benin"). Report. Cotonou. March } 2007 .\end{array}$ \\
\hline Republic of Benin. 2009 A. & $\begin{array}{l}\text { Rapport provisoire des travaux du sous-groupe Climat des Affaires } \\
\text { au Bénin ("Provisional Report on the Work of the 'Business } \\
\text { Climate in Benin' Subgroup"). Report. Cotonou. November } 2009 .\end{array}$ \\
\hline Republic of Benin. 2009 B. & $\begin{array}{l}\text { "Stratégie d'operationnalisation et déclinaison en plans } \\
\text { d'investissements sectoriels de la vision Bénin 2025," Agenda vers } \\
\text { une économie émergeante (“Operationalization Strategy and } \\
\text { Presentation of Sectoral Investment Plans Based on a Vision for } \\
\text { Benin in 2025," Agenda for an Emerging Economy). Final report. } \\
\text { February 2009. }\end{array}$ \\
\hline Republic of Benin. 2009 C. & $\begin{array}{l}\text { Evaluation de la Stratégie de Croissance pour la Réduction de la } \\
\text { Pauvreté 2007-2009 (“Evaluation of the Poverty Reduction } \\
\text { Development Strategy 2007-2009”). Cotonou. August 2009. }\end{array}$ \\
\hline Republic of Benin. 2009 D. & $\begin{array}{l}\text { Report of the thematic drafting groups of the GPRS 2011-2015, } \\
\text { namely the groups on Health; Education; Water; Energy; } \\
\text { Governance; Transport and Public Works; Services and Logistics; } \\
\text { Employment; Tourism, Culture and Handicrafts; Environment and } \\
\text { Urban Development; Decentralization, Devolution and Regional } \\
\text { Development; Diplomacy and Regional Integration; Strengthening } \\
\text { of the Macroeconomic Framework; Logistics and Services; Trade } \\
\text { and Employment; Justice and Human Rights; Security and Peace; } \\
\text { and Agriculture and Land Issues. }\end{array}$ \\
\hline Republic of Benin. 2011. & $\begin{array}{l}\text { Identification et analyse des contraintes des secteurs porteurs pour } \\
\text { une croissance durable et pro-pauvres au Bénin ("Identification } \\
\text { and Analysis of Constraints on Key Sectors for a Sustainable } \\
\text { Development in Favor of the Poor in Benin"). Final report. }\end{array}$ \\
\hline World Bank. 2006. & $\begin{array}{l}\text { Réforme de la Fonction Publique, État des lieux et opportunités } \\
\text { ("Public Service Reform, Assessment and Opportunities"). } \\
\text { Cotonou. } 21 \text { June 2006. Report No. 36034-BJ. }\end{array}$ \\
\hline $\begin{array}{l}\text { World Bank and African } \\
\text { Development Bank. } 2007 .\end{array}$ & $\begin{array}{l}\text { La corruption et la gouvernance au Bénin, Rapport des résultats de } \\
\text { l'enquête diagnostique ("Corruption and Governance in Benin, } \\
\text { Report on the Findings of the Diagnostic Inquiry"). Cotonou. June } \\
2007 .\end{array}$ \\
\hline
\end{tabular}




\section{ANNEXES}

\section{Annex 1: Assumptions Underlying the GPRS 20112015 Macroeconomic Framework}

One of the objectives of the GPRS 2011-2015 is to step up the pace of growth over the period, with an increasingly larger contribution from the private sector, thereby ensuring an improvement in living conditions. This growth must not be inflationary and should facilitate the equal sharing of productivity gains and a sound rate of return on investment. Implementation of the central scenario is based on the following assumptions:

The international environment. The global financial crisis is expected to end in 2010 . The global economy will return to a new growth cycle from 2011, which will impact the regional environment, in particular for Nigeria and Côte d'Ivoire. In addition, the regional sociopolitical environment will remain stable. Thus, the economic situation will be favorable over the GPRS 2011-2015 implementation period.

The political and social environment. The peaceful conduct of presidential, legislative, and municipal elections is a prerequisite for implementation of the GPRS 2011-2015. In addition, the easing of social tensions should permit the GPRS 2011-2015 to benefit from meaningful private sector participation.

Cotton. Monitoring and continuation of reforms already under way should lead to an increase in planted areas and cotton yields. Cotton production should therefore increase to around 500,000 metric tons in 2015.

Food production. Implementation of the Strategic Plan for Agricultural Sector Recovery (PSRSA) will result in an improvement in agricultural productivity and yields. The average growth rate of agricultural production should be around 5 percent over the period against an average growth rate of 4.1 percent for the GPRS 2007-2009 and 2.2 percent for the PRS (20032005).

Agro-industry. The development of agricultural production, particularly of cotton, pineapples, root vegetables, grains, and oilseeds, has a significant impact on the agri-food industry and Beninese exports. To this end, the improvement of the business environment and the promotion of new industrial enterprises and small-scale processing units under the agri-food pillar should contribute to increasing the industrial sector's contribution to growth.

Energy. For some years now Benin has been experiencing an energy crisis, characterized by an increase in the prices of petroleum products and load shedding, which has an impact on business competitiveness. To address this situation, the Government plans to increase production capacities in order to reduce its dependence on external sources. Thus, the installation of the 80 MW Maria-Gléta plant (in Abomey-Calavi) in 2010 and independent power producers (IPPs) for a capacity of $100 \mathrm{MW}$, from 2012, should increase the level of energy production.

Construction and Public Works. This sector will benefit from budgetary allocations in the priority sectors (health, education, sanitation, rural sector) for construction and the Government's major works policy. In addition, the expected increase in private investment, resulting from an improved business climate, should help make the sector more dynamic. 
Consequently, growth of the sector will be ensured throughout the GPRS 2011-2015 implementation period.

Business and services. The development of transport and telecommunications infrastructure will have a significant impact on transaction and production costs. As described in Chapter 5, the establishment of economic infrastructure consistent with international standards, combined with the strengthening of human capital and the capacities of the Port of Cotonou and modernization of the Benin-Niger Railway and Transport Organization (OCBN) railways, will be the main engine of growth in the medium term.

Investments. Poverty reduction requires faster growth and the promotion of sustainable employment. To this end, the Government plans to gradually increase the rate of public investment in the promising and potential sectors identified in the "Agenda for an Emerging Economy" document. This increase in investment will take place in conjunction with improvements to the business climate, governance, and the effectiveness of the administration, as well as the strengthening of partnership with the private sector and technical and financial partners, with a view to attracting private investment and foreign capital flows. As a result of this strategy, the investment rate will increase from 22.6 percent in 2011 to around 24.7 percent in 2015. 


\section{Annex 2: Structure of the Model for the GPRS 20112015 Macroeconomic Framework}

The macroeconomic framework was created with the new version of the Economic Reform Simulation and Analysis Model [Modèle de Simulation et d'Analyse des Réformes Economiques MOSARE ${ }^{32}$ ] using a micro-simulation module (see Figure 16).

The GPRS 2011-2015 macroeconomic framework should facilitate achievement of four of the eight Millennium Development Goals (MDGs), namely, education, health, drinking water, and sanitation. The remaining MDGs may not be achieved, but should approach their targets.

Figure A1: MOSARE Structure

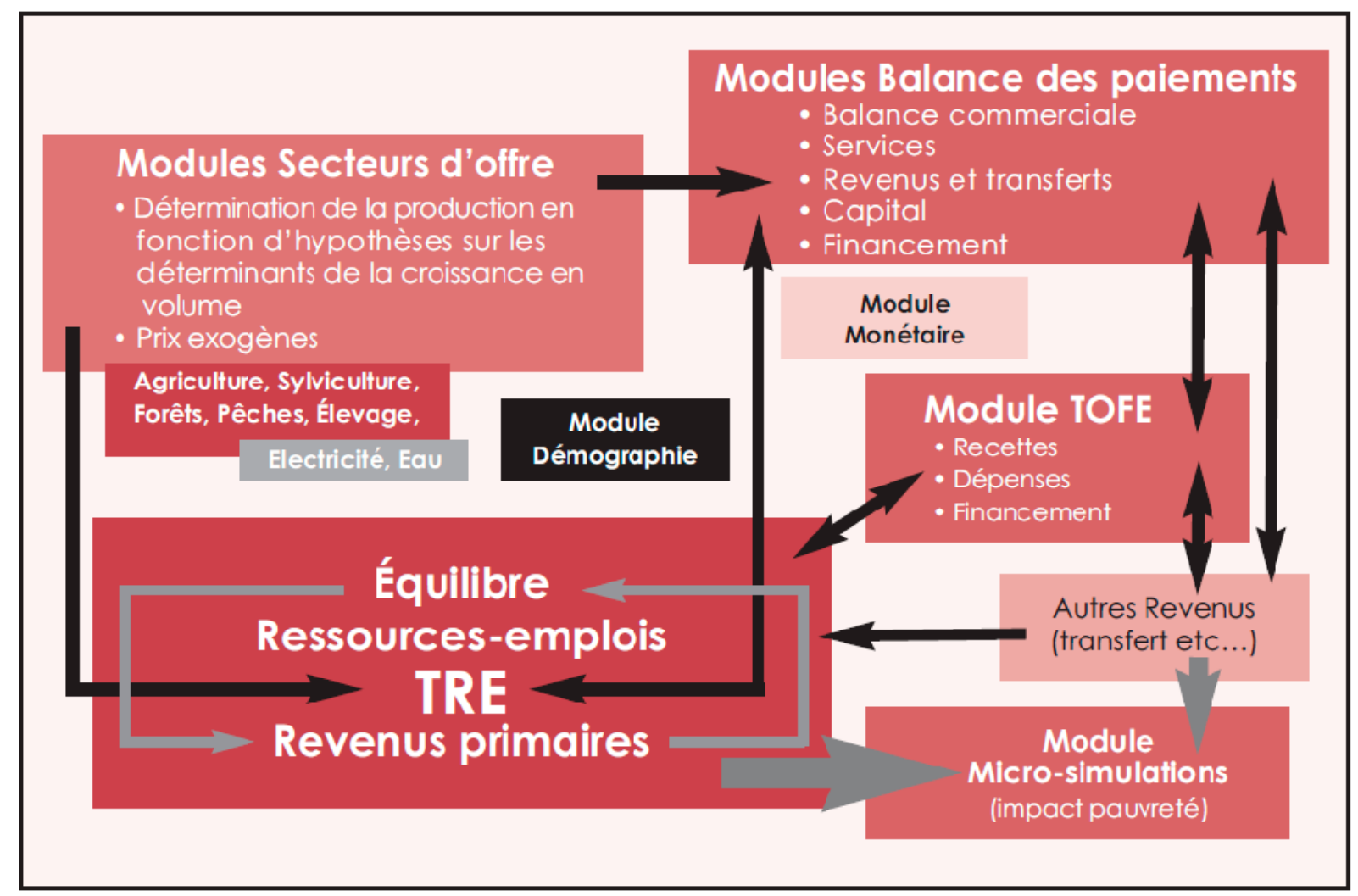

Source: MEF, June 2010.

\section{French}

Modules Secteurs d'offre

- Détermination de la production en fonction d'hypothèses sur les déterminants de la croissance en volume

- Prix exogènes

Agriculture, Sylviculture, Forêts, Pêches, Élevage, Electricité, Eau

Module Démographie

\section{English}

Supply Sector Module

- Determination of production based on hypotheses regarding the determinants of growth by volume

- Exogenous prices

Agriculture, Silviculture, Forests, Fisheries, Livestock Production, Electricity, Water Demographic Module

\footnotetext{
${ }^{32}$ MOSARE is a quasi-accounting model designed to project economic data for countries lacking long time series data. It follows the logical accounting framework for economic accounts.
} 
Équilibre Ressources-emplois

TRE

Revenus primaires

Module Micro-simulations (impact pauvreté)

Autres Revenus (transfert etc...)

Module TOFE

- Recettes

- Dépenses

- Financement

Module Monétaire

Modules Balance des paiements

- Balance commerciale

- Services

- Revenus et transferts

- Capital

- Financement
Balance between resources/jobs

TRE

Primary income

Micro-simulation Module (poverty impact)

Other Income (transfers, etc.)

TOFE Module

- Revenue

- Expenditure

- Financing

Monetary Module

Balance of Payments Module

- Trade balance

- Services

- Income and transfers

- Capital

- Financing 


\section{Box A1: Micro-Simulation Module}

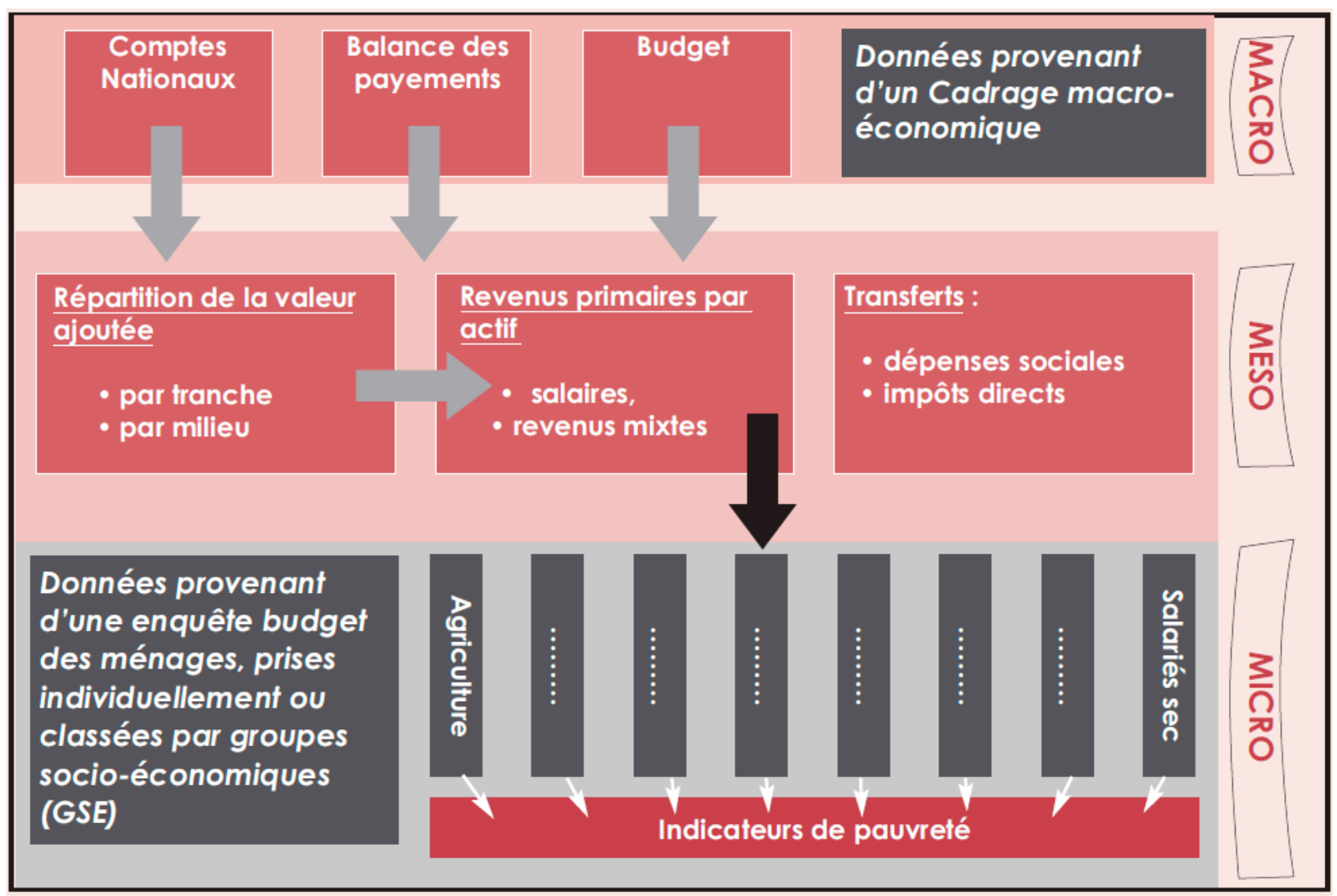

The micro-simulation module is followed by macroeconomic, mesoeconomic, and microeconomic modeling.

The approach adopted is identical to that used for the majority of "micro-macro" instruments. The results of macroeconomic simulations are linked to data from household budget-consumption surveys in order to estimate the impact of shocks on the mean variations in income (or expenditure) for each group as well as for each household within each category. These results allow for the calculation of variations in poverty at the individual level and changes in the distribution among the groups. The methodological approach to developing the microsimulation module is illustrated above.
French
MACRO
English
MACRO

Comptes Nationaux

Balance des payements

Budget

Données provenant d'un Cadrage macroéconomique MESO

Répartition de la valeur ajoutée

National Accounts

Balance of Payments

Budget

Data from the Macroeconomic Framework

MESO

- par tranche

- par milieu

Revenus primaires par actif

- salaires,

- revenus mixtes

Transferts :

- dépenses sociales

Distribution of value added

by tranche

by area

Primary income by asset

salaries

mixed income

Transfers

social expenditure

direct taxation

- impôts directs

MICRO

MICRO

Données provenant d'une enquête budget des ménages, prises individuellement ou classées par groups socio-

Data from a household budget survey, taken individually or classified by socioeconomic group 

économiques (GSE)
Agriculture
Agriculture
Salariés sec
Indicateurs de pauvreté
Sectoral employees
Poverty indicators

\section{Box A2: Debt Sustainability Analysis (DSA) Framework}

Low-income countries have often had to cope with high levels of external debt. Their obligations in this regard have now been reduced, due in large part to international debt relief initiatives (HIPC and MDRI). As a contribution to the Monterrey Consensus, which supports these countries' efforts to achieve the Millennium Development Goals (MDGs), the World Bank and IMF have developed a debt analysis framework to help lowincome countries mobilize the resources needed for their development, while minimizing future risks of excessive indebtedness. The Debt Sustainability Analysis (DSA) framework was adopted by the World Bank and IMF in April 2005 to mitigate the risks of over-indebtedness.

One of the objectives of the debt sustainability analysis is to guide the financial decisions of low-income countries so that their financing needs are in line with their current and prospective ability to service debt, while taking into account each country's unique characteristics.

This new analysis framework classifies low-income countries into three categories based on the quality of their policies and the soundness of their institutions, using the World Bank Country Policy and Institutional Assessment (CPIA), as follows:

$$
\begin{aligned}
& \text { Weak, if the CPIA score is } \leq 3.25 \text {, } \\
& \text { Medium, if } 3.25<\text { CPIA }<3.75, \\
& \text { Strong, if the CPIA score is } \geq 3.75 .
\end{aligned}
$$

For Benin, the average score for the 2006-2008 period is 3.57, which corresponds to "threshold 1" for purposes of analysis. The indicative debt thresholds vary by category. They are higher for countries with high-quality policies, reflecting the fact that for these countries, debt accumulation presents less of a risk. By contrast, the thresholds are relatively low for countries whose policies are in need of structural reform in order to improve productivity and competitiveness.

\begin{tabular}{llllll} 
& \multicolumn{2}{l}{ NPV of debt as \% of } & \multicolumn{2}{l}{ Debt Service as \% of } \\
& Exports & GDP & Revenue & Exports & Revenue \\
Threshold 1 & 100 & 30 & 200 & 15 & 25 \\
Threshold 2 & 150 & 40 & 250 & 20 & 30 \\
Threshold 3 & 200 & 50 & 300 & 25 & 35
\end{tabular}

In order to evaluate a country's debt sustainability, changes in the debt indicators are compared with the indicative thresholds over a period of 20 years. A debt indicator that is higher than the indicative threshold indicates a risk that the country will encounter payment difficulties. There are four levels of risk:

low, if all the debt indicators are well below the thresholds;

moderate, if the debt indicators are below the thresholds in the main scenario but exceed the thresholds in the case of external shocks or abrupt changes in macroeconomic policies;

high, if at least one debt indicator exceeds the thresholds in the main scenario;

in debt distress, if the country is already facing payment difficulties.

The DSA framework is used in IMF evaluations of macroeconomic stability and the long-term sustainability of government finances and public debt, as well as to determine access to IMF resources. The World Bank also uses the evaluation of the risk of payment difficulties from the Debt Sustainability Analysis (DSA) to determine the allocation of grants and loans in its assistance to each low-income country such as Benin.

Source: MEF and the IMF website, www.imf.org, June 2010. 
Figure A2: Public Debt Sustainability Indicators

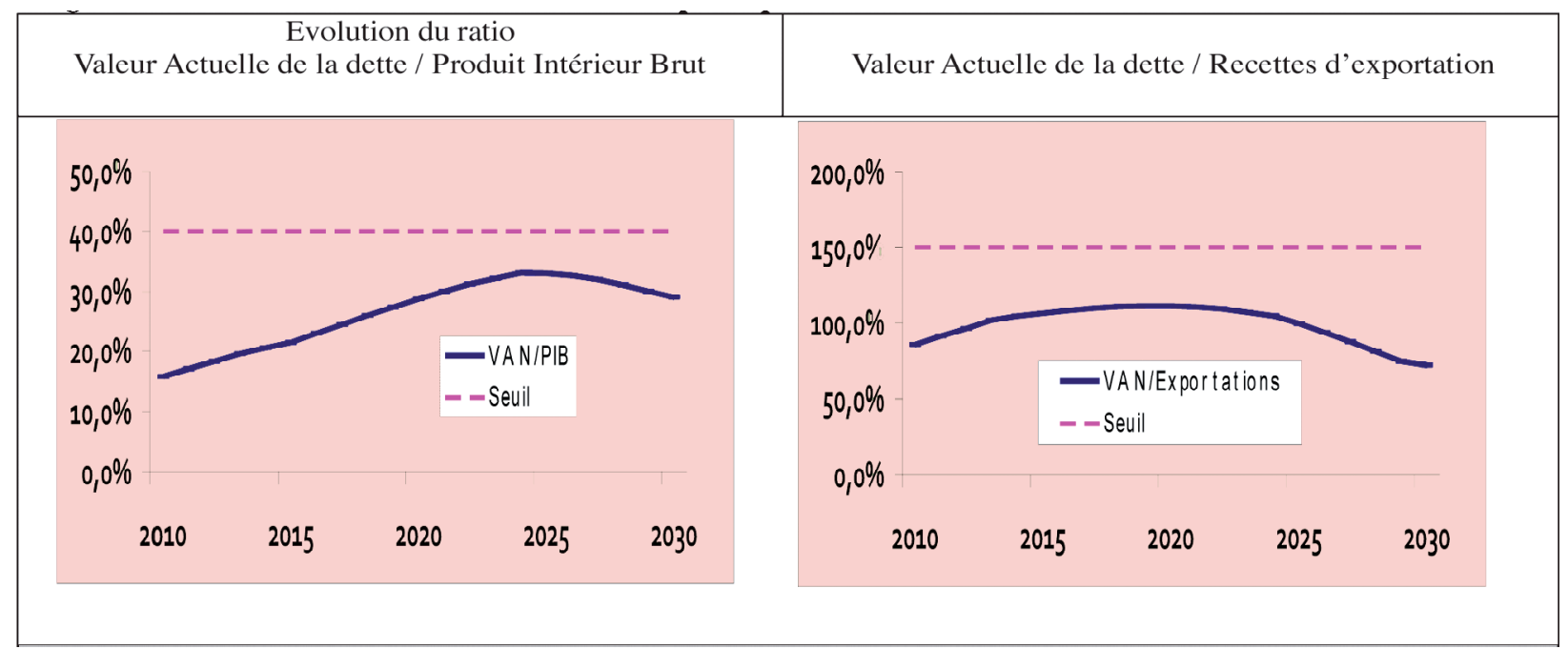

\section{French}

Evolution du ratio Valeur Actuelle [Nette] de la dette/Produit Intérieur Brut

Valeur Actuelle [Nette] de la dette/Recettes d'exportation

VAN/PIB

VAN/Exportations

Seuil

\section{English}

Change in Net Present Value of the Debt-to-GDP ratio

Net Present Value of Debt-to-Export Revenue

NPV-to-GDP

NPV-to-Exports

Threshold

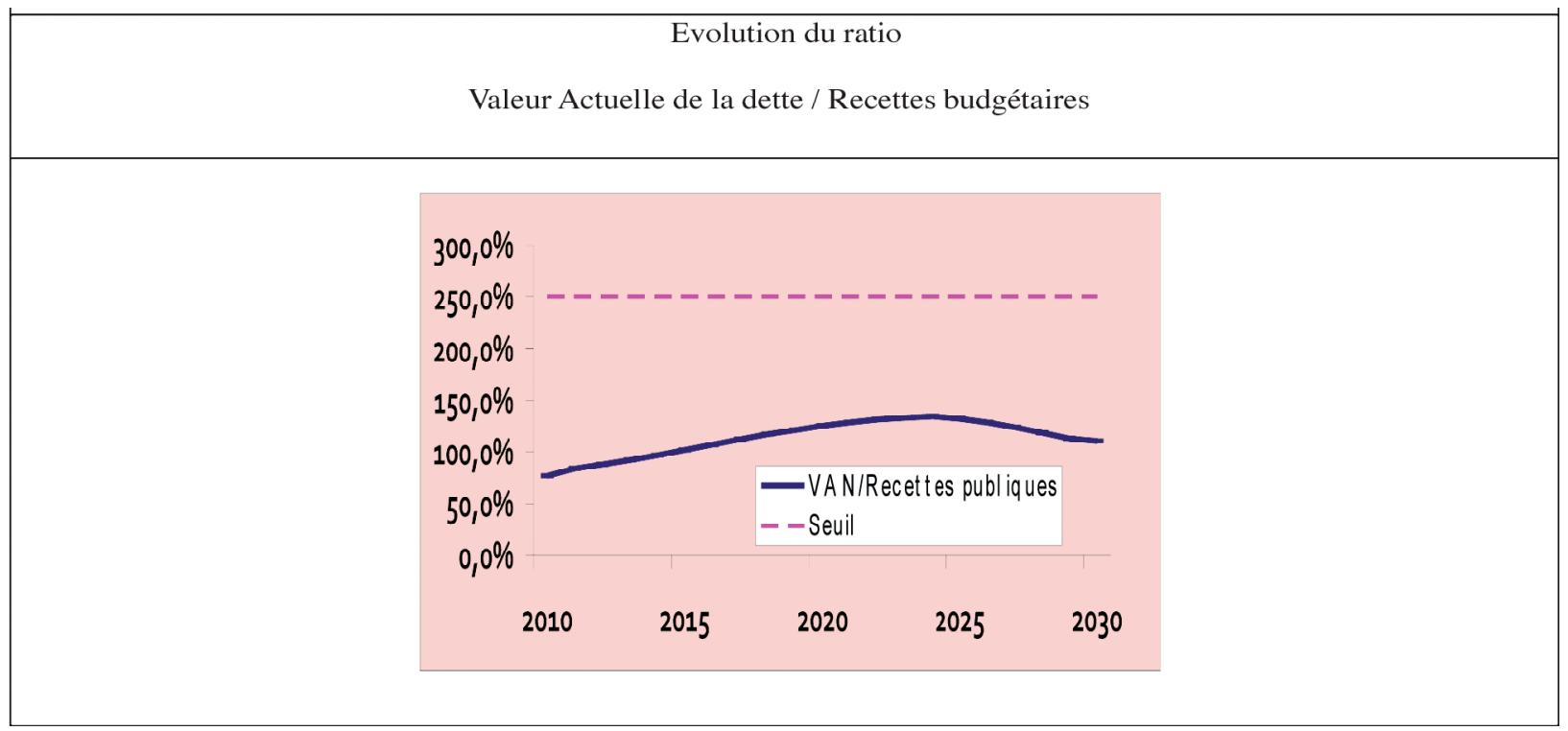

\section{French}

Evolution du ratio Valeur Actuelle [Nette] de la dette/Recettes budgétaires

$\mathrm{VAN} / \mathrm{PIB}$

VAN/Recettes publiques

Seuil

\section{English}

Change in Net Present Value of Debt-to-Budget

Revenue ratio

NPV-to-GDP

NPV-to-Public Revenue

Threshold 


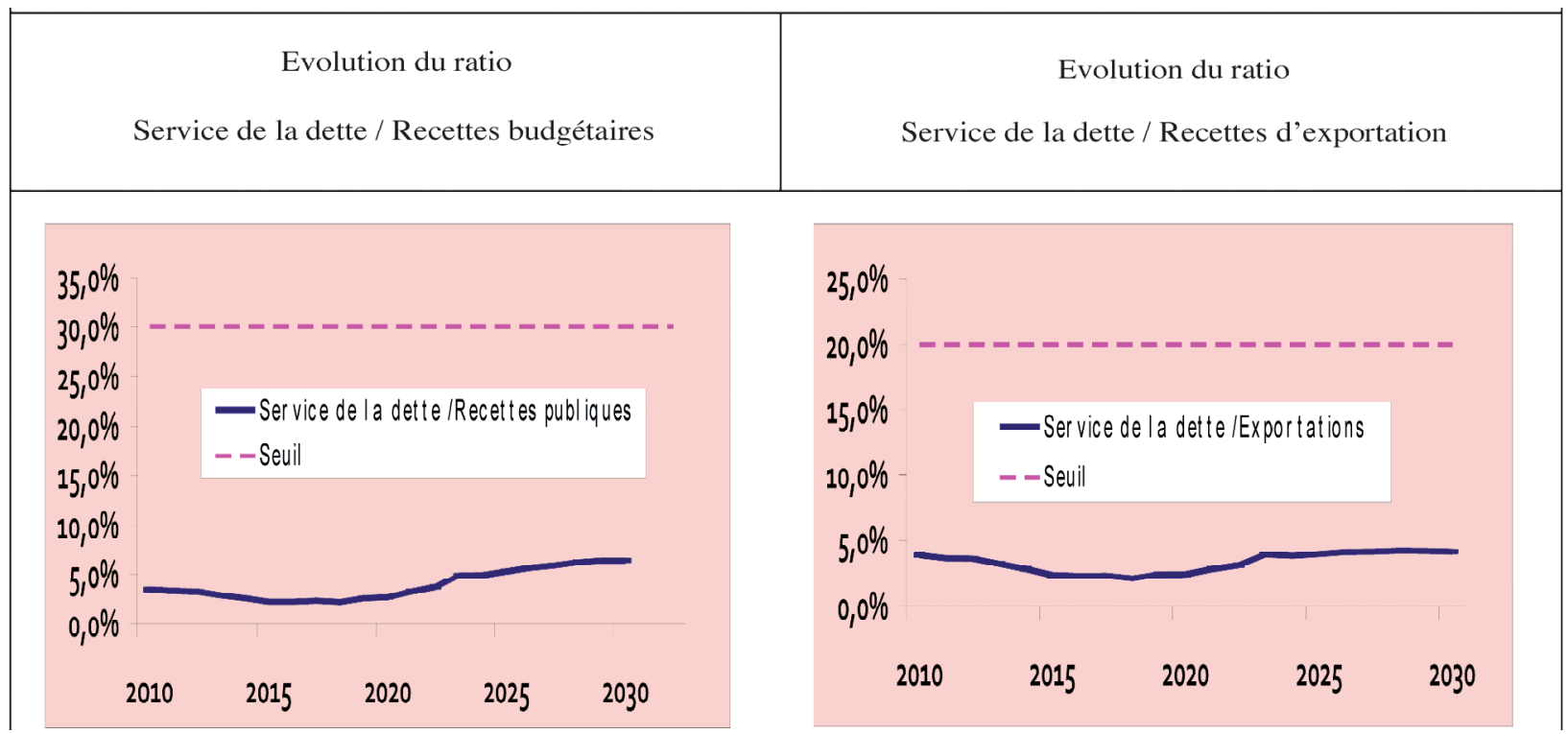

\section{French}

Evolution du ratio Service de la dette/Recettes budgétaires

Evolution du ratio Service de la dette/Recettes d'exportation

Service de la dette/Recettes budgétaires

Service de la dette/Exportations

Seuil

Source: MEF June 2010.

\section{English}

Change in Debt Service-to-Budget Revenue ratio

Change in Debt Service-to-Export Revenue ratio

Debt Service-to-Budget Revenue

Debt Service-to-Exports

Threshold 
Annex 3: GPRS 20112015 Macroeconomic Framework

Table A1: MTEF Scenario for GPRS 2011-2015

\begin{tabular}{|c|c|c|c|c|c|c|}
\hline STRUCTURE (\%) & 2011 & 2012 & 2013 & 2014 & 2015 & $\begin{array}{c}2011- \\
2015 \\
\text { Average }\end{array}$ \\
\hline Social Sectors & 29.6 & 31.6 & 33.5 & 35.8 & 38.3 & 33.8 \\
\hline Education & 16.4 & 17.0 & 17.5 & 18.6 & 20.0 & 17.9 \\
\hline Health & 11.4 & 12.7 & 13.8 & 14.2 & 15.0 & 13.4 \\
\hline Social and Cultural Development & 1.7 & 1.9 & 2.2 & 3.0 & 3.3 & 2.4 \\
\hline Production and Trade & 10.2 & 11.3 & 12.1 & 13.3 & 14.4 & 12.3 \\
\hline Productive Infrastructures & 20.0 & 22.1 & 24.6 & 26.8 & 28.3 & 24.3 \\
\hline Governance & 6.2 & 6.4 & 7.1 & 7.5 & 7.6 & 7.0 \\
\hline Political & 1.6 & 1.2 & 1.0 & 1.0 & 1.0 & 1.2 \\
\hline Economic & 4.5 & 5.2 & 6.1 & 6.5 & 6.6 & 5.8 \\
\hline Defense and Security & 6.5 & 4.6 & 3.8 & 3.0 & 2.3 & 4.0 \\
\hline Sovereignty & 2.9 & 2.5 & 2.5 & 2.4 & $\mathbf{2 . 0}$ & 2.5 \\
\hline Total Ministries and Institutions & 75.3 & 78.5 & 83.7 & 88.9 & 92.9 & 83.8 \\
\hline Other Budgets & 24.7 & 21.5 & 16.3 & 11.1 & 7.1 & 16.2 \\
\hline Total Budget & 100.0 & 100.0 & 100.0 & 100.0 & 100.0 & 100.0 \\
\hline VARIATION & 2011 & 2012 & 2013 & 2014 & 2015 & $\begin{array}{c}2011- \\
2015 \\
\text { Average }\end{array}$ \\
\hline Social Sectors & $46.6 \%$ & $16.0 \%$ & $12.3 \%$ & $13.8 \%$ & $14.5 \%$ & $20.6 \%$ \\
\hline Education & $26.8 \%$ & $12.1 \%$ & $9.4 \%$ & $12.9 \%$ & $15.4 \%$ & $15.3 \%$ \\
\hline Health & $93.5 \%$ & $21.1 \%$ & $15.1 \%$ & $9.3 \%$ & $13.2 \%$ & $30.5 \%$ \\
\hline Social and Cultural Development & $31.2 \%$ & $20.3 \%$ & $18.6 \%$ & $49.6 \%$ & $14.8 \%$ & $26.9 \%$ \\
\hline Production and Trade & $57.6 \%$ & $20.9 \%$ & $13.6 \%$ & $16.9 \%$ & $16.0 \%$ & $25.0 \%$ \\
\hline Productive Infrastructures & $4.8 \%$ & $20.0 \%$ & $17.9 \%$ & $15.9 \%$ & $13.2 \%$ & $14.4 \%$ \\
\hline Governance & $-4.5 \%$ & $13.3 \%$ & $16.6 \%$ & $13.6 \%$ & $8.6 \%$ & $9.5 \%$ \\
\hline Political & $-43.1 \%$ & $-17.1 \%$ & $-15.8 \%$ & $6.5 \%$ & $7.1 \%$ & $-12.5 \%$ \\
\hline Economic & $26.5 \%$ & $24.3 \%$ & $24.4 \%$ & $14.7 \%$ & $8.8 \%$ & $19.7 \%$ \\
\hline Defense and Security & $-4.5 \%$ & $-22.6 \%$ & $-12.1 \%$ & $-15.4 \%$ & $-20.0 \%$ & $-14.9 \%$ \\
\hline Sovereignty & $31.9 \%$ & $-7.9 \%$ & $7.2 \%$ & $1.7 \%$ & $-9.8 \%$ & $4.6 \%$ \\
\hline Total Ministries and Institutions & $23.1 \%$ & $13.3 \%$ & $12.8 \%$ & $13.1 \%$ & $12.0 \%$ & $14.9 \%$ \\
\hline Other Budgets & $-29.8 \%$ & $-5.5 \%$ & $-19.7 \%$ & $-27.4 \%$ & $-31.0 \%$ & $-22.7 \%$ \\
\hline Total Budget & $3.8 \%$ & $8.6 \%$ & $5.9 \%$ & $6.5 \%$ & $7.1 \%$ & $6.4 \%$ \\
\hline
\end{tabular}

Source: MEF, June 2010 
Table A2: MTEF Alternative Scenario

\begin{tabular}{|c|c|c|c|c|c|c|}
\hline STRUCTURE (\%) & 2011 & 2012 & 2013 & 2014 & 2015 & $\begin{array}{c}2011- \\
2015 \\
\text { Average }\end{array}$ \\
\hline Social Sectors & 24.1 & 27.4 & 28.8 & 30.3 & 33.0 & 28.7 \\
\hline Education & 13.7 & 14.6 & 15.4 & 16.8 & 18.9 & 15.9 \\
\hline Health & 8.6 & 10.8 & 11.4 & 11.7 & 12.8 & 11.0 \\
\hline Social and Cultural Development & 1.8 & 2.0 & 2.0 & 1.7 & 1.3 & 1.8 \\
\hline Production and Trade & 10.3 & 10.9 & 11.3 & 11.9 & 13.0 & $\mathbf{1 1 . 5}$ \\
\hline Productive Infrastructures & 30.5 & 31.9 & 35.8 & 38.9 & 40.2 & 35.4 \\
\hline Governance & 4.3 & 3.6 & 2.8 & 2.1 & 1.5 & 2.9 \\
\hline Political & 1.7 & 1.3 & 1.0 & 0.8 & 0.6 & 1.1 \\
\hline Economic & 2.6 & 2.3 & 1.8 & 1.3 & 0.9 & 1.8 \\
\hline Defense and Security & 5.5 & 4.6 & 3.7 & 2.9 & 2.1 & 3.8 \\
\hline Sovereignty & 3.0 & 2.6 & 2.6 & 2.5 & 2.1 & 2.6 \\
\hline Total Ministries and Institutions & 77.6 & 80.9 & 85.1 & 88.6 & 92.0 & 84.8 \\
\hline Other Budgets & 22.4 & 19.1 & 14.9 & 11.4 & 8.0 & 15.2 \\
\hline Total Budget & 100.0 & 100.0 & 100.0 & 100.0 & 100.0 & 100.0 \\
\hline VARIATION & 2011 & 2012 & 2013 & 2014 & 2015 & $\begin{array}{c}2011- \\
2015 \\
\text { Average }\end{array}$ \\
\hline Social Sectors & $19.4 \%$ & $18.9 \%$ & $9.0 \%$ & $11.5 \%$ & $16.1 \%$ & $15.0 \%$ \\
\hline Education & $5.8 \%$ & $11.5 \%$ & $9.7 \%$ & $15.6 \%$ & $19.4 \%$ & $12.4 \%$ \\
\hline Health & $46.0 \%$ & $30.9 \%$ & $9.5 \%$ & $9.1 \%$ & $16.5 \%$ & $22.4 \%$ \\
\hline Social and Cultural Development & $33.5 \%$ & $18.6 \%$ & $1.3 \%$ & $-6.3 \%$ & $-18.8 \%$ & $5.7 \%$ \\
\hline Production and Trade & $60.3 \%$ & $10.4 \%$ & $8.1 \%$ & $11.3 \%$ & $16.3 \%$ & $21.3 \%$ \\
\hline Productive Infrastructures & $59.5 \%$ & $9.6 \%$ & $16.5 \%$ & $15.2 \%$ & $9.9 \%$ & $22.1 \%$ \\
\hline Governance & $-33.5 \%$ & $-13.1 \%$ & $-18.0 \%$ & $-18.9 \%$ & $-23.4 \%$ & $-21.4 \%$ \\
\hline Political & $-42.1 \%$ & $-18.3 \%$ & $-16.5 \%$ & $-14.6 \%$ & $-21.3 \%$ & $-22.6 \%$ \\
\hline Economic & $-26.6 \%$ & $-9.8 \%$ & $-18.9 \%$ & $-21.4 \%$ & $-24.7 \%$ & $-20.3 \%$ \\
\hline Defense and Security & $-19.3 \%$ & $-11.9 \%$ & $-15.5 \%$ & $-17.7 \%$ & $-22.8 \%$ & $-17.4 \%$ \\
\hline Sovereignty & $34.1 \%$ & $-9.2 \%$ & $6.3 \%$ & $1.6 \%$ & $-10.9 \%$ & $4.4 \%$ \\
\hline Total Ministries and Institutions & $26.9 \%$ & $9.1 \%$ & $9.2 \%$ & $10.4 \%$ & $10.4 \%$ & $13.2 \%$ \\
\hline Other Budgets & $-36.4 \%$ & $-10.5 \%$ & $-19.0 \%$ & $-19.1 \%$ & $-25.1 \%$ & $-22.0 \%$ \\
\hline Total Budget & $3.8 \%$ & $4.7 \%$ & $3.8 \%$ & $6.0 \%$ & $6.4 \%$ & $4.9 \%$ \\
\hline
\end{tabular}

Source: MEF, June 2010 
Table A3: Survey Schedule

\begin{tabular}{|c|c|c|c|c|c|c|c|}
\hline Surveys & $\begin{array}{l}\text { Frequency } \\
\text { (in years) }\end{array}$ & 2011 & 2012 & 2013 & 2014 & 2015 & 2016 \\
\hline EMICoV2 & 5 & & & & & & \\
\hline $\begin{array}{c}\text { Tracking } \\
\text { survey }\end{array}$ & 1 & & & & & & \\
\hline DHS & 5 & & & & & & \\
\hline RGPH 4 & 10 & & & & & & \\
\hline RGE & 5 & & & & & & \\
\hline RNA & - & & & & & & \\
\hline
\end{tabular}

Source: National Statistical Development Strategy.

EMICoV2 = Integrated Modular Survey on Household Living Conditions phase 2; DHS = Demographic and Health Survey; RGHP 4 = Fourth General Housing and Population Survey [Quatrième Recensement Général de la Population et de l'Habitation]; RGE = General Survey of Enterprises [Recensement Général des Entreprises]; RNA= National Agricultural Census [Recensement National Agricole] 
Annex 4: List of GRPS Indicators

\begin{tabular}{|l|l|l|l|l|l|l|l|l|l|l|}
\hline \multirow{2}{*}{$\begin{array}{l}\text { OBJECTIVES/ } \\
\text { RESULTS }\end{array}$} & \multirow{2}{*}{ INDICATORS } & \multicolumn{2}{|l|}{\begin{tabular}{l}
\multicolumn{2}{l|}{ BASELINE } \\
DATA
\end{tabular}} & \multicolumn{2}{|l|}{ TARGET } & $\begin{array}{l}\text { ENTITY } \\
\text { RESPONSIBLE }\end{array}$ & $\begin{array}{l}\text { FREQ. } \\
\text { MONITORING } \\
\text { MECHANISM }\end{array}$ \\
\cline { 3 - 9 } & & 2009 & $\begin{array}{l}2010 \\
\text { Target }\end{array}$ & 2011 & 2012 & 2013 & 2014 & 2015 & \\
\hline
\end{tabular}

OVERALL OBJECTIVE: Increase the pace of economic growth and improve living conditions

\section{(IMPACT)}

\begin{tabular}{|c|c|c|c|c|c|c|c|c|c|c|}
\hline $\begin{array}{l}\text { Incidence of national } \\
\text { income poverty }\end{array}$ & $35.21 \%$ & $34.1 \%$ & $32.3 \%$ & $30.1 \%$ & $28 \%$ & $26.5 \%$ & $25 \%$ & INSAE & Annually & $\begin{array}{l}\text { EMICoV } \\
\text { tracking survey }\end{array}$ \\
\hline $\begin{array}{l}\text { Incidence of rural } \\
\text { income poverty }\end{array}$ & $38.36 \%$ & & $32 \%$ & $30 \%$ & $27 \%$ & $26 \%$ & $26 \%$ & INSAE & Annually & $\begin{array}{l}\text { EMICoV } \\
\text { tracking survey }\end{array}$ \\
\hline $\begin{array}{l}\text { Depth of income } \\
\text { poverty }\end{array}$ & $10.44 \%$ & $9.8 \%$ & $9.1 \%$ & $8.3 \%$ & $7.5 \%$ & $7 \%$ & $6.5 \%$ & INSAE & Annually & $\begin{array}{l}\text { EMICoV } \\
\text { tracking survey }\end{array}$ \\
\hline $\begin{array}{l}\text { Severity of income } \\
\text { poverty }\end{array}$ & $4.46 \%$ & $4.2 \%$ & $3.8 \%$ & $3.4 \%$ & $3.1 \%$ & $2.9 \%$ & $2.6 \%$ & INSAE & Annually & $\begin{array}{l}\text { EMICoV } \\
\text { tracking survey }\end{array}$ \\
\hline $\begin{array}{l}\text { Economic growth } \\
\text { rate }\end{array}$ & $4.1 \%$ & & $3.6 \%$ & $5.6 \%$ & $6.5 \%$ & $7.0 \%$ & $7.5 \%$ & INSAE & Annually & $\begin{array}{l}\text { National } \\
\text { accounts }\end{array}$ \\
\hline
\end{tabular}

\section{Achieve a strong and sustainable growth rate}

Develop economic infrastructures
Proportion of population having

access to a source of drinking water 
Annexes

\begin{tabular}{|c|c|c|c|c|c|c|c|c|c|c|c|}
\hline \multirow{2}{*}{$\begin{array}{l}\text { OBJECTIVES/ } \\
\text { RESULTS }\end{array}$} & \multirow[t]{2}{*}{ INDICATORS } & \multicolumn{2}{|c|}{$\begin{array}{l}\text { BASELINE } \\
\text { DATA }\end{array}$} & \multicolumn{5}{|c|}{ TARGET } & \multirow[t]{2}{*}{$\begin{array}{l}\text { ENTITY } \\
\text { RESPONSIBLE }\end{array}$} & \multirow[t]{2}{*}{ FREQ. } & \multirow[t]{2}{*}{$\begin{array}{l}\text { MONITORING } \\
\text { MECHANISM }\end{array}$} \\
\hline & & 2009 & $\begin{array}{l}2010 \\
\text { Target }\end{array}$ & 2011 & 2012 & 2013 & 2014 & 2015 & & & \\
\hline \multirow{6}{*}{$\begin{array}{l}\text { Strengthen human } \\
\text { capital }\end{array}$} & $\begin{array}{l}\text { Proportion of } \\
\text { population having } \\
\text { access to an improved } \\
\text { sanitation system }\end{array}$ & & & & & & & & & & EMICoV/DHS \\
\hline & $\begin{array}{l}\text { Primary net } \\
\text { enrollment ratio }\end{array}$ & & & & & & & & & & EMICoV/DHS \\
\hline & $\begin{array}{l}\text { Literacy rate ages } 15 \\
\text { to } 24\end{array}$ & & & & & & & & & & EMICoV/DHS \\
\hline & $\begin{array}{l}\text { Under-5 mortality } \\
\text { rate }\end{array}$ & & & & & & & & & & EMICoV/DHS \\
\hline & Infant mortality rate & & & & & & & & & & EMICoV/DHS \\
\hline & $\begin{array}{l}\text { Maternal mortality } \\
\text { rate }\end{array}$ & & & & & & & & & & EMICoV/DHS \\
\hline \multicolumn{12}{|l|}{$\begin{array}{l}\text { Strengthen good } \\
\text { governance }\end{array}$} \\
\hline $\begin{array}{l}\text { Implement equal } \\
\text { and sustainable } \\
\text { development at the } \\
\text { national level }\end{array}$ & & & & & & & & & & & \\
\hline
\end{tabular}

\section{STRATEGIC PILLAR I: SPUR GROWTH}

(EFFECT)

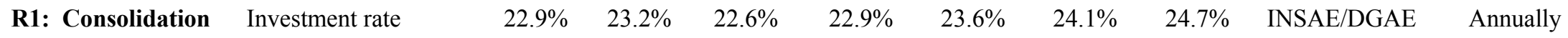




\begin{tabular}{|c|c|c|c|c|c|c|c|c|c|c|c|}
\hline \multirow{2}{*}{$\begin{array}{l}\text { OBJECTIVES/ } \\
\text { RESULTS }\end{array}$} & \multirow[t]{2}{*}{ INDICATORS } & \multicolumn{2}{|c|}{$\begin{array}{l}\text { BASELINE } \\
\text { DATA }\end{array}$} & \multicolumn{5}{|c|}{ TARGET } & \multirow[t]{2}{*}{$\begin{array}{l}\text { ENTITY } \\
\text { RESPONSIBLE }\end{array}$} & \multirow[t]{2}{*}{ FREQ. } & \multirow[t]{2}{*}{$\begin{array}{l}\text { MONITORING } \\
\text { MECHANISM }\end{array}$} \\
\hline & & 2009 & $\begin{array}{l}2010 \\
\text { Target }\end{array}$ & 2011 & 2012 & 2013 & 2014 & 2015 & & & \\
\hline \multirow{6}{*}{$\begin{array}{l}\text { of the } \\
\text { macroeconomic } \\
\text { framework }\end{array}$} & Inflation rate & $2 \%$ & $2.2 \%$ & $2.2 \%$ & $2.3 \%$ & $2.5 \%$ & $2.8 \%$ & $2.8 \%$ & INSAE & Annually & \\
\hline & $\begin{array}{l}\text { Total budget deficit } \\
\text { (based on payment } \\
\text { authorizations) }\end{array}$ & & $-5.8 \%$ & $-5.4 \%$ & $-5.3 \%$ & $-4.9 \%$ & $-4.5 \%$ & $-3.9 \%$ & TOFE/CSPEF & Annually & \\
\hline & as $\%$ of GDP & & & & & & & & & & \\
\hline & $\begin{array}{l}\text { Debt servicing as \% } \\
\text { of exports }\end{array}$ & & & & & & & & & & \\
\hline & $\begin{array}{l}\text { Balance-of-payments } \\
\text { current account } \\
\text { balance as \% of GDP }\end{array}$ & & & & & & & & & & \\
\hline & $\begin{array}{l}\text { Tax revenue } \\
\text { mobilization rates }\end{array}$ & & & $>90 \%$ & $>90 \%$ & $>90 \%$ & $>90 \%$ & $>90 \%$ & TOFE/CSPEF & Annually & \\
\hline \multirow{5}{*}{$\begin{array}{l}\text { R2: Private sector } \\
\text { and enterprise } \\
\text { development }\end{array}$} & $\begin{array}{l}\text { Time required to start } \\
\text { a business }\end{array}$ & 31 & & $<25$ & $<25$ & $<20$ & $<10$ & $<10$ & $\begin{array}{l}\text { DPP/private } \\
\text { sector }\end{array}$ & Annually & \\
\hline & $\begin{array}{l}\text { Improvement of } \\
\text { Benin's rank in the } \\
\text { Doing Business } \\
\text { ratings (\%) }\end{array}$ & 172 & 170 & & & & & & $\begin{array}{l}\text { DPP/private } \\
\text { sector }\end{array}$ & Annually & \\
\hline & $\begin{array}{l}\text { Share of private } \\
\text { investment in GDP }\end{array}$ & & & & & & & & & & \\
\hline & No. of jobs created & & & & & & & & & & \\
\hline & $\begin{array}{l}\text { No. of businesses } \\
\text { operational }\end{array}$ & & & & & & & & & & \\
\hline
\end{tabular}




\begin{tabular}{|c|c|c|c|c|c|c|c|c|c|c|c|}
\hline \multirow{2}{*}{$\begin{array}{l}\text { OBJECTIVES/ } \\
\text { RESULTS }\end{array}$} & \multirow[t]{2}{*}{ INDICATORS } & \multicolumn{2}{|c|}{$\begin{array}{l}\text { BASELINE } \\
\text { DATA }\end{array}$} & \multicolumn{5}{|c|}{ TARGET } & \multirow[t]{2}{*}{$\begin{array}{l}\text { ENTITY } \\
\text { RESPONSIBLE }\end{array}$} & \multirow[t]{2}{*}{ FREQ. } & \multirow[t]{2}{*}{$\begin{array}{l}\text { MONITORING } \\
\text { MECHANISM }\end{array}$} \\
\hline & & 2009 & $\begin{array}{l}2010 \\
\text { Target }\end{array}$ & 2011 & 2012 & 2013 & 2014 & 2015 & & & \\
\hline \multirow[t]{6}{*}{$\begin{array}{l}\text { R3: Diversification } \\
\text { of the economy }\end{array}$} & $\begin{array}{l}\text { Agricultural GDP } \\
\text { growth rate }\end{array}$ & & & $7 \%$ & $10 \%$ & $15 \%$ & $17 \%$ & $20 \%$ & $\begin{array}{l}\text { DPP/MAEP- } \\
\text { INSAE }\end{array}$ & Annually & \\
\hline & $\begin{array}{l}\text { Prevalence of food } \\
\text { insecurity }\end{array}$ & $12 \%$ & & $10 \%$ & $9 \%$ & $8 \%$ & $7 \%$ & $6 \%$ & DPP/MAEP & Annually & \\
\hline & $\begin{array}{l}\text { Agricultural export } \\
\text { growth rate }\end{array}$ & $\begin{array}{l}231,866 \\
\text { billion }^{33}\end{array}$ & & $8 \%$ & $12 \%$ & $17 \%$ & $22 \%$ & $27 \%$ & DPP/MAEP & Annually & \\
\hline & $\begin{array}{l}\text { Coverage of dietary } \\
\text { requirements: }\end{array}$ & & & & & & & & & & \\
\hline & Animal-based & & $58 \%$ & $62 \%$ & $66 \%$ & $79 \%$ & $82 \%$ & $85 \%$ & DPP/MAEP & Annually & \\
\hline & Plant-based & & $150 \%$ & $153 \%$ & $159 \%$ & $165 \%$ & $168 \%$ & $170 \%$ & DPP/MAEP & Annually & \\
\hline
\end{tabular}

R4: Promotion of

regional

integration

\section{STRATEGIC PILLAR II: DEVELOP INFRASTRUCTURE}

$\begin{array}{lllllllllll}\begin{array}{l}\text { R1: Transport } \\ \text { development }\end{array} & \begin{array}{l}\text { Length of road } \\ \text { paved, rehabilitated, } \\ \text { or built }(\mathrm{km})\end{array} & 142.3 & 251.50 & 247.17 & 152.50 & 150.00 & 150.00 & 150.00 & \begin{array}{l}\text { DPP/M. } \\ \text { Transport }\end{array} & \text { Annually } \\ & & & & & & & & \end{array}$

\footnotetext{
${ }^{33}$ Value obtained in current prices (2009). Growth rates will be evaluated based on this value.
} 


\begin{tabular}{|c|c|c|c|c|c|c|c|c|c|c|c|}
\hline \multirow{2}{*}{$\begin{array}{l}\text { OBJECTIVES/ } \\
\text { RESULTS }\end{array}$} & \multirow[t]{2}{*}{ INDICATORS } & \multicolumn{2}{|c|}{$\begin{array}{l}\text { BASELINE } \\
\text { DATA } \\
\end{array}$} & \multicolumn{5}{|c|}{ TARGET } & \multirow[t]{2}{*}{$\begin{array}{l}\text { ENTITY } \\
\text { RESPONSIBLE }\end{array}$} & \multirow[t]{2}{*}{ FREQ. } & \multirow[t]{2}{*}{$\begin{array}{l}\text { MONITORING } \\
\text { MECHANISM }\end{array}$} \\
\hline & & 2009 & $\begin{array}{l}2010 \\
\text { Target }\end{array}$ & 2011 & 2012 & 2013 & 2014 & 2015 & & & \\
\hline & $\begin{array}{l}\text { Length of rural road } \\
\text { constructed or } \\
\text { rehabilitated }(\mathrm{km})\end{array}$ & 2900 & 3200 & 4500 & 4500 & 4500 & 4500 & 4500 & $\begin{array}{l}\text { DPP/M. } \\
\text { Transport }\end{array}$ & Annually & \\
\hline & $\begin{array}{l}\text { Road condition index } \\
(\%)\end{array}$ & 76 & & & & & & & & & \\
\hline & $\begin{array}{l}\text { Air traffic - } \\
\text { passenger }\end{array}$ & & & & & & & & & & \\
\hline & Air traffic - freight & & & & & & & & & & \\
\hline & $\begin{array}{l}\text { Transportation of } \\
\text { import goods }\end{array}$ & & & & & & & & & & \\
\hline & $\begin{array}{l}\text { Transportation of } \\
\text { export goods }\end{array}$ & & & & & & & & & & \\
\hline \multirow[t]{5}{*}{ R2: Energy } & $\begin{array}{l}\text { National } \\
\text { electrification rate } \\
(\%)\end{array}$ & $26.5 \%$ & & $36.6 \%$ & $41.6 \%$ & $46.6 \%$ & $51.5 \%$ & $56.5 \%$ & $\begin{array}{l}\text { DPP- } \\
\text { DGEnergy/MEE }\end{array}$ & Annually & \\
\hline & Urban & $53.3 \%$ & & $60.9 \%$ & $64.7 \%$ & $68.4 \%$ & $72.2 \%$ & $76 \%$ & $\begin{array}{l}\text { DPP- } \\
\text { DGEnergy/MEE }\end{array}$ & Annually & \\
\hline & Rural & $3.1 \%$ & & $14.1 \%$ & $19.6 \%$ & $25 \%$ & $30.5 \%$ & $36 \%$ & $\begin{array}{l}\text { DPP- } \\
\text { DGEnergy/MEE }\end{array}$ & Annually & \\
\hline & $\begin{array}{l}\text { National coverage } \\
\text { rate }\end{array}$ & $28.9 \%$ & $34.9 \%$ & $43.9 \%$ & $51.5 \%$ & $59 \%$ & $66.5 \%$ & $74 \%$ & $\begin{array}{l}\text { DPP- } \\
\text { DGEnergy/MEE }\end{array}$ & Annually & \\
\hline & National service rate & $51.3 \%$ & & $62 \%$ & $69 \%$ & $76 \%$ & $83 \%$ & $90 \%$ & $\begin{array}{l}\text { DPP- } \\
\text { DGEnergy/MEE }\end{array}$ & Annually & \\
\hline
\end{tabular}




\begin{tabular}{|c|c|c|c|c|c|c|c|c|c|c|c|}
\hline \multirow{2}{*}{$\begin{array}{l}\text { OBJECTIVES/ } \\
\text { RESULTS }\end{array}$} & \multirow[t]{2}{*}{ INDICATORS } & \multicolumn{2}{|c|}{$\begin{array}{l}\text { BASELINE } \\
\text { DATA }\end{array}$} & \multicolumn{5}{|c|}{ TARGET } & \multirow[t]{2}{*}{$\begin{array}{l}\text { ENTITY } \\
\text { RESPONSIBLE }\end{array}$} & \multirow[t]{2}{*}{ FREQ. } & \multirow[t]{2}{*}{$\begin{array}{l}\text { MONITORING } \\
\text { MECHANISM }\end{array}$} \\
\hline & & 2009 & $\begin{array}{l}2010 \\
\text { Target }\end{array}$ & 2011 & 2012 & 2013 & 2014 & 2015 & & & \\
\hline \multirow{9}{*}{$\begin{array}{l}\text { R3: Water and } \\
\text { sanitation }\end{array}$} & $\begin{array}{l}\text { No. of electrified } \\
\text { towns }\end{array}$ & 1086 & 1312 & 1650 & 1932 & 2214 & 2496 & 2779 & $\begin{array}{l}\text { DPP- } \\
\text { DGEnergy/MEE }\end{array}$ & Annually & \\
\hline & $\begin{array}{l}\text { Rate of service of } \\
\text { drinking water in } \\
\text { rural and semi-rural } \\
\text { areas }\end{array}$ & & & $60 \%$ & $62.5 \%$ & $65 \%$ & $67.5 \%$ & $69.5 \%$ & DPP/MEE & Annually & \\
\hline & $\begin{array}{l}\text { Rate of service of } \\
\text { drinking water in } \\
\text { urban areas }\end{array}$ & & & $64.5 \%$ & $67.5 \%$ & $70.5 \%$ & $73.5 \%$ & $75 \%$ & DPP/MEE & Annually & \\
\hline & $\begin{array}{l}\text { Breakdown rate of } \\
\text { water points in rural } \\
\text { areas }\end{array}$ & & & & & & & & & & \\
\hline & $\begin{array}{l}\text { Additional population } \\
\text { served in rural areas }\end{array}$ & & & & & & & & & & \\
\hline & $\begin{array}{l}\text { No. of new water } \\
\text { supply points built }\end{array}$ & & & & & & & & & & \\
\hline & $\begin{array}{l}\text { No. of water supply } \\
\text { points rehabilitated }\end{array}$ & & & & & & & & & Annually & \\
\hline & $\begin{array}{l}\text { Length of collection } \\
\text { points built }\end{array}$ & & & & & & & & & Annually & \\
\hline & Length of drains built & & & & & & & & & Annually & \\
\hline
\end{tabular}




\begin{tabular}{|c|c|c|c|c|c|c|c|c|c|c|c|}
\hline \multirow{2}{*}{$\begin{array}{l}\text { OBJECTIVES/ } \\
\text { RESULTS }\end{array}$} & \multirow[t]{2}{*}{ INDICATORS } & \multicolumn{2}{|c|}{$\begin{array}{l}\text { BASELINE } \\
\text { DATA }\end{array}$} & \multicolumn{5}{|c|}{ TARGET } & \multirow[t]{2}{*}{$\begin{array}{l}\text { ENTITY } \\
\text { RESPONSIBLE }\end{array}$} & \multirow[t]{2}{*}{ FREQ. } & \multirow[t]{2}{*}{$\begin{array}{l}\text { MONITORING } \\
\text { MECHANISM }\end{array}$} \\
\hline & & 2009 & $\begin{array}{l}2010 \\
\text { Target }\end{array}$ & 2011 & 2012 & 2013 & 2014 & 2015 & & & \\
\hline & \multicolumn{8}{|l|}{$\begin{array}{l}\text { Rate of coverage of } \\
\text { households with } \\
\text { human waste disposal } \\
\text { facilities }\end{array}$} & \multicolumn{3}{|c|}{ Annually } \\
\hline & $\begin{array}{l}\text { Rate of coverage of } \\
\text { schools with human } \\
\text { waste disposal } \\
\text { facilities }\end{array}$ & & & & & & & & \multicolumn{3}{|c|}{ Annually } \\
\hline
\end{tabular}

STRATEGIC PILLAR III: STRENGTHEN HUMAN CAPITAL

\begin{tabular}{|c|c|c|c|c|c|c|c|c|c|c|}
\hline \multirow[t]{7}{*}{ R1: Education } & $\begin{array}{l}\text { Preschool gross } \\
\text { enrollment ratio }\end{array}$ & $8.04 \%$ & $10 \%$ & $11 \%$ & $12 \%$ & $13 \%$ & $14 \%$ & $15 \%$ & DPP/MEMP & Annually \\
\hline & $\begin{array}{l}\text { Gross enrollment } \\
\text { ratio }\end{array}$ & $109 \%$ & $110 \%$ & $113 \%$ & $116 \%$ & & & $125 \%$ & DPP/MEMP & Annually \\
\hline & $\begin{array}{l}\text { Female gross } \\
\text { enrollment ratio }\end{array}$ & $104 \%$ & $106 \%$ & $110 \%$ & $114 \%$ & & & $125 \%$ & DPP/MEMP & Annually \\
\hline & $\begin{array}{l}\text { Percentage of female } \\
\text { students in primary } \\
\text { education }\end{array}$ & $46.03 \%$ & $46.8 \%$ & $47.4 \%$ & $48.1 \%$ & & & $50 \%$ & DPP/MEMP & Annually \\
\hline & $\begin{array}{l}\text { Gross admission rate } \\
\text { at the CI level }\end{array}$ & $140 \%$ & $136 \%$ & $133 \%$ & $130 \%$ & & & $120 \%$ & DPP/MEMP & Annually \\
\hline & $\begin{array}{l}\text { Gross admission rate } \\
\text { at the CI level for } \\
\text { girls }\end{array}$ & $138 \%$ & $106 \%$ & $110 \%$ & $114 \%$ & & & $125 \%$ & DPP/MEMP & Annually \\
\hline & Student/teacher ratio & $48.3 \%$ & $46.7 \%$ & $46.4 \%$ & $46 \%$ & & & $45 \%$ & DPP/MEMP & Annually \\
\hline
\end{tabular}




\begin{tabular}{|c|c|c|c|c|c|c|c|c|c|c|c|}
\hline \multirow{2}{*}{$\begin{array}{l}\text { OBJECTIVES/ } \\
\text { RESULTS }\end{array}$} & \multirow[t]{2}{*}{ INDICATORS } & \multicolumn{2}{|c|}{$\begin{array}{l}\text { BASELINE } \\
\text { DATA }\end{array}$} & \multicolumn{5}{|c|}{ TARGET } & \multirow[t]{2}{*}{$\begin{array}{l}\text { ENTITY } \\
\text { RESPONSIBLE }\end{array}$} & \multirow[t]{2}{*}{ FREQ. } & \multirow[t]{2}{*}{$\begin{array}{l}\text { MONITORING } \\
\text { MECHANISM }\end{array}$} \\
\hline & & 2009 & $\begin{array}{l}2010 \\
\text { Target }\end{array}$ & 2011 & 2012 & 2013 & 2014 & 2015 & & & \\
\hline & $\begin{array}{l}\text { Percentage of } \\
\text { repeaters }\end{array}$ & $13 \%$ & $10 \%$ & $10 \%$ & $10 \%$ & & & $10 \%$ & DPP/MESFTP & Annually & \\
\hline & $\begin{array}{l}\text { Primary completion } \\
\text { rate }\end{array}$ & $65 \%$ & $75 \%$ & $82 \%$ & $89 \%$ & & & $110 \%$ & DPP/MESFTP & Annually & \\
\hline & $\begin{array}{l}\text { Primary completion } \\
\text { for girls }\end{array}$ & $57 \%$ & $69 \%$ & $77 \%$ & $85 \%$ & & & $110 \%$ & DPP/MESFTP & Annually & \\
\hline & $\begin{array}{l}\text { No. of students in the } \\
\text { final year of training } \\
\text { for the Professional } \\
\text { Accreditation } \\
\text { Certificate (CQP) }\end{array}$ & & & & & & & & DPP/MESFTP & Annually & \\
\hline & $\begin{array}{l}\text { Average success rate } \\
\text { in 2ème cycle } \\
\text { examinations }\end{array}$ & & & & & & & & DPP/MESFTP & Annually & \\
\hline & $\begin{array}{l}\text { Enrollment rate for } \\
\text { girls in Vocational } \\
\text { and Technical } \\
\text { Education }\end{array}$ & & & & & & & & DPP/MESFTP & Annually & \\
\hline & Student/teacher ratio & & & & & & & & DPP/MESFTP & Annually & \\
\hline & $\begin{array}{l}\text { Ratio of textbooks to } \\
\text { student (French and } \\
\text { mathematics) }\end{array}$ & & & & & & & & DPP/MESFTP & Annually & \\
\hline & $\begin{array}{l}\text { No. of literate } \\
\text { individuals }\end{array}$ & & & & & & & & DPP/MESFTP & Annually & \\
\hline
\end{tabular}


Annexes

\begin{tabular}{|c|c|c|c|c|c|c|c|c|c|c|c|}
\hline \multirow{2}{*}{$\begin{array}{l}\text { OBJECTIVES/ } \\
\text { RESULTS }\end{array}$} & \multirow[t]{2}{*}{ INDICATORS } & \multicolumn{2}{|c|}{$\begin{array}{l}\text { BASELINE } \\
\text { DATA }\end{array}$} & \multicolumn{5}{|c|}{ TARGET } & \multirow[t]{2}{*}{$\begin{array}{l}\text { ENTITY } \\
\text { RESPONSIBLE }\end{array}$} & \multirow[t]{2}{*}{ FREQ. } & \multirow[t]{2}{*}{$\begin{array}{l}\text { MONITORING } \\
\text { MECHANISM }\end{array}$} \\
\hline & & 2009 & $\begin{array}{l}2010 \\
\text { Target }\end{array}$ & 2011 & 2012 & 2013 & 2014 & 2015 & & & \\
\hline \multirow[t]{7}{*}{ R2: Health } & $\begin{array}{l}\text { Rate of use of health } \\
\text { services }\end{array}$ & $46.1 \%$ & $47 \%$ & $60 \%$ & $65 \%$ & $70 \%$ & $75 \%$ & $80 \%$ & DPP/MS & Annually & $\begin{array}{l}\text { Statistical } \\
\text { Yearbook }\end{array}$ \\
\hline & $\begin{array}{l}\text { Rate of use of health } \\
\text { serves for children } \\
\text { aged } 0 \text { to } 5 \text { years }\end{array}$ & $76.1 \%$ & $85 \%$ & $89 \%$ & $91 \%$ & $92 \%$ & $94 \%$ & $95 \%$ & DPP/MS & Annually & $\begin{array}{l}\text { Statistical } \\
\text { Yearbook }\end{array}$ \\
\hline & $\begin{array}{l}\text { No. of functional } \\
\text { health zones }\end{array}$ & 29 & 30 & 32 & 34 & 34 & 34 & 34 & DPP/MS & Annually & $\begin{array}{l}\text { Statistical } \\
\text { Yearbook }\end{array}$ \\
\hline & $\begin{array}{l}\text { Incidence of } \\
\text { HIV/AIDS among } \\
\text { pregnant women }\end{array}$ & $2 \%$ & $<2 \%$ & $<2 \%$ & $<2 \%$ & $<2 \%$ & $<2 \%$ & $<2 \%$ & DPP/MS & Annually & $\begin{array}{l}\text { Statistical } \\
\text { Yearbook }\end{array}$ \\
\hline & $\begin{array}{l}\text { Rate of coverage by } \\
\text { the Expanded } \\
\text { Program on } \\
\text { Immunization (EPI) } \\
\text { (Pentavalent vaccine } \\
\text { dose 3) among } \\
\text { children aged } 0 \text { to } 11 \\
\text { months }\end{array}$ & $98 \%$ & $>90 \%$ & $92 \%$ & $94 \%$ & $95 \%$ & $95 \%$ & $95 \%$ & DPP/MS & Annually & $\begin{array}{l}\text { Statistical } \\
\text { Yearbook }\end{array}$ \\
\hline & $\begin{array}{l}\text { Rate of vaccination } \\
\text { (VAR) - children } \\
\text { aged } 0 \text { to } 11 \text { months }\end{array}$ & $95 \%$ & $84 \%$ & $87 \%$ & $90 \%$ & $92 \%$ & $94 \%$ & $95 \%$ & $\mathrm{DPP} / \mathrm{MS}$ & Annually & $\begin{array}{l}\text { Statistical } \\
\text { Yearbook }\end{array}$ \\
\hline & $\begin{array}{l}\text { Rate of births } \\
\text { attended by medical } \\
\text { or paramedical } \\
\text { personnel }\end{array}$ & $78.6 \%$ & $>80 \%$ & $84.79 \%$ & $87.15 \%$ & $95 \%$ & $97 \%$ & $98.5 \%$ & DPP/MS & Annually & $\begin{array}{l}\text { Statistical } \\
\text { Yearbook }\end{array}$ \\
\hline
\end{tabular}


Annexes

\begin{tabular}{|c|c|c|c|c|c|c|c|c|c|c|c|}
\hline \multirow{2}{*}{$\begin{array}{l}\text { OBJECTIVES/ } \\
\text { RESULTS }\end{array}$} & \multirow[t]{2}{*}{ INDICATORS } & \multicolumn{2}{|c|}{$\begin{array}{l}\text { BASELINE } \\
\text { DATA }\end{array}$} & \multicolumn{5}{|c|}{ TARGET } & \multirow[t]{2}{*}{$\begin{array}{l}\text { ENTITY } \\
\text { RESPONSIBLE }\end{array}$} & \multirow[t]{2}{*}{ FREQ. } & \multirow[t]{2}{*}{$\begin{array}{l}\text { MONITORING } \\
\text { MECHANISM }\end{array}$} \\
\hline & & 2009 & $\begin{array}{l}2010 \\
\text { Target }\end{array}$ & 2011 & 2012 & 2013 & 2014 & 2015 & & & \\
\hline & $\begin{array}{l}\text { Rate of prenatal } \\
\text { consultation }\end{array}$ & $91.6 \%$ & $\begin{array}{l}>90 \% \\
*\end{array}$ & $94.93 \%$ & $95.46 \%$ & $96.5 \%$ & $98 \%$ & $98.5 \%$ & DPP/MS & Annually & $\begin{array}{l}\text { Statistical } \\
\text { Yearbook }\end{array}$ \\
\hline & $\begin{array}{l}\text { Rate of use of } \\
\text { modern contraceptive } \\
\text { methods }\end{array}$ & $21.2 \%$ & $>10 \%$ & $>11 \%$ & $>12 \%$ & $>13 \%$ & $>14 \%$ & $>15 \%$ & DPP/MS & Annually & $\begin{array}{l}\text { Statistical } \\
\text { Yearbook }\end{array}$ \\
\hline & $\begin{array}{l}\text { Percentage of } \\
\text { children under } 5 \\
\text { years sleeping under } \\
\text { insecticide-treated } \\
\text { mosquito nets }\end{array}$ & $56.3 \%$ & $60 \% *$ & $80 \%$ & $80 \%$ & $93 \%$ & $95 \%$ & $97 \%$ & DPP/MS & Annually & $\begin{array}{l}\text { Statistical } \\
\text { Yearbook }\end{array}$ \\
\hline & $\begin{array}{l}\text { Percentage of } \\
\text { pregnant women } \\
\text { sleeping under } \\
\text { insecticide-treated } \\
\text { mosquito nets }\end{array}$ & $54.8 \%$ & $60 \% *$ & $80 \%$ & $80 \%$ & $80 \%$ & $90 \%$ & $95 \%$ & DPP/MS & Annually & $\begin{array}{l}\text { Statistical } \\
\text { Yearbook }\end{array}$ \\
\hline & $\begin{array}{l}\text { Rate of coverage of } \\
\text { households with } \\
\text { human waste disposal } \\
\text { facilities }\end{array}$ & $39.40 \%$ & $\begin{array}{c}42.60 \\
\%\end{array}$ & $46.40 \%$ & $50.90 \%$ & $56.20 \%$ & $62.20 \%$ & $69.10 \%$ & $\mathrm{DPP} / \mathrm{MS}$ & Annually & $\begin{array}{l}\text { Statistical } \\
\text { Yearbook }\end{array}$ \\
\hline & $\begin{array}{l}\text { Rate of coverage of } \\
\text { schools with human } \\
\text { waste disposal } \\
\text { facilities }\end{array}$ & $70.92 \%$ & $\begin{array}{c}75.60 \\
\%\end{array}$ & $80.70 \%$ & $85.89 \%$ & $91.03 \%$ & $96.8 \%$ & $100 \%$ & DPP/MS & Annually & $\begin{array}{l}\text { Statistical } \\
\text { Yearbook }\end{array}$ \\
\hline & $\begin{array}{l}\text { Treatment success } \\
\text { rate for new PTB }\end{array}$ & $87 \%$ & $87 \%$ & $87 \%$ & $87 \%$ & $87 \%$ & $87 \%$ & $87 \%$ & DPP/MS & Annually & $\begin{array}{l}\text { Statistical } \\
\text { Yearbook }\end{array}$ \\
\hline
\end{tabular}


Annexes

\begin{tabular}{|c|c|c|c|c|c|c|c|c|c|c|c|}
\hline \multirow{2}{*}{$\begin{array}{l}\text { OBJECTIVES/ } \\
\text { RESULTS }\end{array}$} & \multirow[t]{2}{*}{ INDICATORS } & \multicolumn{2}{|c|}{$\begin{array}{l}\text { BASELINE } \\
\text { DATA } \\
\end{array}$} & \multicolumn{5}{|c|}{ TARGET } & \multirow[t]{2}{*}{$\begin{array}{l}\text { ENTITY } \\
\text { RESPONSIBLE }\end{array}$} & \multirow[t]{2}{*}{ FREQ. } & \multirow[t]{2}{*}{$\begin{array}{l}\text { MONITORING } \\
\text { MECHANISM }\end{array}$} \\
\hline & & 2009 & $\begin{array}{l}2010 \\
\text { Target }\end{array}$ & 2011 & 2012 & 2013 & 2014 & 2015 & & & \\
\hline
\end{tabular}

STRATEGIC PILLAR IV: STRENGTHEN GOOD GOVERNANCE

\begin{tabular}{|c|c|c|c|c|c|c|c|c|c|c|c|}
\hline \multirow[t]{6}{*}{ R1: Public finances } & $\begin{array}{l}\text { Rate of use of } \\
\text { payment orders }\end{array}$ & $4.98 \%$ & - & $<8 \%$ & $<8 \%$ & $<8 \%$ & $<8 \%$ & $<8 \%$ & $\begin{array}{l}\text { DGB- } \\
\text { CSPEF/MEF }\end{array}$ & Annually & SIGFIP \\
\hline & $\begin{array}{l}\text { Average payment } \\
\text { time frame (in days) }\end{array}$ & $\begin{array}{l}19.5 \\
\text { days }\end{array}$ & - & $\begin{array}{l}<24 \\
\text { days }\end{array}$ & $\begin{array}{l}<24 \\
\text { days }\end{array}$ & $\begin{array}{l}<24 \\
\text { days }\end{array}$ & $\begin{array}{l}<24 \\
\text { days }\end{array}$ & $\begin{array}{l}<24 \\
\text { days }\end{array}$ & $\begin{array}{l}\text { DGB- } \\
\text { CSPEF/MEF }\end{array}$ & Annually & SIGFIP \\
\hline & $\begin{array}{l}\text { Rate of use of } \\
\text { advance payment } \\
\text { accounts }\end{array}$ & $21.11 \%$ & - & $<8 \%$ & $<8 \%$ & $<8 \%$ & $<8 \%$ & $<8 \%$ & $\begin{array}{l}\text { DGB- } \\
\text { CSPEF/MEF }\end{array}$ & Annually & SIGFIP \\
\hline & Supplies & 54 days & - & 55 days & 55 days & 55 days & 55 days & 55 days & DNMP/MEF & Annually & SIGFIP \\
\hline & Services & 62 days & - & 65 days & 65 days & 65 days & 65 days & 65 days & DNMP/MEF & Annually & SIGFIP \\
\hline & MS & & & $\geq 80 \%$ & $\geq 80 \%$ & $\geq 80 \%$ & $\geq 80 \%$ & $\geq 80 \%$ & DGB/MS & Annually & SIGFIP \\
\hline & MEE & & & $\geq 80 \%$ & $\geq 80 \%$ & $\geq 80 \%$ & $\geq 80 \%$ & $\geq 80 \%$ & DGB/MEE & Annually & SIGFIP \\
\hline
\end{tabular}


Annexes

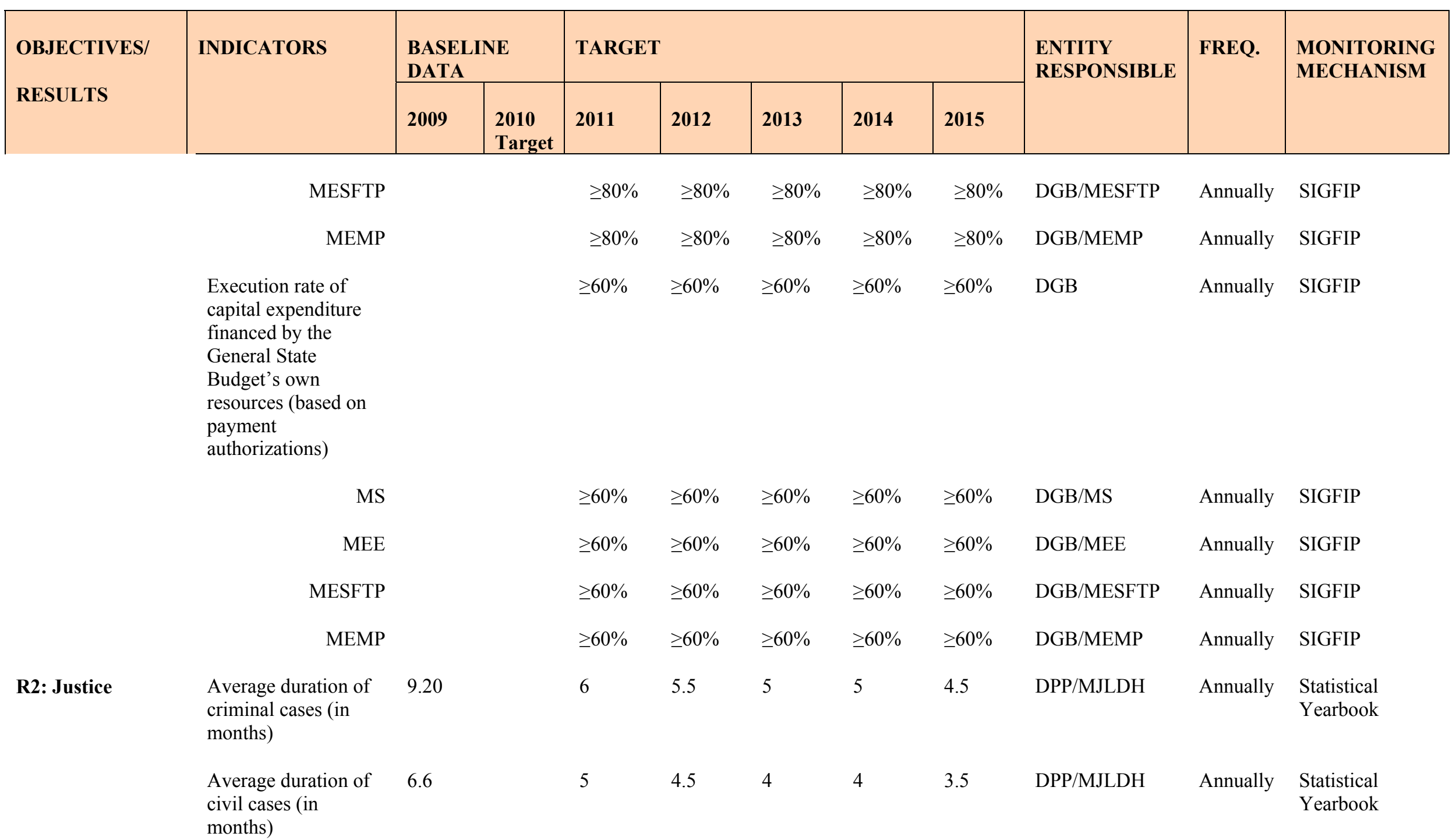




\begin{tabular}{|c|c|c|c|c|c|c|c|c|c|c|c|}
\hline \multirow{2}{*}{$\begin{array}{l}\text { OBJECTIVES/ } \\
\text { RESULTS }\end{array}$} & \multirow[t]{2}{*}{ INDICATORS } & \multicolumn{2}{|c|}{$\begin{array}{l}\text { BASELINE } \\
\text { DATA } \\
\end{array}$} & \multicolumn{5}{|c|}{ TARGET } & \multirow[t]{2}{*}{$\begin{array}{l}\text { ENTITY } \\
\text { RESPONSIBLE }\end{array}$} & \multirow[t]{2}{*}{ FREQ. } & \multirow[t]{2}{*}{$\begin{array}{l}\text { MONITORING } \\
\text { MECHANISM }\end{array}$} \\
\hline & & 2009 & $\begin{array}{l}2010 \\
\text { Target }\end{array}$ & 2011 & 2012 & 2013 & 2014 & 2015 & & & \\
\hline
\end{tabular}

\begin{tabular}{|c|c|c|c|c|c|c|c|c|c|}
\hline $\begin{array}{l}\text { Average duration of } \\
\text { preventive detention } \\
\text { of persons detained } \\
\text { by investigation } \\
\text { departments }\end{array}$ & 11.95 & 11 & 10 & 8 & 8 & 7.5 & DPP/MJLDH & Annually & $\begin{array}{l}\text { Statistical } \\
\text { Yearbook }\end{array}$ \\
\hline $\begin{array}{l}\text { Total average } \\
\text { duration of } \\
\text { preventive detentions }\end{array}$ & & & & & & & DPP/MJLDH & Annually & $\begin{array}{l}\text { Statistical } \\
\text { Yearbook }\end{array}$ \\
\hline Cases settled & $34.71 \%$ & $38 \%$ & $40 \%$ & $45 \%$ & $45 \%$ & $42 \%$ & DPP/MJLDH & Annually & $\begin{array}{l}\text { Statistical } \\
\text { Yearbook }\end{array}$ \\
\hline $\begin{array}{l}\text { Population/judge } \\
\text { ratio }\end{array}$ & 43633 & 43000 & 42500 & 42300 & 42100 & 42000 & DPP/MJLDH & Annually & $\begin{array}{l}\text { Statistical } \\
\text { Yearbook }\end{array}$ \\
\hline $\begin{array}{l}\text { Prison occupancy } \\
\text { rate }\end{array}$ & $205 \%$ & $150 \%$ & $145 \%$ & $135 \%$ & $125 \%$ & $125 \%$ & DPP/MJLDH & Annually & $\begin{array}{l}\text { Statistical } \\
\text { Yearbook }\end{array}$ \\
\hline $\begin{array}{l}\text { Proportion of at-risk } \\
\text { children or young } \\
\text { people who have } \\
\text { benefited from legal } \\
\text { protection }\end{array}$ & $86.86 \%$ & $87 \%$ & $87 \%$ & $89 \%$ & $90 \%$ & $95 \%$ & DPP/MJLDH & Annually & $\begin{array}{l}\text { Statistical } \\
\text { Yearbook }\end{array}$ \\
\hline $\begin{array}{l}\text { Average distance to } \\
\text { the court of first }\end{array}$ & & & & & & & DPP/MJLDH & Annually & $\begin{array}{l}\text { Statistical } \\
\text { Yearbook }\end{array}$ \\
\hline
\end{tabular}


Annexes

\begin{tabular}{|c|c|c|c|c|c|c|c|c|c|c|c|}
\hline \multirow{2}{*}{$\begin{array}{l}\text { OBJECTIVES/ } \\
\text { RESULTS }\end{array}$} & \multirow[t]{2}{*}{ INDICATORS } & \multicolumn{2}{|c|}{$\begin{array}{l}\text { BASELINE } \\
\text { DATA }\end{array}$} & \multicolumn{5}{|c|}{ TARGET } & \multirow[t]{2}{*}{$\begin{array}{l}\text { ENTITY } \\
\text { RESPONSIBLE }\end{array}$} & \multirow[t]{2}{*}{ FREQ. } & \multirow[t]{2}{*}{$\begin{array}{l}\text { MONITORING } \\
\text { MECHANISM }\end{array}$} \\
\hline & & 2009 & $\begin{array}{l}2010 \\
\text { Target }\end{array}$ & 2011 & 2012 & 2013 & 2014 & 2015 & & & \\
\hline
\end{tabular}

instance (in km)

OPERATIONAL PILLAR V: ACHIEVE EQUAL AND SUSTAINABLE DEVELOPMENT AT THE NATIONAL LEVEL

R1:

Decentralization

and Land Use

Planning

\begin{abstract}
Proportion of territoria
government

expenditure of total

BGE expenditure

Share of transfers to

territorial governments

of total BGE

expenditure
\end{abstract}

$5.3 \%$

Execution rate of

allocated and non-

allocated FADeC

transfers

$\mathrm{CDCC}$ and $\mathrm{CAD}$

operating conditions

$90 \%$

Municipal budget

execution rate

Rate of compliance

with the law on

municipal

administrative and

budgetary decisions

No. of development

areas established and

formalized

\section{$57 \%$}

$74 \%$

8

$2.5 \% \quad 3 \%$

$100 \% \quad 100 \%$

$100 \%$

$100 \%$

$100 \%$

$100 \%$

$\mathrm{DP}$
$\mathrm{T}$

Annually Statistical

Yearbook

$85 \%$

$85 \%$

$90 \%$

$90 \%$

$\mathrm{T}$

Annually Statistical

Yearbook

T

Statistical

Yearbook

\begin{tabular}{|c|c|c|c|c|c|c|c|}
\hline $90 \%$ & $95 \%$ & $95 \%$ & $95 \%$ & $95 \%$ & $\begin{array}{l}\text { DPP/MDGLAA } \\
\mathrm{T}\end{array}$ & Annually & $\begin{array}{l}\text { Statistical } \\
\text { Yearbook }\end{array}$ \\
\hline $80 \%$ & $80 \%$ & $80 \%$ & $80 \%$ & $80 \%$ & $\begin{array}{l}\text { DPP/MDGLAA } \\
\mathrm{T}\end{array}$ & Annually & $\begin{array}{l}\text { Statistical } \\
\text { Yearbook }\end{array}$ \\
\hline $80 \%$ & $85 \%$ & $85 \%$ & $90 \%$ & $90 \%$ & $\begin{array}{l}\text { DPP/MDGLAA } \\
\mathrm{T}\end{array}$ & Annually & $\begin{array}{l}\text { Statistical } \\
\text { Yearbook }\end{array}$ \\
\hline
\end{tabular}

10

13

16

19

22

24

DPP/MDGLAA

Annually

Statistical

Yearbook 
Annexes

\begin{tabular}{|c|c|c|c|c|c|c|c|c|c|c|c|}
\hline \multirow{2}{*}{$\begin{array}{l}\text { OBJECTIVES/ } \\
\text { RESULTS }\end{array}$} & \multirow[t]{2}{*}{ INDICATORS } & \multicolumn{2}{|c|}{$\begin{array}{l}\text { BASELINE } \\
\text { DATA }\end{array}$} & \multicolumn{5}{|c|}{ TARGET } & \multirow[t]{2}{*}{$\begin{array}{l}\text { ENTITY } \\
\text { RESPONSIBLE }\end{array}$} & \multirow[t]{2}{*}{ FREQ. } & \multirow[t]{2}{*}{$\begin{array}{l}\text { MONITORING } \\
\text { MECHANISM }\end{array}$} \\
\hline & & 2009 & $\begin{array}{l}2010 \\
\text { Target }\end{array}$ & 2011 & 2012 & 2013 & 2014 & 2015 & & & \\
\hline \multirow{4}{*}{$\begin{array}{l}\text { R2: Environment } \\
\text { and living } \\
\text { conditions }\end{array}$} & $\begin{array}{l}\text { No. of land use projects } \\
\text { drawn up }\end{array}$ & 2 & 3 & 4 & 5 & 7 & 9 & 11 & $\begin{array}{l}\text { DPP/MDGLAA } \\
\mathrm{T}\end{array}$ & Annually & $\begin{array}{l}\text { Statistical } \\
\text { Yearbook }\end{array}$ \\
\hline & $\begin{array}{l}\text { Proportion of protected } \\
\text { forest zones in relation } \\
\text { to the total forest area }\end{array}$ & & $35 \%$ & $35 \%$ & $40 \%$ & $40 \%$ & $40 \%$ & $40 \%$ & DGFRN/MEPN & Annually & $\begin{array}{l}\text { Statistical } \\
\text { Yearbook }\end{array}$ \\
\hline & $\begin{array}{l}\text { Rate of reforestation in } \\
\text { the context of } \\
\text { sustainable } \\
\text { management of long- } \\
\text { term resources } \\
\text { (hectares) }\end{array}$ & & $\begin{array}{l}6545 . \\
7 \text { ha }\end{array}$ & 6873 & 7216 & 7577 & 7956 & 8354 & DGFRN/MEPN & Annually & $\begin{array}{l}\text { Statistical } \\
\text { Yearbook }\end{array}$ \\
\hline & $\begin{array}{l}\text { Proportion of the } \\
\text { population served by } \\
\text { waste pre-collection }\end{array}$ & & $32 \%$ & $35 \%$ & $40 \%$ & $44 \%$ & $47 \%$ & $52 \%$ & DGFRN/MEPN & Annually & $\begin{array}{l}\text { Statistical } \\
\text { Yearbook }\end{array}$ \\
\hline
\end{tabular}




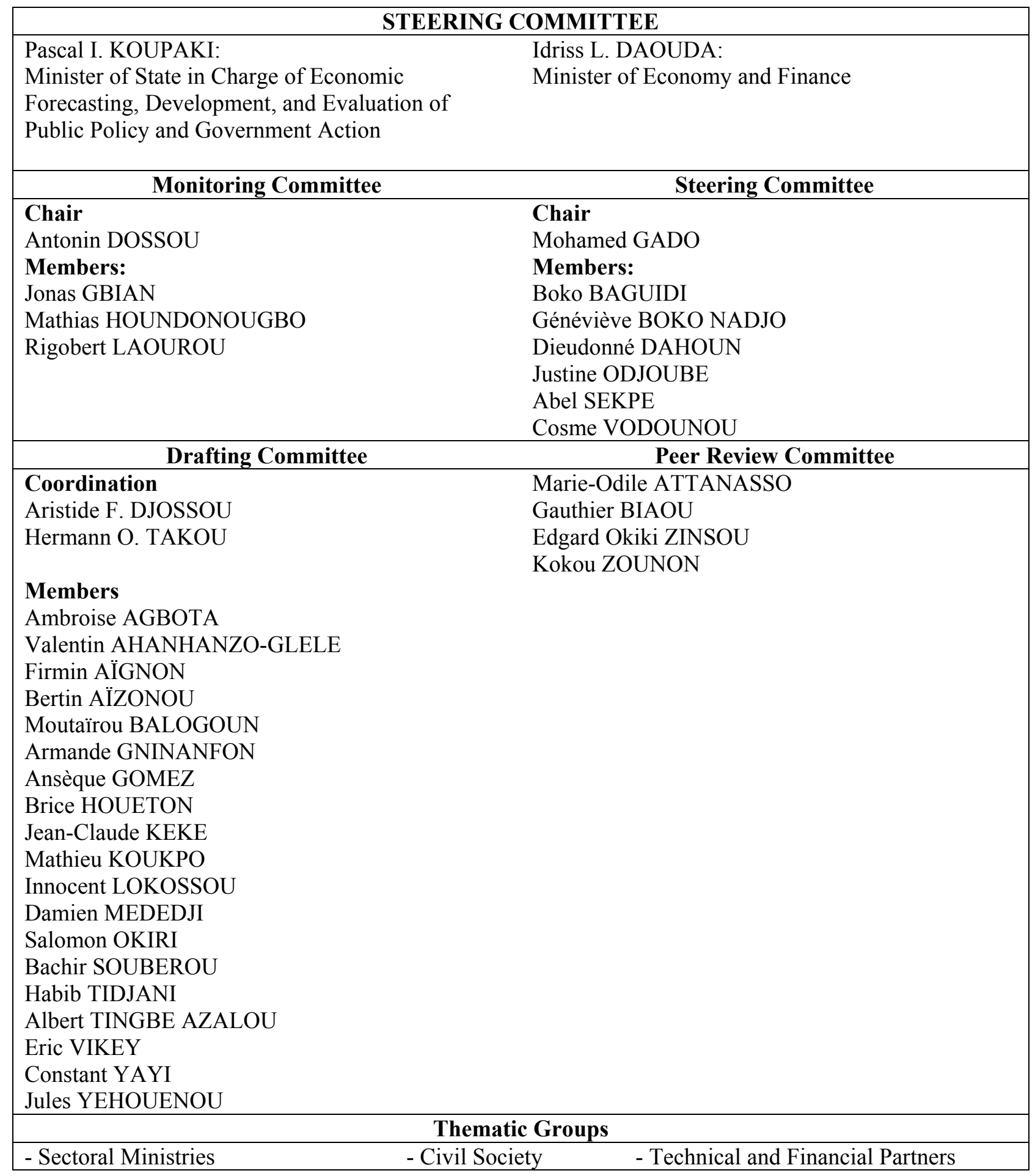

